LA-14419-T

Thesis

Approved for public release;

distribution is unlimited.

Long-Term Desorption Behavior of Uranium and Neptunium in Heterogeneous Volcanic Tuff Materials 
This thesis was accepted by the Department of Chemical and Nuclear Engineering, University of New Mexico, Albuquerque, New Mexico, in partial fulfillment of the requirements for the degree of Doctor of Philosophy in Engineering. The text and illustrations are the independent work of the author, and only the front matter has been edited by the IRM-CAS Writing and Editing staff to conform with Department of Energy and Los Alamos National Laboratory publication policies.

Los Alamos National Laboratory, an Affirmative Action/ Equal Opportunity Employer, is operated by Los Alamos National Security, LLC, for the National Nuclear Security Administration of the U.S. Department of Energy under contract DE-AC52-06NA25396.

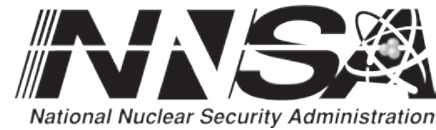

National Nuclear Security Administration

This report was prepared as an account of work sponsored by an agency of the U.S. Government. Neither Los Alamos National Security, LLC, the U.S. Government nor any agency thereof, nor any of their employees make any warranty, express or implied, or assume any legal liability or responsibility for the accuracy, completeness, or usefulness of any information, apparatus, product, or process disclosed, or represent that its use would not infringe privately owned rights. Reference herein to any specific commercial product, process, or service by trade name, trademark, manufacturer, or otherwise does not necessarily constitute or imply its endorsement, recommendation, or favoring by Los Alamos National Security, LLC, the U.S. Government, or any agency thereof. The views and opinions of authors expressed herein do not necessarily state or reflect those of Los Alamos National Security, LLC, the U.S. Government, or any agency thereof. Los Alamos National Laboratory strongly supports academic freedom and a researcher's right to publish; as an institution, however, the Laboratory does not endorse the viewpoint of a publication or guarantee its technical correctness. 
LA-14419-T

Thesis

Issued: May 2010

Long-Term Desorption Behavior of Uranium

and Neptunium in Heterogeneous Volcanic

Tuff Materials

Cynthia A. Dean

- Los Alamos 

Cynthia A. Dean

candadate

Chemical and Nuclear Engineering

एस्यागाला

This dissertation is approved, and it is acceptable in quality and form for publication:

Approved by the Dissertation Committee:
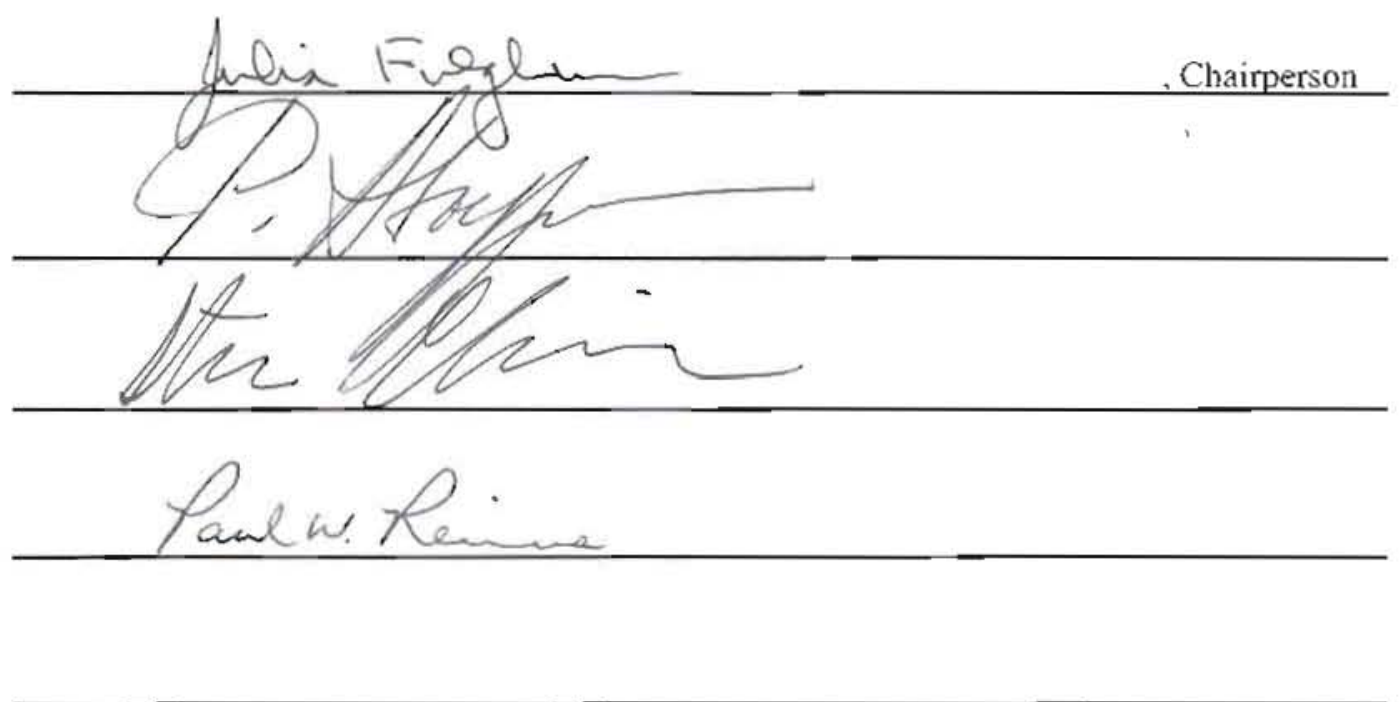



\title{
LONG-TERM DESORPTION OF URANIUM AND NEPTUNIUM IN HETEROGENEOUS VOLCANIC TUFF MATERIALS
}

\author{
BY \\ CYNTHIA A. DEAN \\ B.S. Environmental Science, University of Houston-Clear Lake, 2001 \\ M.S. Chemical Engineering, University of New Mexico, 2005
}

\author{
DISSERTATION \\ Submitted in Partial Fulfillment of the \\ Requirements for the Degree of

\section{Doctorate of Philosophy} \\ Engineering \\ The University of New Mexico \\ Albuquerque, New Mexico
}

May, 2010 



\section{ACKNOWLEDGEMENTS}

Financial support for this research was provided by the U.S. Department of Energy through the Office of Civilian Radioactive Waste Management, Office of the Chief Scientist. Portions of this research were carried out at the Stanford Synchrotron Radiation Lightsource, a national user facility operated by Stanford University on behalf of the U.S. Department of Energy, Office of Basic Energy Sciences. The SSRL Structural Molecular Biology Program is supported by the Department of Energy, Office of Biological and Environmental Research, and by the National Institutes of Health, National Center for Research Resources, Biomedical Technology Program.

Special thanks to my mentor and research advisor at Los Alamos National Laboratory, Dr. Paul W. Reimus. I would like to thank my research and academic advisor at the University of New Mexico, Dr. Julia E. Fulghum. I would also like to thank my committee members Dr. Steve Cabaniss and Dr. Plamen Atanassov.

I would like to thank my co-workers at Los Alamos National Laboratory, especially Doug Ware for sharing with me his extensive technical experience, Dr. Florie Caporuscio for sharing his knowledge of mineralogy and petrology, and Dr. Steve Conradson for his help processing and fitting the X-ray Adsorption Spectroscopy.

Special thanks to the Stanford Synchrotron Radiation Laboratory and Dr. John Bargar and Dr. Sam Webb for their assistance in collecting the XAS data. Thanks to Mike Spilde of the Earth and Planetary Sciences at the University of New Mexico for providing his expert technical support for the Electron Probe Microanalysis. 
Finally, I would like to thank those close to me who had to endure the pursuit of this degree right along with me, especially my daughter, Taylor, who has kept me going all these years with her pearls of wisdom way beyond her years, and my son, Kyle, who likes to give me grief, but knows when I have had enough. And I would like to thank God for always giving me the strength and courage to keep going, even when things seem impossible, and for watching over my children and keeping them safe. 


\title{
LONG-TERM DESORPTION BEHAVIOR OF URANIUM AND NEPTUNIUM IN HETEROGENEOUS VOLCANIC TUFF MATERIALS
}

BY

CYNTHIA A. DEAN

\author{
ABSTRACT OF DISSERTATION \\ Submitted in Partial Fulfillment of the \\ Requirements for the Degree of \\ Doctorate of Philosophy \\ Engineering \\ The University of New Mexico \\ Albuquerque, New Mexico
}

May, 2010 


\title{
Long-Term Desorption Behavior of Uranium and Neptunium in Heterogeneous Volcanic Tuff Materials
}

\author{
By \\ Cynthia A. Dean \\ B.S., Environmental Science, University of Houston-Clear Lake, 2001 \\ M.S., Chemical Engineering, University of New Mexico, 2005 \\ Ph.D. Engineering (Chemical), University of New Mexico, 2010
}

\begin{abstract}
Uranium and neptunium desorption were studied in long-term laboratory experiments using four well-characterized volcanic tuff cores collected from southeast of Yucca Mountain, Nevada. The objectives of the experiments were to

1. Demonstrate a methodology aimed at characterizing distributions of sorption parameters (attributes of multiple sorption sites) that can be applied to moderately-sorbing species in heterogeneous systems to provide more realistic reactive transport parameters and a more realistic approach to modeling transport in heterogeneous systems.

2. Focus on uranium and neptunium because of their high solubility, relatively weak sorption, and high contributions to predicted dose in Yucca Mountain performance assessments. Also, uranium is a contaminant of concern at many DOE legacy sites and uranium mining sites.
\end{abstract}


3. Focus on desorption measurements rather than classic emphasis on sorption measurements. Desorption measurements are the key to interrogating the desired multi-site distributions of sorption parameters.

4. Investigate the effects of mineralogy on the sorption/desorption of uranium and neptunium to obtain mechanistic insights into the measured distributions of sorption parameters.

In the long term desorption experiments, the percentages of uranium and neptunium sorbed as a function of time to zeolitic and devitrified volcanic tuffs of varying mineralogy were determined. In addition, the desorbed activity as a function of time was fit using a multi-site, multi-rate model to demonstrate that different desorption rate constants ranging over several orders of magnitude exist for the desorption of uranium and neptunium from Yucca Mountain volcanic tuff. To evaluate the applicability of rate constants obtained from the long-term desorption experiments under more realistic flow conditions and with more realistic solid to solution ratios, scaled up experiments were conducted in which uranium and neptunium were eluted at different flow rates through columns packed with one of the volcanic tuffs used in the desorption experiments. The up-scaled column breakthrough curves and sorbed concentration profiles (obtained after the experiments were terminated) were fit using a multi-site, multi-rate advection-dispersion-reaction model. However, this model could not simultaneously provide a good description of both the column profiles and the breakthrough data (using the same rate constants) for either the uranium or neptunium columns. In general, the combined breakthrough and profile data suggest that while the majority of the radionuclide mass was strongly retarded (profile data), there was a minor 
fraction that was less strongly retarded (breakthrough data). The inability to simultaneously model these two fractions of radionuclide mass might be explained by (1) disequilibria of uranium and neptunium solution species and/or (2) a dual porosity flow regime within the up-scaled columns.

To further investigate the possibility of multiple sorption sites for uranium in the volcanic tuff, the average local structural features of uranium freshly sorbed to and after one week of desorption from volcanic tuff was compared using Extended X-ray Adsorption Fine Structure (EXAFS) measurements. To complement the EXAFS, Electron Probe Microanalysis and x-ray mapping of similar samples was used to probe uranium spatial distributions and elemental associations within the volcanic tuff.

The multiple methods employed in this study provide many more insights and more realistic parameterization of sorption and desorption than simple batch experiments. When coupled with knowledge of mineralogical and geochemical heterogeneities along groundwater flow paths, this multi-method approach should result in significant improvements to predictions of subsurface contaminant transport. 


\section{TABLE OF ConTENTS}

Acknowledgements............................................................................................ii

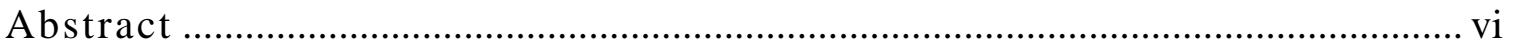

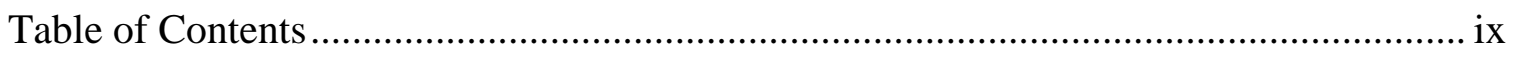

List of Figures ...................................................................................................

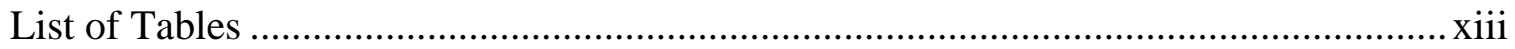

List of Appendices ................................................................................................. xiv

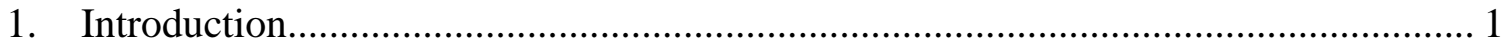

1.1. Research Motivation and Objectives .......................................................... 1

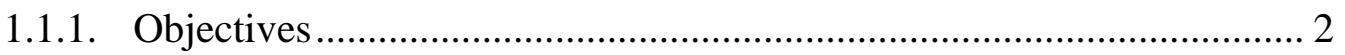

1.1.2. Conceptual Model ............................................................................. 3

1.2. Background and Literature Review ......................................................... 5

1.2.1. Previous studies in Yucca Mountain Saturated Zone Volcanic Tuffs.... 5

1.2.2. Previous Studies in Yucca Mountain Saturated Zone Alluvium............. 6

1.2.3. Uranium and neptunium solution speciation........................................... 9

1.2.4. Uranium and neptunium sorption mechanisms ..................................... 12

1.2.5. The Yucca Mountain Project approach to modeling uranium and

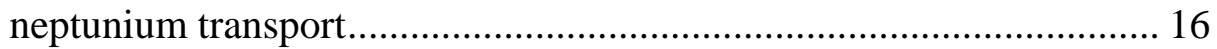

1.2.6. Component Additivity Methodology ...................................................... 16

1.2.7. More complex models of sorption/desorption (non-species specific) in

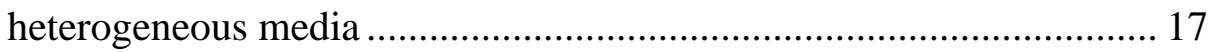

1.2.8. Mineralogical Effects on Uranium and Neptunium Sorption .............. 23

1.2.9. Influence of Natural Organic Matter and Microbial Processes on

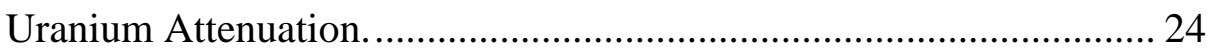

2. Experimental Materials and Methods ...................................................................... 25

2.1. General Approach ................................................................................ 25

2.2. Characterization of Groundwater............................................................ 26

2.2.1. Water Chemistry................................................................................. 26

2.2.2. Uranium and Neptunium Speciation ...................................................... 26

2.3. Preparation and characterization of volcanic tuff materials ..................... 29

2.3.1. Surface Area......................................................................................... 30 
2.3.2. Quantitative X-ray Diffraction (QXRD) ............................................... 31

2.3.3. Isoelectric Point (IEP) ....................................................................... 35

2.3.4. Cation Exchange Capacity (CEC) ......................................................... 39

2.4. Sorption and Desorption Experiments .................................................. 40

2.4.1. Batch Sorption and Flow Desorption Experiments ................................ 40

2.4.2. Up-scaled Column Experiments............................................................ 44

2.5. Spectroscopic Methods Used to Probe Uranium Sorption/Desorption

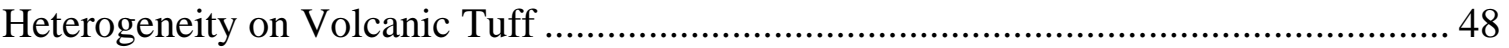

2.5.1. X-Ray Absorption Fine Structure Spectroscopy (EXAFS) Sample

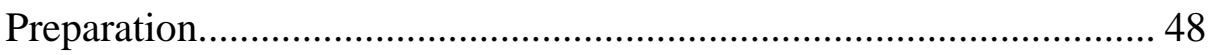

2.5.2. X-ray Mapping .................................................................................. 49

2.5.3. Electron Probe Microanalysis (EPMA).................................................. 50

3. Interpretive Methods.......................................................................................... 52

3.1. Batch Sorption/Long-Term Desorption Column Data Modeling .............. 52

3.2. Up-scaled Column Data Modeling ………………………………............. 53

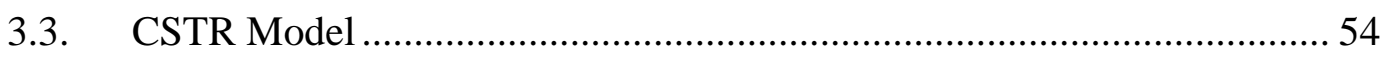

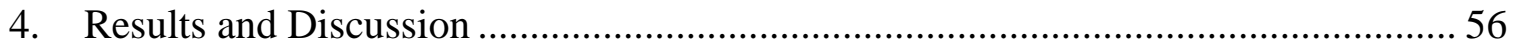

4.1. Sorption and Desorption Experiments ...................................................... 56

4.1.1. Uranium Batch Sorption and Flow Desorption Experiments................ 56

4.1.2. Up-scaled Uranium Column Experiments ............................................ 67

4.1.3. Neptunium Batch Sorption and Flow Desorption Experiments............ 82

4.1.4. Up-scaled Neptunium Column Experiments......................................... 90

4.2. Spectroscopic Methods to Probe Uranium Sorption/Desorption

Heterogeneity with Volcanic Tuff ................................................................................... 99

4.2.1. Extended X-Ray Absorption Fine Structure Spectroscopy (EXAFS).. 99

4.2.2. X-Ray Mapping................................................................................. 106

4.2.3. Electron Probe Microanalysis .............................................................. 110

4.2.4. Proposed Uranium Surface Complexes................................................. 114

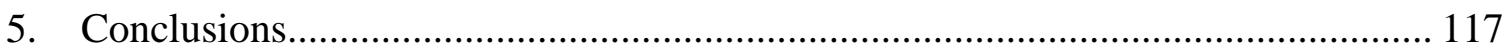

6. Recommendations for future work ……………….............................................. 122

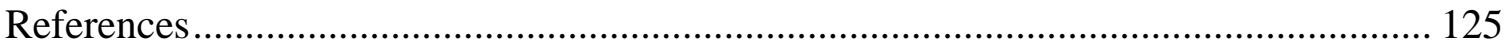




\section{LIST OF FIGURES}

Figure 1.1. Conceptual model of the fraction of radionuclide mass experiencing different $K_{d}$ values as a function of number of distance units through which transport occurs....................................................................... 5

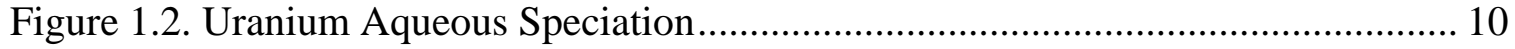

Figure 1.3 (a). Neptunium Eh-Ph Stability Diagram ................................................. 11

Figure 1.3 (b). Neptunium Speciation Plot .............................................................. 11

Figure 2.1. Location Map of the C-Wells and Well J-13............................................. 28

Figure 2.2 (a). Zeta Potential of a Smectite-rich tuff as a Function of $\mathrm{pH}$..................... 38

Figure 2.2 (b). Zeta Potential of a Mordenite-rich Zeolitic Tuff as a Function of pH..... 38

Figure 2.3. Schematic (a) and photo (b) of batch sorption reactor/flow desorption

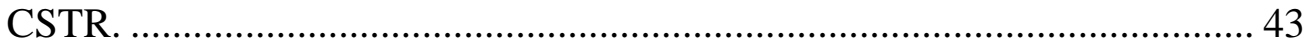

Figure 2.4. Schematic of Up-scaled Columns. ...................................................... 47

Figure 4.1. Uranium batch sorption and column desorption in the analcime-rich tuff.... 62

Figure 4.2. Uranium batch sorption and column desorption in the mordenite-rich tuff. 62

Figure 4.3. Uranium batch sorption and column desorption in the smectite-rich tuff..... 63

Figure 4.4. Uranium batch sorption and column desorption in the illite-rich tuff........... 63

Figure 4.5. Fraction of uranium sorbed normalized to surface area. ............................. 64

Figure 4.6. Alkaline/acid leach of remaining uranium in desorption columns................ 64

Figure 4.7. Uranium batch sorption and column desorption control samples. ................ 65

Figure 4.8. Tritium breakthrough from the $7 \mathrm{ml} / \mathrm{hr}$ (Column 1) flow rate experiments in the smectite-rich tuff up-scaled columns.

Figure 4.9. Tritium breakthrough from the $28 \mathrm{ml} / \mathrm{hr}$ (Column 3) flow rate experiments in the smectite-rich tuff up-scaled columns. 79

Figure 4.10. Uranium breakthrough from the $7 \mathrm{ml} / \mathrm{hr}$ and $28 \mathrm{ml} / \mathrm{hr}$ flow rate experiments in the smectite-rich tuff up-scaled columns.

Figure 4.11. Uranium concentration profiles in the $7 \mathrm{ml} / \mathrm{hr}$ (column 1) and $28 \mathrm{ml} / \mathrm{hr}$ (column 3) flow rate experiments in the smectite-rich tuff up-scaled columns. 80

Figure 4.12. Uranium batch sorption and column desorption in the smectite-rich tuff... 80 
Figure 4.13. Neptunium batch sorption and column desorption in the analcime-rich tuff. 85

Figure 4.14. Neptunium batch sorption and column desorption in the mordenite-rich tuff. 86

Figure 4.15. Neptunium batch sorption and column desorption in the smectite-rich tuff. 86

Figure 4.16. Neptunium batch sorption and column desorption in the illite-rich tuff. .... 87

Figure 4.17. Fraction of neptunium sorbed normalized to surface area. 87

Figure 4.18. Alkaline/acid leach of remaining neptunium in desorption Columns. 88

Figure 4.19. Tritium breakthrough from the $7 \mathrm{ml} / \mathrm{hr}$ (Column 2) flow rate experiments in the smectite-rich tuff up-scaled columns. 97

Figure 4.20. Neptunium breakthrough from the $7 \mathrm{ml} / \mathrm{hr}$ flow rate experiment in the smectite-rich tuff up-scaled columns.

Figure 4.21. Neptunium concentration profiles in the $7 \mathrm{ml} / \mathrm{hr}$ flow rate experiment in the smectite-rich tuff up-scaled columns. 98

Figure 4.22. Smectite-rich batch sorption and column desorption data with fits using up-scaled column parameters. 98

Figure 4.23. Fourier Transform Moduli and Real Components of the smectite-rich volcanic tuff EXAFS data comparing the sorption and desorption sample. 101

Figure 4.24. Fourier Transform Moduli and Real Components for the mordenite-rich volcanic tuff EXAFS data comparing the sorption and desorption sample. 101

Figure 4.25. Fourier Transform Moduli and Real Components for the smectite-rich sorption and desorption sample and the mordenite-rich sorption sample EXAFS data. 102

Figure 4.26. $\mu$-XAS images of freshly-sorbed $U$ (a,b,c) and post-desorption $U$ (d,e,f) thin sections of smectite-rich tuff 108

Figure 4.27. Electron Probe Microanalysis images of freshly-sorbed U (left) and post-desorption $U$ (right) thin sections of smectite-rich tuff. 
Figure 4.28. Electron Probe Microanalysis images of freshly-sorbed U (left) and post-desorption $U$ (right) thin sections of mordenite-rich tuff.

Figure 4.29. Structural Representation of Proposed Uranium Surface Complexes....... 115

\section{LIST OF TABLES}

Table 2.1. Chemistry of Water from Well J-13.

Table 2.2. Speciation of uranium $\left(10^{-6} \mathrm{M} \mathrm{U}(\mathrm{VI})\right)$ in $\mathrm{J}-13$ groundwater calculated by

PHREEQC at $\mathrm{pH}=7.8$

Table 2.3. Volcanic Tuff Surface Area

Table 2.4 Quantitative X-ray Diffraction Analysis of wet sieved tuff samples $(75 \mu \mathrm{m}$

$-500 \mu \mathrm{m})$ used in the long-term desorption and saturated column

experiments.

Table 2.5 Quantitative X-ray Diffraction Analysis of tuff samples used in the

EXAFS, $\mu$-XAS and X-ray mapping. 33

Table 2.6 Summary of Mineral Properties/Sorption Mechanisms for U and Np ............ 34

Table 2.7 Cation Exchange Capacity Measurements ................................................. 40

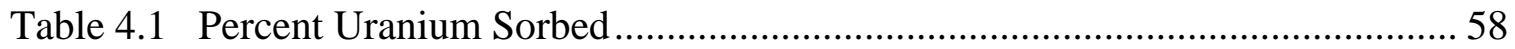

Table 4.2 Parameters used in uranium multi-site kinetic model, calculated effective

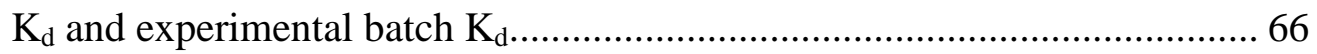

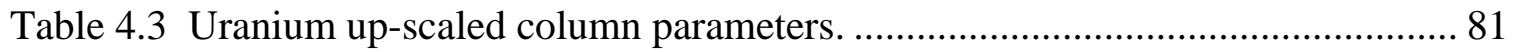

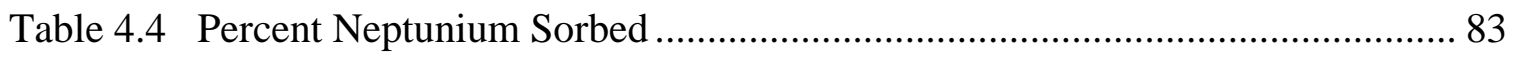

Table 4.5 Parameters used in neptunium multi-site kinetic model, calculated

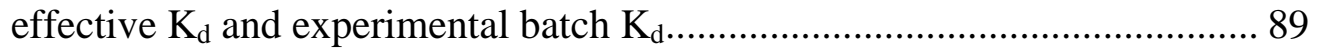

Table 4.6 Neptunium up-scaled column parameters................................................. 99 


\section{LisT OF APPENDICES}

APPENDIX 1-PHREEQC Output-uranium speciation in J-13 groundwater

133

APPENDIX 2A-BET Surface Area Measurements-Bedded Prow Pass (SMF

\#01006006)

APPENDIX 2B-BET Surface Area Measurements-Lower Bullfrog (SMF

\#01006012)

APPENDIX 2C-BET Surface Area Measurements-Central Bullfrog (SMF

\#0016536)

APPENDIX 2D-BET Surface Area Measurements-Upper Prow Pass (SMF \#0047478)

APPENDIX 3A-QXRD Analysis and XRD Patterns-75-500 $\mu \mathrm{m}$ grain size fraction used in column experiments

APPENDIX 3B-QXRD Analysis and XRD Patterns-fine fraction from settling procedure for EXAFS samples 157

APPENDIX 4-Zeta Potential Analysis. 160 


\section{INTRODUCTION}

Yucca Mountain, Nevada is the proposed site of a geologic repository for the disposal of spent nuclear fuel and high-level radioactive waste. In the event repository engineered barriers fail, the unsaturated volcanic tuffs underlying the repository and the saturated volcanic tuffs and alluvium beneath and to the south of Yucca Mountain are expected to retard the migration of radionuclides to the accessible environment. The purpose of this study is to improve the understanding of uranium and neptunium retardation in the saturated tuff at Yucca Mountain. In particular, this study focuses on kinetically controlled reactions that will ultimately control the transport of radionuclides over long-distance and time scales. Focusing on desorption and the associated desorption rate constants instead of the classic emphasis on sorption increases understanding of kinetically slower reactions that are not observable in short term batch studies. In addition, studying the geochemical processes and mechanisms controlling sorption and desorption enhances the ability to predict subsurface transport and fate of contaminants with greater accuracy in a variety of host media and geochemical conditions.

\subsection{Research Motivation and Objectives}

Understanding partitioning of contaminants between aqueous and solid phases in the subsurface at the macro- and molecular-scale is essential to estimating the risk associated with a potential release of radionuclides to the environment (Arai, McBeath et al. 2006). Often the partitioning of radionuclides in the subsurface is estimated using batch sorption and short-term desorption experiments, which are typically designed to

yield only a single distribution coefficient or equilibrium partition coefficient (ratio of sorbed radionuclide per unit mass of solid to non-sorbed radionuclide per unit volume of 
solution, or $\mathrm{K}_{\mathrm{d}}$ value, $\mathrm{ml} / \mathrm{g}$ ) suitable for incorporation into models that assume reversible, linear, first-order sorption kinetics (Scism (Dean), Reimus et al. 2006). $K_{d}$ distributions used for the saturated tuff and alluvium in the Yucca Mountain flow and transport models are based largely on batch sorption experiments (Arnold, Kuzio et al. 2003; Eddebbarh, Zyvoloski et al. 2003). These experimental methods do not effectively interrogate stronger sorption sites with slower desorption kinetics because the influence of stronger sites is not readily apparent during a short-term batch sorption or desorption experiment. This behavior is observed in column experiments where there is an apparent increase in the retardation of radionuclides in the column as the flow rate through the column is decreased (Keller 2004). Consequently, $K_{d}$ values obtained from short-term batch experiments may underestimate $\mathrm{K}_{\mathrm{d}}$ values that radionuclides will experience over long time and distance scales, and if the short-term $K_{d}$ values are used in models, they will result in conservative predictions. In addition, a mechanistic determination of radionuclide sorption associated with stronger sorption sites present in the host media will help reveal key mineral characteristics that govern strong sorption and slow desorption, thus allowing quantitative links to be made between sorption behavior and media properties.

\subsubsection{Objectives}

The objective of this work is to build on a previous study of radionuclide desorption from alluvium taken from the saturated zone down gradient of Yucca Mountain (Scism (Dean) 2005; Scism (Dean), Reimus et al. 2006). Experiments were conducted to interrogate strong sorption sites with slow desorption kinetics in addition to the weaker sorption sites in the tuffs. These experiments were used to develop effective 
$\mathrm{K}_{\mathrm{d}}$ values and an easily-implemented modeling approach capable of accounting for such distributions. $\mathrm{U}$ and $\mathrm{Np}$ were selected because of their significant contributions to offsite doses in many Yucca Mountain performance assessment scenarios due to their longhalf lives and relatively weak sorption under ambient geochemical conditions. The experiments were conducted under both static (batch) and flowing (column) conditions using water chemistries and geologic materials representative of potential flow pathways in the saturated volcanic tuff. In addition to the batch and column studies, various methods were utilized to further evaluate the mechanisms involved in the attenuation of uranium in the tuff materials. Extended X-ray Adsorption Fine Structure (EXAFS), $\mu$-XAS and Electron Probe Microanalysis (EPMA) were performed with materials from sorption and desorption experiments to better understand the elemental associations and local bonding environment of uranium. X-ray Diffraction Analysis (QXRD) was used to quantify crystalline mineral phases present in the tuff. The isoelectric point and surface area were also measured to support possible mechanisms of uranium and neptunium attenuation in the tuff materials.

\subsubsection{Conceptual Model}

A conceptual model was developed to consider the effects of stronger sorption sites with slower desorption kinetics. Figure 1.1 shows the results of a simplistic analysis to illustrate the impact of strong sorption sites over long time and distance scales. In this example, a large-scale flow system is conceptualized as a large number of ideally-mixed reactors in series, each containing the same solid mass to solution volume ratio. The solid is considered to have two types of sorption sites, with the first site having a $K_{d}$ value of $3 \mathrm{ml} / \mathrm{g}$ and representing $80 \%$ of the total available sites, and the second site having a 
$\mathrm{K}_{\mathrm{d}}$ value of $1000 \mathrm{ml} / \mathrm{g}$ and representing $20 \%$ of the available sites. These values are consistent with previous results (Scism (Dean) 2005; Scism (Dean), Reimus et al. 2006) where frequently $20 \%$ or more of the sorbed radionuclide tended to desorb very slowly (i.e., high $K_{d}$ value), but the slowly desorbing fraction would not be noticed in a batch sorption experiment or short-duration desorption experiment. The apparent $\mathrm{K}_{\mathrm{d}}$ value in each reactor (a.k.a., small batch sorption experiment) would be $\sim 3 \mathrm{ml} / \mathrm{g}$, or approximately the value corresponding to the weaker sorption site. If it is assumed that transport in the saturated zone over a small distance unit (i.e., distance associated with one reactor) results in an 80:20 split of radionuclide mass experiencing the 3 and $1000 \mathrm{ml} / \mathrm{g} \mathrm{K} \mathrm{d}_{\mathrm{d}}$ values, respectively, then transport over $n$ distance units will result in only $0.8^{n}$ of the radionuclide mass experiencing a $\mathrm{K}_{\mathrm{d}}$ value of $3 \mathrm{ml} / \mathrm{g}$, with the remaining radionuclide mass experiencing much greater $K_{d}$ values. Figure 1.1 shows the fraction of mass experiencing different effective $K_{d}$ values for different values of $n$, the number of distance units. For large values of $n$, all of the mass converges toward experiencing a weighted average of the $K_{d}$ values, in this case $0.8(3)+0.2(1000)=202.4 \mathrm{ml} / \mathrm{g}$. That is, a $K_{d}$ value of $3 \mathrm{ml} / \mathrm{g}$ will be effectively experienced over $80 \%$ of the transport distance, while a $\mathrm{K}_{\mathrm{d}}$ value of $1000 \mathrm{ml} / \mathrm{g}$ will be experienced over $20 \%$ of the transport distance. This simple analysis illustrates how effective $K_{d}$ values will be much larger over long time and distance scales if stronger sorption sites with slower desorption kinetics are present and are interrogated in experiments other than batch sorption and short-duration desorption experiments. 


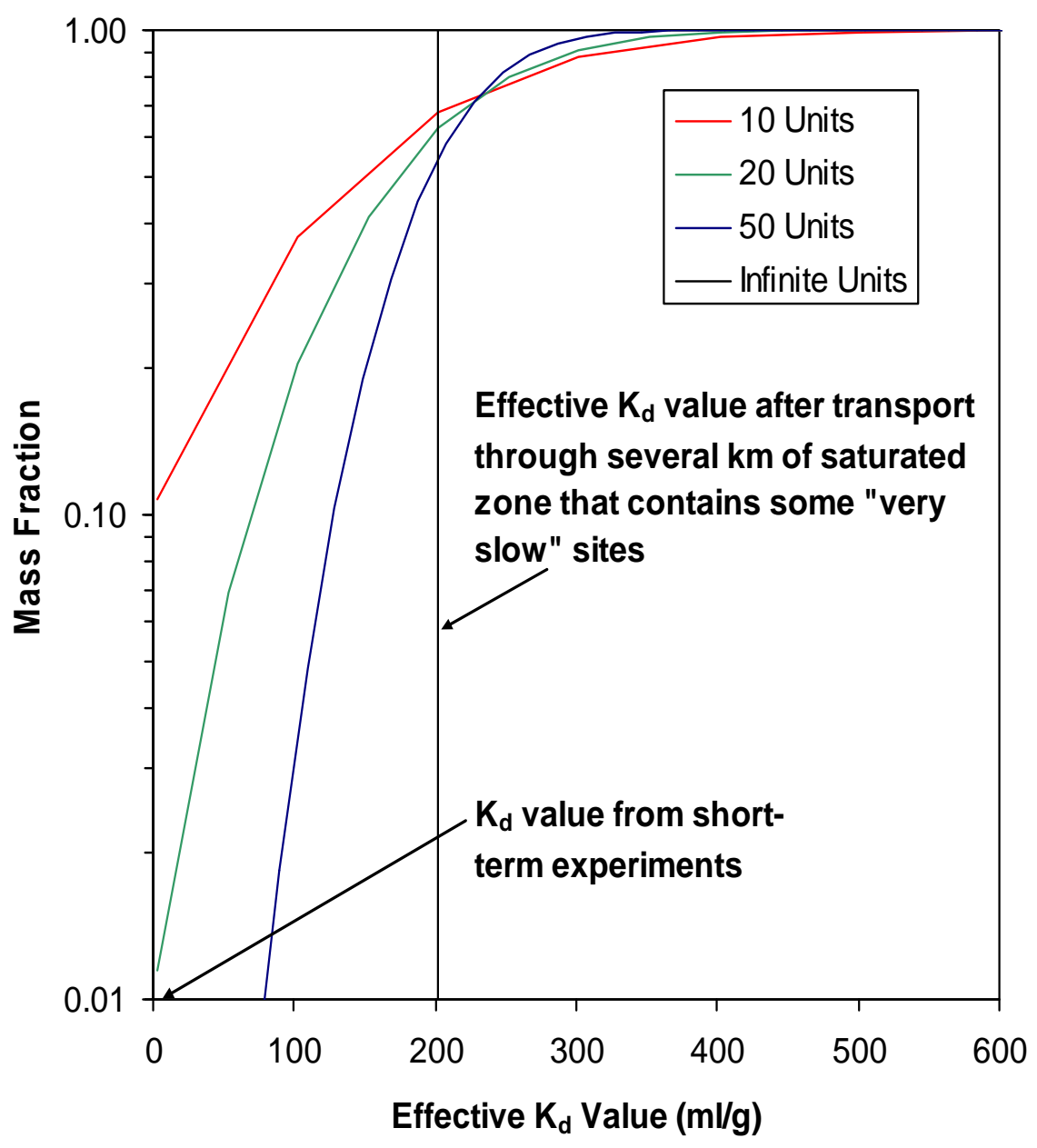

Figure 1.1. Conceptual model of the fraction of radionuclide mass experiencing different $K_{d}$ values as a function of number of distance units through which transport occurs. Calculations assume a simple two-site model with $80 \%$ of the sites having a $\mathrm{K}_{\mathrm{d}}$ value of $3 \mathrm{ml} / \mathrm{g}$ and $20 \%$ of the sites having a $\mathrm{K}_{\mathrm{d}}$ value of $1000 \mathrm{ml} / \mathrm{g}$.

\subsection{Background and Literature Review}

\subsubsection{Previous studies in Yucca Mountain Saturated Zone Volcanic Tuffs}

Batch sorption results suggest that Yucca Mountain devitrified and zeolitic tuff materials have a low affinity for neptunium and uranium (Triay 1997). In addition, a hysteresis effect was observed during subsequent batch desorption of these radionuclides, where desorption of the radionuclides from the tuff materials often resulted in larger $\mathrm{K}_{\mathrm{d}}$ values than those obtained from sorption experiments. This behavior suggests that 
uranium and neptunium sorption to these materials is not an entirely reversible process or has slow desorption kinetics (Triay 1997). In another study comparing batch sorption results with that of columns packed with vitrified, devitrified and zeolitic crushed tuff (same size fraction and material used in batch studies), it was found that the first arrival time of the $\mathrm{Np}$ in the column breakthrough could be predicted from a value for $\mathrm{K}_{\mathrm{d}}$ obtained from batch studies. However, incomplete recovery of the neptunium and long tailing of the column Np breakthrough curve suggests that sorption to zeolitic tuff is not linear or possibly not even entirely reversible and can not be described using a sorption distribution coefficient. It was also found that the Np did not break through prior to a non-sorbing tracer, tritium, indicating that ion exclusion of the neptunyl carbonate anion was not taking place in the crushed tuff columns (Triay 1996).

\subsubsection{Previous Studies in Yucca Mountain Saturated Zone Alluvium}

$\mathrm{K}_{\mathrm{d}}$ values were estimated through batch sorption of uranium and neptunium to alluvium from the saturated zone at Yucca Mountain. To complement the batch sorption experiments, uranium and neptunium transport experiments were carried out under fullysaturated, steady flow conditions in columns packed with the same alluvial materials used in the batch experiments. Uranium was eluted through three columns at the same flow rate, each packed with alluvium samples collected from different boreholes. In all cases, a small fraction of the uranium broke through at almost the same time as the conservative tracer (tritium), but the vast majority of the radionuclide mass was significantly retarded, resulting in a breakthrough curve with a long tail and incomplete recovery of the tracer (Ding 2003). These observations suggest that some of the uranium was slow to desorb from the columns within the time frame of the experiments. A long-tailing curve may 
also indicate the presence of stagnant areas and preferential flow within the column (Schweich and Sardin 1981), but this possibility can be ruled out because the conservative tracer did not exhibit this behavior. In a separate set of experiments, neptunium was eluted through columns packed with alluvium from the same borehole at different flow rates. Neptunium breakthrough at the slower flow rates also exhibited long tailing behavior and incomplete recovery. In addition, the retention of neptunium increased as flow rate through the column decreased, suggesting a residence time dependence of neptunium sorption. The observed behavior may be a consequence of radionuclides having a greater probability of encountering stronger sorption sites as the transport time through the column increased. Both the uranium and neptunium column experiments do not correlate well with the batch experiments in that the column transport of these radionuclides could not be explained by either slow sorption kinetics or equilibrium sorption with a single $K_{d}$ value (i.e., a single sorption and desorption rate). Rather, the column experiments suggested a distribution of $K_{d}$ values for uranium and neptunium that appear to be governed by a distribution of desorption rates (or $K_{d}$ values) that result in long-tailed responses and incomplete recovery of the radionuclides from the columns.

To better understand the early breakthrough of a portion of the radionuclide mass and long tailing behavior of the recovery curves from the column transport experiments, specially designed column experiments were performed after one to fourteen days of batch sorption of uranium (Scism (Dean) 2005). Several alluvium and groundwater combinations were used in the experiments to study the effects of water chemistry and secondary mineral phases on radionuclide desorption behavior. Sorption and desorption 
rate constants from these experiments were obtained by fitting the desorption data with a multi-site explicit kinetic model. The multiple sorption and desorption rates obtained from the fit of the data were used to calculate an effective $K_{d}$ value for each of the experiments that would account for strong sorption sites with slow desorption kinetics while also accounting for weaker uranium and neptunium sorption sites in the alluvium. For almost all groundwater/alluvium combinations, a four-site model with desorption rates ranging over three orders of magnitude was required to fit the data.

As the batch sorption period for neptunium was increased, the portion of radionuclide desorbing from the alluvium decreased for all groundwater/alluvium combinations. The strong sorption sites are believed to be associated with smectite clays and zeolites in the alluvium, which is consistent with batch and column experiments that result in higher attenuation of uranium and neptunium in alluvium with a higher zeolite + smectite weight percent. In addition, the strength of sorption increases as carbonate concentrations in the groundwater decrease. This observation is consistent with a surface complexation sorption process that is suppressed by carbonate complexation in solution. The uranium and neptunium desorption rate constants decreased as a function of desorption time, suggesting that the alluvium has multiple types of active sorption sites with different affinities for uranium and neptunium. While a significant fraction of the initially sorbed radionuclide desorbed from the alluvium quite rapidly, a roughly equivalent amount remained sorbed after several months of testing. The information obtained through this research suggests that uranium and neptunium may experience greater effective retardation in the alluvium than simple batch sorption experiments would suggest. In addition, Electron Probe Microanalysis showed that uranium was 
associated with both clay minerals and iron oxides after sorption to alluvial material. These results provide further evidence that the alluvium contains heterogeneous sorption sites for uranium and neptunium. It is believed that the saturated volcanics from which the alluvium is derived, will also have heterogeneous sorption sites for these radionuclides and that the same type of long-term desorption behavior will be observed.

\subsubsection{Uranium and neptunium solution speciation}

The aqueous speciation of $\mathrm{U}$ and $\mathrm{Np}$ is a major factor in how they will be attenuated by a host media whether by cation exchange, surface complexation, or precipitation on or co-precipitation with other mineral phases. A sodium bicarbonate groundwater from well J-13 was used in the current study. The literature reports a measured Eh of $\mathrm{J}-13$ groundwater of $482 \pm 10$ to $497 \pm 10$ (mV vs. NHE) at $\mathrm{pH} 6.9$ and 8.5, respectively, and $25^{\circ} \mathrm{C}$ (Nitsche 1993), $340 \mathrm{mV}$ (sampled using an evacuated stainless steel bottle in the field) (Ogard and Kerrisk 1984; Orgard and Kerrisk 1984; Triay 1997) and $700 \mathrm{mV}$ (Orgard and Kerrisk 1984). A pH value of 6.9 was measured in the field (Orgard and Kerrisk 1984) and the laboratory measured $\mathrm{pH}$ is 7.4, as shown in Table 2.1. Figure 1.2 below indicates that the dominant aqueous uranium species expected at a pH of $\sim 7.0$ are $\mathrm{CaUO}_{2}\left(\mathrm{CO}_{3}\right)_{3}^{2-}$ and $\mathrm{Ca}_{2} \mathrm{UO}_{2}\left(\mathrm{CO}_{3}\right)_{3}^{0}$ (Dong and Brooks 2006). According to the Eh-Ph diagram shown in Figure 1.3a below, the stable neptunium species at a $\mathrm{pH}$ of 7 to 8 under oxidizing conditions $(\mathrm{Eh}=430 \mathrm{~V})$ at $25^{\circ} \mathrm{C}, 1$ bar of pressure and a neptunium concentration of $10^{-5} \mathrm{M}$ and a carbonate concentration of $10^{-2.6} \mathrm{M}$ in $\mathrm{J}-13$ groundwater is the neptunyl cation $\left(\mathrm{NpO}_{2}^{+}\right)$. In the speciation diagram shown in Figure 1.3b, the dominant neptunium species in solution under the same conditions is $\mathrm{NpO}_{2}^{+}$and $\mathrm{NpO}_{2} \mathrm{CO}_{3}^{-}$(Kaszuba and Runde 1999). Nitsche (1993) reported 
a neptunium speciation of $46 \% \mathrm{NpO}_{2}^{+}$and $54 \% \mathrm{NpO}_{2} \mathrm{CO}_{3}^{-}$at a $\mathrm{pH}$ of 7 and at $\mathrm{pH} 8.5$, $38 \% \mathrm{NpO}_{2}^{+}$and $62 \% \mathrm{NpO}_{2} \mathrm{CO}_{3}^{-}$for $\mathrm{J}-13$ groundwater at $25^{\circ} \mathrm{C}$ and oxidizing conditions. Neptunium tends to form complexes with carbonate species at higher $\mathrm{pH}$ than uranium and therefore a less pronounced effect of carbonate complexes on sorption is expected at the $\mathrm{pH}$ of the groundwater (7 to 8.5). The experiments in this study were performed under ambient conditions and the groundwater/tracer solutions used in the experiments are assumed to be in equilibrium with the ambient atmosphere (oxidizing conditions, $P_{\mathrm{CO}_{2}}=$ $10^{-3.5}$ ). The prevailing oxidation states for $\mathrm{U}$ and $\mathrm{Np}$ in $\mathrm{J}-13$ groundwater are $\mathrm{VI}$ and $\mathrm{V}$, respectively (Triay 1997).
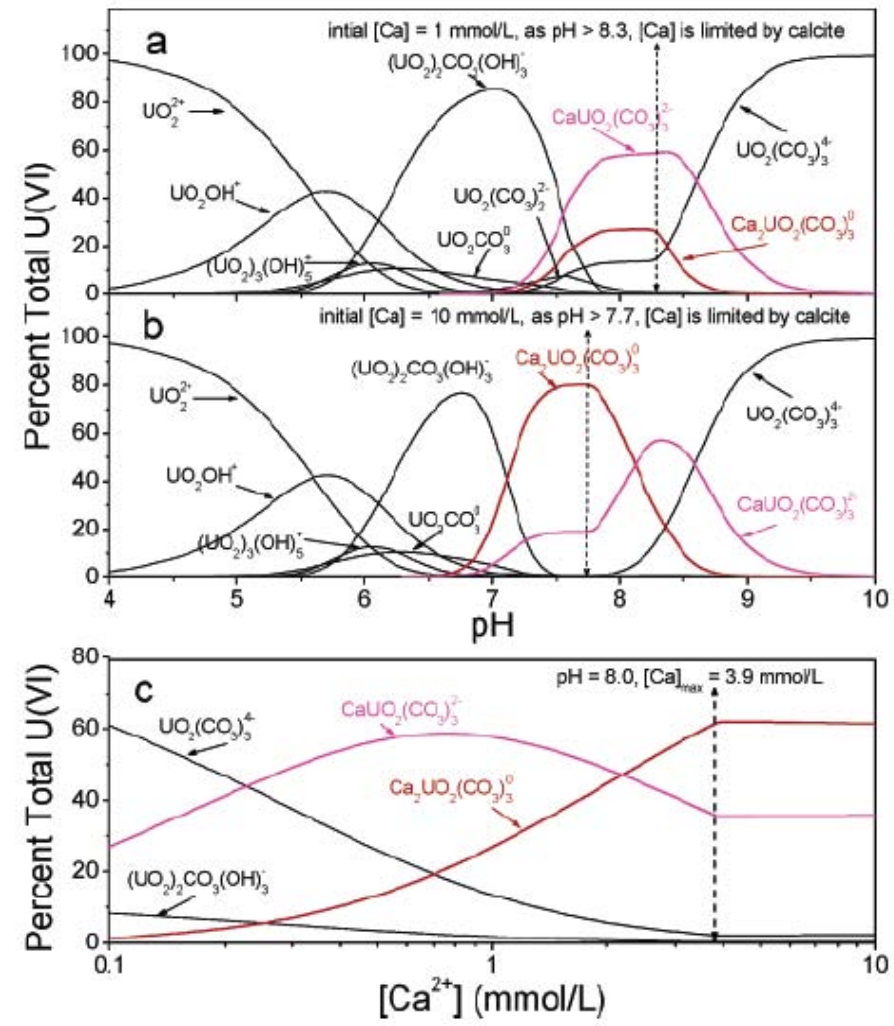

Figure 1.2. Uranium Aqueous Speciation. Aqueous (VI) speciation distribution in the absence and presence of $\mathrm{Ca}^{2+}$ at $[\mathrm{U}(\mathrm{VI})]=1 \mu \mathrm{mol} / \mathrm{L}, \mathrm{I}=0.1 \mathrm{~mol} / \mathrm{L} \mathrm{NaNO}_{3}, P_{\mathrm{CO}_{2}}=10^{-35} \mathrm{~atm}$, and $25^{\circ} \mathrm{C}$. (Dong and Brooks 2006). 


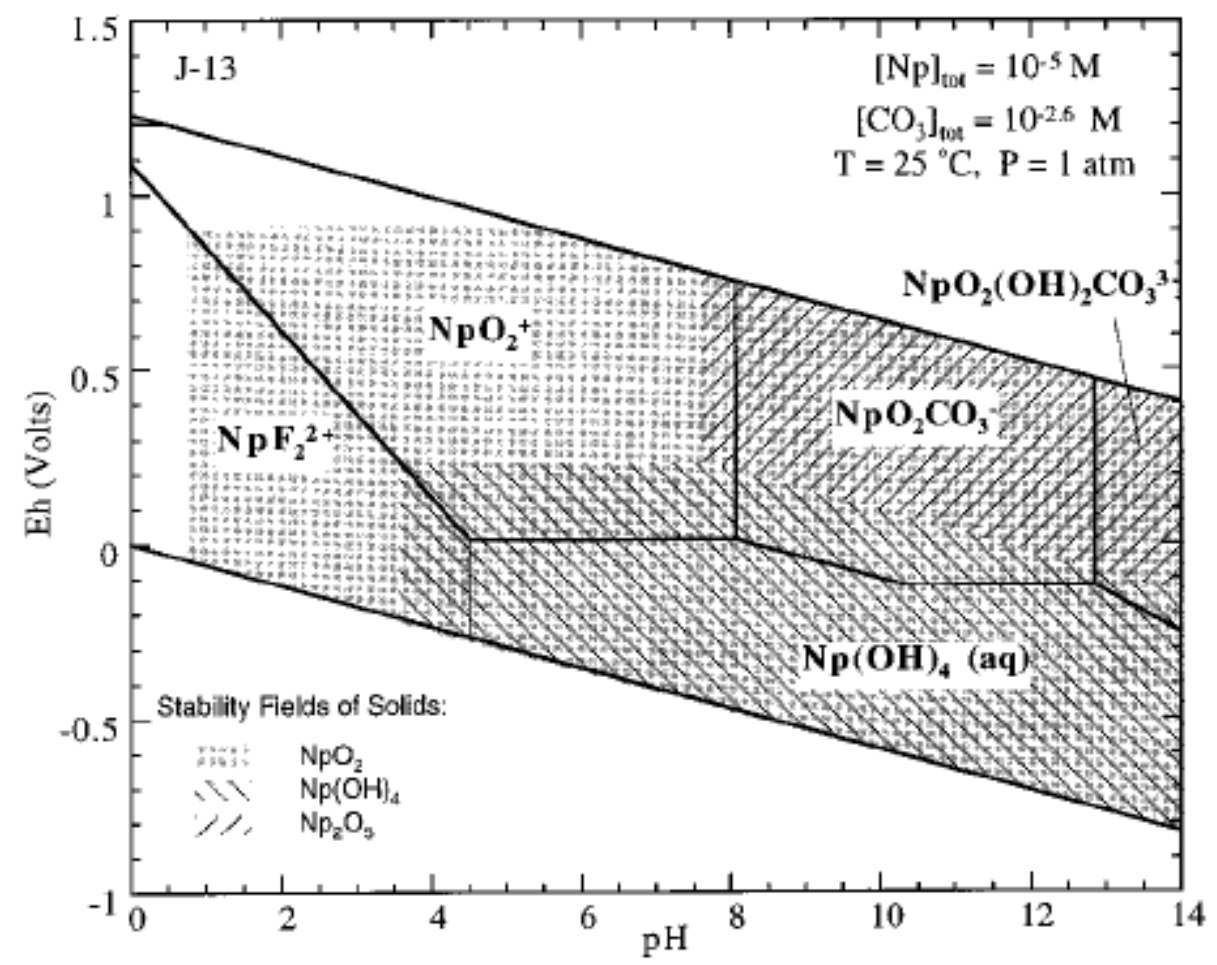

Figure 1.3 (a). Neptunium Eh-Ph Stability Diagram (Kaszuba and Runde 1999)

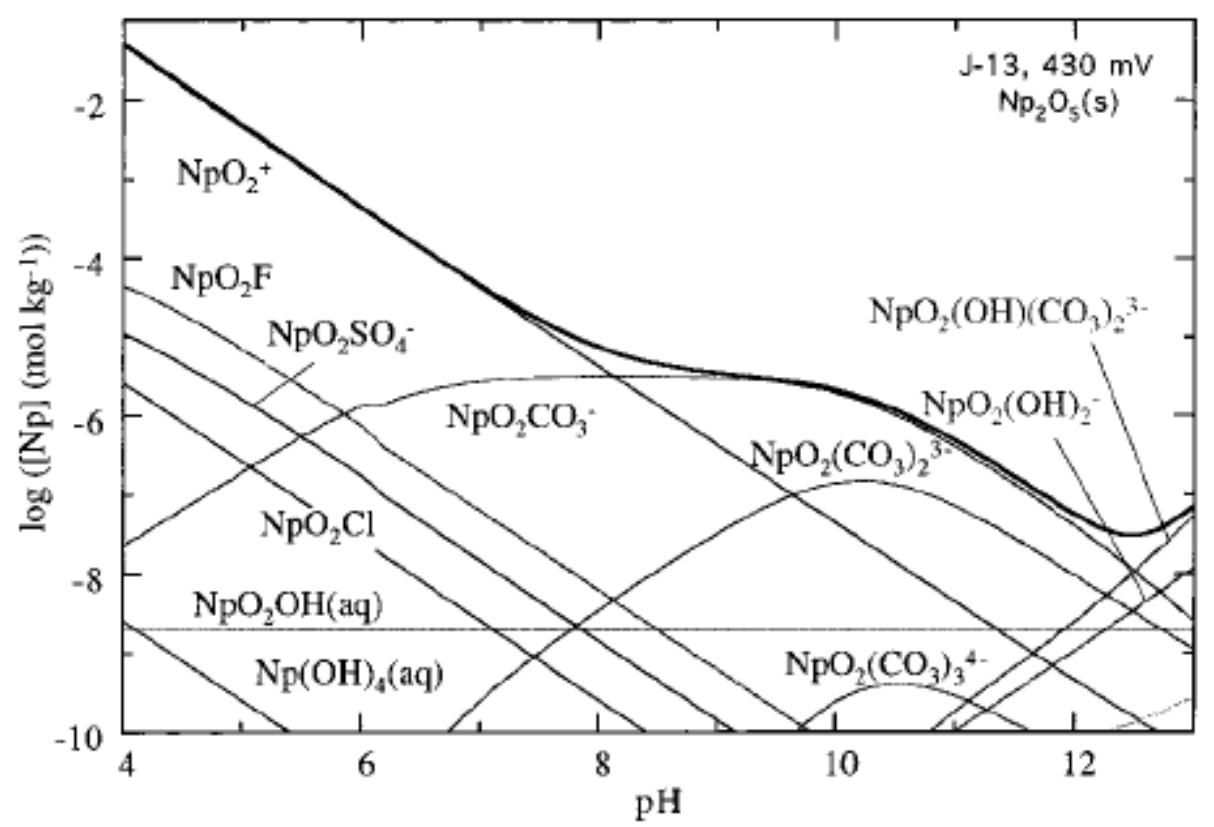

Figure 1.3 (b). Neptunium Speciation Plot (Kaszuba and Runde 1999) 


\subsubsection{Uranium and neptunium sorption mechanisms}

Stammose et al. (1992) performed batch sorption and desorption measurements of uranium and neptunium to purified clay minerals (mixture of smectite and kaolinite) for potential use as an engineered barrier in radioactive waste disposal. Surface complexation at hydroxyl groups and cation exchange within the smectite lattice and at exposed edge sites are two mechanisms considered in their study. Neptunium and uranium sorption was carried out while varying the $\mathrm{pH}$ and ionic strength in solution. The $\mathrm{K}_{\mathrm{d}}$ for neptunium increased between $\mathrm{pH} 3$ to 6 with decreasing ionic strength and increased with increasing ionic strength above $\mathrm{pH}$ 6. The desorption of neptunium exhibited a hysteresis effect at $0.5 \mathrm{M}$ ionic strength from $\mathrm{pH} 3$ to 7 , suggesting that neptunium sorption is not entirely reversible and/or encounters slow desorption kinetics in the purified clay at these conditions. The neptunium sorption data as a function of $\mathrm{pH}$ was fit well with a 2-site cation-exchange model. For uranium, the $\mathrm{K}_{\mathrm{d}}$ increased from $\mathrm{pH}$ 3 to $\mathrm{pH}$ of 6 and then decreased from $\mathrm{pH} 6$ to 10 . The higher ionic strength solution resulted in higher $\mathrm{K}_{\mathrm{d}}$ values for uranium from $\mathrm{pH} 5$ to 6 , with the lower ionic strength solutions resulting in higher $\mathrm{K}_{\mathrm{d}}$ values for $\mathrm{pH} 3$ to 5 and $\mathrm{pH} 6$ to 9 . Desorption of uranium was found to be reversible for an ionic strength of $1 \mathrm{M}$ from $\mathrm{pH} 3$ to 9 in the purified clay mineral. The sorption of uranium as a function of $\mathrm{pH}$ was fit well with a 1site cation exchange model, although above $\mathrm{pH}$ of 8 , the model fails to describe the data. The authors conclude that the model failed at higher $\mathrm{pH}$ because polynuclear uranium species were not considered.

Attenuation of species by cation exchange in zeolites is dependent on the diameter

of the pore channel opening of the zeolite (average of $5 \AA \hat{\text { ) }}$ being greater than that of the 
ionic radius of the cation in solution (Krestou, Xenidis et al. 2003). The hydrated ionic radius of the $\mathrm{UO}_{2}^{2+}$ cation (estimated by Krestou to be $6.5 \AA$ ) is greater than that of the pore channel diameter of the zeolite, therefore cation exchange is not a likely uranium sorption mechanism in zeolites. The hydrated ionic radius of neptunium was not found in the literature although, neptunium’s ionic radius is .02 $\AA$ greater than uranium’s ionic radius, therefore the hydrated ionic radius of neptunium is mostly likely similar to uranium. In addition, cation exchange would be expected to be $\mathrm{pH}$ dependent in that above a $\mathrm{pH}$ of 7.5 (Figure 1.2) the uranium in solution is dominated by negatively charged uranyl-carbonate complexes. The most likely mechanism for uranium attenuation between pH 5.4 to 9 (range of maximum attenuation) in zeolites is adsorption to edge sites via silanol groups. In this $\mathrm{pH}$ region, the silanol groups have a positive charge and the negative uranyl carbonate complexes in solution are attracted to these groups (Krestou, Xenidis et al. 2003). However, by adding $400 \mathrm{mg} / \mathrm{L}$ of $\mathrm{CO}_{3}^{2-}$ to solution in a closed system, the attenuation of uranium was suppressed at $\mathrm{pH} 5.9$ and totally inhibited at $\mathrm{pH}$ 9, due to sorption of carbonates altering the surface potential of the zeolitic tuff. Triay (1997) also found that sorption to zeolites could not be predicted by the materials cation exchange capacity. A large amount of sorption would be expected if cation-exchange is the dominant mechanism in a material with a large cation-exchange capacity (such as clinoptilolite). This was not the case for either uranium or neptunium, suggesting a surface complexation reaction rather than ion exchange mechanism for these radionuclides in zeolitic tuff materials. In addition, uranium and neptunium $K_{d}$ 's are more positively correlated with tuff surface area than cation exchange capacity, which further suggests a surface complexation reaction mechanism (Triay 1997). 
Several groups (Hsi and Langmuir 1985; Ho and Miller 1986; Waite, Davis et al. 1994; Duff 1996; Lenhart and Honeyman 1999) have speculated that U(VI)-carbonato complexes adsorb on $\mathrm{Fe}$ oxides (i.e., forming $\mathrm{Fe}$ oxide-U(VI)-carbonato ternary complexes), greatly retarding U(VI) transport. Bargar, Reitmeyer et al. (2000) used Extended X-Ray Adsorption Fine Structure (EXAFS) spectroscopy and electrophoresis to study U(VI) complexes sorbed onto hematite. The electrophoresis mobility measurements suggest that uranium complexes are anionic and bond strongly to hematite to form inner-sphere ternary complexes. EXAFS analysis of the adsorbed U(VI) species indicate that they are predominately monomeric (no near $U$ neighbors). This finding is not consistent with a precipitation or co-precipitation of ordered solids as a mode of sorption for $\mathrm{U}(\mathrm{VI})$. The authors concluded that $\mathrm{U}(\mathrm{VI})$-carbonato-hematite ternary complexes occur and are important species between $\mathrm{pH} 4.5$ and 8.5. Catalano and Brown (2005) used EXAFS analysis to investigate the adsorption of the uranyl ion onto montmorillonite. In solutions containing $10^{-3} \mathrm{Na} \mathrm{NO}_{3}$ at $\mathrm{pH} 4.2$ to 7.2 in $\mathrm{CO}_{2}$ containing systems, the formation of uranyl-carbonato ternary surface complexes on edge sites of montmorillonite appears to dominate the sorbed speciation of uranium. Sample EXAFS spectra were compared to the spectra of uranyl adsorbed onto hematite and uranyl was found to preferential bind to $\mathrm{Fe}(\mathrm{O}, \mathrm{OH})_{6}$ sites over $\mathrm{Al}(\mathrm{O}, \mathrm{OH})_{6}$ sites on the edges of Wyoming montmorillonite in $\mathrm{CO}_{2}$ containing systems, most likely to $\mathrm{Fe}(\mathrm{O}, \mathrm{OH})_{6}$ present in clay octahedral sheets. Bostick, Fendorf et al. (2002) studied uranium sorption on natural soils and sediments from the DOE facilities. Spectroscopic examination suggested the presence of disordered inner-sphere complexes and outer-sphere 
complexes, both ternary in nature. Iron (hydr)oxides were found at least partially responsible for uranyl retention.

Jerden and Kropf (2007) studied surface complexation of $\mathrm{Np}(\mathrm{V})$ on goethite. Their X-ray absorption spectroscopic data indicate that the neptunium uptake in a sodium chloride solution is significantly influenced by outer-sphere surface complexation. Another set of experiments performed in simulated groundwater solutions show evidence for inner-sphere complexation of neptunium on goethite. Desorption tests indicate that samples in which neptunium is bound as inner-sphere complexes show significant sorption hysteresis relative to samples in which neptunium is bound largely as outersphere complexes. Reich, Reich et al. (2007) studied the sorption of neptunium onto kaolinite. EXAFS data indicated inner and outer-sphere sorption of neptunyl carbonate in experiments equilibrated with the atmosphere and inner-sphere sorption of the neptunyl cation in a $\mathrm{CO}_{2}$-free system. Combes, Chisholm-Brause et al. (1992) studied sorption of aqueous $\mathrm{Np}(\mathrm{V})$ on goethite by EXAFS. Their data provide evidence for the formation of inner-sphere complexes of $\mathrm{Np}$ at the goethite/water interface. EXAFS spectroscopic data for $\mathrm{Np}(\mathrm{V})$ sorption onto goethite indicated that $\mathrm{Np}(\mathrm{V})$ solution species sorbed to the surface of the goethite as the solution species, namely $\mathrm{NpO}_{2}^{+}$. The study did not rule out the possibility that the surface complex included hydroxide or carbonate ligands. The study did rule out the possibility of diffusion into the solid and precipitation or co-precipitation of ordered solids as modes of sorption for Np onto goethite because the XANES and EXAFS spectrum for a crystalline $\mathrm{NpO}_{2}$ standard were different from the spectra of the unknown samples. 
1.2.5. The Yucca Mountain Project approach to modeling uranium and neptunium transport

Various transport codes such as FEHM (Finite Element Heat and Mass Transfer) (Zyvoloski 1997) have been used to model transport of uranium and neptunium (Viswanathan, Robinson et al. 1998) species in the saturated zone at Yucca Mountain. These models consider only a single $\mathrm{K}_{\mathrm{d}}$ value for the partitioning of uranium between the solid and solution phases. This is a conservative approach to modeling uranium transport because $K_{d}$ values assume fast, reversible sorption, and they tend to significantly underestimate sorption if they are derived from short-duration batch experiments. Desorption rates likely control radionuclide fate and transport to a much greater degree than sorption rates. Based on the available background information, it is expected that uranium sorption to Yucca Mountain tuffs will be dominated by surface complexation of uranyl ions that are present in solution predominantly as metal-uranyl-carbonate complexes. The sorption/desorption equilibria and rates are expected to depend most strongly on groundwater $\mathrm{pH}$ and alkalinity as well as on clay, zeolite and iron oxide content of the host matrix. Freundlich and Langmuir isotherms, cation exchange models and surface complexation models have been used successfully by Hsi and Langmuir (1985) and Davis and Kent (1990) and many others to explain uranium sorption behavior in heterogeneous systems.

\subsubsection{Component Additivity Methodology}

The component additivity approach is a method of determining the sorption of a solute in a complex mineral assemblage by determining its partitioning to wellcharacterized pure mineral phases. The "component" for each pure mineral phase is 
added together proportionately for each phase present in the mineral assemblage to predict the solute transport within the complex media (Davis, Coston et al. 1998). There are several limitations to this method, most notably the presence of surface coatings on mineral grains or secondary mineral phases such as iron and aluminum oxides not present in the pure mineral phases and that represent only a small weight percentage of the complex assemblage. Davis, Coston et al. (1998) were unable to predict radionuclide transport behavior by employing the component additivity model to U(VI) adsorption onto aquifer sediments. Additional parameters were needed to fit the experimental data. The errors identified in their study arose from their inability to quantify the proportion and type of surface functional groups available for sorption in surface coatings, interacting double layers of heterogeneous particles and competing ions in solution. The component additivity method underestimates overall radionuclide retardation in aquifer materials through the use of $K_{d}$ values obtained from pure mineral/radionuclide batch reaction experiments and neglecting surface coatings and non-equilibrium sorption reactions.

1.2.7. More complex models of sorption/desorption (non-species specific) in heterogeneous media

Hull, Grossman et al. (2004) developed a semi-empirical theoretical model based on partition coefficients and surface complexation theory to predict sorption isotherms for uranium in a heterogeneous material. Partition coefficients were experimentally derived through batch sorption of uranium at varying concentrations to material samples from the Subsurface Disposal Area (SDA) at Idaho Engineering and Environmental Laboratory. The log transform of the experimental data were fit using a Freundlich 
isotherm $\left(\log \left[C_{a d s}\right]=\log \left[K_{f}\right]+n \cdot \log \left[C_{\text {sol }}\right]\right)$. A $K_{f}$ (intercept) value and $n$ (slope) was determined from the isotherm for each sediment sample. The best fit model uses a unique $K_{f}$ for each sample set, while keeping $n$ constant over all sample sets. The empirical coefficient, $n$, was found to correlate more closely with surface area, rather than cation exchange capacity, suggesting a surface site mechanism. A theoretical surface complexation model was used to account for the aqueous solution chemistry. The formation of metal-ligand complexes in solution is described by a Langmuir isotherm which includes terms describing the thermodynamic adsorption coefficient, solution chemistry and total surface sites. The semi empirical theoretical model was found to predict $\log K_{a d s}$ for uranium in samples from the SDA within an uncertainty of $\log K_{a d s}$ \pm 1.8 . The model does not account for changes in surface charge as a function of $\mathrm{pH}$ and therefore it is valid over a limited range of $\mathrm{pH}$ values.

Culver, Brown et al. (2000) proposed a variation of the Advective Dispersive model with multiple site mass transfer to fit packed column recovery data for 1,2Dichlorobenzene (DCB) in a natural sand soil column. The authors conclude that allowing gamma-distributions of rates to differ between uptake and desorption improved the ability to fit the observed data. Previous DCB batch studies indicated irreversible sorption or extremely slow desorption. Culver concluded that extremely slow desorption was not present in the DCB columns and that the mixing action of batch reactors may cause an increase in sorption to sites that are not available in a packed soil column and that the effects of advection and dispersion may be masking the effects of sorption hysteresis in a packed column system. 
A gamma distribution based on a uranium $K_{d}$ value assigned to a specific site group has been used (Yabusaki, Fang et al. 2007; Yabusaki 2008) to populate a ratelimited mass transfer model to fit uranium transport data collected from the Hanford 300 Area based on the laboratory results of Qafoku, Zachara et al. (2005) that suggested $\mathrm{U}(\mathrm{VI})$ release and transport in the field are likely to be kinetically controlled. The kinetically controlled sorption and desorption of uranium has been attributed to intraparticle diffusion, sites with different reactivities and surface precipitation. In the Qafoku, Zachara et al. study, a series of columns packed with U-contaminated Hanford sediment were used to perform desorption and sorption experiments. Two of the columns were leached of uranium while 3 were left contaminated to look at sorption-desorption coupling by effectively simulating a groundwater rise into the capillary fringe (a source of $U$ contamination). The stop flow technique was used to evaluate whether the $U$ transport process was at equilibrium by looking at the concentration in solution both before and after a stop flow event, which revealed significant non-equilibrium sorption behavior. CXTFIT (Toride 1999) was used to calculate transport parameters based on $\mathrm{Br}$ breakthrough curves. An equilibrium adsorption model (assuming physical equilibrium) in CXTFIT was used to calculate a dispersion and retardation coefficient. The authors tried to fit $\mathrm{Br}$ data with a physical non-equilibrium model (2 domain or dual porosity model) and the results indicated that all water was mobile and that physical nonequilibrium played no significant role in $\mathrm{Br}$ transport. A one-dimensional distributed rate coefficient model (Culver, Hallisey et al. 1997) was used fit the U column data. Mass transfer coefficients were obtained from a gamma distribution and a single value of $\mathrm{K}_{\mathrm{d}}$ was assumed for all sorption sites. The governing equations included terms for 
advection, hydrodynamic dispersion and the sorption/desorption terms. The authors found that the use of the gamma distribution for time-dependent processes in soil and sediments is consistent with two conceptual models: (i) a chemically controlled system containing a large number of binding site groups that exhibit similar sorption but different desorption rates and (ii) a mass transfer controlled system containing a wide distribution of pore or diffusion path lengths, but the latter can be ruled out based on the lack of a diffusion signature from the conservative tracer, bromide in this study. The authors found that the mean rate constant for desorption was greater in the fast-flow column (shorter residence time) suggesting that either the attenuation processes are diffusion limited or kinetically slow. Retardation was found to decrease with increasing $\mathrm{U}$ concentration in the injecting solution. The authors believe that a possible conceptual model to explain the observed behavior is that poorly accessible sorbent domains exist within the sediment fine fraction and are responsible for the non-equilibrium sorptiondesorption behavior of $\mathrm{U}(\mathrm{VI})$. Thin sections showed sand grains and lithic fragments were coated with layers of phyllosilicates (smectite, vermiculite, chlorite). These may be sorbent domains that exhibit limited diffusivity, although the two-region model used to fit the $\mathrm{Br}$ breakthrough indicated that all water was mobile. Under oxidizing conditions chlorite weathers to soluble Fe(II) that oxidized to form ferrihydrite which is a strong $\mathrm{U}(\mathrm{VI})$ adsorbent. The authors hypothesize that ferrihydrite existed in the sediment in both accessible and restricted domains. Model calculations based on extractable FeOX concentrations suggested a higher $K_{d}$ than observed, supporting this hypothesis. This model was updated recently by replacing the linear sorption isotherm $\left(\mathrm{K}_{\mathrm{d}}\right)$ with uranyl surface complexation reactions (Liu, Zachara et al. 2008) and accounting for changes in 
$\mathrm{pH}$, and calcium and carbonate concentrations in solution by adding multi-rate ion exchange reactions (Liu, Shi et al. 2009).

Culver, Hallisey et al. (1997) found that the fraction of initial mass of organic contaminants remaining on contaminated sediment versus time indicated an increase in resistance to desorption with time. The authors found that a compartmentalized model representing soil mass fractions with different mass transfer rates taken from a lognormal or gamma distribution fit tailing behavior in column experiments more accurately than a one or two-site model, which assumes that mass transfer rates do not vary. To fit the data, up to 100 compartments, each representing a single site in a one-site model, were used although it was found that after 50 compartments, the fit was not greatly improved. To reduce the number of variables, each kinetic compartment is assumed to occupy an equal fraction of the soil. This method does not weight mass transfer rates based on the fraction of the contaminant desorbed at a particular rate; therefore, many equallyweighted compartments are needed to fit the desorption curve. Although this method is useful in developing a continuous distribution of mass transfer rates that describe a particular system, it is not useful in understanding the underlying mechanisms of mass transfer or sorption/desorption.

The research of Deitsch, Smith et al. (2000) focuses on the rate limited sorption/desorption of an organic pollutant 1,2-Dichlorobenzene from 5 different soils. The authors propose that sterically hindered diffusion through the intra-particle pore network and/or through the soil organic matter results in kinetically controlled sorption and desorption. Some studies have shown that the resistant fraction of the sorbed contaminant appears to increase with longer soil/contaminant contact times. This 
phenomena has been attributed to solute/soil system not reaching a true equilibrium before the desorption phase was initiated. To test this hypothesis, efforts have been made to compare the rate of solute uptake with solute desorption. An intraparticle diffusion model with parameters determined from uptake experiments was able to account for the majority of sorption hysteresis (Miller and Pedit 1992).

Cunningham and Deitsch et al. (2005) quantify sorption and desorption time scales for an organic contaminant onto four natural sorbents from the previous study above (Deitsch, Smith et al. 2000) using temporal moment analysis. The authors develop a probability distribution by integrating the mean and variance of sorption and desorption time scales obtained from batch experimental data. The first temporal moment, the mean time scale, is assumed to be the time to reach equilibrium. The higher the value of the first temporal moment, the slower the desorption kinetics. The second temporal moment is the variance and represents the range of sorption time scales. While this method is useful in quantifying observations made from short-term batch sorption and desorption experiments, it still relies on the equilibrium assumption. In fact, one of the sorbents in the original batch experiments was not analyzed with this method because it did not reach the assumed equilibrium during the sorption experiment. The authors admit that this method is not useful in describing more complicated processes like sorption/desorption hysteresis. When comparing results of the temporal moment analysis to a curve fitting method, one of the sorbents (a silty clay) exhibits both the fastest (moment analysis) and the slowest sorption rates (best gamma-fit). 


\subsubsection{Mineralogical Effects on Uranium and Neptunium Sorption}

Clay minerals are expected to sorb uranium and neptunium to a greater extent and more strongly than other mineral phases due to their high surface area and negative surface charge. Previous batch sorption experiments performed by the author and colleagues suggest a positive correlation between the increased presence of smectite in the alluvium and sorption of uranium and neptunium. Reimus et. al. (2005) also performed batch sorption of uranium and neptunium onto purified clay minerals at varying $\mathrm{pH}$. The results were similar to Stammose (1992) in that sorption increased from a $\mathrm{pH} \approx 3$ up to around $\mathrm{pH} \approx 6.5$ and decreased toward more alkaline $\mathrm{pH}$ for uranium. Although there is a positive correlation between clay mineral content and sorption of uranium and neptunium, water chemistry also plays an important role in uranium sorption to clay minerals.

Iron or manganese oxides or hydroxides present in the alluvium as crystalline mineral phases or as amorphous coatings on mineral grains are expected to have a high affinity for heavy metals (Drever 1997). It has been shown by Hsi and Langmuir (1985) that Fe(III) oxyhydroxides play an important role in U(VI) adsorption. Their study also indicated that carbonate played a critical role in the distribution of $\mathrm{U}(\mathrm{VI})$ between the surfaces of iron oxide phases and solution. Microscopy performed by Stewart et. al. (2000) on pre- and post-leach roll-front uranium deposits indicated that uranium was widely associated with pyrite and pyrite partially dissolved by a mine leaching solution. Pyrite is known to reduce $\mathrm{U}(\mathrm{VI})$ to $\mathrm{U}(\mathrm{IV})$, thus decreasing solubility and increasing sorption. 
1.2.9. Influence of Natural Organic Matter and Microbial Processes on Uranium Attenuation.

Lenhart et. al. (1999) found that Uranium (VI) sorption to hematite in the presence of humic acid is increased at lower $\mathrm{pH}$ and decreases at more alkaline $\mathrm{pH}$ when compared to experimental sorption results of a binary Uranium (VI)/hematite system. Microbial activity may affect the solubility of uranium directly by enzymatic oxidation/reduction or biosorption. Yabusaki et al. (2007) used a multi-component reactive transport to model the immobilization of hexavalent uranium by bio-reduction to the less soluble U(IV) in a acetate-stimulated system at the Old Rifle UMTRA field site. It was found in this study that the bio-reduction and immobilization of U(VI) was most efficient in the presence of Fe(III) reducing bacteria in an Fe (III) rich environment. The depletion of $\mathrm{Fe}(\mathrm{III})$ in a high sulfate groundwater posed serious implications for the effective bio-reduction/immobilization of uranium because the acetate was consumed by sulfate reduction reactions before reaching the iron-reducing bacteria down-gradient of the injection site (Yabusaki, Fang et al. 2007). Microbes may also indirectly affect uranium sorption by changing the geochemistry of the system including $\mathrm{pH}$ and the formation of organic acids and chelates (Francis 1998). These processes can either precipitate uranium minerals, increasing retardation or cause mobilization of uranium, decreasing retardation. The survival and effectiveness of microbes is dependent on several factors (i.e. $\mathrm{pH}$, redox conditions, and nutrients) and it is difficult to explain the effect that microbes may have on one system by studying another. Microbes and organics are not expected to play a significant role at Yucca Mountain because of the arid environment and deep water table. 


\section{EXPERIMENTAL MATERIALS AND METHOdS}

\subsection{General Approach}

The primary objective was investigation of the distribution of desorption rate constants of uranium and neptunium from Yucca Mountain volcanic tuff. This was accomplished by performing uranium and neptunium sorption/desorption experiments that involved a sorption phase followed by a desorption phase that was conducted under continuous flow conditions. The experimental results were interpreted using a multi-site kinetic model. In addition, the effects of mineralogy on sorption and desorption were studied using four volcanic tuff samples of varying mineral composition. The volcanic tuff was characterized to quantify minerals such as clays and zeolites to investigate possible correlations with sorption/desorption behavior. Extended X-ray Adsorption Fine Structure (EXAFS) spectroscopy was used to determine the local structure surrounding freshly sorbed uranium, and uranium remaining sorbed after the desorption phases. Electron probe microanalysis (EPMA), micro X-ray absorbance spectroscopy ( $\mu$-XAS) and $\mathrm{x}$-ray mapping on paired thin sections subjected to sorption and desorption treatments were conducted to investigate the spatial distribution and elemental associations of sorbed uranium on the tuffs.

Up-scaled experiments, in which radionuclides were eluted at different flow rates through columns packed with crushed tuff, were conducted using one of the volcanic tuffs from the long-term desorption experiments. The purpose of the up-scaled column experiments was to evaluate the applicability of rate constants obtained from the long- 
term desorption experiments under more realistic flow conditions with more realistic solid to solution ratios.

\subsection{Characterization of Groundwater}

Groundwater from well J-13 at the Nevada Test Site was used in the experiments and is shown on the location map in Figure 2.1. The groundwater was collected from the site in 55 gallon drums and transported to Los Alamos National Laboratory. The groundwater was filtered with a $.2 \mu \mathrm{m}$ filter before use in the experiments. Major ion analysis of the groundwater was used determine the speciation of uranium and neptunium in the tracer solution with the geochemical code PHREEQC Version 2.15.05 using the default database and updated uranium thermodynamic data from Dong and Brooks (2003). Knowledge of the aqueous speciation is helpful in determining sorption mechanisms and the speciation of sorbed radionuclides.

\subsubsection{Water Chemistry}

A recent analysis of $\mathrm{J}-13$ well water $(0.22-\mu \mathrm{m}$-filtered) collected from the field and stored at Los Alamos in a sealed 55 gallon plastic drum is provided in Table 2.1. J13 is a sodium bicarbonate-dominated water with a near neutral $\mathrm{pH}$. The carbonate equilibrium is stable from field to laboratory and the chemistry of $\mathrm{J}-13$ well water has changed little over the past thirty years (Triay 1997).

\subsubsection{Uranium and Neptunium Speciation}

The dominant uranium species in $\mathrm{J}-13$ groundwater ( $\mathrm{pH} 7.8$ ) calculated using the PHREEQC geochemical code is shown in Table 2.2 and PHREEQC output is attached as Appendix 1. The dominant Np species in solution has been previously determined for J- 
13 groundwater by Kaszuba and Runde (1999) and are $\mathrm{NpO}_{2}^{+}$and $\mathrm{NpO}_{2} \mathrm{CO}_{3}^{-}$as shown in Figure 1.3b.

Table 2.1. Chemistry of Water from

Well J-13

\begin{tabular}{|l|l|}
\hline Parameter & Concentration (mg/l) \\
\hline $\mathrm{Na}^{+}$ & 44.6 \\
\hline $\mathrm{HCO}_{3}{ }^{-}$ & 128.0 \\
\hline $\mathrm{Ca}^{2+}$ & 12.5 \\
\hline $\mathrm{K}^{+}$ & 4.66 \\
\hline $\mathrm{Mg}^{2+}$ & 1.97 \\
\hline $\mathrm{SO}_{4}{ }^{2-}$ & 21.0 \\
\hline $\mathrm{NO}_{3}$ & 8.57 \\
\hline $\mathrm{Cl}^{-}$ & 8.33 \\
\hline $\mathrm{F}^{-}$ & 2.28 \\
\hline $\mathrm{SiO}_{2}$ & 64.9 \\
\hline $\mathrm{Sr}^{2+}$ & 0.038 \\
\hline $\mathrm{Ba}^{2+}$ & 0.002 \\
\hline $\mathrm{pH}$ & 7.4 \\
\hline Ionic Strength & $0.0035 \mathrm{M}$ \\
\hline
\end{tabular}

Table 2.2. Speciation of uranium $\left(10^{-6} \mathrm{M} \mathrm{U}(\mathrm{VI})\right)$ in $\mathrm{J}$ 13 groundwater calculated by PHREEQC at $\mathbf{p H}=7.8$

\begin{tabular}{|c|r|r|}
\hline Species & Concentration (m) & \% of Total \\
\hline $\mathrm{CaUO}_{2}\left(\mathrm{CO}_{3}\right)_{3}^{2-}$ & $5.841 \mathrm{e}-07$ & $59.66 \%$ \\
\hline $\mathrm{Ca}_{2} \mathrm{UO}_{2}\left(\mathrm{CO}_{3}\right)_{3}^{0}$ & $3.442 \mathrm{e}-07$ & $35.15 \%$ \\
\hline $\mathrm{UO}_{2}\left(\mathrm{CO}_{3}\right)_{3}^{4-}$ & $2.495 \mathrm{e}-08$ & $2.55 \%$ \\
\hline $\mathrm{MgUO}_{2}\left(\mathrm{CO}_{3}\right)_{3}^{2-}$ & $1.300 \mathrm{e}-08$ & \\
\hline $\mathrm{UO}_{2}\left(\mathrm{CO}_{3}\right)_{2}^{2-}$ & & $1.33 \%$ \\
& $1.198 \mathrm{e}-08$ & \\
\hline
\end{tabular}




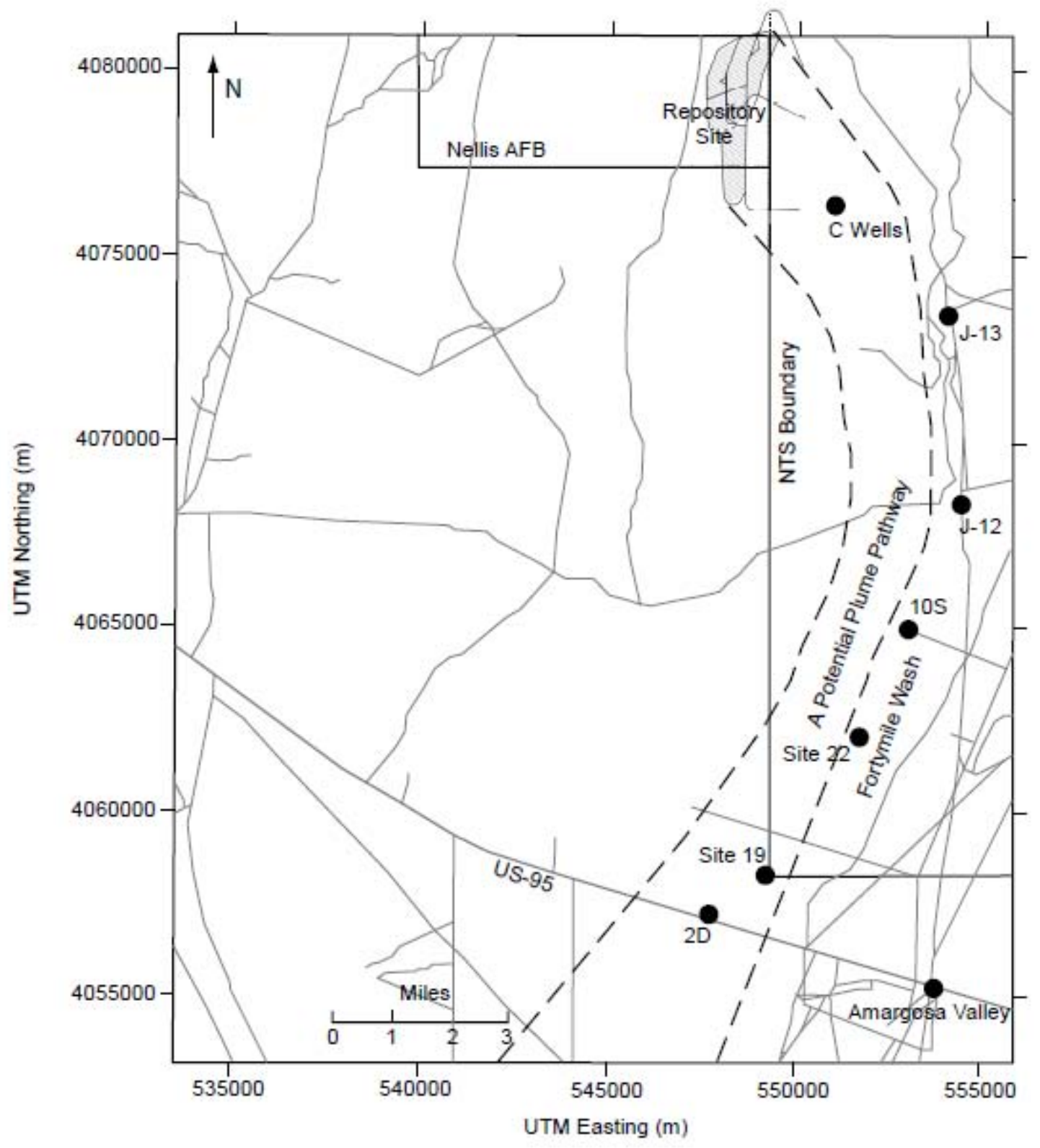

Figure 2.1. Location Map of the C-Wells and Well J-13. 


\subsection{Preparation and characterization of volcanic tuff materials}

The samples used in this study were taken from boreholes completed in the saturated volcanic tuff at Yucca Mountain. Core samples were chosen from wells UE25c\#2 and UE-25c\#3 shown in the location map in Figure 2.1. The samples were taken from the Bullfrog and Prow Pass members of the Crater Flat Tuff, selected to cover a wide range of smectite and zeolite content in the tuffs. The four samples used in the experiments were:

(1) A zeolitic volcanic tuff core taken from the UE-25c\#2 borehole from 640.32 to 640.6 meters below land surface from the Bedded Prow Pass member. This sample will be referred to as the "analcime-rich" tuff.

(2) A zeolitic volcanic tuff core taken from the UE-25c\#3 borehole from 802.26 to 802.63 meters below land surface from the Lower Bullfrog member. This sample will be referred to as the "mordenite-rich" tuff.

(3) A devitrified volcanic tuff core taken from the UE-25c\#2 borehole from 733.50 to 735.18 meters below land surface from the Central Bullfrog member. This sample will be referred to as the "smectite-rich" tuff.

(4) A devitrified volcanic tuff core taken from the UE-25c\#2 borehole from 532.15 to 533.28 meters below land surface from the Upper Prow Pass member. This sample will be referred to as the "illite-rich" tuff. 
The volcanic tuff cores were pulverized to a size fraction less than $2 \mathrm{~mm}$. The tuff was sieved into three size fractions of 500-2000 $\mu \mathrm{m}$; 75-500 $\mu \mathrm{m}$; and a fine fraction (less than $75 \mu \mathrm{m})$. The materials for the long-term desorption and dynamic transport experiments consisted of the wet sieved 75-500 $\mu \mathrm{m}$ portion of each sample. Previous experiments using 63-500 and 75-500 $\mu \mathrm{m}$ fraction were considered experimentally ideal, providing optimum compromise between sampling error due to too large a grain size and creation of active surfaces and mineral fractionation through excessive grinding (Rogers and Meijer 1993). This same study also found that grinding does not influence the sorption behavior of tuff samples until the particles size falls below $63 \mu \mathrm{m}$.

\subsection{1. $\quad$ Surface Area.}

Surface area measurements were used to determine if surface area plays a role in sorption and long-term desorption behavior of uranium and neptunium. Smaller particles sizes have greater surface area per unit mass resulting in increased properties such as surface charge density or sorption site density per unit mass (Langmuir 1997). The increase in the surface charge and site densities should result in an increase in uranium and neptunium sorption per unit weight of material. The surface area for each tuff reported in Table 2.3 was measured using the 6-point Brunauer Emmett Teller (BET) $\mathrm{N}_{2}$ adsorption method adapted from Brunauer (1938) with a NOVA 1200 high-speed gas sorption analyzer. Approximately 1 gram of material was used for the BET measurements to obtain an optimal total surface area between $2 \mathrm{~cm}^{2} / \mathrm{g}$ and $50 \mathrm{~cm}^{2} / \mathrm{g}$. 
Table 2.3. Volcanic Tuff Surface Area

\begin{tabular}{|l|c|c|c|}
\hline Sample & $\begin{array}{c}\text { Surface Area } \\
\left(\mathbf{m}^{\mathbf{2}} \mathbf{g}\right)\end{array}$ & $\begin{array}{c}\text { Wt. } \% \\
\text { Smectite }\end{array}$ & Wt. \% Zeolite \\
\hline Analcime-rich & 2.7201 & none detected & 19.9 \\
\hline Mordenite-rich & 7.5085 & none detected & 30.5 \\
\hline Smectite-rich & 4.2017 & 2.2 & none detected \\
\hline Illite-rich & 1.9962 & none detected & none detected \\
\hline
\end{tabular}

Surface area is expected to be positively correlated with smectite clay and zeolite content in the tuff. The mordenite-rich tuff is the only sample that follows this trend, having the highest zeolite weight percent and the highest surface area. This correlation is not seen in the analcime and smectite-rich tuffs. The surface area is higher in the smectite-rich tuff, which has only $2.2 \%$ smectite. Analcime is a microporous material that has one of the smallest pore diameters in the zeolite class of minerals (Kim and Kirkpatrick 1998). Adsorption of gases in microporous materials occurs at lower relative pressures to those in macroporous material such as clay, resulting in slower diffusion into pores, increasing the time required to reach sorption equilibrium. The mordenite and analcime-rich samples were run at a lower range of $\mathrm{N}_{2}$ pressure; the equilibration time may have been inadequate for the nitrogen gas to diffuse into the pores, resulting in an underestimation of surface area for both of these tuffs. The 6-point BET results, plots and sorption isotherms are included in Appendix 2.

\subsubsection{Quantitative X-ray Diffraction (QXRD)}

To study the effects of mineralogy on sorption and desorption of uranium, QXRD analyses were used to determine the weight percent of mineral phases present in the volcanic tuff samples. The quantitative mineral abundances summarized in Table 2.4 were obtained from the x-ray powder diffraction data using the FULLPAT procedure developed by Chipera and Bish (2002). In addition, the mineral abundances in a finer 
fraction of the tuff representing the materials used in the EXAFS, $\mu$-XAS, $x$-ray mapping were also determined by QXRD and are summarized in Table 2.5. The X-ray Diffraction Patterns are included as Appendix 3.

The major mineral phases common to all of the samples in the 75-500 $\mu \mathrm{m}$ size range include quartz, K-feldspar and plagioclase. The tuffs selected for this study differ primarily in their zeolite and smectite content. By varying the amount of these mineral phases a possible correlation may be developed between sorption and long-term desorption of uranium and neptunium and clay and zeolite abundance in the tuff. In addition, the structure of the zeolite framework can influence the sorption and desorption behavior of radionuclides. The analcime-rich volcanic tuff includes $20 \%$ analcime and the mordenite-rich tuff includes $12 \%$ analcime and $18 \%$ mordenite. These minerals are both in the zeolite group but the mordenite elliptical pore dimensions are 6.7 x $7 \AA ̊$ and 2.6 x $5.7 \AA$ (Hincapie, Garces et al. 2004) and the average pore diameter of analcime is 2.6 Á, one of the smallest pore zeolites (Kim and Kirkpatrick 1998). If molecular adsorption is the dominating mechanism, sorption would tend to be greater in the sample with the larger surface area. A brief summary of the mineral properties of each mineral phase, and the chemical formula are provided in Table 2.6. 
Table 2.4 Quantitative X-ray Diffraction Analysis of wet sieved tuff samples ( $75 \mu \mathrm{m}-500 \mu \mathrm{m})$ used in the long-term desorption and saturated column experiments.

\begin{tabular}{|c|c|c|c|c|c|c|c|c|c|c|}
\hline \multirow[t]{2}{*}{ Sample I.D. } & \multicolumn{5}{|l|}{ Well/Depth (m) } & \multicolumn{5}{|c|}{ Mineral Phase Abundance (wt\%) } \\
\hline & & Quartz & $\begin{array}{l}\text { K- } \\
\text { Feldspar }\end{array}$ & Plagioclase & Analcime & Illite/Mica & Smectite & Mordenite & Kaolinite & Total \% \\
\hline Analcime-rich & C2/640.32-640.6 & 29.5 & 28.3 & 17.6 & 19.9 & 7.2 & --- & --- & --- & 102.5 \\
\hline Mordenite-rich & C3/802.26-802.63 & 24.1 & 22.4 & 11.2 & 12.2 & 13.0 & --- & 18.3 & --- & 101.2 \\
\hline Smectite-rich & C2/733.50-735.18 & 26.2 & 29.1 & 31.1 & --- & 11.2 & 2.2 & --- & --- & 99.8 \\
\hline Illite-rich & $\mathrm{C} 2 / 532.15-533.28$ & 36.0 & 27.0 & 26.6 & --- & 4.6 & -- & -- & 5.9 & 100.1 \\
\hline
\end{tabular}

Table 2.5 Quantitative X-ray Diffraction Analysis of tuff samples used in the EXAFS, $\mu$-XAS and X-ray mapping

\begin{tabular}{|c|c|c|c|c|c|c|c|c|c|c|}
\hline \multirow{2}{*}{$\begin{array}{l}\text { Sample } \\
\text { I.D./description }\end{array}$} & \multicolumn{5}{|l|}{ Well/Depth (m) } & \multicolumn{5}{|c|}{ Mineral Phase Abundance (wt\%) } \\
\hline & & Quartz & $\begin{array}{l}\text { K- } \\
\text { Feldspar }\end{array}$ & Plagioclase & Analcime & Illite/Mica & Smectite & Mordenite & Kaolinite & Total \% \\
\hline $\begin{array}{l}\text { Mordenite- } \\
\text { rich/fine matrix }\end{array}$ & С3/802.26-802.63 & 3.3 & 9.5 & 2.4 & 1.6 & 5.0 & 19.5 & 59.0 & --- & 100.3 \\
\hline $\begin{array}{l}\text { Mordenite- } \\
\text { rich/black fines }\end{array}$ & C3/802.26-802.63 & 0.8 & 6.8 & 6.9 & 1.4 & --- & 49.4 & 34.4 & --- & 99.7 \\
\hline $\begin{array}{l}\text { Smectite-rich/fine } \\
\text { matrix }\end{array}$ & C2/733.50-735.18 & 9.5 & 37.6 & 37.4 & --- & 4.7 & 12.6 & --- & --- & 101.8 \\
\hline $\begin{array}{l}\text { Smectite- } \\
\text { rich/black fines }\end{array}$ & C2/733.50-735.18 & 2.2 & 23.8 & 29.3 & --- & -- & 45.4 & --- & --- & 100.7 \\
\hline
\end{tabular}


Table 2.6 Summary of Mineral Properties/Sorption Mechanisms for U and Np.

\begin{tabular}{|c|c|c|}
\hline Mineral Phase & Formula & Properties/Potential Sorption Mechanisms \\
\hline Quartz & $\mathrm{SiO}_{2}$ & $\begin{array}{l}\text { Sorption of Np and U occurs as surface complexes } \\
\text { (Triay, Robinson et al. 1993) (Froideval, Del Nero } \\
\text { et al. 2003). }\end{array}$ \\
\hline K-Feldspar & $\mathrm{K}_{0.75} \mathrm{Na}_{0.25} \mathrm{AlSi}_{3} \mathrm{O}_{8}$ & $\begin{array}{l}\text { Aluminosilicate framework with a net negative } \\
\text { charge-subgroup of Feldspars containing K. } \\
\text { Sorption of U and Np occurs as ion exchange and } \\
\text { surface complexes. (Walter, Arnold et al. 2005; } \\
\text { Chardon, Bosbach et al. 2008). }\end{array}$ \\
\hline Plagioclase & $\mathrm{Na}_{0.5} \mathrm{Ca}_{0.5} \mathrm{Si}_{3} \mathrm{AlO}_{8}$ & $\begin{array}{l}\text { Aluminosilicate framework with a net negative } \\
\text { charge-subgroup of Feldspars containing Na and } \\
\text { Ca. Sorption of U and Np occurs as ion exchange } \\
\text { and surface complexes. (Walter, Arnold et al. 2005; } \\
\text { Chardon, Bosbach et al. 2008) }\end{array}$ \\
\hline Illite & $\begin{array}{l}\mathrm{K}_{0.6}\left(\mathrm{H}_{3} \mathrm{O}\right)_{0.4} \mathrm{Al}_{1.3} \mathrm{Mg}_{0.3} \mathrm{Fe}^{2+} \\
0.1 \mathrm{Si}_{3.5} \mathrm{O}_{10}(\mathrm{OH})_{2} \cdot\left(\mathrm{H}_{2} \mathrm{O}\right)\end{array}$ & $\begin{array}{l}\text { Dioctahedral, interlayer-deficient clay (non swelling } \\
\text { clay)-interlayer potassium ions prevent liquids, as } \\
\text { well as other cations from entering the structure. A } \\
\text { small amount of cation exchange can occur at } \\
\text { crystal edges. Basal plane has no silanol or } \\
\text { aluminol groups; metal sorption occurs at defects in } \\
\text { the crystal structure. (Deer 1966) }\end{array}$ \\
\hline $\begin{array}{l}\text { Smectite } \\
\text { (Montmorillonite) }\end{array}$ & $\begin{array}{l}\mathrm{Na}_{0.2} \mathrm{Ca}_{0.1} \mathrm{Al}_{2} \mathrm{Si}_{4} \mathrm{O}_{10} \\
(\mathrm{OH})_{2}\left(\mathrm{H}_{2} \mathrm{O}\right)_{10}\end{array}$ & $\begin{array}{l}\text { 2:1 layer type clay-high CEC. Sorption may occur } \\
\text { via cation exchange or surface complexation at the } \\
\text { basal layer, amphoteric edge sites of aluminol and } \\
\text { silanol groups and metal hydroxide species. There } \\
\text { is also the possibility of interlayer sorption. } \\
\text { (Thompson, Parks et al. 1994) }\end{array}$ \\
\hline Kaolinite & $\mathrm{Al}_{2} \mathrm{Si}_{2} \mathrm{O}_{5}(\mathrm{OH})_{4}$ & $\begin{array}{l}\text { 1:1 layer type clay mineral with an aluminol sheet } \\
\text { and siloxane sheet. Low cation exchange capacity } \\
\text { compared to other clays. Sorption may occur as } \\
\text { cation exchange edge sites and as surface } \\
\text { complexes at amphoteric edge sites. Sorption of } \\
\text { cations occurs at structural O and OH. Additional } \\
\text { sorption sites can be found at imperfections in the } \\
\text { crystal structure. Impurities may also contribute to } \\
\text { sorption. (Thompson, Parks et al. 1994) }\end{array}$ \\
\hline Mordenite & $\begin{array}{l}\mathrm{Na}_{1.1} \mathrm{Ca}_{0.5} \mathrm{~K}_{0.1} \mathrm{Al}_{2.2} \\
\mathrm{Si}_{9.8} \mathrm{O}_{24} \cdot 5.9\left(\mathrm{H}_{2} \mathrm{O}\right)\end{array}$ & $\begin{array}{l}\text { Hydrated aluminosilicate (Zeolite Group). Cation } \\
\text { exchange is unlikely because the hydrated radius of } \\
\text { the uranyl and neptunyl cations are estimated to be } \\
\text { larger than that of the zeolitic channel opening. } \\
\text { Surface complexation can occur at the negatively } \\
\text { charged zeolite surface, or at amphoteric edge sites } \\
\text { of aluminol and silanol groups. (Triay, Robinson et } \\
\text { al. 1993; Krestou, Xenidis et al. 2003) }\end{array}$ \\
\hline Analcime & $\mathrm{Na}\left(\mathrm{AlSi}_{2} \mathrm{O}_{6}\right) \cdot\left(\mathrm{H}_{2} \mathrm{O}\right)$ & $\begin{array}{l}\text { Hydrated aluminosilicate (Zeolite Group). Cation } \\
\text { exchange is unlikely because the hydrated radius of } \\
\text { the uranyl and neptunyl cations are estimated to be } \\
\text { larger than that of the zeolitic channel opening. . } \\
\text { Surface complexation can occur at the negatively } \\
\text { charged zeolite surface, or at amphoteric edge sites } \\
\text { of aluminol and silanol groups. (Triay, Robinson et } \\
\text { al. 1993; Krestou, Xenidis et al. 2003) }\end{array}$ \\
\hline
\end{tabular}




\subsubsection{Isoelectric Point (IEP)}

The zeta $(\zeta)$ potential of a dilute suspension of the smectite and mordenite-rich tuff samples in $\mathrm{J}-13$ groundwater at a range of $\mathrm{pH}$ values bracketing the expected IEP was measured using a Malvern Instruments Zetasizer Nano with auto titration. The Zeta potential versus $\mathrm{pH}$ curve is normally positive at low $\mathrm{pH}$ and lower or negative at high $\mathrm{pH}$. The point where the plot passes through zero Zeta potential is called the IEP (or the $\mathrm{pH}$ at the point of zero charge, $\mathrm{pH}_{\mathrm{PzC}}$ ). Zeta potential is determined by the electrophoretic mobility using Smoluchowski's equation $(\mu=\zeta \varepsilon / \eta$, where mu is the electrophoretic mobility, epsilon is the electric permittivity of the liquid and eta is the viscosity) and the Malvern Zetasizer Software 6.01. Smoluchowski’s equation assumes that the ionic strength of the solution is sufficiently large and/or that the particle size is large enough that the thickness of the electrical double layer is small compared to the mean diameter of the particles. Smoluchowski's equation is valid for most particles in polar solvents with a dielectric constant (ع) greater than 20 (Malvern Instruments 2008). The dielectric constant is a unitless number and is a measure of the relative effect a solvent has (relative to that of free space in a vacuum) on the force with which two oppositely charged plates attract each other. It is also known as the electric permittivity. For the measurements in the J-13 groundwater, a dielectric constant of 79.6 was used. The reported dielectric constant of water is 80.20 at $20^{\circ} \mathrm{C}$ (Dean 1999). It is important to note that zeta potential is a measure of the potential drop within the electric double layer of the particle between the shear plane and the bulk solution, not the actual charged surface. The behavior of the zeta potential in the $\mathrm{pH}$ range of this study $(\mathrm{pH}=7-8.5)$ can be used to determine if the amphoteric edge sites of smectite and zeolite are becoming 
protonated. The edge sites are more likely to sorb the negatively charged uranyl and neptunyl carbonate species from solution in the protonated state.

The samples were prepared by agitating the $<45 \mu \mathrm{m}$ size fraction of the tuff in J13 groundwater, and allowing the solution/tuff mixture to settle for approximately 24 hours at room temperature. The suspension was removed with a plastic syringe and dispensed into the sample container. The $\mathrm{pH}$ was adjusted by adding increasing amounts of standardized $0.1 \mathrm{M} \mathrm{HNO}_{3}$ to the sample and measuring the $\zeta$ potential at $1 \mathrm{pH}$ unit decrements from a pH of approximately 8 to a $\mathrm{pH}$ of approximately 1.7 .

Plots of the zeta potential as a function of $\mathrm{pH}$ are presented in Figures 2.2 (a) and (b) for the smectite and mordenite-rich zeolitic tuff samples, respectively. The complete Zeta Potential report is included in Appendix 4. There is no observable isoelectric point for either the smectite and mordenite-rich tuffs between a $\mathrm{pH}$ of 1.75 to the ambient $\mathrm{pH}$ of the suspensions (approximately pH 8.4). The smectite-rich sample contains significant weight percents of smectite, K-feldspar and plagioclase and the mordenite-rich sample contains significant weight percents of smectite and mordenite, as shown in the QXRD analysis in Table 2.5. The surface charge of zeolites is altered through protonation and deprotonation of silanol and aluminol groups. For zeolites, the number of silanol and aluminol groups within the crystal structure influences the IEP. As the ratio of Si/Al decreases, the IEP shifts to lower $\mathrm{pH}$. In addition, deprotonated silanol groups result in a negative surface charge over a wider range of $\mathrm{pH}$ vales (Kuzniatsova, Kim et al. 2007). Smectites have been shown to remain negative with no observable IEP between $\mathrm{pH} 2$ to 12 due to permanent basal plane charge, and overlapping of negative charges masking amphoteric edge sites. As the $\mathrm{pH}$ is decreased the edge sites, which constitute about $1 \%$ 
of the total site density, become protonated causing a shift in the zeta potential toward less negative values. The theoretical IEP of the edge sites calculated from a weighted linear combination of silica and alumina occurs at a $\mathrm{pH}$ of 7 (Çelik, Fernando et al. 2004). The zeta potential of the smectite and mordenite-rich samples show a significant decrease in zeta potential between the lowest $\mathrm{pH}$ up to a $\mathrm{pH}$ of 5 . The zeta potential gradually becomes more negative after $\mathrm{pH} 5$. This is in agreement with acid-base titrations of a natural zeolite suspension in the presence of $1 \mathrm{M} \mathrm{NaNO}$ where the specific edge surface charge decreased from $\mathrm{pH} \sim 4$ to $\sim 5.5$, remained close to 0 (albeit positive) between $\mathrm{pH} 5.5$ and 9 and decreased to a negative or deprotonated state beyond a $\mathrm{pH}$ of 9 (Krestou, Xenidis et al. 2003).

At a $\mathrm{pH}$ of 7 under oxidizing conditions, neptunium is predominately present as $\mathrm{NpO}_{2}^{+}$and $\mathrm{NpO}_{2} \mathrm{CO}_{3}^{-}$(See Figures $1.3 \mathrm{a}$ and b). The dominant aqueous uranium species at a pH of $\sim 7.0$ are $\mathrm{Ca}_{2} \mathrm{UO}_{2}\left(\mathrm{CO}_{3}\right)_{3}^{0}$ and $\mathrm{CaUO}_{2}\left(\mathrm{CO}_{3}\right)_{3}^{2-}$ (See Figure 1.2 and Table 2.2). Under these conditions, the positively charged neptunyl cation would be attracted to the negatively charged surfaces and deprotonated edge sites. The negatively charged neptunyl and uranyl carbonate aqueous complexes would favor the weakly positive edge sites. 


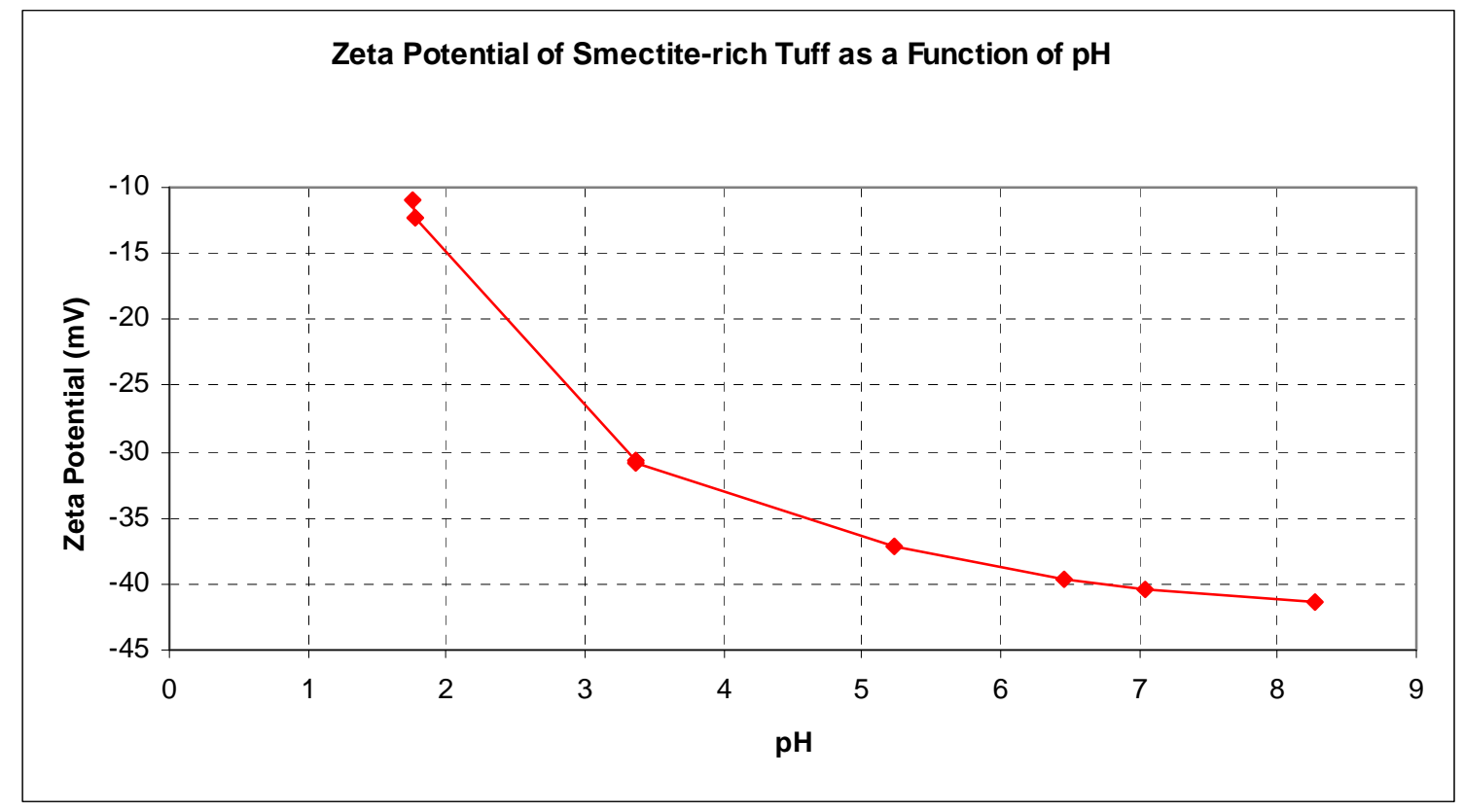

Figure 2.2 (a). Zeta Potential of a Smectite-rich tuff as a Function of pH.

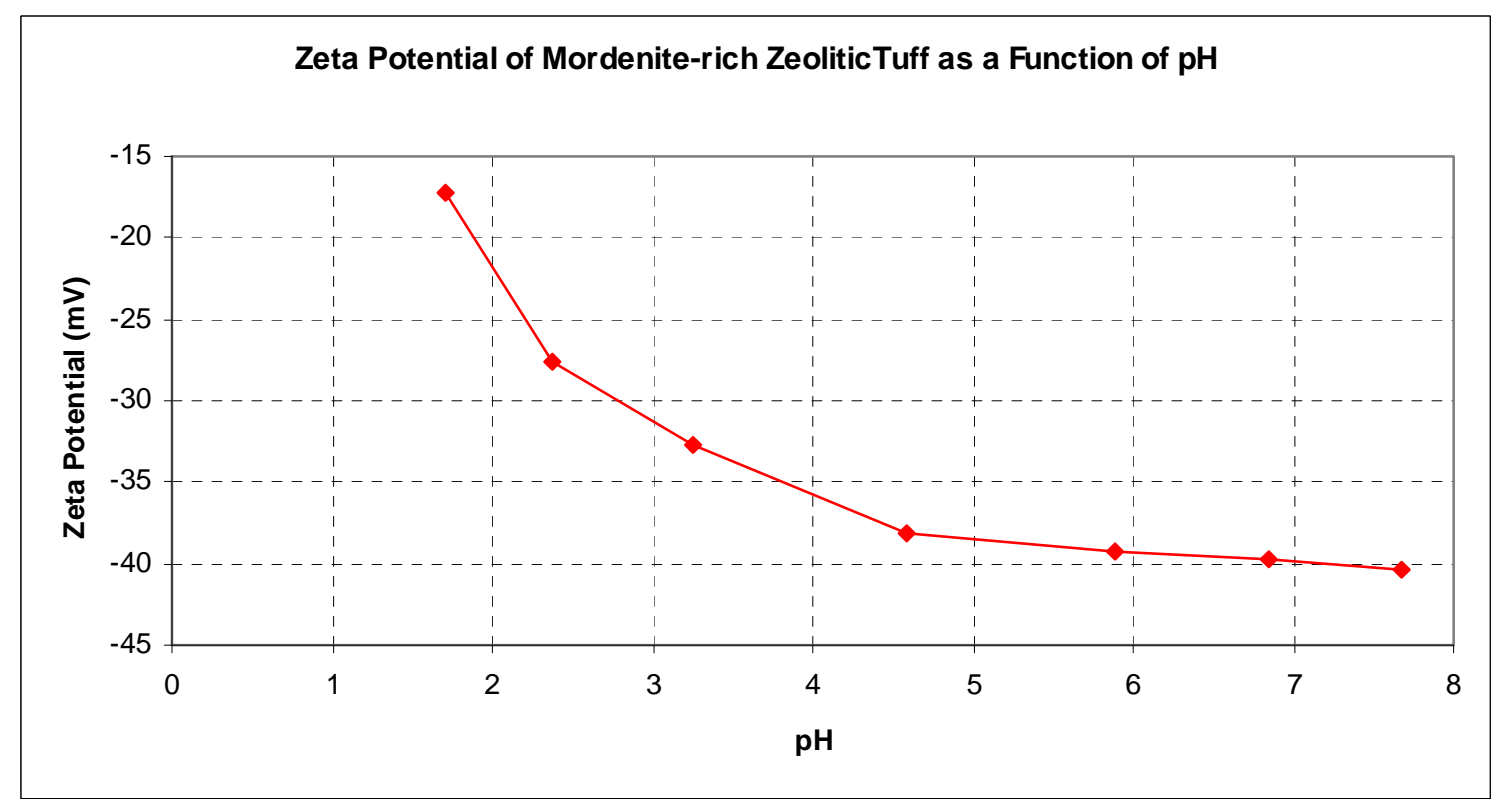

Figure 2.2 (b). Zeta Potential of a Mordenite-rich Zeolitic Tuff as a Function of pH. 


\subsubsection{Cation Exchange Capacity (CEC)}

Minerals in the zeolite group (analcime and mordenite) and smectite have attributes important to radionuclide sorption that include a high cation exchange capacity and a large specific surface area. Although illite has a surface area comparable to that of smectite and zeolite, interlayer potassium ions prevent water, organic liquids and other cations from entering the structure. Radionuclide cation exchange is likely to only take place at crystal edges where unsatisfied valences may exist, resulting in a CEC of illite that is much less than that of smectite and zeolite. The cation exchange capacity or "CEC" was not measured directly on the samples used in this study. Previous measurements of CEC on volcanic tuff samples adjacent or very close to the samples used in this study were reported in Anghel, Turin et al. (2002). Table 2.7 is the reported total cesium CEC $\left(\mathrm{CEC}-\mathrm{Cs}_{\mathrm{T}}\right)$ and the location of the samples relative to those used in this study. The Bedded Prow Pass has the largest total CEC, followed by the Lower Bullfrog, Central Bullfrog and Upper Prow Pass. The CEC appears to be correlated with the clay and zeolite weight percent in the tuff. 
Table 2.7 Cation Exchange Capacity Measurements of samples from the same volcanic tuff members as the samples used in this study.

\begin{tabular}{|l|r|r|r|r|r|}
\hline \multicolumn{1}{|c|}{ Sample } & $\begin{array}{c}\text { Depth } \\
\text { (m) }\end{array}$ & $\begin{array}{c}\text { Depth (m) } \\
\text { (study } \\
\text { sample) }\end{array}$ & $\begin{array}{r}\text { Depth } \\
\text { Difference } \\
\text { (m) }\end{array}$ & $\begin{array}{r}\text { Smectite } \\
\text { + Zeolite } \\
\text { Difference } \\
\text { (wt \%) }\end{array}$ & $\begin{array}{r}\text { CEC-Cs } \\
\text { (meq/100g) }\end{array}$ \\
\hline Analcime-rich & 642.21 & 640.6 & 1.61 & $\begin{array}{r}39 \% \\
\text { (more than } \\
\text { study } \\
\text { sample) }\end{array}$ & \\
\hline & & & & $\begin{array}{r}10 \% \\
\text { (more than } \\
\text { study } \\
\text { sample) }\end{array}$ & \\
Mordenite-rich & 794.92 & 802.26 & 7.34 & \\
\hline Smectite-rich & 715.06 & 733.50 & 18.44 & & \\
\hline Illite-rich & 531.88 & 532.15 & 0.27 & & \\
\hline a(Anghel, Turin et al. 2002) & & & & & \\
\hline
\end{tabular}

\subsection{Sorption and Desorption Experiments}

\subsubsection{Batch Sorption and Flow Desorption Experiments}

${ }^{233} \mathrm{U}(\mathrm{VI})$ tracer solution was prepared by adding $4 \mathrm{ml}$ of $2.43 \times 10^{-4} \mathrm{M}{ }^{233} \mathrm{U}(\mathrm{VI})$ stock solution $\left(\mathrm{UO}_{2}\left(\mathrm{NO}_{3}\right)_{2}\right.$ in dilute $\left.\mathrm{HNO}_{3}\right)$ obtained from Isotope Products Laboratories to the filtered $\mathrm{J}-13$ groundwater described above to a total volume of $500 \mathrm{ml}$. The ${ }^{237} \mathrm{~Np}(\mathrm{~V})$ tracer solution was prepared by adding $4.6 \mathrm{ml}$ of $2.13 \times 10^{-4} \mathrm{M}{ }^{237} \mathrm{~Np}(\mathrm{~V})$ stock solution $\left(\mathrm{NpO}_{2}{ }^{+}\right.$in $\left.\mathrm{HCl}\right)$ obtained from Los Alamos National Laboratory to the filtered J13 groundwater to a total volume of $422 \mathrm{ml}$. Approximately $30 \mathrm{ml}$ of $\mathrm{Np}$ or $\mathrm{U}$ tracer solution was added to the batch sorption tubes which contained approximately $10 \mathrm{~g}$ of volcanic tuff sample. The initial sampling of the Np tracer solution was below the target activity/concentration for the experiment; therefore $1.3 \mathrm{ml}$ of stock solution was added to the tracer in each $\mathrm{Np}$ batch sorption tube before the second sampling, for a total $\mathrm{Np}$ concentration of $3.58 \times 10^{-6} \mathrm{M}$. The molarity of the stock solution was re-calculated 
based on the measured activity and was found to be $1.9 \times 10^{-4} \mathrm{M}$. The exact $\mathrm{Np}$ concentration, as long as it is below the solubility limit, is not important because the activity in the sample solutions is normalized to the activity in control solutions.

The concentrations of the ${ }^{233} \mathrm{U}(\mathrm{VI})$ and ${ }^{237} \mathrm{~Np}(\mathrm{~V})$ tracer solutions of $\sim 10^{-6} \mathrm{M}$ is an order of magnitude below the measured solubility limits of $\sim 10^{-5} \mathrm{M}$ (Langmuir 1997) and $3 \times 10^{-5} \mathrm{M}$ (Efurd, Runde et al. 1998) for $\mathrm{U}$ and $\mathrm{Np}$, respectively at the $\mathrm{pH}$ and temperature of the experiments. The experiments were performed at ambient laboratory temperature and pressure $\left(\sim 23^{\circ} \mathrm{C}\right.$ and $\sim 0.8$ bars, respectively) and it was assumed that the groundwater/tracer solutions used in the experiments were in equilibrium with the ambient atmosphere (oxidizing conditions, $\sim 0.033 \% \mathrm{CO}_{2}$ ).

For the sorption phase of the experiments, $10 \mathrm{~g}$ (as well as the additional 3-gram smectite-rich samples) of volcanic tuff was equilibrated with approximately $30 \mathrm{ml}$ of tracer-free J-13 groundwater in $50 \mathrm{ml}$ Oakridge centrifuge tubes for a period of 10 days before it was brought into contact with $30 \mathrm{ml}$ of tracer solution containing one of the radionuclides of interest $\left({ }^{233} \mathrm{U}\right.$ or $\left.{ }^{237} \mathrm{~Np}\right)$ for two weeks. In addition, control samples containing $30 \mathrm{ml}$ of uranium or neptunium tracer solution and no solid phase were also treated in the same manner as the samples. The control samples are used to verify that sorption to container walls is insignificant, and to normalize sample $K_{d}$ calculations based on the activity in the control samples. Periodic sampling ( 1 day, 2 days, 3 days, 1 week, 2 weeks) and determination of the activity in solution was performed during the sorption phase by centrifuging the samples and removing approximately $1 \mathrm{ml}$ of tracer at each sampling. The periodic samples were analyzed for radionuclide concentration (using a 
2500TR Packard liquid scintillation counter) to determine the rate at which the radionuclide was sorbing to the volcanic tuff.

After the sorption phase was complete, the samples were centrifuged, the supernatant removed, and the remaining solid was re-suspended with approximately 30 $\mathrm{ml}$ of tracer-free groundwater. The sample was then shaken by hand and poured into the flow desorption column in Figure 2.3 (a). The control samples were also poured into desorption columns. The volume of the column was approximately $50 \mathrm{ml}$, leaving space in the column for the solid and solution to mix, as the column was placed on an end-overend shaker as shown in Figure 2.3 (b) to maximize tuff-solution contact, minimizing concentration gradients within the column. Flow was initiated through the columns at 1 $\mathrm{ml} / \mathrm{hr}$ and collected in fractions. The activity in the eluant was measured using a Packard 2500TR liquid scintillation counter. The radionuclide was desorbed from the samples until the activity of the eluant was less than $1 \mathrm{cpm} / \mathrm{g}$ above background activity in the J13 groundwater. The activity remaining sorbed at the conclusion of the experiment was then leached from the tuff sample by eluting a sodium bicarbonate enriched J-13 groundwater $(\mathrm{pH} \sim 11)$ through the column, followed by a nitric acid enriched J-13 groundwater ( $\mathrm{pH} \sim 2)$. 


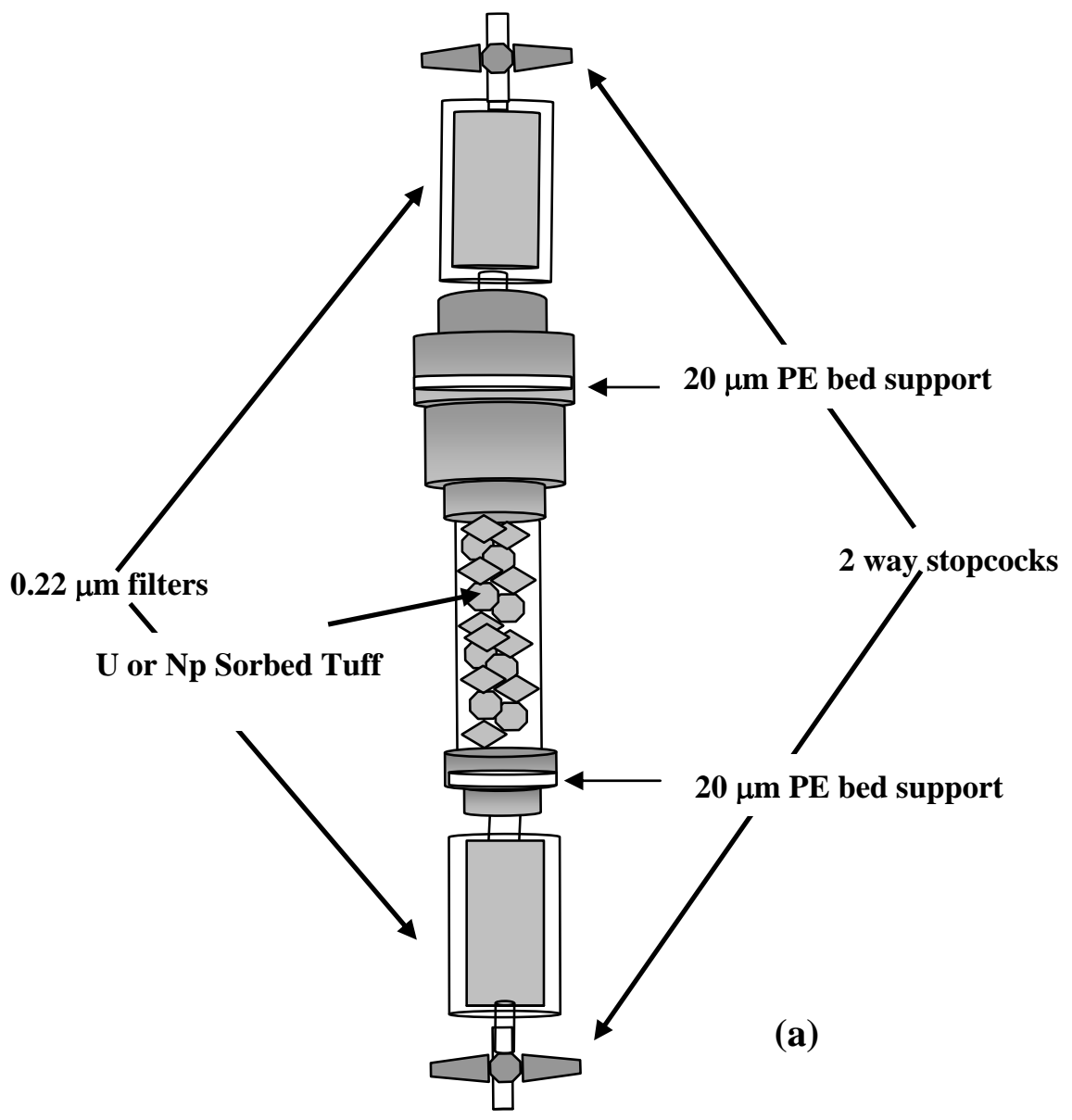

Flex Column

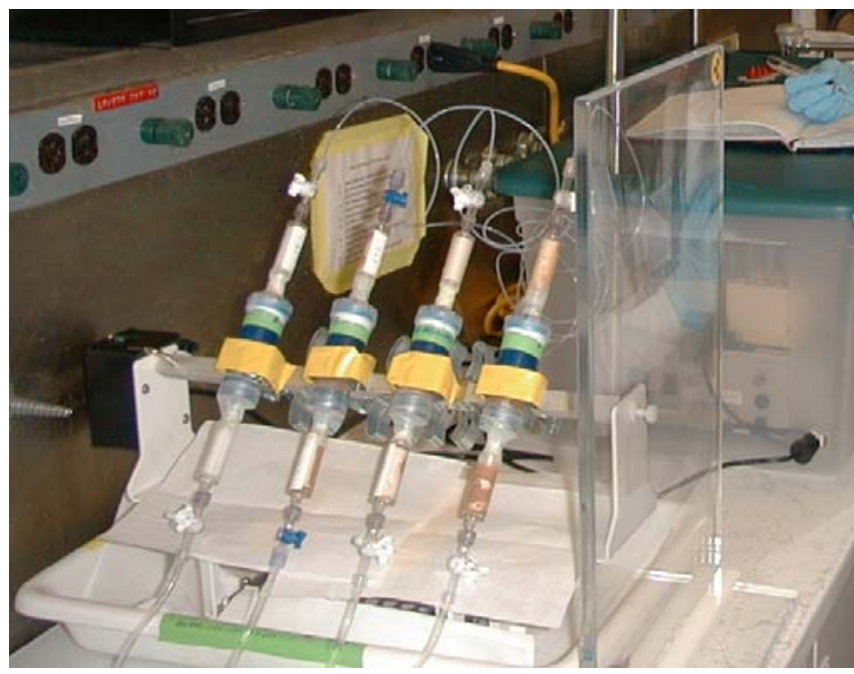

(b)

Figure 2.3. Schematic (a) and photo (b) of batch sorption reactor/flow desorption CSTR. The volcanic tuff is pre-sorbed with uranium and neptunium (separately) prior to the column flow desorption. The column is placed on an end-over-end shaker to maximize tuff-solution contact during both the sorption and desorption phases. 


\subsubsection{Up-scaled Column Experiments}

Uranium $\left({ }^{233} \mathrm{U}(\mathrm{VI})\right)$ tracer solution was prepared by adding $0.812 \mathrm{ml}$ of $2.43 \times 10^{-}$ ${ }^{4} \mathrm{M}{ }^{233} \mathrm{U}(\mathrm{VI})$ stock solution $\left(\mathrm{UO}_{2}\left(\mathrm{NO}_{3}\right)_{2}\right.$ in dilute $\left.\mathrm{HNO}_{3}\right)$ obtained from Isotope Products Laboratories to the filtered J-13 groundwater to a total volume of $200 \mathrm{ml}$. $3.373 \mathrm{ml}$ of $8.12 \times 10^{-11} \mathrm{M}$ tritium $\left(\mathrm{H}^{3}\right)$ was also added as a conservative tracer to evaluate the hydrologic properties of the column. The neptunium $\left({ }^{237} \mathrm{~Np}(\mathrm{~V})\right)$ tracer solution was prepared by adding $4.759 \mathrm{ml}$ of $2.13 \times 10^{-4} \mathrm{M}{ }^{237} \mathrm{~Np}(\mathrm{~V})$ stock solution and $0.910 \mathrm{ml}$ of $8.12 \times 10^{-11} \mathrm{M} \mathrm{H}^{3}$ to the filtered J-13 groundwater to a total volume of $200 \mathrm{ml}$.

Three glass columns (Figure 2.4) were packed with crushed, sieved and J-13 groundwater-washed 75-500 $\mu \mathrm{m}$ size fraction of the smectite-rich volcanic tuff. Two separate columns were injected with approximately $50 \mathrm{ml}$ of uranium/tritium tracer solution, one at $7 \mathrm{ml} / \mathrm{hr}$ and the other at $28 \mathrm{ml} /$ hour. Another column was injected with approximately $50 \mathrm{ml}$ of neptunium/tritium tracer solution at $7 \mathrm{ml} /$ hour. Prior to the tracer injection, the columns were saturated by evacuating the air from the column and flushing $\mathrm{CO}_{2}$ through the column and then switching from the gas to a reservoir containing the $\mathrm{J}$ 13 groundwater to slowly saturate the column under a vacuum. The columns were then equilibrated by slowly $(\sim .5 \mathrm{ml} / \mathrm{hr})$ flowing $\mathrm{J}-13$ groundwater through the column for approximately 1 month ( $7 \mathrm{ml} / \mathrm{hr}$ columns) and 4 days ( $28 \mathrm{ml} / \mathrm{hr}$ column). After the tracer injection was complete the columns were flushed with tracer-free J13 groundwater at the injection flow rates. The column eluant was collected in fractions and the activity in the samples was measured using a Packard 2500TR liquid scintillation counter. Samples were collected in the following manner during the $7 \mathrm{ml} / \mathrm{hr}$ column runs: 
- $\quad$ 0-3 pore volumes: $2 \mathrm{ml}$ samples were collected and every sample was analyzed;

- 3-18 pore volumes: $\sim 4 \mathrm{ml}$ were collected and every fifth sample was analyzed;

- 18-264 pore volumes: $\sim 6 \mathrm{ml}$ were collected and every fifth sample was analyzed;

- $\quad$ 264-350 pore volumes: $13 \mathrm{ml}$ were collected and every third sample was analyzed.

Samples were collected in the following manner during the $28 \mathrm{ml} / \mathrm{hr}$ uranium column run:

- $\quad$-3 pore volumes: $\sim 2 \mathrm{ml}$ samples were collected and every sample was analyzed;

- 3-29 pore volumes: $\sim 6 \mathrm{ml}$ were collected and every tenth sample was analyzed;

- 29-40pore volumes: $\sim 6 \mathrm{ml}$ were collected and every fifth sample was analyzed;

- $\quad$ 40-144 pore volumes: 13 ml were collected and every fourth sample was analyzed.

Solution parameters (e.g., $\mathrm{pH}$, carbonate concentrations, ionic strength, U/Np concentrations) were held constant. Previous studies with Yucca Mountain tuff materials indicate that surface complexation reactions dominate (Triay 1997) as discussed in Section 1.2.4, Uranium and Neptunium Sorption Mechanisms. 
Because of very low recovery in both the uranium and neptunium column experiments, the columns were frozen, segmented and the tuff in each segment leached of activity using J-13 groundwater adjusted to a $\mathrm{pH}$ of approximately 2 with $\mathrm{HNO}_{3}$. Each segment was batch leached until no measureable activity (or the majority of the activity) was recovered. Figure 2.4 shows a photo of the frozen-segmented column. 

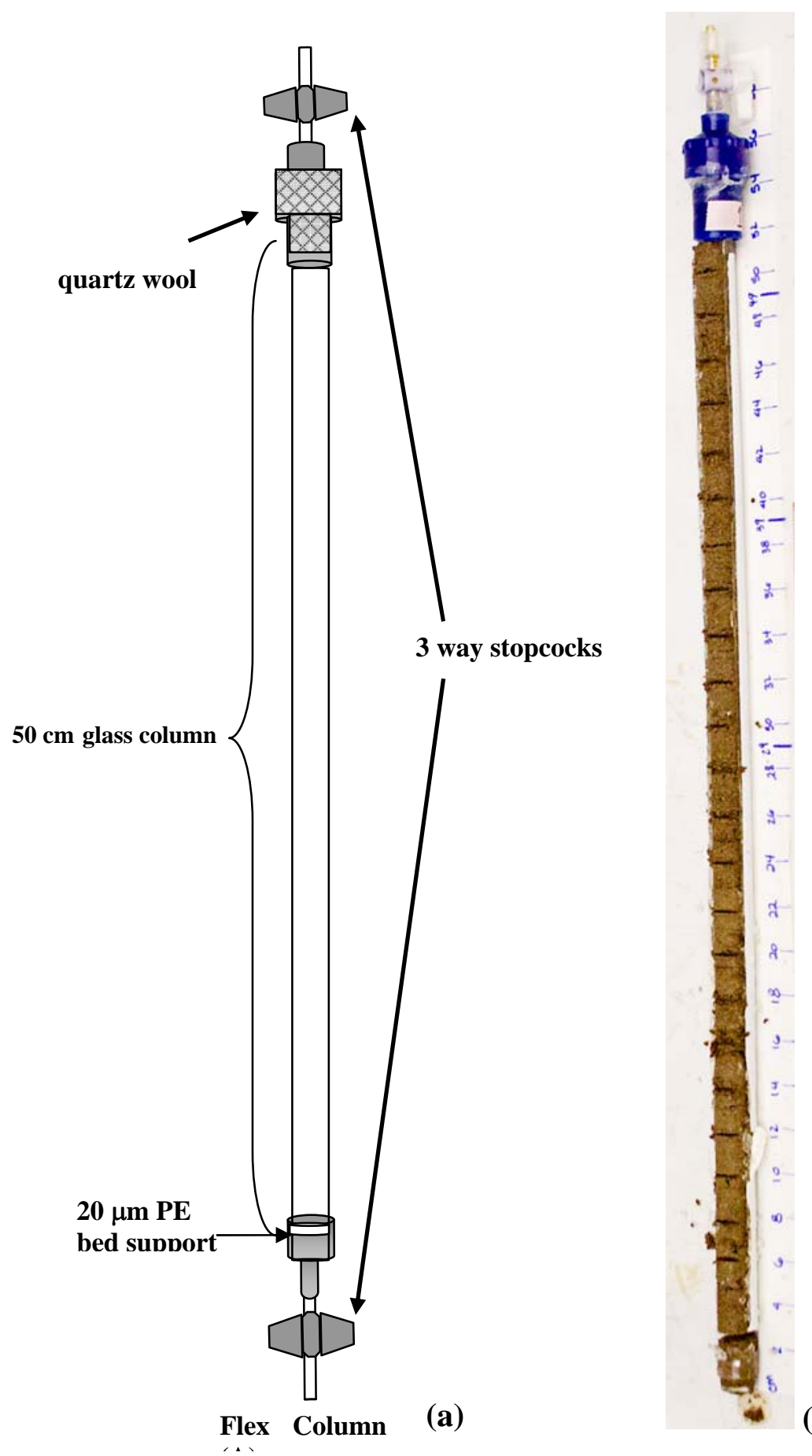

(b)

Figure 2.4. Schematic of Up-scaled Columns. The volcanic tuff is washed, crushed and packed into a glass column (a). After the columns were stopped, they were frozen and segmented and leached of any remaining activity (b). 


\subsection{Spectroscopic Methods Used to Probe Uranium Sorption/Desorption Heterogeneity on Volcanic Tuff}

2.5.1. X-Ray Absorption Fine Structure Spectroscopy (EXAFS) Sample Preparation

The objective of this work was to probe the average local structure surrounding uranium sorbed to a zeolitic and smectite-rich volcanic tuff, both at the conclusion of a sorption experiment (prior to desorption) and at the conclusion of a desorption experiment. Comparisons of the EXAFS spectra of the sorption and desorption samples were expected to reveal differences in the bonding environments of the surface species remaining on the samples, with the desorption sample presumed to have a greater fraction of more strongly bound species because weakly-bound species would desorb more readily. These measurements were conducted to provide evidence to support the theory of "strong" and "weak" sites for uranium sorption in heterogeneous tuff materials.

The EXAFS samples were prepared by sorbing U-238 to each of two volcanic tuff samples and in a separate experiment desorbing the U-238 from a portion of the sorption sample under continuous flow conditions for 1 week prior to EXAFS measurement. A total of 4 samples were prepared, smectite-rich tuff sorption (1), smectite-rich tuff desorption (2), mordenite-rich tuff sorption (3) and mordenite-rich tuff desorption (4). The total uranium concentration on the solid for the sorption samples was approximately 230-250 PPM, and approximately 20-50\% less for the desorption samples.

The tuffs were physically separated prior to introducing the U-238 by agitating and settling out the larger particles in J-13 groundwater leaving the very fine material from the bulk sample in the supernatant. The samples were decanted into Oakridge tubes and 
centrifuged. The very fine fraction was used to maximize surface area, increasing surface coverage of $\mathrm{U}-238$ in an attempt to achieve the lower limit $\mathrm{U}$ concentration of approximately 100 PPM required for the measurements.

The tracer solution used in the sorption phase of the experiments consisted of U-238 stock solution made by dissolving solid depleted $\mathrm{UO}_{2}$ in strong $\mathrm{HNO}_{3}$. The stock was diluted with J-13 groundwater for a final U-238 concentration of $10^{-5} \mathrm{M}$. The tracer solution was adjusted to a $\mathrm{pH}$ of 7-8 to match the original groundwater solution $\mathrm{pH}$. The tracer solution was replaced periodically during the sorption phase until no significant decrease in U-238 concentration in solution was observed; indicating the concentration of U-238 on the solid phase was maximized. U-238 was desorbed from the sample by flowing tracer-free groundwater through a .22 micron Millipore cartridge filter containing a portion of the sorption sample. The concentration of U-238 in the sorption and desorption solutions was measured using ICP-OES and the concentration on the solid phase post sorption and desorption was calculated by mass balance. XAS data were measured at the Stanford Synchrotron Radiation Lightsource (SSRL) on beamline 11-2 under dedicated operating conditions (3.0 GeV, 80-100 mA) using a $\mathrm{Si}(220)$ double crystal monochromator. The $\mathrm{U}_{\mathrm{II}}$ absorption edge $(20948 \mathrm{eV})$ was measured at room temperature in fluorescence mode using a 30-element Ge solid state detector.

\subsubsection{X-ray Mapping}

$\mathrm{X}$-ray mapping was used to investigate the spatial distribution and elemental associations of uranium sorbed to thin sections of volcanic tuff. Clay mineral components were physically separated to the extent possible from the volcanic tuff by agitating and settling out the larger particles in J-13 groundwater leaving the very fine 
material from the bulk sample in the supernatant. The samples were decanted into Oakridge tubes and centrifuged. Two polished thin sections were prepared by embedding the smectite-rich mineral sample in an epoxy resin, and polishing to a thickness of approximately $23 \mu \mathrm{m}$, and mounting on a pure quartz slide. The thin sections were exposed to a $10^{-5} \mathrm{M}$ depleted uranium solution by submerging the microscope slide in the solution inside a Teflon container. The bottle containing the depleted uranium solution and the thin section slide was rocked back and forth on a shaker for a period of one week. Depleted uranium from one thin section was then desorbed for a period of 1 week by a batch method. The samples were taken to Beam Line 2-3 at the Stanford Synchrotron Radiation Laboratory. Data were collected at the $\mathrm{U} \mathrm{L}_{\mathrm{III}}$-edge. The concentration of uranium on in the samples was too low to collect useable EXAFS data, but it was possible to obtain qualitative information on elemental associations and spatial distribution of uranium on the thin sections.

\subsubsection{Electron Probe Microanalysis (EPMA)}

Electron Probe Microanalysis was used to investigate the elemental associations of uranium sorbed to thin sections of volcanic tuff. Two polished thin sections were prepared for each of the smectite-rich and mordenite-rich mineral samples consisting of a dry-sieved fine particle size fraction $(>75 \mu \mathrm{m})$ with an epoxy resin and polished to a thickness of approximately $23 \mu \mathrm{m}$. The thin sections were exposed to a $10^{-5} \mathrm{M}$ depleted uranium solution by submerging the microscope slide in the solution inside a Falcon tube. The bottle containing the depleted uranium solution and the thin section slide was rocked back and forth on a shaker for a period of one week. Depleted uranium from one thin section from both the smectite and mordenite-rich samples was then desorbed for a 
period of 1 week by a batch method. EPMA of the samples was performed using a JEOL 8200 electron microprobe at the Department of Earth and Planetary Science/Institute of Meteoritics, University of New Mexico. The microprobe is equipped with 5 wavelength dispersive $\mathrm{x}$-ray spectrometers (WDS) and an ultrathin-window energy dispersive spectrometer (EDS). Natural mineral standards from C.M. Taylor Corporation (Sunnyvale, CA) were used as calibration standards, except U, which is calibrated on a U-metal also from Taylor. A ZAF correction program (Yakowitz, Myklebust et al. 1973) from Oxford was used to reduce the raw data. 


\section{INTERPRETIVE METHODS}

To estimate effective $K_{d}$ values for uranium and neptunium, the long-term column desorption data were fit with a multi-rate first-order kinetic model in which different types of sorption sites were assumed to have different sorption and desorption rate constants. Effective $K_{d}$ values were estimated from mass-weighted averages of the ratios of forward to reverse rate constants $\left(k_{f} / k_{r}\right)$ for each site. To model U and Np transport in the saturated columns packed with the clay-rich tuff, a one-dimensional advectiondispersion-reaction model that simulates first-order reactions onto multiple sorption sites was employed. This model was used in conjunction with the sorption and desorption rate constants estimated from the long-term desorption experiments to evaluate whether the effective $K_{d}$ values from the desorption experiments described reactive transport at two different flow rates in the columns.

\subsection{Batch Sorption/Long-Term Desorption Column Data Modeling}

The batch sorption/long-term desorption column experimental data were fit using a mathematical model written in FORTRAN that simulates adsorption and desorption onto multiple sorption sites with different first-order forward and reverse reaction rate constants. The model provides a least-squares fit to the data by adjusting the sorption and desorption rate constants and maximum sorption capacities for up to four different types of sites. The experimental data were initially fit as well as possible with one site, and then sites were incrementally added to improve the fit. Effective $K_{d}$ values were calculated by taking weighted means of the $K_{d}$ values $\left(K_{d}=k_{f} / k_{r}\right)$ for the individual sites in the model. The weighting factors used to calculate the weighted means were the fractions of radionuclide activity on each site type at the beginning of the desorption experiment. 
Equations 3.1 and 3.2 below were used in the model to fit the experimental column desorption data with up to four different sites. In equation 3.1 it is assumed that the reaction vessel is a well-mixed volume.

$$
\begin{aligned}
\frac{d C}{d t}=\frac{1}{V_{T}}\left\{Q\left(C_{i n}-C\right)-\left[\sum_{i=1}^{4} k_{f i}\left(1-\frac{s_{i}}{s_{i \max }}\right)\right] C+\sum_{i=1}^{4} k_{r i} s_{i}\right\} \text { (Equation 3.1) } \\
\frac{d s_{i}}{d t}=\left[\frac{k_{f i}\left(1-s_{i} / s_{i \max }\right) C-k_{r i} s_{i}}{M}\right](\text { Equation 3.2) } \\
C=\text { concentration out of column, CPM } / \mathrm{mL} \\
s_{i}=\text { concentration sorbed to site } \mathrm{i}, \mathrm{CPM} / \mathrm{g} \\
C_{i n}=\text { concentration in solution flowing into column, CPM } / \mathrm{mL} \\
V_{T}=\text { volume of solution in column, } \mathrm{mL} \\
Q=\text { flow rate through column, mL } / \mathrm{hr} \\
M=\text { mass of solid, g } \\
k_{f i}=\text { forward rate constant for site } i, \mathrm{~mL} / \mathrm{hr} \\
k_{r i}=\text { desorption rate constant for site } i, \mathrm{~g} / \mathrm{hr}
\end{aligned}
$$

\subsection{Up-scaled Column Data Modeling}

The uranium and neptunium breakthrough curves from saturated columns packed with the smectite-rich mineral volcanic tuff were fit using an advection-dispersionreaction solute transport model (Equation 3.3) that simulates first-order reactions onto multiple sorption site types. The model parameters (forward and reverse reaction rates 
and maximum sorption capacities for each site) from the fits of the batch sorption/longterm desorption column data were used in the model (Equation 3.3). Mean water residence time $(\tau)$, bulk density $(\rho)$ and porosity $(\theta)$ were calculated or measured for each column. The Peclet number (Pe) and mean water residence time $(\tau)$ was estimated by fitting the tritium breakthrough data for each column using the ReLap modeling program (Humphrey 2001). Pe and $\tau$ are related to the mean pore velocity ( $v$ ) and the solute dispersion coefficient (D) by $P e=v L / D$, where $L$ is the length of the column and $\tau=L / v$.

$$
\begin{aligned}
& \frac{\partial C}{\partial t}=D \frac{\partial^{2} C}{\partial x^{2}}-v \frac{\partial C}{\partial x}-\frac{\rho}{\theta}\left\{\left[\sum_{i=1}^{4} k_{f i}\left(1-\frac{s_{i}}{s_{i \max }}\right)\right] C-\sum_{i=1}^{4} k_{r i} s_{i}\right\} \\
& C=\text { concentration out of column, } \mathrm{CPM} / \mathrm{mL} \\
& D=\text { solute dispersion coefficient }\left(\mathrm{L}^{2} / t\right) \\
& v=\text { mean pore velocity }(\mathrm{L} / \mathrm{t}) \\
& x=\text { distance along the column (L) } \\
& t=\text { time (hr) } \\
& \rho=\text { Bulk denisty of volcanic tuff in column }\left(\mathrm{g} / \mathrm{cm}^{3}\right) \\
& \theta=\text { porosity }
\end{aligned}
$$

\subsection{CSTR Model}

The cumulative activity flushed from the column in long-term desorption control experiments was compared to the predicted cumulative activity flushed using an ideal continuous-stirred tank reactor (CSTR) model (equation 3.4). Equation 3.4 is the solution to equation 3.1 when there are no reactions and with $V=Q t$. The purpose of the control experiment was to confirm that the activity leaving the column (tracer with no 
solid phase present) was not influenced in any way by the column materials (glass barrel, filters, fittings and tubing). The model was also used to subtract the un-sorbed residual activity in solution after the sorption phase of the experiment from the activity eluted from the columns in the long-term desorption phase.

$$
\begin{aligned}
& C=C_{0}\left(1-\exp \left[\frac{V}{V_{T}}\right]\right) \quad \text { (Equation 3.4) } \\
& C=\text { cumulative eluted activity, } \mathrm{CPM} \\
& C_{0}=\text { intial activity in solution, } \mathrm{CPM} \\
& V=\text { cumulative volume collected, } \mathrm{ml} \\
& V_{T}=\text { volume of column, ml }
\end{aligned}
$$




\section{RESUlts AND Discussion}

\subsection{Sorption and Desorption Experiments}

\subsubsection{Uranium Batch Sorption and Flow Desorption Experiments}

Uranium was sorbed for a period of approximately 14 days to each of four volcanic tuff samples with the varying mineralogical properties described in Section 2.3.2. The uranium was then desorbed from each sample for a period of over 1900 hours ( 79 days). The method of sorption and desorption are described in Section 2.4. The sorption and subsequent desorption results for each sample are shown in Figures 4.1 through 4.4, along with the fit to each data set using the multi-site kinetic model described in Section 3.1. The uranium sorption/desorption experiments for each of the analcime, mordenite, smectite and illite-rich tuffs were carried out with duplicate 10 grams samples. Additionally, a second set of smectite-rich experiments were conducted using duplicate 3 gram samples.

Uranium Sorption. Sorption in each of the uranium/tuff combinations appears to be kinetically controlled up until about 100 hours when apparent equilibrium is established. Greater partitioning of uranium to the solid phase was observed in the smectite-rich sample (Table 4.1), followed by the analcime, mordenite and illite-rich samples. These results do not correlate with the measured surface area, reported CEC, or smectite and zeolite abundance. One possible explanation for the lack of correlation to any of these parameters is the predominance of calcium uranyl-carbonate complexes in solution (Table 2.2). The negatively charged complexes would not favor a cation exchange mechanism, nor would an electrostatic (outer-sphere) mechanism be 
energetically favored on the negatively-charged clays and zeolites. Both smectite clays and zeolites have amphoteric edge sites. A comparison of the Zeta potential results in Figures 2.2 (a) and (b) for the smectite-rich and mordenite-rich tuffs, respectively, shows that the surfaces have approximately the same charge at a $\mathrm{pH}$ of 7 , indicating that the protonated edge site density for these two samples are approximately the same. As mentioned above, as the ratio of $\mathrm{Si} / \mathrm{Al}$ decreases, IEP shifts to lower $\mathrm{pH}$. Analcime has a lower $\mathrm{Si} / \mathrm{Al}$ ratio, and the edge sites would be less protonated than those of mordenite so one would expect that analcime would sorb less negatively charged uranyl complexes. The question remains as to why the smectite-rich sample (2 wt \% smectite) sorbed more uranium than both the zeolites (20-30 wt \% zeolite), and why the analcime-rich (20 wt \% analcime) sample sorbed more uranium than the mordenite-rich (18 wt \% mordenite, 12 $\mathrm{wt} \%$ analcime) sample. If cation exchange was a viable mechanism, the analcime sample would sorb more than both the smectite-rich and mordenite-rich samples due to its higher CEC, but this mechanism has been ruled out due to the lack of uranyl cations in solution and steric limitations imposed by the narrow channel structure of zeolites, especially analcime. One possibility for the greater amount of sorption in the smectite-rich sample could be that the smectite edge sites are more accessible than the edge sites of zeolites. Smectite has a 2:1 layer structure in contrast to the complex ring-like structure of zeolites. The edge sites of zeolites may exhibit steric limitations once an upper limit surface coverage of uranyl-carbonate is reached (Catalano, Trainor et al. 2005). The sorbed complexes may crowd adjacent edge sites and prohibit additional complexes from approaching the surface. This effect may be more pronounced in mordenite than in analcime. Another possibility is sorption to plagioclase, which is more abundant in the 
smectite-rich sample than in any of the others. This can be ruled out due to the relatively low uranium sorption (42\% less than smectite) in the illite-rich sample, which has only 4.5\% less plagioclase than the smectite-rich sample. If plagioclase were playing an important role in uranium sorption, it stands to reason that higher uranium sorption in the illite-rich sample would have been observed. The relatively low amount of uranium sorption in the illite-rich sample is most likely due to uranyl cation sorption occurring predominately at unsatisfied valences at defects in the crystal structure, where sorption of negatively charged complexes would not be energetically favored. The uranyl cation is not a dominant solution species in J-13 groundwater. Given the chemistry of the systems in this study and the unchanging concentrations in control experiments, precipitation reactions can most likely be ruled out as a mechanism of uranium removal from solution.

Table 4.1 Percent Uranium Sorbed

\begin{tabular}{|c|c|c|c|c|c|}
\hline Mineralogical I.D. & $\begin{array}{c}\text { Sample } \\
\text { No. }\end{array}$ & $\begin{array}{c}\% \text { U } \\
\text { sorbed }\end{array}$ & $\begin{array}{c}\text { Average } \\
\% \text { U } \\
\text { sorbed }\end{array}$ & $\begin{array}{c}\text { \% of } \\
\text { initial U } \\
\text { tracer not } \\
\text { desorbed }\end{array}$ & $\begin{array}{c}\text { Average } \\
\% \text { of } \\
\text { initial U } \\
\text { tracer not } \\
\text { desorbed }\end{array}$ \\
\hline \multirow{2}{*}{ Analcime-rich } & 1 & 32.80 & \multirow{2}{*}{33.09} & 8 & \multirow{2}{*}{8.50} \\
\hline & 2 & 33.39 & & 9 & \\
\hline \multirow{2}{*}{ Mordenite-rich } & 1 & 18.67 & \multirow{2}{*}{18.23} & 5 & \multirow{2}{*}{5.00} \\
\hline & 2 & 17.80 & & 5 & \\
\hline \multirow{4}{*}{ Smectite-rich } & 1 & 53.80 & \multirow{4}{*}{51.80} & 26 & \multirow{4}{*}{18.75} \\
\hline & 2 & 50.06 & & 23 & \\
\hline & 3 & 51.58 & & 16 & \\
\hline & 4 & 51.75 & & 10 & \\
\hline \multirow{2}{*}{ Illite-rich } & 1 & 9.44 & \multirow{2}{*}{9.75} & 2 & \multirow{2}{*}{2.00} \\
\hline & 2 & 10.06 & & 2 & \\
\hline
\end{tabular}

Uranium Desorption. All of the samples had a fraction of uranium remaining sorbed at the conclusion of the experiments (2-26\%) suggesting very slow desorption, or irreversible sorption. As in the sorption phase of the experiments, the smectite and 
analcime-rich samples had the greatest fraction of uranium remaining sorbed to the solid phase at the conclusion of the desorption phase. The greater amount of uranium remaining in the smectite and analcime-rich samples compared to that of the mordenite samples could be due to the low likelihood of cation exchange being a predominant sorption mechanism in these samples. For instance, mordenite has a more open cage structure than analcime and would allow more cation exchange type reactions, which exhibit a higher degree of reversibility. Even though the illite-rich sample had little uranium sorbed initially, a very small fraction of uranium remained sorbed at the end of the desorption period ( 1900 hours). This is most likely due to inter-layer sorption of a small fraction of uranyl cations which are very strongly bound (Helios Rybicka, Calmano et al. 1995). As a fraction of what sorbed, the smectite-rich sample retained the most uranium after desorption ( $36 \%)$, followed by the mordenite-rich ( $27 \%)$ and analcimerich $(\sim 26 \%)$ samples, while the illite-rich sample retained the least $(\sim 20 \%)$. Figure 4.5 contains plots of the sorption and desorption data normalized to the measured surface area in Table 2.3 to establish that the differences in sorption/desorption of uranium in the tuffs are not strictly due to differences in surface area. The normalized data suggest that mineralogy is important in the sorption and desorption of uranium, although surface area may play a role in sorption and desorption of uranium in the illite-rich tuff.

There is good agreement between all duplicate sample runs for both the sorption and desorption of uranium, with the exception of one of the 10-gram clay samples where the uranium desorbed faster as shown in Figure 4.3. It is also interesting to note that both the 10-gram samples and the 3-gram samples sorbed similar fractions of uranium and exhibited similar desorption behavior. These observations are most likely due to mineral 
or surface area heterogeneities between the samples. At the conclusion of the long-term desorption experiments, the remaining activity was leached from the solid phase. The initial leaching solution consisted of the $\mathrm{J}-13$ water adjusted to a $\mathrm{pH}$ of greater than 11 using sodium hydroxide. There was very little recovery of the uranium with this solution as shown in Figure 4.6. The solid phase was then subsequently washed with J-13 water adjusted to a $\mathrm{pH}$ of less than 2 with nitric acid. Most of the remaining activity was desorbed (within 10\% of the original activity sorbed for all samples except for mordeniterich ( 20\%)) from the solid phase. A good mass balance indicates that the fraction not desorbed from the tuff is distinguishable from zero. This is especially important in the illite-rich sample where only $20 \%$ of the uranium sorbed was retained at the conclusion of the experiment and $\pm 4 \%$ of the $20 \%$ remaining sorbed was recovered from the leaching solutions.

Control samples consisting of tracer solution with no solid phase were run concurrently with the long-term desorption experiments. The cumulative recovery of uranium from the control samples shown in Figure 4.7 follows that predicted by an ideal CSTR model indicating that the desorption of uranium was not being influenced by the column, filters or tubing used in the experiments.

Uranium Multi-site Kinetic Modeling. The sorption and desorption experimental data were fit using the multi-site kinetic model described in Section 3.1 to determine sorption and desorption rate constants that were consistent with the observed behavior. Although the sorption and desorption rate constants given in Table 4.2 are not unique, they show that desorption rate constants that vary over several orders of magnitude are required to fit the data. This suggests that while a fraction of the sites may be in 
equilibrium with the solution phase, not all of the sites are, and the equilibrium assumption inferred by the use of a $K_{d}$ value is not valid in this case. For the analcime, mordenite and smectite-rich samples, the slow desorbing fraction of the data were initially fit using an irreversible site $\left(\mathrm{k}_{\mathrm{r}}=0\right)$. The desorption rate constant for this site was then incrementally increased to an upper limit, while still providing a good fit to the data, thus providing an upper bound for the effective $K_{d}$ value. The use of an irreversible site for the illite-rich desorption data resulted in overprediction of the activity remaining on the solid phase at the conclusion of the long-term desorption experiment, therefore a slower, reversible rate constant was initially used for the slow desorbing fraction of uranium.

The effective $K_{d}$ values in Table 4.2 are an average of the $K_{d}$ values for each site weighted by the fraction of the total sorbed concentration on the site at the start of desorption. These results indicate that the $\mathrm{K}_{\mathrm{d}}$ values inferred from the sorption phase of the experiment are much less than those obtained from the long-term desorption experiments. Batch-derived $K_{d}$ values are typically determined from batch sorption and short-term desorption experiments that do not effectively interrogate stronger sorption sites with slower desorption kinetics because the effects of the stronger sites are not evident during a batch sorption or sort-term desorption experiment. The results of the uranium long-term desorption experiments suggest that there are multiple types of sites for uranium sorption reactions with widely-varying desorption kinetics. 


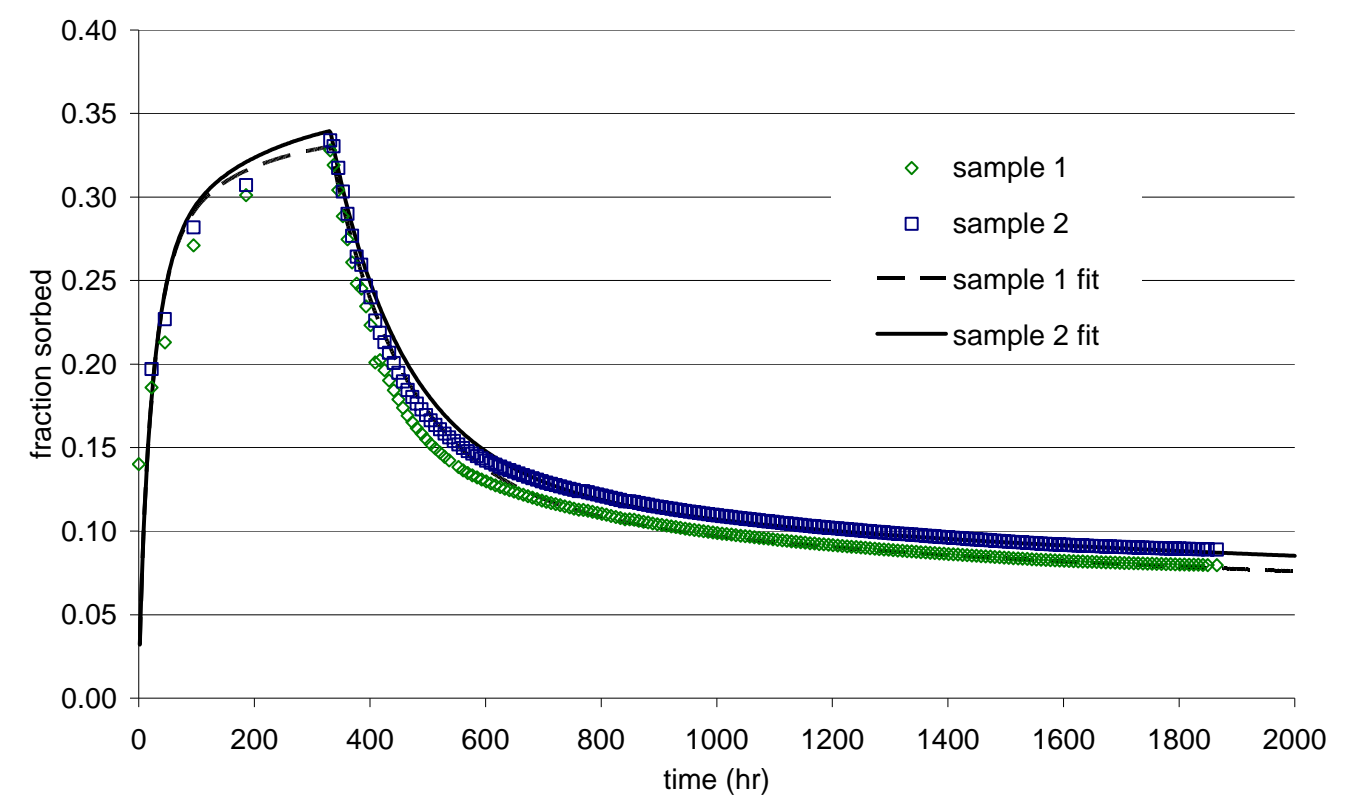

Figure 4.1. Uranium batch sorption and column desorption in the analcime-rich tuff. The data are fit by using the multi-site kinetic model described in Section 3.1 and the parameters given in Table 4.2.

$\mathrm{U}$ batch sorption and column desorption mordenite/analcime-rich tuff

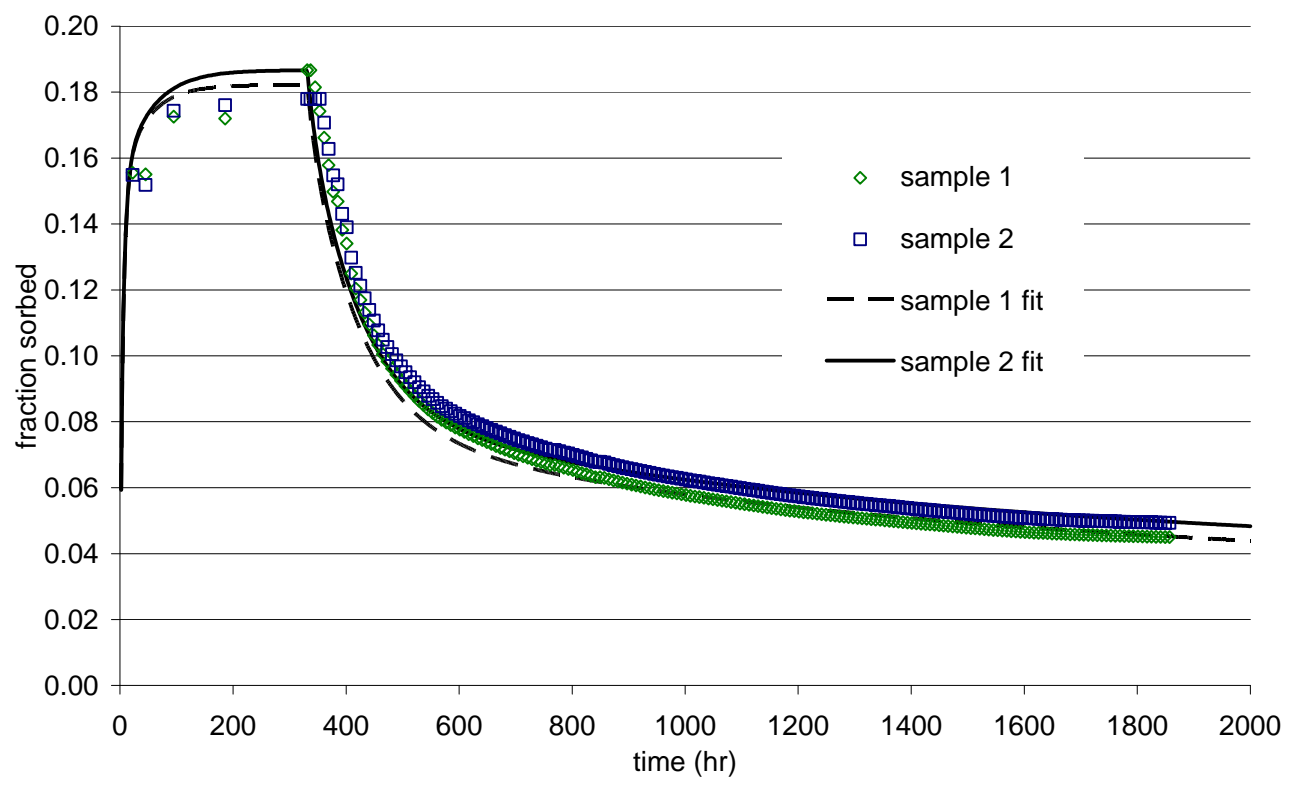

Figure 4.2. Uranium batch sorption and column desorption in the mordenite-rich tuff. The data are fit by using the multi-site kinetic model described in Section 3.1 and the parameters given in Table 4.2. 


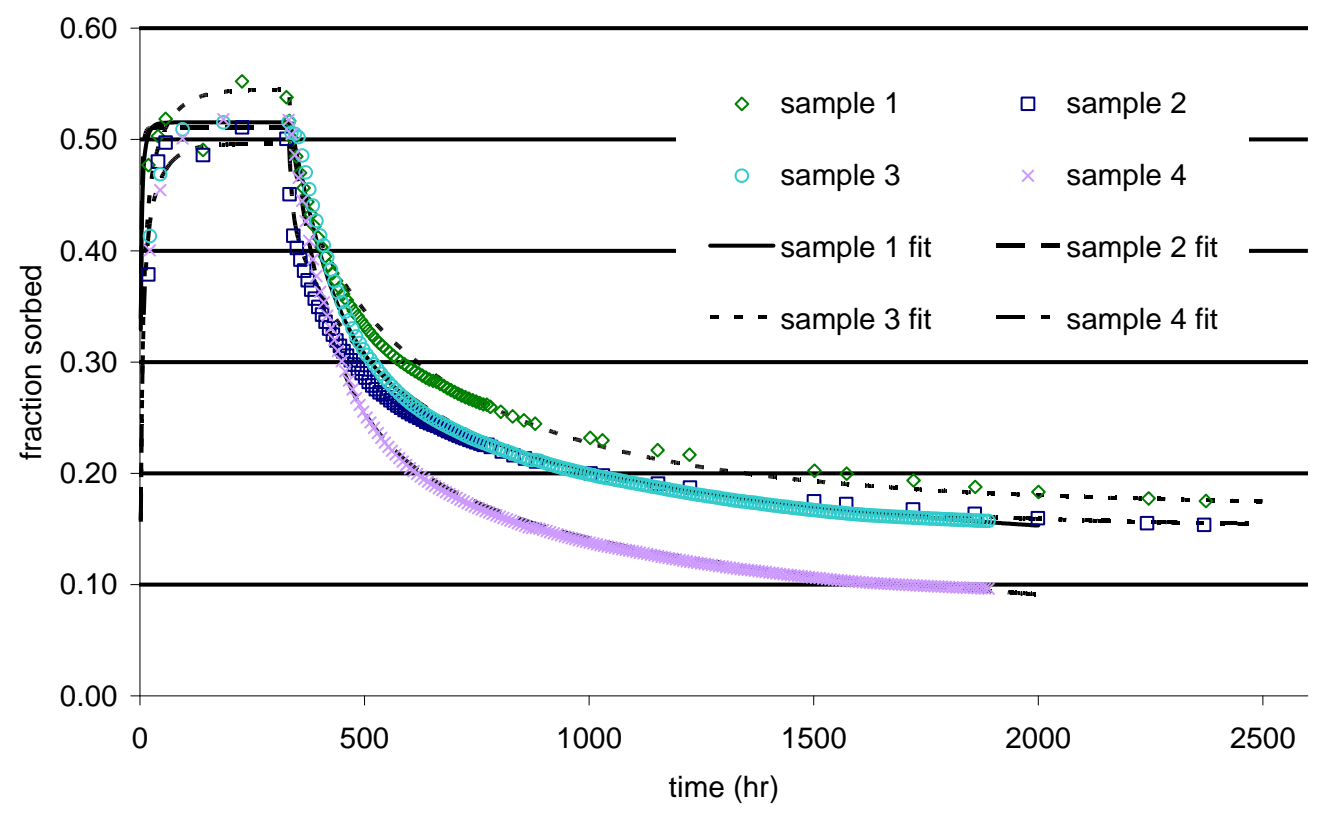

Figure 4.3. Uranium batch sorption and column desorption in the smectite-rich tuff. The data are fit by using the multi-site kinetic model described in Section 3.1 and the parameters given in Table 4.2.

U Batch Sorption and Column Desorption Illite-rich Tuff

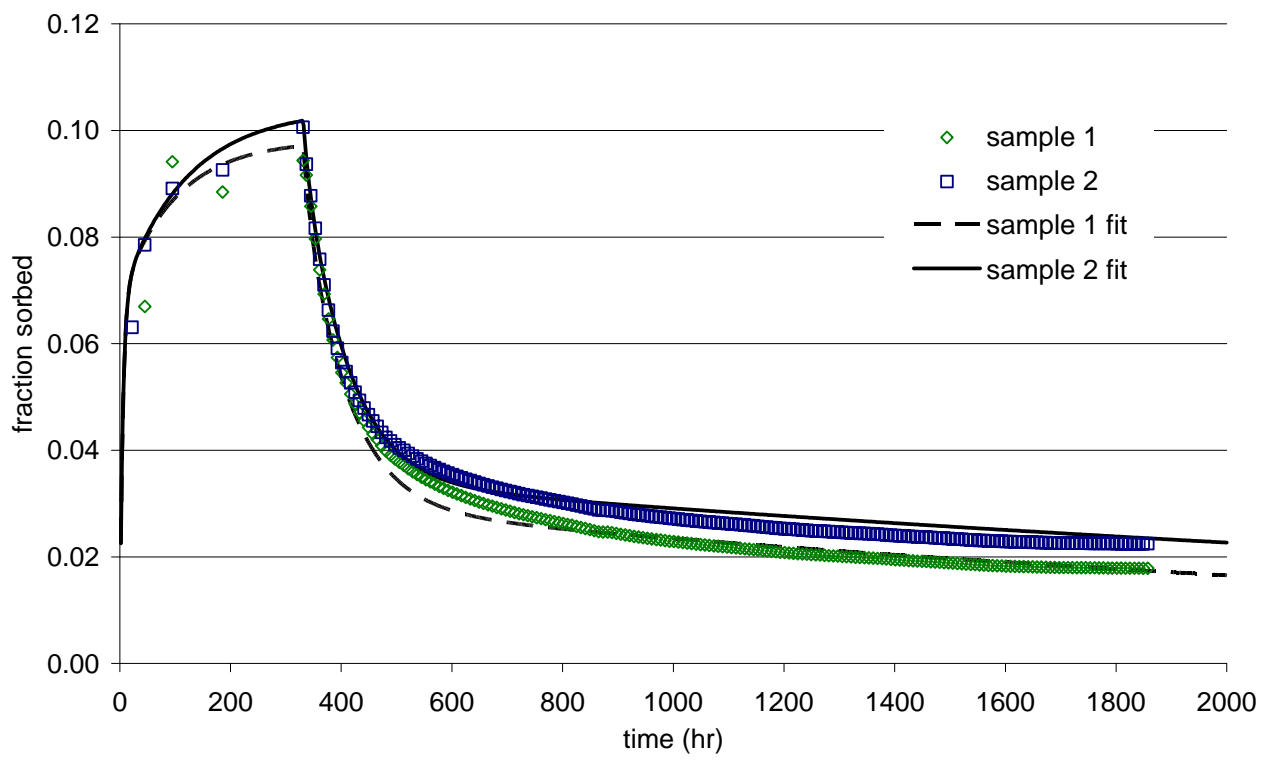

Figure 4.4. Uranium batch sorption and column desorption in the illite-rich tuff. The data are fit by using the multi-site kinetic model described in Section 3.1 and the parameters given in Table 4.2. 
Normalzed to Surface Area

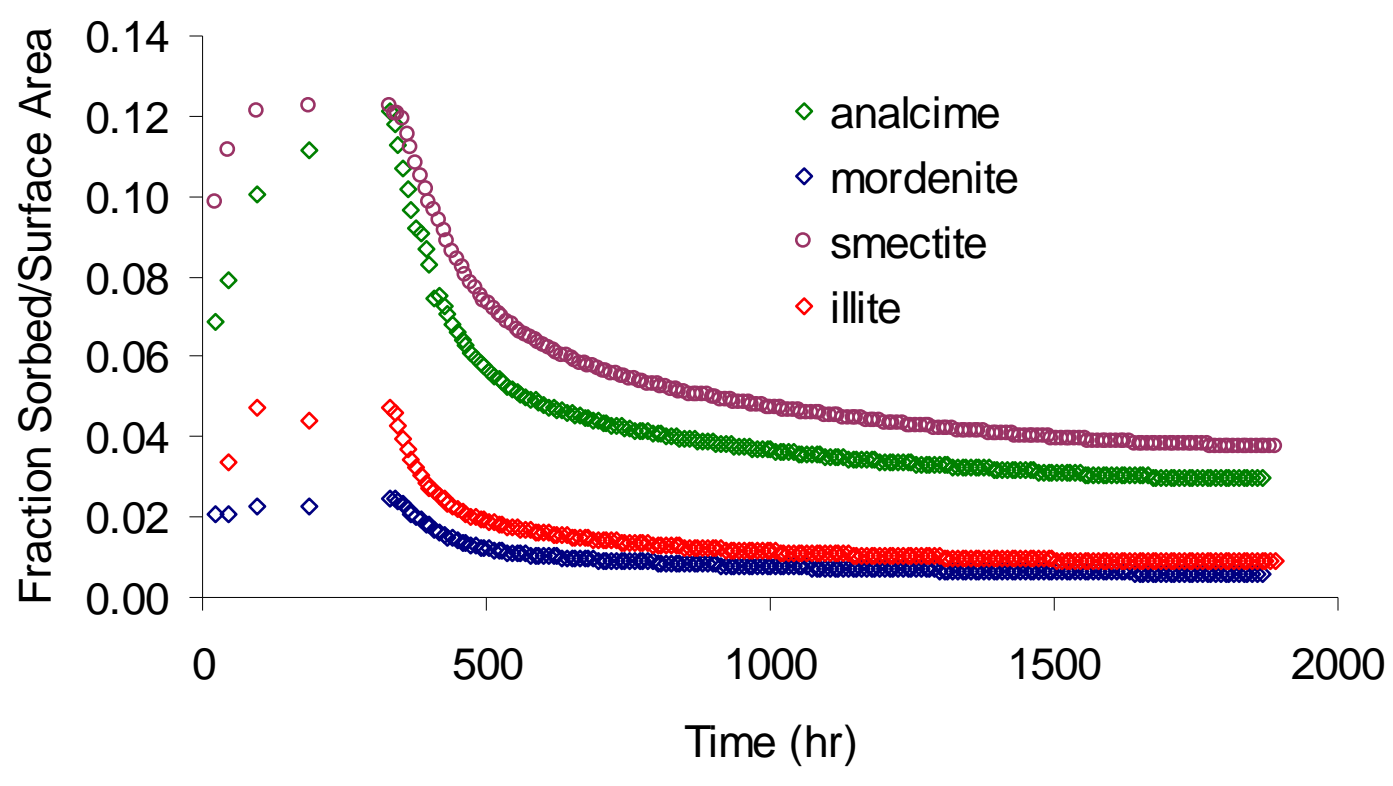

Figure 4.5. Fraction of uranium sorbed normalized to surface area. The fraction remaining sorbed is normalized to the measured surface area for each tuff in Table 2.3.

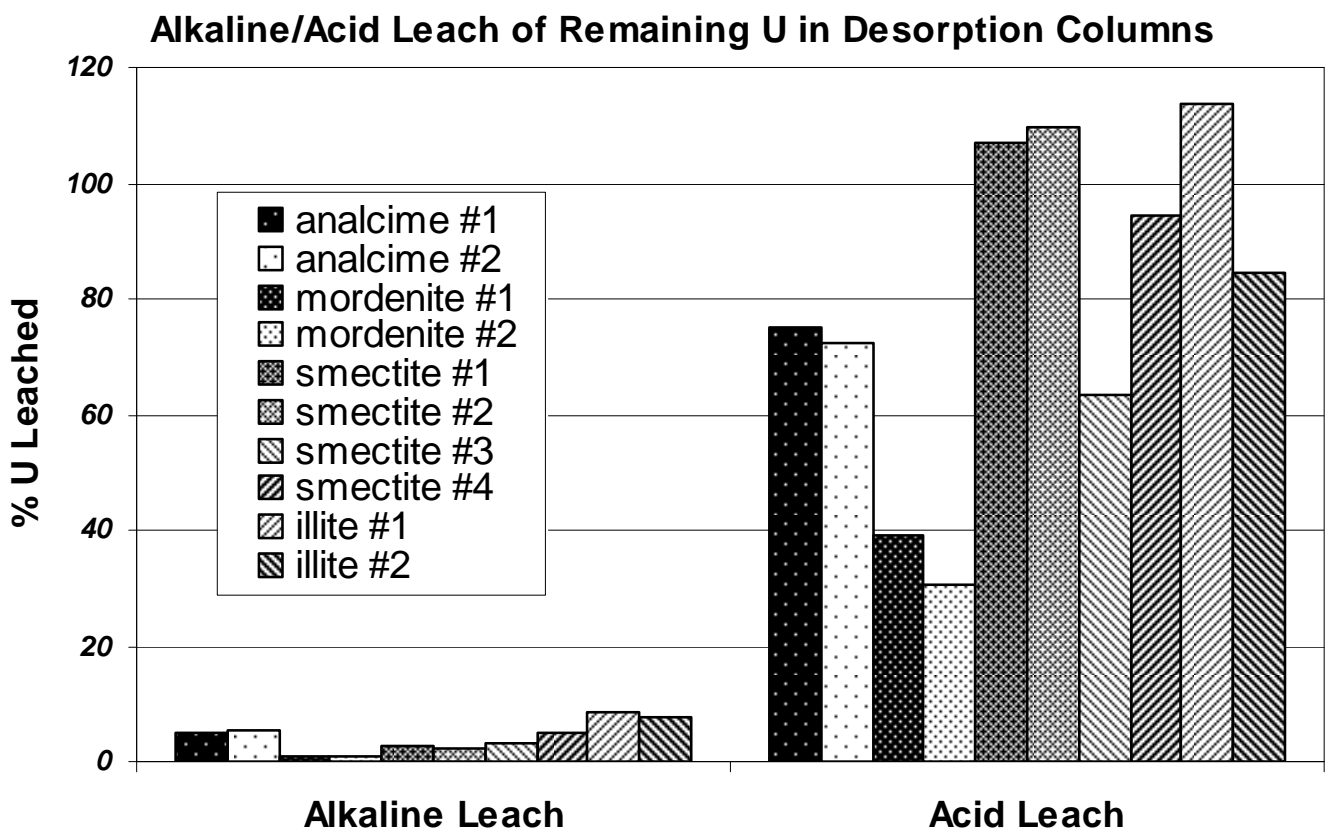

Figure 4.6. Alkaline/acid leach of remaining uranium in desorption columns. The uranium that remained on the volcanic tuff at the conclusion of the experiment was more effectively leached by the acid solution from all of the volcanic tuffs. 


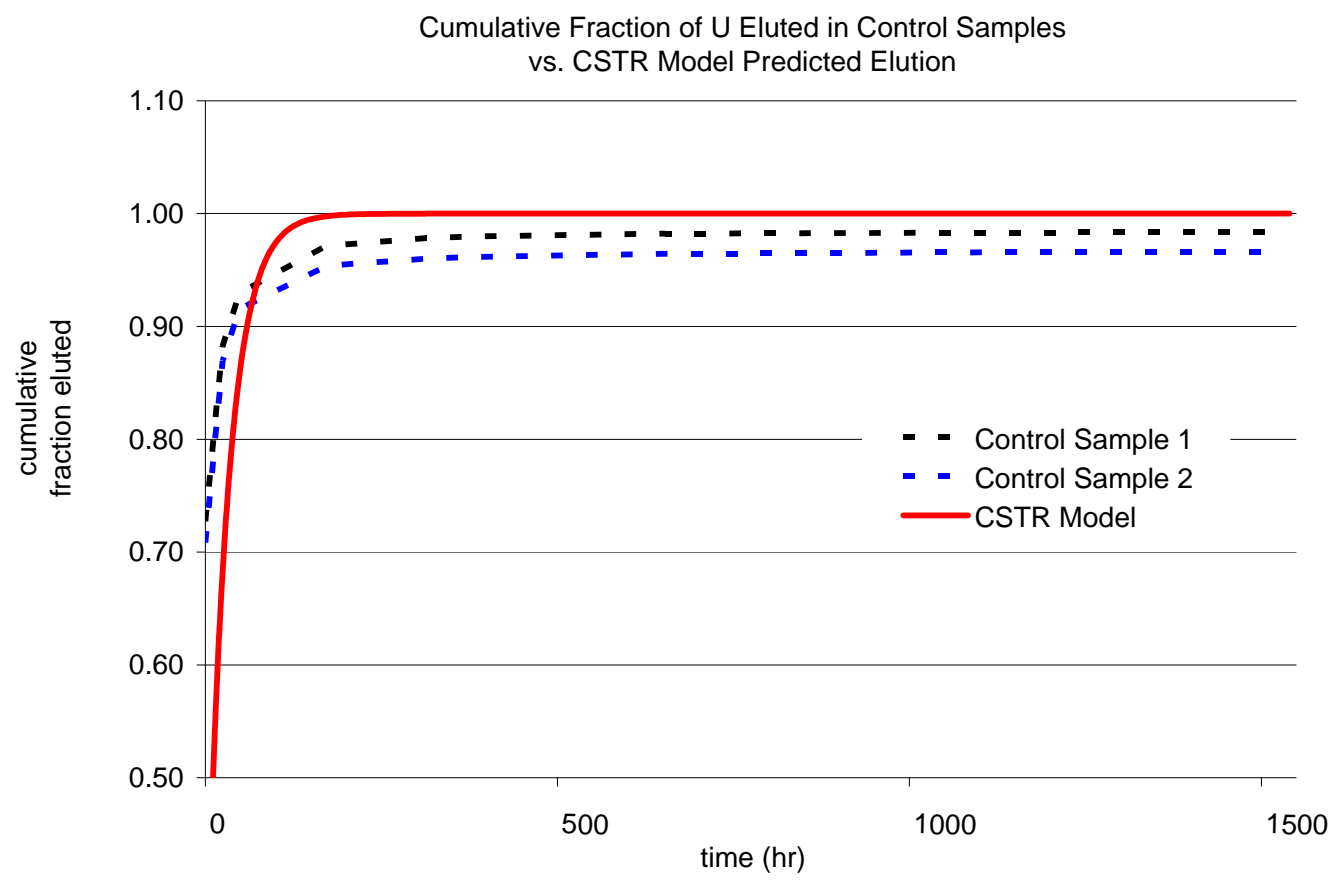

Figure 4.7. Uranium batch sorption and column desorption control samples. The eluted activity in the control samples compare well to the CSTR model described in Section 3.3 suggesting that the uranium desorption behavior is not affected by the experimental apparatus. 
Table 4.2 Parameters used in uranium multi-site kinetic model, calculated effective $K_{d}$ and experimental batch $K_{d}$

\begin{tabular}{|c|c|c|c|c|c|c|c|c|c|}
\hline Mineralogical I.D. & $\begin{array}{l}\text { Sample } \\
\text { No. }\end{array}$ & Site No. & $\mathbf{K}_{\mathbf{f}}$ & $\mathrm{K}_{\mathrm{r}}$ & $S_{\max }$ & $\mathbf{W}^{*}$ & $\begin{array}{l}\text { Effective } K_{d} \\
\text { from } \\
\text { desorption } \\
\text { modeling } \\
\text { for each } \\
\text { site }(\mathrm{ml} / \mathrm{g})\end{array}$ & $\begin{array}{l}\text { Effective } K_{d} \\
\text { Total }(\mathrm{ml} / \mathrm{g})\end{array}$ & $\begin{array}{l}\mathrm{K}_{\mathrm{d}} \text { from } \\
\text { Batch } \\
\text { Sorption } \\
(\mathrm{ml} / \mathrm{g})\end{array}$ \\
\hline \multirow[t]{3}{*}{ analcime-rich } & 1 & 1 & 0.03 & 0.0095 & 10000 & 0.59 & 1.9 & & \\
\hline & & 2 & 0.022 & 0.0015 & 1000 & 0.36 & 5.3 & & \\
\hline & & 3 & 0.0025 & 0.0001 & 3000 & 0.05 & 1.3 & 8.41 & 2.95 \\
\hline \multirow[t]{3}{*}{ analcime-rich } & 2 & 1 & 0.03 & 0.0095 & 10000 & 0.59 & 1.9 & & \\
\hline & & 2 & 0.022 & 0.0015 & 1000 & 0.36 & 5.3 & & \\
\hline & & 3 & 0.0025 & 0.0001 & 3600 & 0.05 & 1.3 & 8.41 & 3.03 \\
\hline \multirow[t]{3}{*}{ mordenite-rich } & 1 & 1 & 0.06 & 0.02 & 4050 & 0.55 & 1.7 & & \\
\hline & & 2 & 0.06 & 0.001 & 1300 & 0.42 & 25.3 & & \\
\hline & & 3 & 0.0025 & 0.00001 & 1000 & 0.03 & 6.6 & 33.56 & 1.38 \\
\hline \multirow[t]{3}{*}{ mordenite-rich } & 2 & 1 & 0.06 & 0.02 & 4050 & 0.55 & 1.7 & & \\
\hline & & 2 & 0.06 & 0.001 & 1300 & 0.42 & 25.3 & & \\
\hline & & 3 & 0.0025 & 0.00001 & 1145 & 0.03 & 6.6 & 33.58 & 1.27 \\
\hline \multirow[t]{3}{*}{ smectite-rich-3 g } & 1 & 1 & 0.5 & 0.1 & 20000 & 0.42 & 2.1 & & \\
\hline & & 2 & 0.5 & 0.0052 & 27000 & 0.49 & 46.9 & & \\
\hline & & 3 & 0.08 & 0.00001 & 17000 & 0.09 & 706.9 & 755.95 & 6.13 \\
\hline \multirow[t]{3}{*}{ smectite-rich-3 g } & 2 & 1 & 0.5 & 0.1 & 20000 & 0.43 & 2.1 & & \\
\hline & & 2 & 0.5 & 0.0052 & 23238 & 0.48 & 46.4 & & \\
\hline & & 3 & 0.08 & 0.00001 & 15000 & 0.09 & 711.8 & 760.28 & 6.10 \\
\hline \multirow[t]{3}{*}{ smectite-rich-10 g } & 3 & 1 & 0.5 & 0.1 & 10500 & 0.50 & 2.5 & & \\
\hline & & 2 & 0.5 & 0.0052 & 5000 & 0.39 & 37.2 & & \\
\hline & & 3 & 0.08 & 0.00001 & 4000 & 0.11 & 872.2 & 911.90 & 6.48 \\
\hline \multirow[t]{3}{*}{ smectite-rich-10 g } & 4 & 1 & 0.5 & 0.1 & 14500 & 0.53 & 2.7 & & \\
\hline & & 2 & 0.5 & 0.0052 & 5000 & 0.37 & 36.0 & & \\
\hline & & 3 & 0.08 & 0.00001 & 2000 & 0.09 & 722.9 & 761.59 & 6.31 \\
\hline \multirow[t]{2}{*}{ illite-rich } & 1 & 1 & 0.04 & 0.024 & 2500 & 0.97 & 1.6 & & \\
\hline & & 2 & 0.001 & 0.00034 & 1000 & 0.03 & 0.1 & 1.70 & 0.63 \\
\hline \multirow[t]{2}{*}{ illite-rich } & 2 & 1 & 0.04 & 0.024 & 2500 & 0.97 & 1.6 & & \\
\hline & & 2 & 0.001 & 0.00034 & 1189 & 0.03 & 0.1 & 1.70 & 0.69 \\
\hline \multicolumn{5}{|c|}{${ }^{\star}$ Fraction of total sorbed concentration on site at start of desorption } & & & & & \\
\hline
\end{tabular}




\subsubsection{Up-scaled Uranium Column Experiments}

Scaled up experiments using $50-\mathrm{cm}$ long, $1.5-\mathrm{cm}$ diameter, fully packed columns were conducted to complement the long-term desorption experiments. Tritium and uranium tracers were introduced into the columns packed with the smectite-rich tuff and saturated with J-13 groundwater as described in Section 2.4.2. Two separate columns containing the smectite-rich tuff were run at two different flow rates, one at $7 \mathrm{ml} / \mathrm{hr}$ (column 1) and the other at $28 \mathrm{ml} / \mathrm{hr}$ (column 3). The purpose of these experiments were two-fold: 1) to study the residence time dependence of uranium transport by conducting the experiments at different flow rates; and 2) to evaluate the applicability of the sorption and desorption rate constants determined in the long-term desorption experiments under dynamic transport conditions.

Tritium Breakthrough. Tritium was used as a conservative (non-sorbing) tracer in the column experiments. The breakthrough of tritium and the fit of the experimental data using the modeling program ReLap are shown in Figures 4.8 and 4.9. The column parameters are detailed in Table 4.3. $\mathrm{C} / \mathrm{C}_{0}=.5$ occurred at 1 pore volume and .95 pore volumes for the 7 and $28 \mathrm{ml} / \mathrm{hr}$ columns, respectively. Approximately $96 \%$ of the tritium was recovered from the two columns within 2.3 pore volumes. The ReLap models of the tritium breakthrough curves were used to obtain the Peclet number (Pe) and mean water residence time ( $\tau$ ) (Table 4.3) used in the multi-site transport model. The symmetric breakthrough curve and near complete recovery of tritium in both columns indicates that preferential flow paths and dead volume were not major contributors to flow within the column. 
Uranium Breakthrough. From past observations (Ding 2003) it was expected that a small fraction of the uranium tracer would break through at almost the same time as the conservative tracer (tritium) and that a vast majority of the tracer mass would be significantly retarded and that all of the tracer would not be recovered within the time-frame of the experiment (see Section 1.2.2.). The previous experiments also used materials that had a higher smectite and zeolite weight percent than the materials of the current study, so an even larger fraction of early-arriving uranium was expected in the columns used in this study. However, based on a simple calculation of the retardation factor (Equation 4.1) using the batch $K_{d}$ value for the smectite-rich tuff (Table 4.2), uranium breakthrough at approximately 14 and 15 pore volumes was predicted for columns 1 and 3 , respectively. When the effective $K_{d}$ (Table 4.2) was used to calculate the retardation factor, uranium breakthrough at approximately 1,600 and 1,750 pore volumes was predicted for columns 1 and 3, respectively. Differences in the predicted breakthrough between the two columns are a result of differences in the bulk density $\left(\rho_{\mathrm{b}}\right)$ and porosity $(n)$ of the crushed tuff within the columns.

$$
\begin{gathered}
R_{d}=\frac{\bar{v}_{i}}{\bar{v}_{c}}=\frac{X_{i}}{X_{c}}=1+\left(\frac{\rho_{b}}{n}\right) K_{d} \text { (Equation 4.1) } \\
\text { where } X_{i}=\bar{v}_{i} t
\end{gathered}
$$


$R_{d}=$ retardation factor

$\bar{v}=$ average groundwater velocity (determined by ReLap fit of tritium breakthrough) (cm/s)

$\bar{v}_{i}=$ average velocity of adsorbed species at location $\mathrm{i}$ in the column profile $(\mathrm{cm} / \mathrm{s})$

$\mathrm{X}=$ migration distance of the conserved species $(\mathrm{cm})$

$\mathrm{X}_{i}=$ migration distance of the adsorbed species at location $\mathrm{i}$ in the column profile $(\mathrm{cm})$

$\rho_{b}=\operatorname{dry}$ bulk density $\left(\mathrm{g} / \mathrm{cm}^{3}\right)$

$n=$ porosity

$K_{d}=$ distribution coeficient $(\mathrm{ml} / \mathrm{g})$

$\mathrm{t}=$ duration of column experiment $(\mathrm{hr})$

Not only did uranium not break through at the same time as the conservative tracer, but significant breakthrough was not observed until 100 pore volumes for both the $7 \mathrm{ml} / \mathrm{hr}$ and $28 \mathrm{ml} / \mathrm{hr}$ columns (Figure 4.10). It is difficult to determine by inspection of the breakthrough curve if the elevated recovery of uranium around 100 pore volumes in column 3 is significant (see inset Figure 4.10). A Student's t-test indicated that the mean activity in the samples collected after 100 pore volumes is greater than the sample means (95\% confidence level, 2-tailed probability) of the samples collected prior to 100 pore volumes, indicating that the breakthrough observed after 100 pore volumes is significant. In addition, elevated activity in column 3 prior to 100 pore volumes (as well as column 1) occurred in only a few sporadically distributed samples, and filtration of samples adjacent to the elevated activity to remove colloids ( $0.22 \mu \mathrm{m}$ filter) reduced the activity in the filtrate to below or very close to background levels. In both columns a Students t-test indicated that the mean activities in the filtered and unfiltered samples after breakthrough are not equal (95\% confidence level, 2- tailed probability) suggesting that at least some of the activity was associated with colloids, although the activity in the filtrate consistently 
increased above background. A Students t-test in the filtered and unfiltered samples in both columns prior to 100 pore volumes indicated that the means are equal for column 1, and not equal in column 3 (95\% confidence level, 2- tailed probability), suggesting that the faster flow column had more activity associated with colloids prior to breakthrough. These results suggest that the small amount of elevated activity observed before 100 pore volumes in column 3 was due to breakthrough of uranium associated with colloidal material (most likely uranium attached to clay colloids) and the elevated activity after 100 pore volumes in column 1 was due to both uranium in solution and uranium associated with colloidal material. Filtered samples were not measured in column 3 after 100 pore volumes; therefore the contribution from uranium associated with colloidal material after breakthrough in this column was not determined.

The observed behavior in the earlier alluvial columns discussed in Section 1.2.2 (Ding 2003) could have been the result of experimental column design. To avoid local velocity effects such as channeling and wall effects, the ratio of the column diameter to the largest particle diameter should be 30-40 (Relyea 1982). This ratio in the previous alluvial experiments was only 12.5 and could have resulted in the observed behavior. The ratio of column diameter to largest particle diameter used in this study was 30, which was apparently large enough to avoid early breakthrough caused by wall effects (assuming that was the cause in the earlier experiments). In both of the columns, a vast majority of the uranium was retarded, and very low recovery was observed (Table 4.3). There did not appear to be a residence time dependence due to the concurrent breakthrough in both columns at 100 pore volumes, 
despite that fact that column 1 had a residence time four times that of column 3 . Column 1 ran over ten times longer and eluted 207 more pore volumes than column 3. A higher relative recovery of uranium may have been observed from column 3 if the experiment were allowed to continue.

Uranium Concentration Profile. At the conclusion of the up-scaled experiments the columns were frozen, segmented and the sorbed uranium leached from the solid material as described in Section 2.4.2. Although not apparent from the uranium breakthrough curves, a residence time dependence is observed in the uranium concentration profiles in Figure 4.11. The mean residence time for column 1 was four times that of column 3 . In column 1 the majority of the uranium mass ( $71 \%$ of total leached) was in the first 0 to $8 \mathrm{~cm}$ from the column inlet, while column 3 had the majority of uranium mass (47\% of total leached) between 10 and $20 \mathrm{~cm}$ from the column inlet. Column 1 also ran 10 times longer than column 3 . If column 3 had run longer, the profile might have shifted toward the end of the column, and a higher uranium recovery would have been observed. This behavior can be explained by a fraction of the uranium mass being sorbed to slow or irreversible sites, while a fraction desorbs much faster and continues to travel through the column. The faster traveling uranium may have different speciation in solution that does not sorb to the slower desorbing sites. As the solution equilibrium adjusts to accommodate for the loss of the stronger sorbing species, the weaker sorbing species are converted to more strongly sorbing species, resulting in the low uranium recovery from the column. Another explanation could be a dual porosity flow/transport regime within the column. Although the tritium breakthrough curves suggest very minimal secondary 
porosity in the columns (porosity in which water is not flowing; e.g., dead-end pores), it is possible that diffusion occurred over relatively short distance scales into secondary porosity without having much effect on tritium transport. However, if the secondary porosity contained an abundance of strong uranium sorption sites relative to the primary porosity, the secondary porosity could have a dramatic effect on uranium transport through the column. This could result in a portion of the uranium being held up in "dead-end pores" while the other portion continues to flow through the column with less retardation. Such behavior could conceivably result in the residual profiles observed in the columns at the conclusion of the experiments.

In addition, the column 1 profile reflects a very large amount of uranium within the first $8 \mathrm{~cm}$, then a drop off in uranium concentration and a small spike in concentration about midway through the column. The spike can be explained by either mineral or surface area heterogeneities within the column (with a greater density of strong sorbing sites at the location of the spike), or flow heterogeneities such as a crack in the porous medium, effectively creating a fracture flow regime over a small portion of the column. Flow within the fracture would be greater than that within the porous matrix, resulting in a region of relatively stagnant water in the matrix into which uranium could diffuse and sorb, thus becoming effectively immobilized in that part of the column (Wu, Ye et al. 2009). Interestingly, the column 3 concentration profile also shows a dual peak, although less resolved, suggesting that column 3 also had these same types of heterogeneities.

Uranium Multi-site Transport Model. The up-scaled column experimental data were fit using the advection-dispersion-reaction transport equation described in 
Section 3.2, modified to include up to 4 parallel reactions. The rate constants obtained from the long-term desorption experiments were used in the multi-site transport model along with the column parameters provided in Table 4.3. Use of these rate constants resulted in an over-prediction of initial uranium breakthrough and recovery from the up-scaled columns (Figure 4.10). There are four conceivable explanations for this behavior: 1) abrasion of the crushed tuff due to the end-over-end mixing in the long-term desorption experiment enhanced the desorption rates by disrupting the surfaces and providing the extra energy needed to cause desorption and/or created colloids to which uranium was attached; 2) more strong sites were available per unit mass in the up-scaled columns to sorb the $\mathrm{CaUO}_{2}\left(\mathrm{CO}_{3}\right)_{3}^{2-}$ solution species; 3) the number of strong sites per unit mass of tuff is limited, and these sites were close to fully occupied in the desorption experiments, but they were not fully occupied in the up-scaled column experiments and 4) Ca removal from solution via cation exchange with $\mathrm{Na}$ in the clay resulting in a lower concentration of $\mathrm{Ca}$ in solution available to complex $\mathrm{UO}_{2}\left(\mathrm{CO}_{3}\right)_{3}^{4-}$ and $\mathrm{UO}_{2}\left(\mathrm{CO}_{3}\right)_{2}^{2-}$, resulting in a lower percentage of the non-sorbing solution species $\left(\mathrm{Ca}_{2} \mathrm{UO}_{2}\left(\mathrm{CO}_{3}\right)_{3}^{0}\right)$ (Meleshyn, Azeroual et al. 2009). The enhancement of desorption rates by disrupting the surfaces in the first explanation is more feasible than generation of uranium attached-colloids in that the colloid particle size would have to be less than $0.22 \mu \mathrm{m}$ in order to pass through the filter cartridge attached to the end of the desorption column. The second explanation would require a more reactive mineralogy or greater surface area per unit mass of material in the up-scaled columns than in the long-term desorption experiments. The third explanation would result in the suppression of sorption and 
apparent desorption enhanced in the desorption experiments relative to the up-scaled columns because there would be many more strong sites per mole of uranium introduced to the up-scaled columns than in the desorption experiments. Based on the injection volumes and concentrations and the solid masses in the two types of experiments, at least 6 times as many sites are available per mole of $U$ in the upscaled experiments as in the desorption experiments. The fourth explanation involving the Ca-Na cation exchange scenario would require disequilibrium between the solid and solution phases of the column. Although the volcanic tuff had been in equilibrium with groundwater in-situ, QXRD analysis of the crushed and sieved smectite-rich tuff indicated that the clay mineral phase is largely Na-montmorillonite. The intact tuff core might have been in equilibrium with the J-13 groundwater, but the crushing of the tuff cores in preparation for these experiments could have created new surfaces for cation exchange to take place (Rogers and Meijer 1993). The tuff samples used in the long-term desorption experiments were equilibrated with $30 \mathrm{ml} \mathrm{J}$ 13 groundwater for a period of 10 days prior to the batch sorption phase of the longterm desorption experiments. The up-scaled columns were equilibrated with J-13 groundwater for approximately 1 month $(7 \mathrm{ml} / \mathrm{hr}$ columns) and for 4 days $(28 \mathrm{ml} / \mathrm{hr}$ column), which represents considerably more volume of equilibration solution coming in contact with the rock than in the desorption experiments. Based on the J13 equilibration volumes, solution calcium concentration and the cation exchange capacity of the bulk material, it is likely that the solution and solid phases of the all the experiments were in equilibrium prior to introduction of uranium. Additionally, re-establishment of the solution species equilibrium would have to be kinetically 
limited for the cation-exchange scenario to be a valid explanation for the observed concentration profiles.

Sorption rate constants ranging over an order of magnitude and desorption rate constants ranging over several orders of magnitude were required for the fit of the uranium breakthrough curves. The data for both the column breakthrough and profile were initially fit using an irreversible site $\left(k_{r}=0\right)$ for the $3^{\text {rd }}$ and slowest site. The desorption rate constant for this site was then incrementally increased to an upper limit, while still providing a good fit to the data, thus providing an upper bound for the slowest desorption rate constant. The use of an upper limit rate constant is based on the hypothesis that if the experiment were allowed to continue, the sorbed uranium may have desorbed and eventually broken through, resulting in a slow but non-zero desorption rate constant. The fitting parameters providing good fits to the breakthrough curves result in predicted column profiles that do not match the observed behavior of the uranium that remained in the column (Figure 4.11). For both of the columns, the predicted profiles were flattened, and the large mass of uranium sorbed at the front of the column was not reproduced using the column breakthrough fitting parameters. To obtain a better fit to the uranium profiles in Figure 4.11, a $K_{d}$ value was estimated from $R_{d}$ using equation 4.1 and the uranium concentration profile and breakthrough from the $7 \mathrm{ml} / \mathrm{hr}$ column.

A total of three sites were used to initially account for the large uranium concentrations in the column 1 profile at $0-2 \mathrm{~cm}$ from the column inlet $\left(\mathrm{X}_{1}\right)$, the small spike in concentration mid-way through the column $\left(\mathrm{X}_{2}\right)$, and the actual breakthrough of uranium after 100 pore volumes of elution. Average velocities were calculated for 
the concentration spikes in the uranium column using the migration distance $\mathrm{X}_{\mathrm{i}}$, and the duration of the experiment $t$, to obtain a $K_{d}$ value for location $i$ in the column profile. The $K_{d}$ for the third site was calculated from the estimated $R_{d}$ value for the uranium breakthrough at 100 pore volumes, using equation 4.1. The ratios of $k_{f i}$ to $k_{r i}$ were set equal to the resulting $K_{d}$ values and the values of $k_{f i}$ and $k_{r i}$ were adjusted while maintaining this ratio to fit the profile data. The long-term uranium sorption and desorption data from the smectite-rich sample are again presented in Figure 4.12, along with desorption predicted by the breakthrough and profile fitting parameters for column 1 and 3 . In generating the predicted curves, the number of sites $\left(\mathrm{S}_{\max }\right)$ were allowed to vary from what provided the best fits to the breakthrough and profile data, but the rate constants were fixed. Although the fit to the data is quite good, both the breakthrough and profile parameters underestimate the fraction of uranium sorbed in the sorption phase, and predict a slower rate of desorption in the desorption phase. In both cases, the value of $S_{\max }$ for the slower sites providing the best fit to the long-term desorption data was an order of magnitude lower than the value of $S_{\max }$ that provided the best fit to the up-scaled column data. This may suggest that either slower sites were more available in the up-scaled experiments than in the long-term desorption experiments, or that stronger sorbing species were more abundant in the up-scaled experiments than in the long-term desorption experiments, or both.

Other Transport Models. The multi-site transport model was modified to simulate first order reactions in series and $2^{\text {nd }}$ order reactions in parallel in an attempt to better fit the experimental data. The reaction-in-series model was not able to fit the profile data and the breakthrough data with the same fitting parameters, and thus it 
offered no improvement over the first-order reactions-in-parallel model (the base model presented above). Reactions in series cannot be ruled out, although evidence supporting such a conceptual model was not found in the literature. A time-resolved spectroscopic study would aid in determining surface species, and if sorption complexes change from outer-sphere to inner-sphere as the bond ages. Although the $2^{\text {nd }}$ order reaction model was able to reasonably fit both the breakthrough and the profile in column 1, it was unable to reasonably fit the column 3 data with the same parameters, where it over-predicted both the breakthrough time and recovery and under-predicted the amount remaining sorbed in the column profile. In addition, there is a lack of spectroscopic evidence that second or higher order reactions occur for uranium on montmorillonite (Catalano and Brown 2005), so a second-order mechanism cannot be defended as plausible for uranium sorption in the volcanic tuff samples and groundwater used in this study.

The results of the up-scaled columns suggest that there are multiple site types for uranium sorption reactions with varying desorption kinetics. Although not apparent in the breakthrough curves, the uranium concentration profiles indicate that there is residence time dependence for uranium migration in the column. Because the multi-site kinetic and transport models were unable to simultaneously fit the longterm desorption data and the up-scaled column breakthrough and profile data using the same fitting parameters, further explanation is needed to fully understand uranium transport in the smectite-rich volcanic tuff. Previous experiments examined only sorption and short-term desorption batch results and uranium breakthrough from upscaled columns such as the ones conducted in this study. Although a multi-site 
transport model can account for the early breakthrough and long-tailing behavior observed in the previous up-scaled columns described in Section 1.2.2 where uranium was eluted through columns packed with alluvium, the behavior of the uranium remaining sorbed within the column has not been previously considered. The new information obtained from this study provides evidence that batch derived $\mathrm{K}_{\mathrm{d}}$ values over-predict the transport of uranium in volcanic tuff, and that the use of a simple multi-site model is not adequate in describing uranium transport. This study suggests that to fully understand the behavior of uranium in volcanic tuff a model that accounts for very strong sites for uranium, as well as the possibility of kinetically limited reestablishment of uranium solution speciation and dual porosity flow regimes, must be considered.

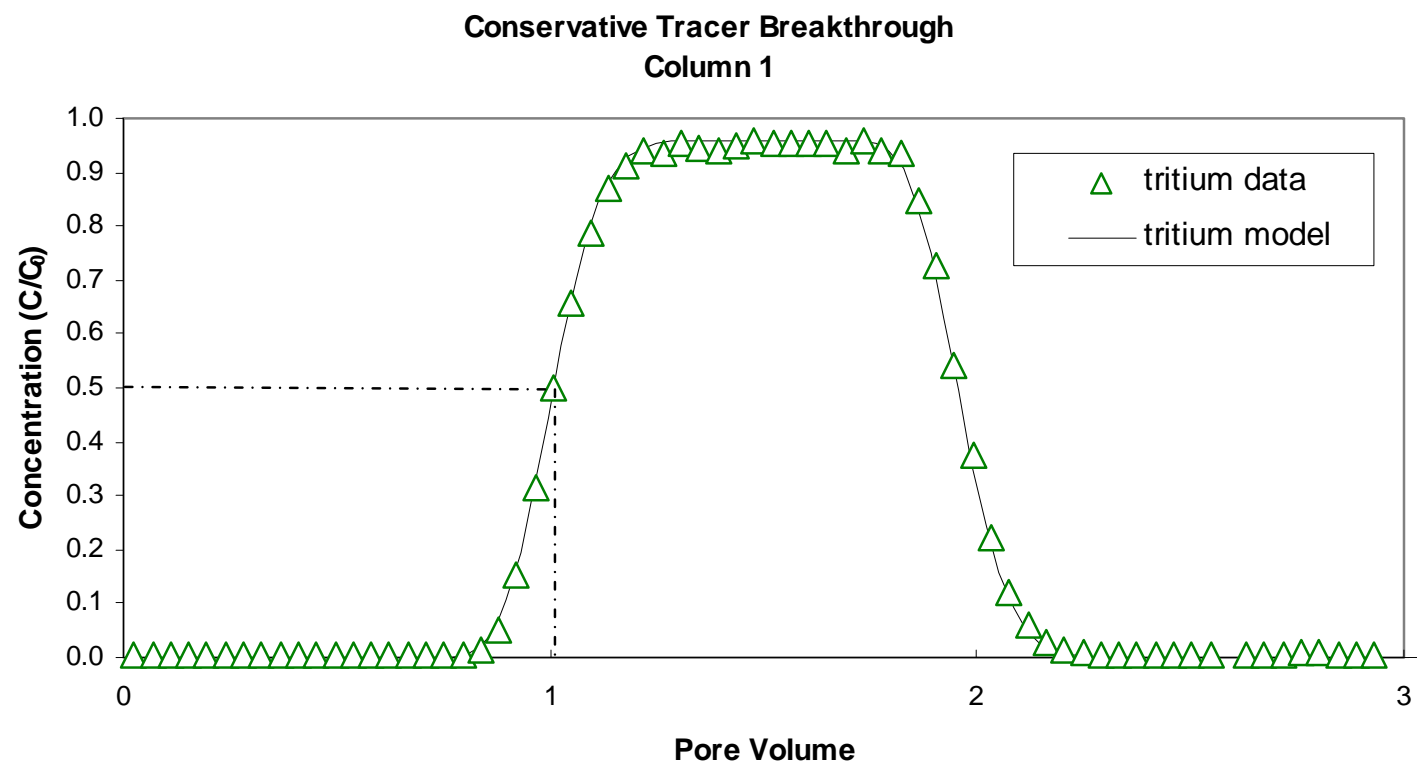

Figure 4.8. Tritium breakthrough from the $7 \mathrm{ml} / \mathrm{hr}$ (Column 1) flow rate experiments in the smectite-rich tuff up-scaled columns. The data are fit by using the ReLap Program described in Section 3.2. The dashed line at $C / C_{0}=.5$ occurs at 1 pore volume. 
Column 3

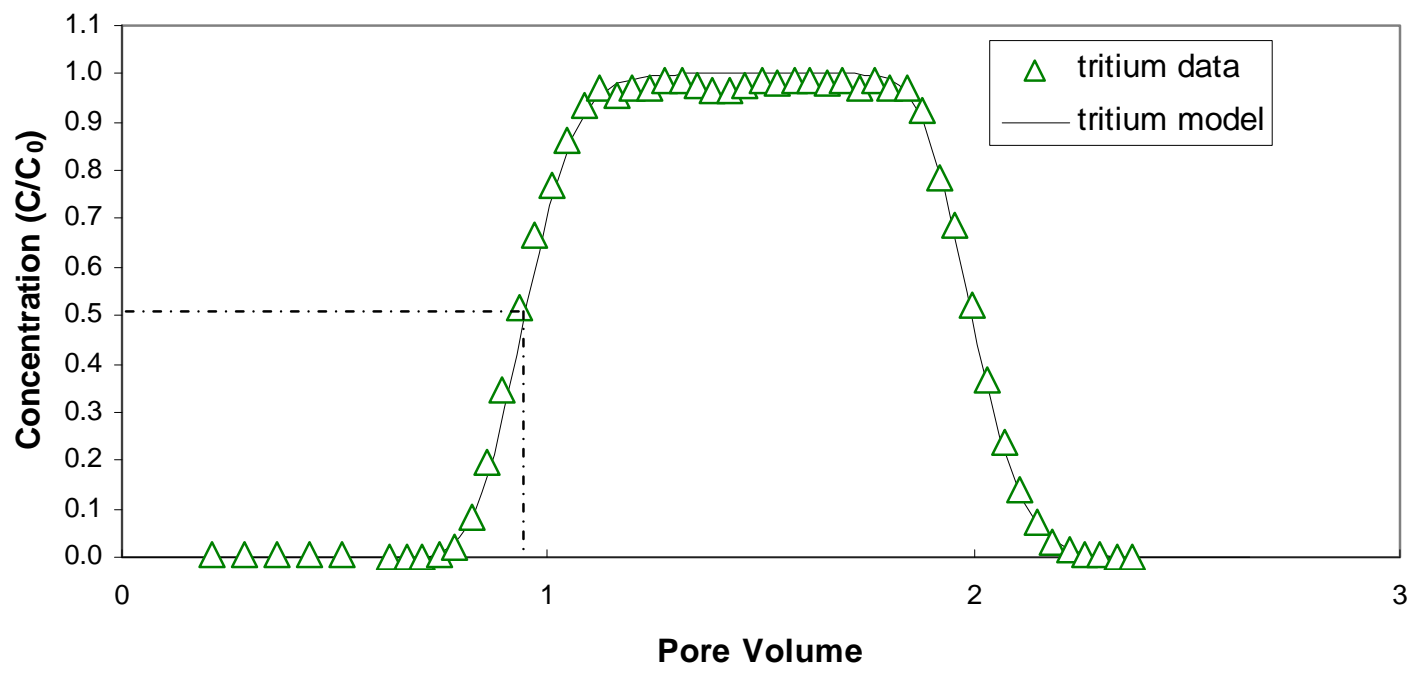

Figure 4.9. Tritium breakthrough from the $28 \mathrm{ml} / \mathrm{hr}$ (Column 3) flow rate experiments in the smectite-rich tuff up-scaled columns. The data are fit by using the ReLap Program described in Section 3.2. The dashed line at $C / C_{0}=.5$ occurs at 0.95 pore volumes.

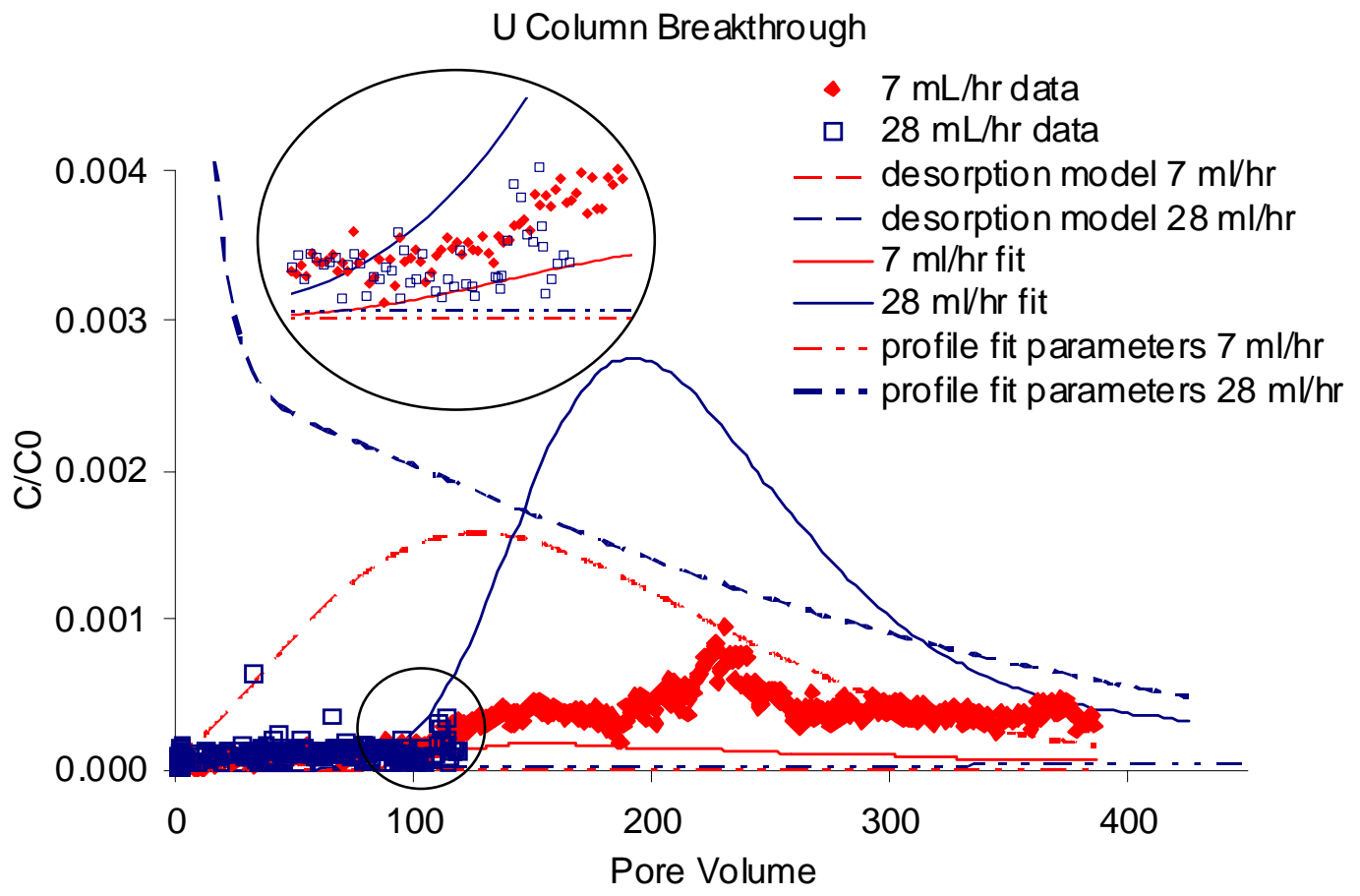

Figure 4.10. Uranium breakthrough from the $7 \mathrm{ml} / \mathrm{hr}$ and $28 \mathrm{ml} / \mathrm{hr}$ flow rate experiments in the smectite-rich tuff up-scaled columns. The data are fit by using the multi-site kinetic transport model described in Section 3.2 and the parameters given in Table 4.3. 
U Column Concentration Profile

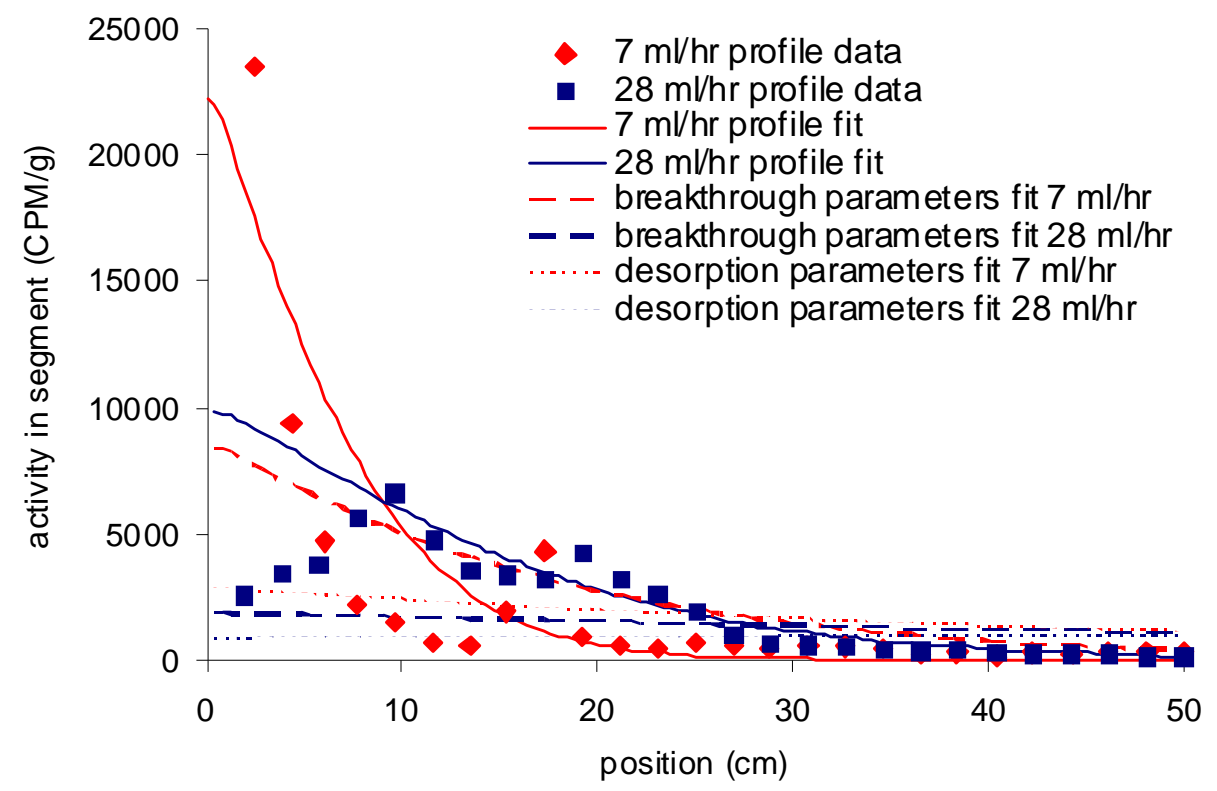

Figure 4.11. Uranium concentration profiles in the $7 \mathrm{ml} / \mathrm{hr}$ (column 1) and 28 $\mathrm{ml} / \mathrm{hr}$ (column 3) flow rate experiments in the smectite-rich tuff up-scaled columns. The data are fit by using the multi-site kinetic transport model described in Section 3.2 and the parameters given in Table 4.3.

U Batch Sorption and Column Desorption

Comparison with U Column Model Parameters

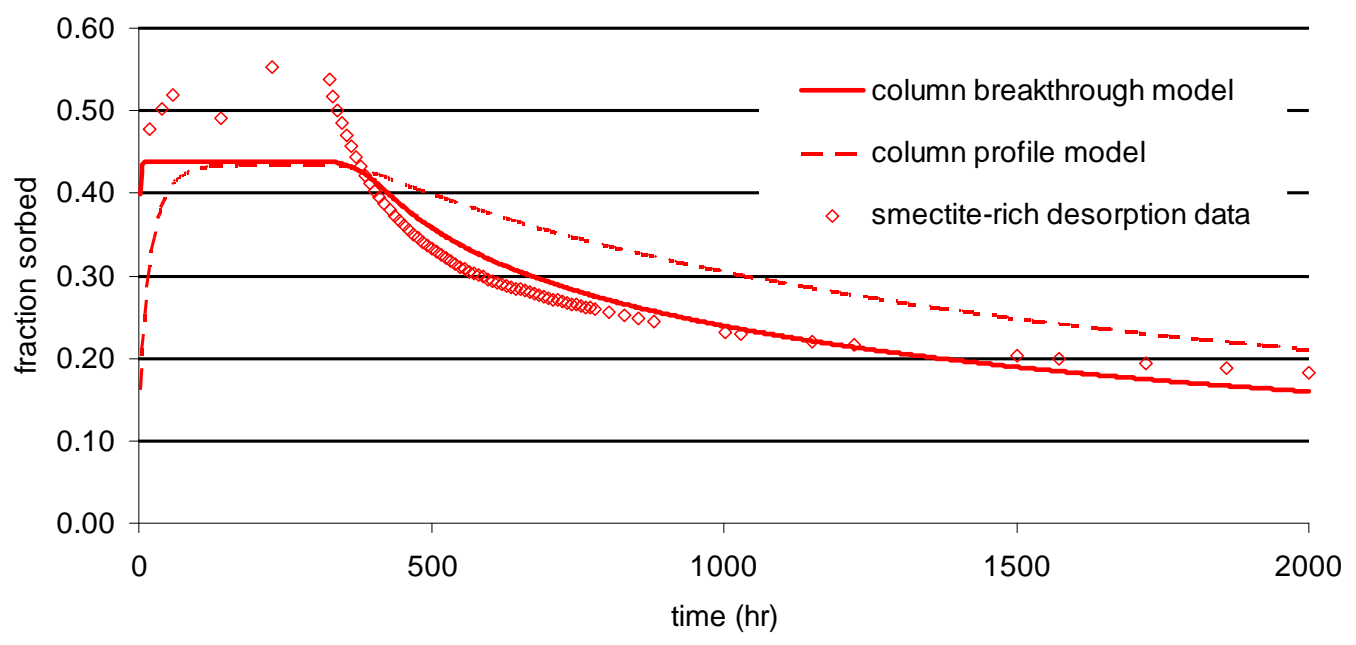

Figure 4.12. Uranium batch sorption and column desorption in the smectite-rich tuff. The model fits are from the packed column model fit parameters for both the breakthrough and concentration profile for the $7 \mathrm{ml} / \mathrm{hr}$ column and are listed in Table 4.3. Note that the number sites $\left(S_{\max }\right)$ were allowed to vary to obtain the best fit to the data using the pre-defined forward and reverse rate constants. 
Table 4.3 Uranium up-scaled column parameters.

\begin{tabular}{|c|c|c|c|c|c|c|c|c|}
\hline Parameter & \multicolumn{4}{|c|}{ Column 1 (7 ml/hr flow rate) } & \multicolumn{4}{|c|}{ Column 3 (28 ml/hr flow rate) } \\
\hline Material & \multicolumn{4}{|c|}{ Smectite-rich Volcanic Tuff } & \multicolumn{4}{|c|}{ Smectite-rich Volcanic Tuff } \\
\hline Particle size & \multicolumn{4}{|c|}{$75-500 \mu \mathrm{m}$} & \multicolumn{4}{|c|}{$75-500 \mu \mathrm{m}$} \\
\hline Mass & \multicolumn{4}{|c|}{$105.1 \mathrm{~g}$} & \multicolumn{4}{|c|}{$116.5 \mathrm{~g}$} \\
\hline $\begin{array}{l}\text { Column } \\
\text { Diameter }\end{array}$ & \multicolumn{4}{|c|}{$1.5 \mathrm{~cm}$} & \multicolumn{4}{|c|}{$1.5 \mathrm{~cm}$} \\
\hline Column Length & \multicolumn{4}{|c|}{$50 \mathrm{~cm}$} & \multicolumn{4}{|c|}{$50 \mathrm{~cm}$} \\
\hline Porosity & \multicolumn{4}{|l|}{0.59} & \multicolumn{4}{|l|}{0.57} \\
\hline $\begin{array}{l}\text { Calculated Pore } \\
\text { Volume }\end{array}$ & \multicolumn{4}{|c|}{$52.13 \mathrm{ml}$} & \multicolumn{4}{|c|}{$50.36 \mathrm{ml}$} \\
\hline Dry Bulk Density & \multicolumn{4}{|c|}{$1.19 \mathrm{~g} / \mathrm{cm}^{3}$} & \multicolumn{4}{|c|}{$1.32 \mathrm{~g} / \mathrm{cm}^{3}$} \\
\hline $\begin{array}{l}\text { Calculated Flow } \\
\text { Rate }\end{array}$ & \multicolumn{4}{|c|}{$6.68 \mathrm{ml} / \mathrm{hr}$} & \multicolumn{4}{|c|}{$26.62 \mathrm{ml} / \mathrm{hr}$} \\
\hline $\begin{array}{l}\text { Mean residence } \\
\text { time (tau) }\end{array}$ & \multicolumn{4}{|c|}{$7.4 \mathrm{hr}$} & \multicolumn{4}{|c|}{$1.7 \mathrm{hr}$} \\
\hline $\begin{array}{l}\text { Duration of } \\
\text { Experiment }\end{array}$ & \multicolumn{4}{|c|}{$2731 \mathrm{hr}(351 \mathrm{PV})$} & \multicolumn{4}{|c|}{$267 \mathrm{hr}(144 \mathrm{PV})$} \\
\hline Peclet No.* & \multicolumn{4}{|l|}{220} & \multicolumn{4}{|l|}{175} \\
\hline \multirow{5}{*}{$\begin{array}{l}\text { Multi-site } \\
\text { Transport Model } \\
\text { Parameters- } \\
\text { breakthrough fit }\end{array}$} & \multicolumn{4}{|c|}{ Column \#1 (7 ml/hr) } & \multicolumn{4}{|c|}{ Column \#3 (28 ml/hr) } \\
\hline & Site & $\begin{array}{l}\mathbf{K}_{\mathbf{f}} \\
(\mathrm{ml} / \mathrm{g}- \\
\mathbf{h r})\end{array}$ & $\begin{array}{l}K_{r} \\
(\mathbf{1} / \mathbf{h r})\end{array}$ & $\begin{array}{l}S_{\max } \\
(C P M / g)\end{array}$ & Site & $\begin{array}{l}\mathrm{K}_{\mathrm{f}} \\
(\mathrm{ml} / \mathrm{g}- \\
\mathrm{hr})\end{array}$ & $\begin{array}{l}K_{r} \\
(1 / h r)\end{array}$ & $\begin{array}{l}S_{\max } \\
(C P M / g)\end{array}$ \\
\hline & 1 & 13.5 & .1 & 5000 & 1 & 13.5 & .1 & 30000 \\
\hline & 2 & 0.125 & .002 & 1100 & 2 & 0.125 & .002 & 11000 \\
\hline & 3 & 0.25 & 0.00001 & 55000 & 3 & 0.25 & .00001 & 5000 \\
\hline \multirow{5}{*}{$\begin{array}{l}\text { Multi-site } \\
\text { Transport Model } \\
\text { Parameters- } \\
\text { profile fit*** }\end{array}$} & \multicolumn{4}{|c|}{ Column \#1 (7 ml/hr) } & \multicolumn{4}{|c|}{ Column \#3 (28 ml/hr) } \\
\hline & Site & $\begin{array}{l}\mathrm{K}_{\mathrm{f}} \\
(\mathrm{ml} / \mathrm{g}- \\
\mathrm{hr})\end{array}$ & $\begin{array}{l}K_{r} \\
(1 / h r)\end{array}$ & $\begin{array}{l}S_{\max } \\
(C P M / g)\end{array}$ & Site & $\begin{array}{l}\mathrm{K}_{\mathrm{f}} \\
(\mathrm{ml} / \mathrm{g}- \\
\mathrm{hr})\end{array}$ & $\begin{array}{l}K_{r} \\
(1 / h r) \\
\end{array}$ & $\begin{array}{l}S_{\max } \\
(C P M / g)\end{array}$ \\
\hline & 1 & .06 & .001 & 1000 & 1 & .06 & .001 & 1000 \\
\hline & 2 & 1.5 & .003 & 50000 & 2 & 1.5 & .003 & 50000 \\
\hline & 3 & .82 & .00001 & 50000 & 3 & .82 & .00001 & 50000 \\
\hline Percent Recovery & & & & 11 & & & & 1.3 \\
\hline $\mathbf{K}_{\mathbf{d}} * *$ & & & & 49.1 & & & & 43.2 \\
\hline
\end{tabular}

*Obtained from ReLap fit of tritium data.

$* *$ Retardation factor $\left(\mathrm{R}_{\mathrm{d}}\right)$ is calculated as the ratio of the conserved species average velocity to that of the adsorbed species. This measurement is normally made at $\mathrm{C} / \mathrm{C}_{0}=.5$. The $\mathrm{U}$ recovery did not reach $\mathrm{C} / \mathrm{C}_{0}=.5$, therefore this measurement was made at the first significant solute breakthrough at approximately 100 pore volumes.

***The profile fit parameters were estimated by using Equation 4.2. 


\subsubsection{Neptunium Batch Sorption and Flow Desorption Experiments}

Neptunium was sorbed for a period of approximately 14 days to each of the four volcanic tuff samples with the varying mineralogical properties described in Section 2.3. The neptunium was then desorbed from each sample for a period of over 1500 hours ( 63 days). The method of sorption and desorption are described in Section 2.4. The sorption and subsequent desorption results for each sample are shown in Figures 4.13 through 4.16, along with the fit to each data set using the multi-site kinetic model described in Section 3.1. The neptunium sorption/desorption experiments for each of the analcime, mordenite, smectite and illite-rich tuffs were carried out with duplicate 10 grams samples.

Neptunium Sorption. Sorption in each of the neptunium/tuff combinations is very fast, reaching apparent equilibrium within 24 hours. The partitioning of neptunium to the solid phase is high for all of the samples (86-93\% sorbed), regardless of the tuff surface area, reported CEC, and smectite and zeolite abundance. Greater partitioning of neptunium to the solid phase was observed in the smectite-rich and mordenite-rich samples (Table 4.4), followed by the illite and analcime-rich samples. Neptunium speciation in solution is predominately $\mathrm{NpO}_{2}^{+}$and $\mathrm{NpO}_{2} \mathrm{CO}_{3}^{-}$in

J-13 groundwater (Kaszuba and Runde 1999). Although the positively charged neptunyl ion would favor a cation exchange mechanism, a surface reaction mechanism is more likely in the zeolitic samples due to the size and shape of the neptunyl cation limiting its access to cation exchange sites within zeolitic cages (Triay 1997). It is possible that the initial sorption of the $\mathrm{NpO}_{2}^{+}$species in the smectite-rich sample was by outer-sphere electrostatic sorption to negatively charged 
surfaces, followed by desorption and re-sorption via an inner-sphere chemisorption mechanism to negative edge sites, or a bond-aging mechanism that converts from an outer-sphere complex to an inner-sphere complex on the same site over time. The negatively charged neptunyl-carbonate complex would favor positively charged edge sites. Given the chemistry of the systems in this study and the unchanging concentrations (within error for LCS measurements of neptunium activity) in control experiments, precipitation reactions can be ruled out as a mechanism of neptunium removal from solution.

Table 4.4 Percent Neptunium Sorbed

\begin{tabular}{|c|c|c|c|c|c|}
\hline Mineralogical I.D. & $\begin{array}{c}\text { Sample } \\
\text { No. }\end{array}$ & $\%$ sorbed & $\begin{array}{c}\text { Average } \\
\% \text { sorbed }\end{array}$ & $\begin{array}{c}\% \text { of } \\
\text { initial } \\
\text { tracer not } \\
\text { desorbed }\end{array}$ & $\begin{array}{l}\text { Average } \\
\% \text { of } \\
\text { initial } \\
\text { tracer not } \\
\text { desorbed }\end{array}$ \\
\hline \multirow{2}{*}{ Analcime-rich } & 1 & 88 & \multirow{2}{*}{86.0} & 77 & \multirow{2}{*}{74.5} \\
\hline & 2 & 84 & & 72 & \\
\hline \multirow{2}{*}{ Mordenite-rich } & 1 & 93 & \multirow{2}{*}{93.0} & 86 & \multirow{2}{*}{86.0} \\
\hline & 2 & 93 & & 86 & \\
\hline \multirow{2}{*}{ Smectite-rich } & 1 & 93 & \multirow{2}{*}{93.0} & 91 & \multirow{2}{*}{90.5} \\
\hline & 2 & 93 & & 90 & \\
\hline \multirow{2}{*}{ Illite-rich } & 1 & 88 & \multirow{2}{*}{87.5} & 78 & \multirow{2}{*}{78.0} \\
\hline & 2 & 87 & & 78 & \\
\hline
\end{tabular}

Neptunium Desorption. Very little neptunium desorbed from the volcanic tuff, with 72 to $91 \%$ remaining sorbed at the conclusion of the experiments. These results suggest very slow desorption, or irreversible sorption of this fraction of neptunium. The smectite and mordenite-rich samples had the greatest fraction of neptunium remaining sorbed to the solid phase at the conclusion of the experiments. There is good agreement between all duplicate sample runs for both the sorption and desorption of neptunium. At the conclusion of the long-term desorption experiments, the remaining activity was leached from the solid phase. The initial leaching solution 
consisted of the $\mathrm{J}-13$ water adjusted to a $\mathrm{pH}$ of greater than 11 using sodium hydroxide. There was very little recovery of the neptunium with this solution as shown in Figure 4.18. The solid phase was then subsequently washed with J-13 water adjusted to a $\mathrm{pH}$ of less than 2 with nitric acid. In this step approximately 60-80 percent of the neptunium was desorbed from the samples. Continued leaching with nitric acid did not remove significant amounts of additional neptunium. This implies that a portion (20 to $40 \%$ ) of the neptunium is very strongly sorbed to the samples, even under acidic conditions. As a fraction of what sorbed, the smectite-rich sample retained the most uranium after desorption ( 97\%), followed by the mordenite-rich ( 92\%) and illite-rich ( $\sim 89 \%)$ samples, while the analcime-rich sample retained the least ( 87\%). Figure 4.17 contains plots of the sorption and desorption data for each of the tuffs normalized to the measured surface area in Table 2.3 to establish that the differences in sorption/desorption of neptunium in the tuffs are not strictly due to differences in surface area. Normalization of the data to surface area results in the highest fraction of neptunium being sorbed in the illite-rich sample, bringing out the strong-sorbing character of this tuff. The increase in normalized fraction of sorbed neptunium in the analcime-rich sample is most likely due to the underestimation of the surface area for this tuff by the $\mathrm{N}_{2}$ BET method as described in Section 2.3.1.

Neptunium Multi-site Kinetic Modeling. The sorption and desorption experimental data were fit using the multi-site kinetic model described in Section 3.1 to determine sorption and desorption rates constants that were consistent with the observed behavior. Although the sorption and desorption rate constants given in Table 4.5 are not unique, they show that desorption rate constants that vary over 
several orders of magnitude are required to fit the data. This suggests that while a fraction of the sites may be in equilibrium with the solution phase in these experiments, not all of the sites are, and the equilibrium assumption inferred by the use of a $K_{d}$ value is therefore not valid for these experiments. For all of the tuff samples, the slow desorbing fraction of the data were initially fit using an irreversible site $\left(\mathrm{k}_{\mathrm{r}}=0\right)$. The desorption rate constant for this site was then incrementally increased to an upper limit, while still providing a good fit to the data, thus providing an upper bound for the effective $K_{d}$ value. The results of the neptunium long-term desorption experiments suggest that there are multiple types of sites for neptunium sorption reactions with widely-varying desorption kinetics.

Np Batch Sorption and Column Desorption

Analcime-rich Tuff

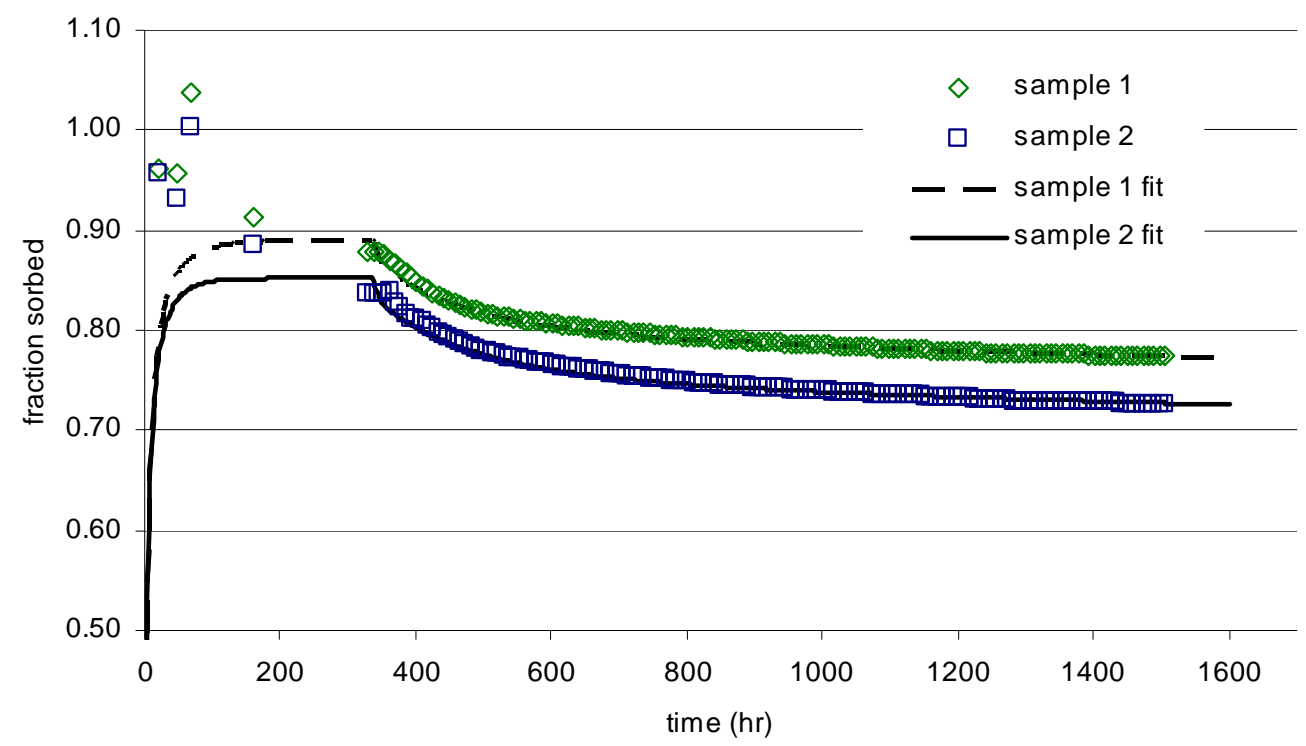

Figure 4.13. Neptunium batch sorption and column desorption in the analcimerich tuff. The data are fit by using the multi-site kinetic model described in Section 3.1 and the parameters given in Table 4.5. 


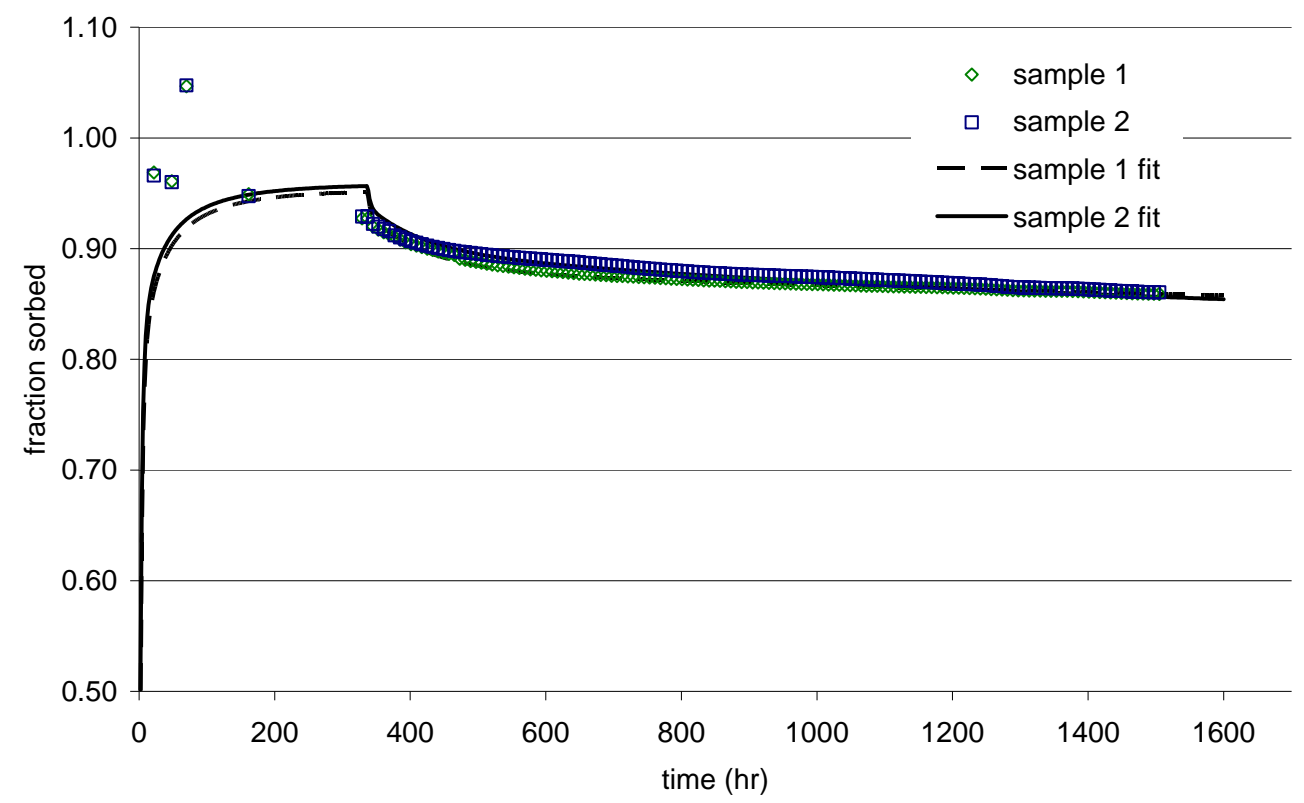

Figure 4.14. Neptunium batch sorption and column desorption in the mordenite-rich tuff. The data are fit by using the multi-site kinetic model described in Section 3.1 and the parameters given in Table 4.5.

Np Batch Sorption and Column Desorption Smectite-rich Tuff

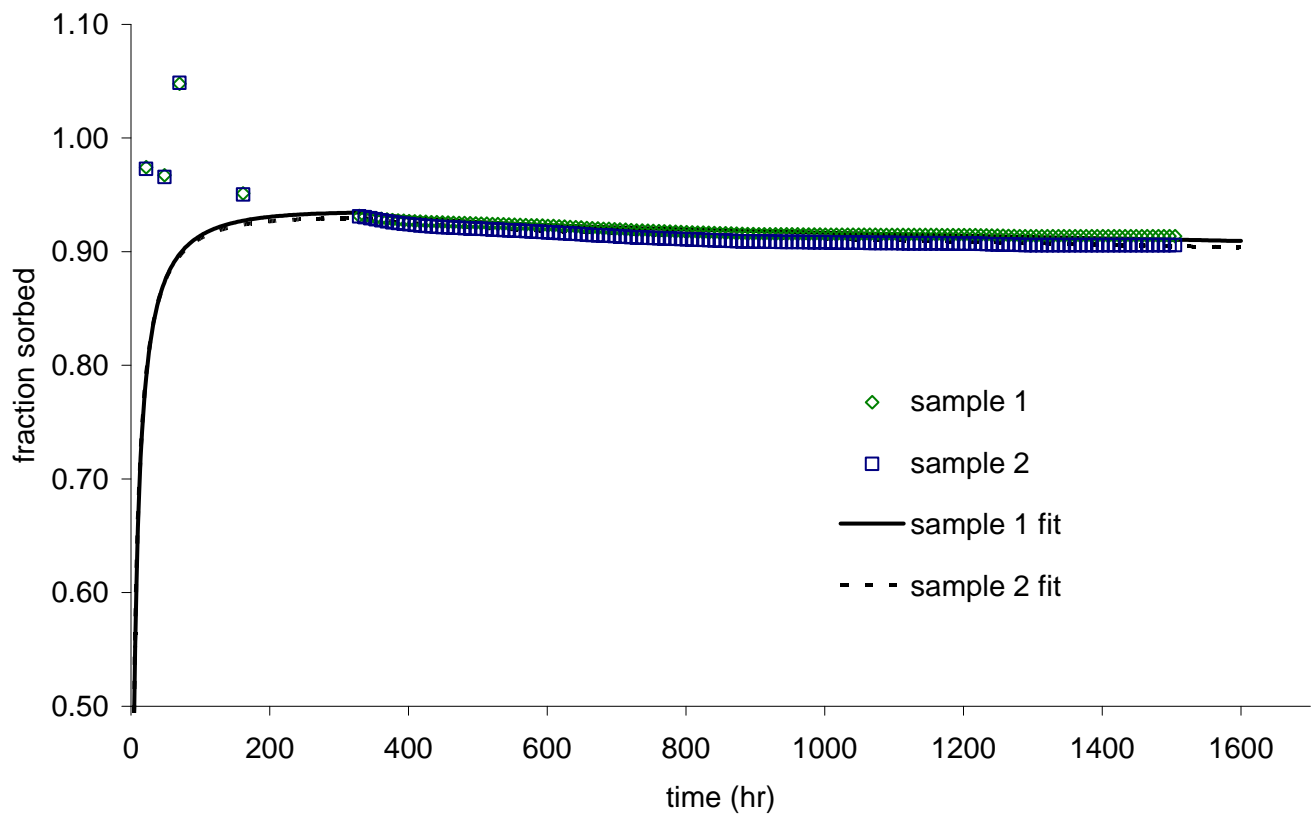

Figure 4.15. Neptunium batch sorption and column desorption in the smectiterich tuff. The data are fit by using the multi-site kinetic model described in Section 3.1 and the parameters given in Table 4.5. 
Np Batch Sorption and Column Desorption Illite-rich Tuff

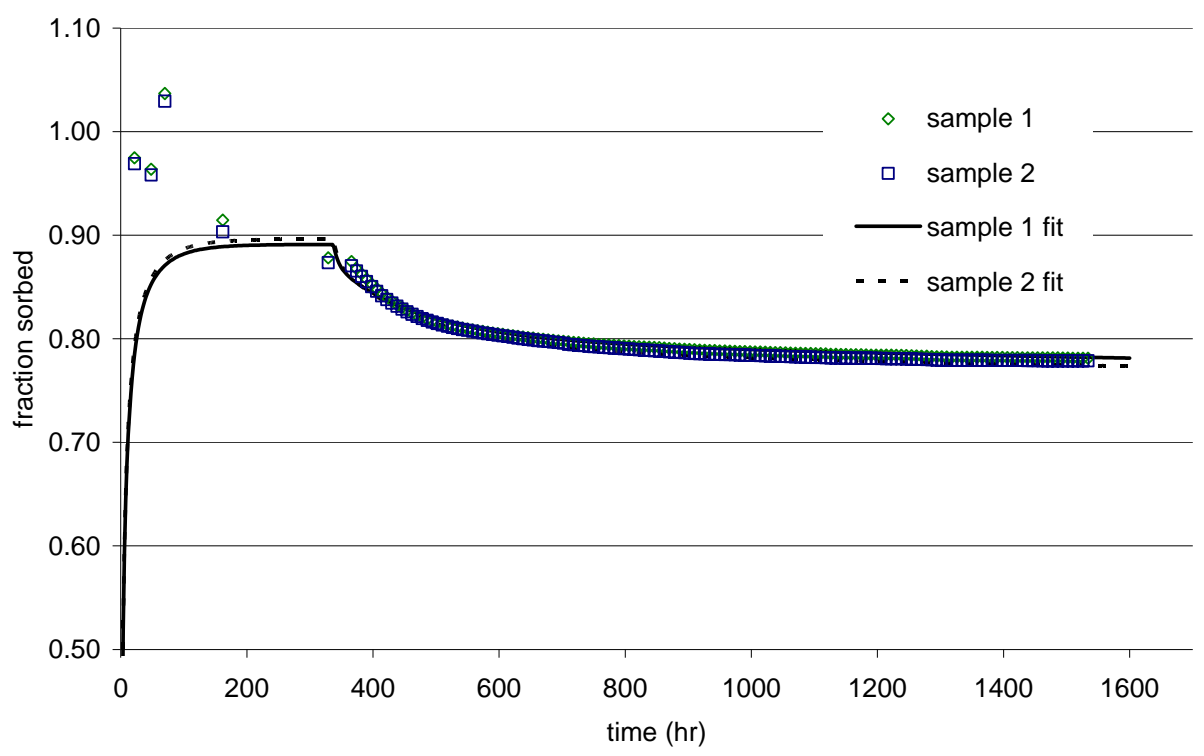

Figure 4.16. Neptunium batch sorption and column desorption in the illite-rich tuff. The data are fit by using the multi-site kinetic model described in Section 3.1 and the parameters given in Table 4.5.

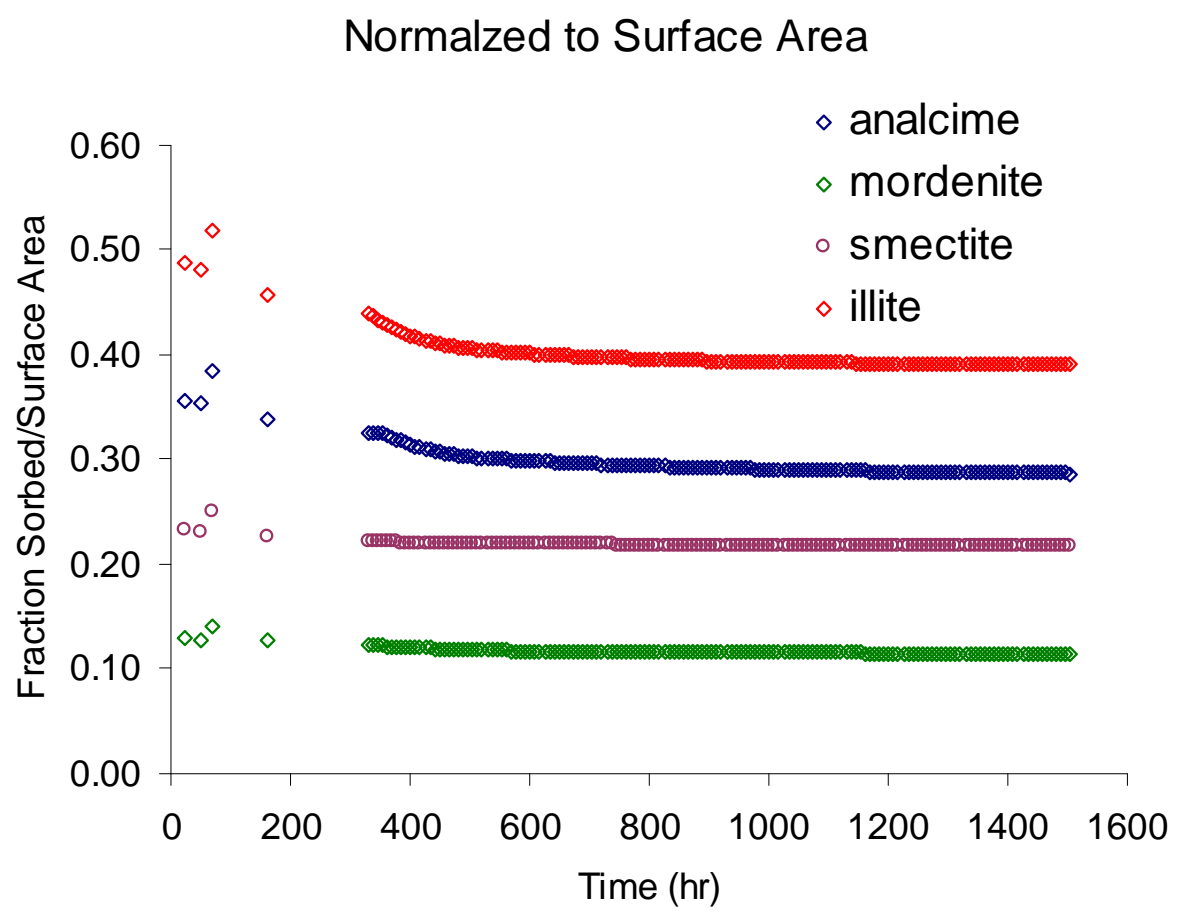

Figure 4.17. Fraction of neptunium sorbed normalized to surface area. The fraction remaining sorbed is normalized to the measured surface area for each tuff in Table 2.3. 

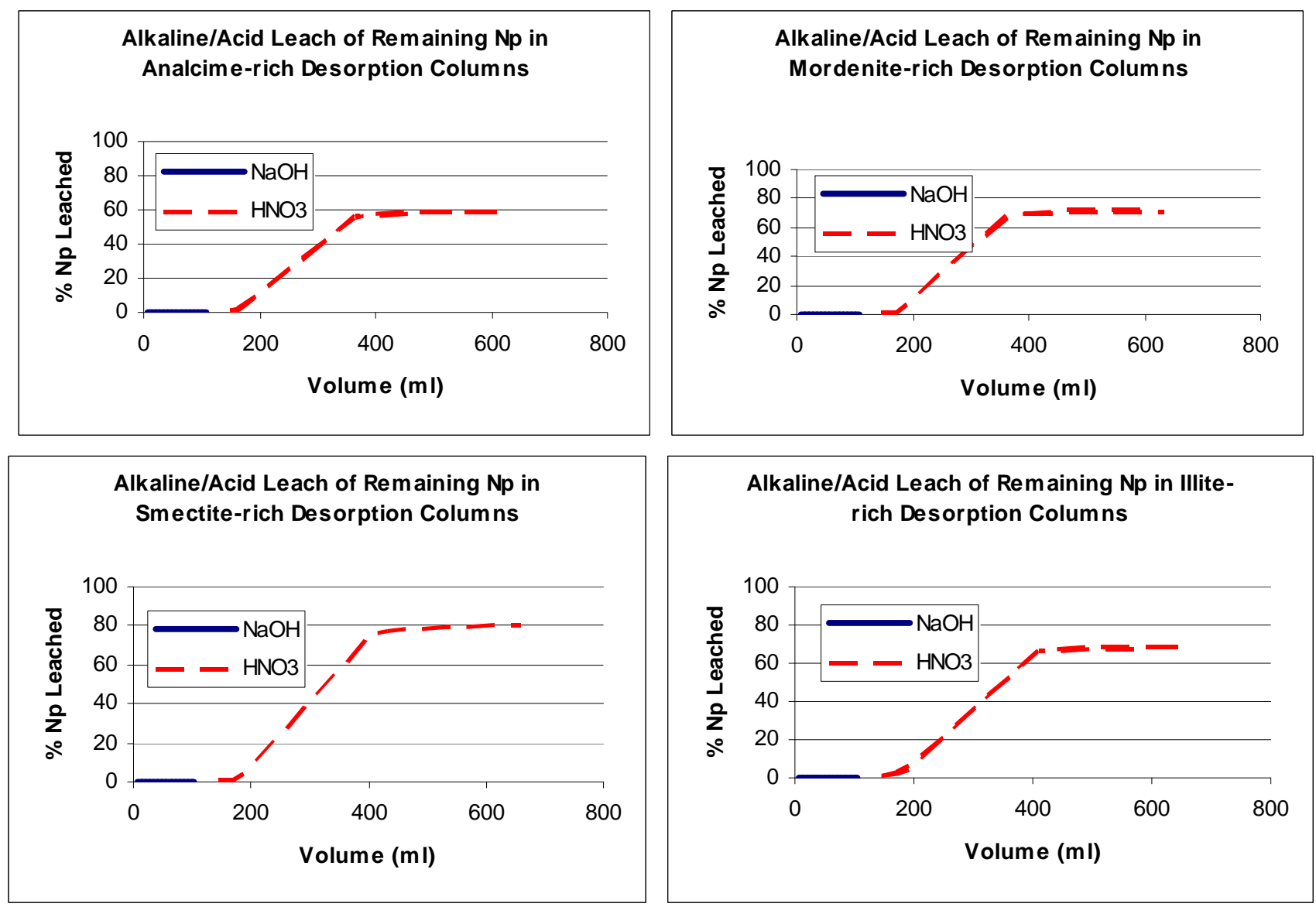

Figure 4.18. Alkaline/acid leach of remaining neptunium in desorption Columns. The neptunium that remained on the volcanic tuff at the conclusion of the experiment was more effectively leached by the acid solution from all of the volcanic tuffs. 
Table 4.5 Parameters used in neptunium multi-site kinetic model, calculated effective $K_{d}$ and experimental batch $K_{d}$

\begin{tabular}{|c|c|c|c|c|c|c|c|c|c|}
\hline $\begin{array}{l}\text { Mineralogical } \\
\text { I.D. }\end{array}$ & Sample No. & Site No. & $K_{f}$ & $\mathbf{K}_{\mathbf{r}}$ & $\mathbf{S}_{\max }$ & $\mathbf{W}^{*}$ & $\begin{array}{l}\text { Effective } K_{d} \\
\text { from } \\
\text { desorption } \\
\text { modeling } \\
\text { for each } \\
\text { site }(\mathrm{ml} / \mathrm{g})\end{array}$ & $\begin{array}{l}\text { Effective } \\
\mathrm{K}_{\mathrm{d}} \text { Total } \\
(\mathrm{ml} / \mathrm{g})\end{array}$ & $\begin{array}{l}K_{d} \text { from } \\
\text { Batch } \\
\text { Sorption } \\
(\mathrm{ml} / \mathrm{g})\end{array}$ \\
\hline \multirow[t]{3}{*}{ analcime-rich } & 1 & 1 & 0.4 & 0.035 & 518 & 2.49E-01 & $2.84 \mathrm{E}+00$ & & \\
\hline & & 2 & 0.4 & 0.0001 & 800 & 3.19E-01 & $1.28 \mathrm{E}+03$ & & \\
\hline & & 3 & 0.4 & 0.00001 & 2409 & 4.32E-01 & $1.73 E+04$ & 6187 & 22.52 \\
\hline \multirow[t]{3}{*}{ analcime-rich } & 2 & 1 & 0.4 & 0.035 & 518 & 2.67E-01 & $3.05 E+00$ & & \\
\hline & & 2 & 0.4 & 0.0001 & 800 & 3.14E-01 & $1.26 \mathrm{E}+03$ & & \\
\hline & & 3 & 0.4 & 0.00001 & 2214 & 4.19E-01 & $1.67 \mathrm{E}+04$ & 6002 & 16.08 \\
\hline \multirow[t]{3}{*}{ mordenite-rich } & 1 & 1 & 0.5 & 0.1 & 5000 & 4.25E-01 & $2.12 \mathrm{E}+00$ & & \\
\hline & & 2 & 0.5 & 0.0004 & 239 & 1.25E-01 & $1.57 \mathrm{E}+02$ & & \\
\hline & & 3 & 0.5 & 0.00001 & 3325 & 4.50E-01 & $2.25 E+04$ & 7553 & 40.87 \\
\hline \multirow[t]{3}{*}{ mordenite-rich } & 2 & 1 & 0.5 & 0.1 & 5000 & 3.78E-01 & $1.89 \mathrm{E}+00$ & & \\
\hline & & 2 & 0.5 & 0.0004 & 569 & 2.26E-01 & $2.82 \mathrm{E}+02$ & & \\
\hline & & 3 & 0.5 & 0.00001 & 3052 & 3.97E-01 & $1.98 \mathrm{E}+04$ & 6706 & 41.79 \\
\hline \multirow[t]{3}{*}{ smectite-rich } & 1 & 1 & 0.5 & 0.025 & 50 & 3.69E-02 & 7.38E-01 & & \\
\hline & & 2 & 0.5 & 0.0007 & 418 & 2.86E-01 & $2.04 \mathrm{E}+02$ & & \\
\hline & & 3 & 0.5 & 0.00001 & 3323 & $6.78 \mathrm{E}-01$ & $3.39 E+04$ & 34082 & 43.10 \\
\hline \multirow[t]{3}{*}{ smectite-rich } & 2 & 1 & 0.5 & 0.025 & 97 & 3.57E-02 & 7.15E-01 & & \\
\hline & & 2 & 0.5 & 0.0007 & 292 & 3.16E-01 & $2.25 E+02$ & & \\
\hline & & 3 & 0.5 & 0.00001 & 3400 & 6.49E-01 & $3.24 \mathrm{E}+04$ & 32660 & 42.09 \\
\hline \multirow[t]{3}{*}{ illite-rich } & 1 & 1 & 0.4 & 0.035 & 782 & 2.56E-01 & $2.92 E+00$ & & \\
\hline & & 2 & 0.4 & 0.0001 & 635 & 2.94E-01 & $1.18 \mathrm{E}+03$ & & \\
\hline & & 3 & 0.4 & 0.00001 & 2579 & 4.50E-01 & $1.80 \mathrm{E}+04$ & 6390 & 23.14 \\
\hline \multirow[t]{3}{*}{ illite-rich } & 2 & 1 & 0.4 & 0.035 & 518 & 2.79E-01 & $3.19 E+00$ & & \\
\hline & & 2 & 0.4 & 0.0001 & 635 & $2.80 \mathrm{E}-01$ & $1.12 \mathrm{E}+03$ & & \\
\hline & & 3 & 0.4 & 0.00001 & 2579 & 4.40E-01 & $1.76 \mathrm{E}+04$ & 6247 & 21.96 \\
\hline
\end{tabular}




\subsubsection{Up-scaled Neptunium Column Experiments}

A scaled up experiment using a 50-cm long, 1.5-cm diameter, fully packed column was conducted to complement the long-term desorption experiments. Tritium and neptunium were introduced into the column packed with the smectite-rich tuff and saturated with J-13 groundwater as described in Section 2.4.2. One column (column 2) containing the smectite-rich tuff was run a at $7 \mathrm{ml} / \mathrm{hr}$ flow rate. The purpose of this experiment was to evaluate the applicability of the sorption and desorption rate constants determined in the long-term desorption experiments under dynamic transport conditions.

Tritium Breakthrough. Tritium was used as a conservative or non-sorbing tracer in the column experiment. The breakthrough of tritium and the fit of the experimental data using the modeling program ReLap are shown in Figure 4.19. The column parameters are detailed in Table 4.6. $\mathrm{C} / \mathrm{C}_{0}=.5$ occurred at .95 pore volumes and $100 \%$ of the tritium was recovered from the column within 2.3 pore volumes. The ReLap model of the tritium breakthrough curve was used to obtain the Peclet number $(\mathrm{Pe})$ and mean water residence time $(\tau)$ (Table 4.6) used in the multi-site transport model. The symmetric breakthrough curve and near complete recovery of tritium in the column indicates that preferential flow paths and regions of dead volume (i.e., secondary porosity) were not major contributors to flow within the column.

Neptunium Breakthrough. Based on a simple calculation of the retardation factor (Equation 4.1) using the batch sorption $\mathrm{K}_{\mathrm{d}}$ value for neptunium in the smectite rich tuff (Table 4.5) breakthrough at 97.6 pore volumes is predicted. A small amount 
of neptunium breakthrough ( $\sim 8 \%$ total recovery) began at around 100 pore volumes (Figure 4.20). Nevertheless, a vast majority of the tracer was retarded, and low recovery was observed (Table 4.6). A Students t-test indicated that the mean activities of the samples between 100 to 160 pore volumes are above the mean activity of the background at a 95\% confidence level. A few samples had elevated neptunium activity prior to 100 pore volumes, but in each case, filtration of adjacent samples ( $0.22 \mu \mathrm{m}$ filter) reduced the elevated activity in the filtrate to below or very close to background levels. These results suggest that the elevated activity observed before 100 pore volumes was due to neptunium associated with colloidal material, most likely neptunium attached to clay colloids. A Students t-test indicated that the mean activities in the filtered and unfiltered samples taken after 100 pore volumes were equal at the $95 \%$ confidence level suggesting that the activity recovered after 100 pore volumes is due to neptunium in solution.

Neptunium Concentration Profile. At the conclusion of the up-scaled experiment, the column was frozen, segmented and the sorbed neptunium leached from the solid material as described in Section 2.4.2. In contrast to the $7 \mathrm{ml} / \mathrm{hr}$ uranium profile in Figure 4.11 where most of the uranium was at the inlet of the column $(0-2 \mathrm{~cm})$, more of the neptunium mass sorbed 2 to $4 \mathrm{~cm}$ from the column inlet. The dominant solution species are $\mathrm{NpO}_{2}^{+}$and $\mathrm{NpO}_{2} \mathrm{CO}_{3}^{-}$. One possible explanation for the difference in the uranium and neptunium profiles is that in the neptunium column, $\mathrm{NpO}_{2}^{+}$is sorbing via an outer-sphere mechanism at the negatively charged basal plain, followed by desorption and re-sorption via an inner-sphere mechanism at positively charged edge sites. This scenario would not have been 
apparent in a batch experiment, where the desorption and re-sorption could have taken place between sample collections and was not noticed. Another possibility is that the more favored species for strong sorption, either $\mathrm{NpO}_{2} \mathrm{CO}_{3}^{-}$or $\mathrm{NpO}_{2}^{+}$, is sorbing as inner-sphere complexes on edge sites and as the $\mathrm{NpO}_{2} \mathrm{CO}_{3}^{-}$(or $\mathrm{NpO}_{2}^{+}$) is removed from solution the speciation shifts to accommodate the change, and more $\mathrm{NpO}_{2} \mathrm{CO}_{3}^{-}$(or $\mathrm{NpO}_{2}^{+}$) is formed at the expense of $\mathrm{NpO}_{2}^{+}$(or $\mathrm{NpO}_{2} \mathrm{CO}_{3}^{-}$). Another explanation could be a dual porosity flow/transport regime within the column. Although the tritium breakthrough curves suggest very minimal secondary porosity in the columns (porosity in which water is not flowing; e.g., dead-end pores), it is possible that diffusion occurred over relatively short distance scales into secondary porosity without having much effect on tritium transport. However, if the secondary porosity contained an abundance of strong neptunium sorption sites relative to the primary porosity, the secondary porosity could have a dramatic effect on neptunium transport through the column. This could result in a portion of the neptunium being held up in "dead-end pores" while the other portion continues to flow through the column with less retardation. Such behavior could conceivably result in the residual profile observed in the column at the conclusion of the experiment.

In any case, $28 \%$ of the neptunium recovered from the acid leach was sorbed to the first 0 to $2 \mathrm{~cm}$ of the column, while $45 \%$ was sorbed 2 to $4 \mathrm{~cm}$ from the inlet of the column. In the uranium columns the solution speciation was even less favorable for sorption due to the presence of both a negatively charged and neutral species in solution, yet somehow $42 \%$ of the uranium was sequestered in the first $0-2 \mathrm{~cm}$ of column 1. Although a shift in equilibrium is thought to be a rapid process, a kinetic 
limitation is necessary for this to be considered as a possible explanation for the observed residence time dependence between the concentration profiles in the fast and slow flow columns. A shift in equilibrium would also be expected in the neptunium column if one of the species $\left(\mathrm{NpO}_{2} \mathrm{CO}_{3}^{-}\right.$or $\left.\mathrm{NpO}_{2}^{+}\right)$is considered to be a stronger sorber. Because a large fraction of neptunium traveled a greater distance in the column than uranium, it is reasonable to assume that a slower chemical process than re-establishment of the aqueous speciation of neptunium is responsible. A slower process would be that of sorption via outer-sphere to the surface of the mineral followed by desorption and re-sorption via inner-sphere complex on edge sites, conversion of the complex form outer-sphere to inner-sphere on the same site, as described above. Much care was taken in the preparation of the columns to eliminate differences in mineral phase and particle size distribution. The tritium breakthrough in the $7 \mathrm{ml} / \mathrm{hr}$ uranium and neptunium columns is very similar. This leaves the above chemical explanation as the most likely reason for differences in the column profiles.

Neptunium Multi-site Transport Model. The packed and saturated (up-scaled) column experimental data were fit using the advection-dispersion-reaction transport equation described in Section 3.2, modified to include up to 4 parallel reactions. The rate constants obtained from the long-term desorption experiments were used in the multi-site transport model along with the column parameters outlined in Table 4.6. Use of these rate constants resulted in a model that predicted no breakthrough within 420 pore volumes. A possible explanation is that the 14-day sorption period in the long-term desorption column experiments was adequate for the desorption and resorption process (described in the previous section) to reach equilibrium. This 
suggests a residence-time dependence of sorption for neptunium. Other neptunium complexing ligands exist in the $\mathrm{J}-13$ groundwater such as $\mathrm{F}^{-}$and $\mathrm{SO}_{4}{ }^{2-}$, but account for less than $1 \%$ of the solution species and are not expected to affect the solution equilibrium.

The data for both the column breakthrough and profile were initially fit using an irreversible site $\left(\mathrm{k}_{\mathrm{r}}=0\right)$ for the $3^{\text {rd }}$ and slowest site. The desorption rate constant for this site was then incrementally increased to an upper limit, while still providing a good fit to the data, thus providing an upper bound for the slowest desorption rate constant. The use of an upper limit desorption rate constant is based on the hypothesis that if the experiment were allowed to continue, the sorbed neptunium may have desorbed and eventually broken through, resulting in a slow but non-zero desorption rate constant. The sorption rate constants did not vary much and given the very fast sorption that occurred in the batch sorption experiment, this is not surprising. Desorption rate constants ranging over several orders of magnitude were required to fit the data. This, along with the long-term desorption column results, give further evidence that there are multiple sorption sites for neptunium and that the sorption/desorption kinetics vary between these sites. The fitting parameters providing good fits to the breakthrough curve results in a predicted column profile that does not match the observed behavior of the neptunium that remained in the column (Figure 4.21). The predicted profile was flattened, and the large mass of neptunium sorbed at $2-4 \mathrm{~cm}$ from the inlet of the column was not reproduced using the column breakthrough fitting parameters. To obtain a better fit to the neptunium 
profile in Figure 4.21, a $K_{d}$ was estimated from $R_{d}$ using equation 4.1 and the neptunium concentration profile and breakthrough from the column.

A total of two sites were used to initially account for the spike in neptunium concentration at 2 to $4 \mathrm{~cm}$ from the column inlet and the actual breakthrough of neptunium at 100 pore volumes. An average velocity was calculated for the neptunium 2 to $4 \mathrm{~cm}$ from the column inlet using the migration distance $\mathrm{X}$, and the duration of the experiment $t$, to obtain a $\mathrm{K}_{\mathrm{d}}$ value. The $\mathrm{K}_{\mathrm{d}}$ for the third site was calculated from the estimated $R_{d}$ value for the neptunium breakthrough at 100 pore volumes, and equation 4.1. The ratio of $k_{f i}$ to $k_{r i}$ was set equal to the calculated $\mathrm{K}_{\mathrm{d}}$ value for the neptunium remaining in the column and for the breakthrough, and the values of $k_{f i}$ and $k_{r i}$ were adjusted while preserving this ratio to fit the profile data. It was necessary to include a $3^{\text {rd }}$ slower site to capture the high neptunium concentration 2 to $4 \mathrm{~cm}$ from the column inlet. The long-term neptunium sorption and desorption data from the smectite-rich sample are again presented in Figure 4.22, along with desorption predicted by the breakthrough and profile fitting parameters for the upscaled column. In generating the predicted curves, the number of sites $\left(S_{\max }\right)$ was allowed to vary from what provided good fits to the breakthrough and profile data, but the rate constants were fixed. The value of $S_{\max }$ providing a good fit to the longterm desorption data using the profile parameters was approximately 3 times lower than that for the profile. The breakthrough parameters fit the long-term desorption data well using the same value of $S_{\max }$. Both the breakthrough and profile parameters provide a good fit to the long-term desorption data, only slightly over-predicting the 
fraction of sorbed neptunium at the start of the desorption phase, and the profile parameters slightly overestimate the rate of desorption.

The range of desorption rate-constants required to fit the neptunium breakthrough and sorbed profile data from the up-scaled column provide evidence of multiple types of sites for neptunium sorption reactions with varying desorption kinetics. In addition, the batch sorption $\mathrm{K}_{\mathrm{d}}$ value predicted the initial breakthrough of neptunium at around 90 to 100 pore volumes in the up-scaled column, although only approximately $8 \%$ of the neptunium was recovered, whereas a $K_{d}$ value predicts breakthrough of $100 \%$ of the solute concentration. The incomplete recovery of neptunium in the up-scaled column cannot be described by a single sorption and desorption rate constant, suggesting again that there are multiple sites involved in neptunium retardation. The good fit of the long-term desorption data obtained from the breakthrough parameters indicates that a multi-site model is adequate in describing these data, although the same parameters were unable to describe the high fraction of neptunium sorbed 2 to $4 \mathrm{~cm}$ from the inlet of the column in the postmortem concentration profile. 


\section{Conservative Tracer Breakthrough \\ Column 2}

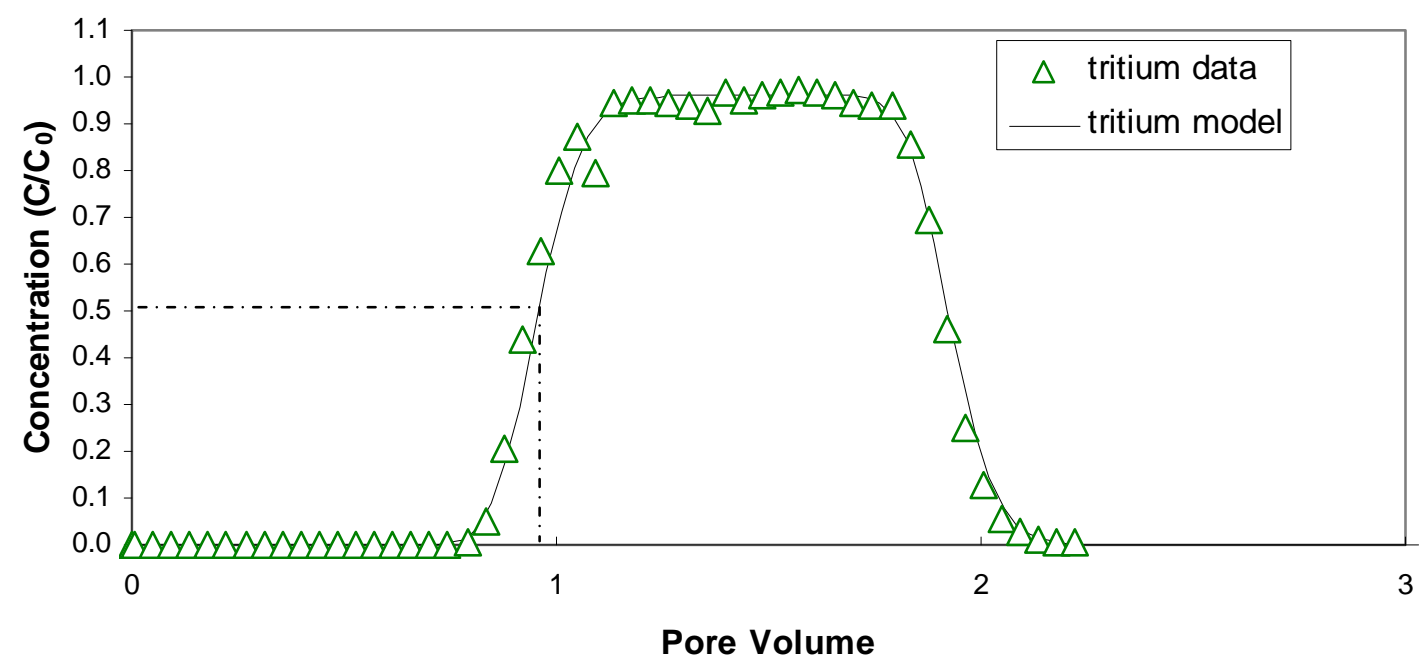

Figure 4.19. Tritium breakthrough from the $7 \mathrm{ml} / \mathrm{hr}$ (Column 2) flow rate experiments in the smectite-rich tuff up-scaled columns. The data are fit by using the ReLap Program described in Section 3.2. The dashed line at $\mathrm{C} / \mathrm{C}_{0}=.5$ occurs at 0.95 pore volumes.

Np Column Breakthrough

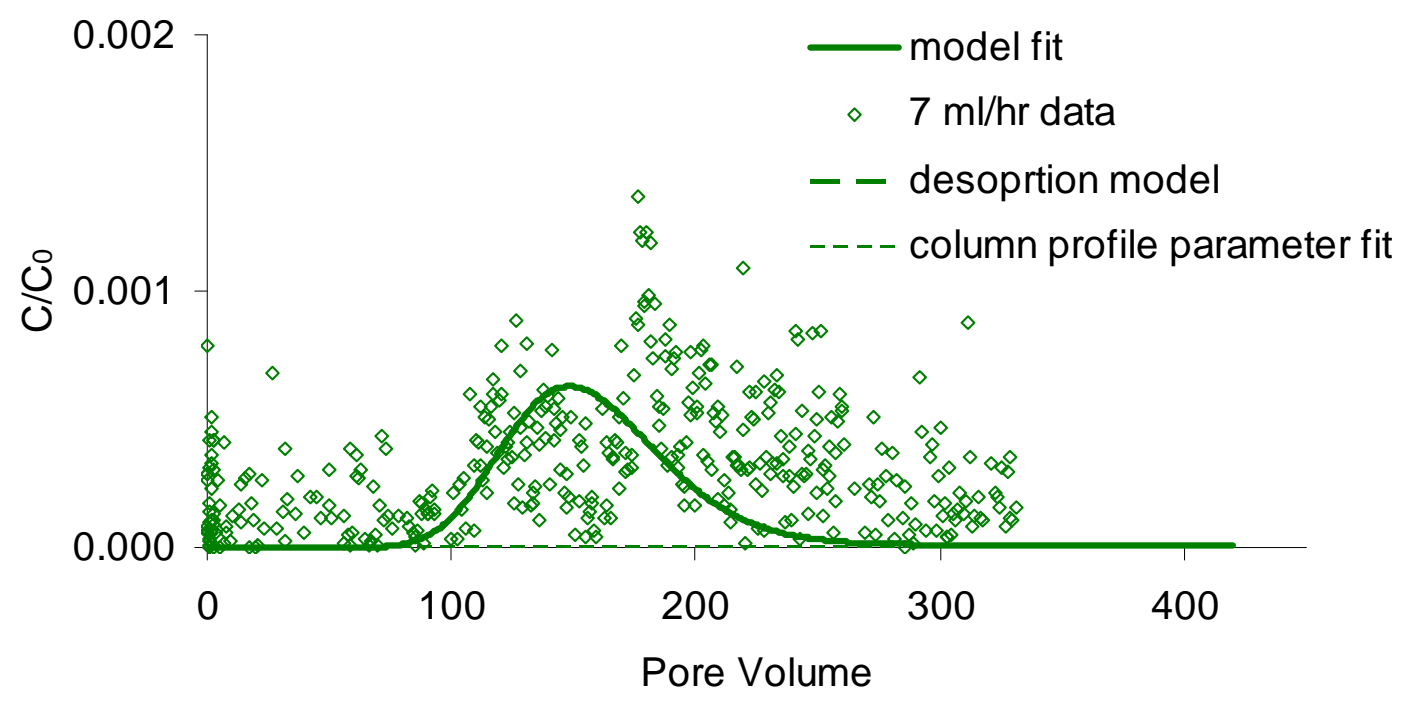

Figure 4.20. Neptunium breakthrough from the $7 \mathrm{ml} / \mathrm{hr}$ flow rate experiment in the smectite-rich tuff up-scaled columns. The data are fit by using the multi-site kinetic transport model described in Section 3.2 and the parameters given in Table 4.6. 


\section{Np Column Concentration Profile}

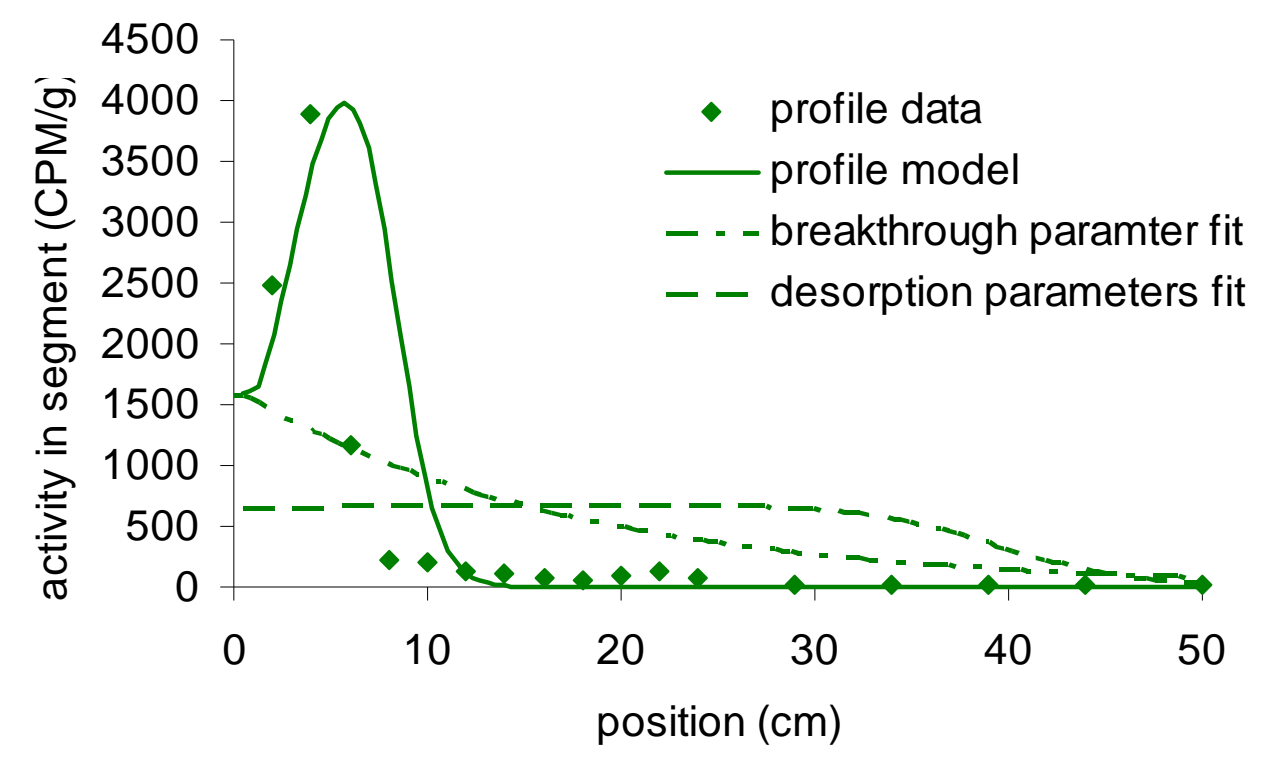

Figure 4.21. Neptunium concentration profiles in the $7 \mathrm{ml} / \mathrm{hr}$ flow rate experiment in the smectite-rich tuff up-scaled columns. The data are fit by using the multi-site kinetic transport model described in Section 3.2 and the parameters given in Table 4.6.

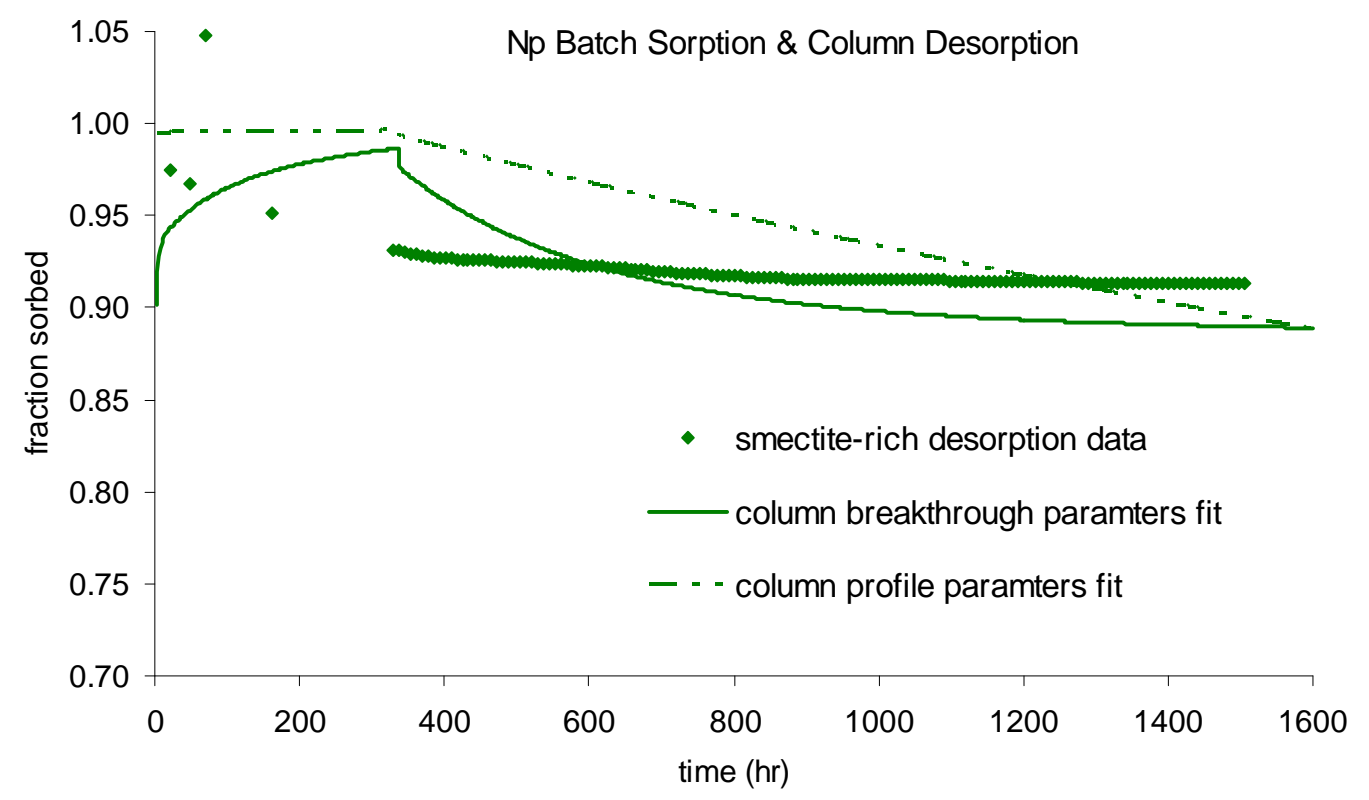

Figure 4.22. Smectite-rich batch sorption and column desorption data with fits using up-scaled column parameters. The model fits are from the packed column model fit parameters for both the breakthrough and concentration profile and are listed in Table 4.6. 
Table 4.6 Neptunium up-scaled column parameters.

\begin{tabular}{|c|c|c|c|c|}
\hline Parameter & \multicolumn{4}{|c|}{ Column $2(7 \mathrm{ml} / \mathrm{hr}$ flow rate) } \\
\hline Material & \multicolumn{4}{|c|}{ Smectite-rich Volcanic Tuff } \\
\hline Particle size & \multicolumn{4}{|c|}{$75-500 \mu \mathrm{m}$} \\
\hline Mass & \multicolumn{4}{|c|}{$112.57 \mathrm{~g}$} \\
\hline Column Diameter & \multicolumn{4}{|c|}{$1.5 \mathrm{~cm}$} \\
\hline Column Length & \multicolumn{4}{|c|}{$50 \mathrm{~cm}$} \\
\hline Porosity & \multicolumn{4}{|c|}{0.56} \\
\hline Calculated Pore Volume & \multicolumn{4}{|c|}{$49.48 \mathrm{ml}$} \\
\hline Dry Bulk Density & \multicolumn{4}{|c|}{$1.27 \mathrm{~g} / \mathrm{cm}^{3}$} \\
\hline Calculated Flow Rate & \multicolumn{4}{|c|}{$6.45 \mathrm{ml} / \mathrm{hr}$} \\
\hline Mean residence time (tau) & \multicolumn{4}{|c|}{$6.9 \mathrm{hr}$} \\
\hline Duration of Experiment & \multicolumn{4}{|c|}{$2561 \mathrm{hr}$} \\
\hline Peclet No.* & \multicolumn{4}{|l|}{220} \\
\hline \multirow{5}{*}{$\begin{array}{l}\text { Multi-site Transport Model } \\
\text { Parameters-breakthrough fit }\end{array}$} & \multicolumn{4}{|c|}{ Column \#2 (7 ml/hr) } \\
\hline & Site & $\begin{array}{l}\mathrm{K}_{\mathrm{f}}(\mathrm{ml} / \mathrm{g}- \\
\mathrm{hr})\end{array}$ & $K_{\mathbf{r}}(\mathbf{1} / \mathbf{h r})$ & $S_{\max }(\mathbf{c p m} / \mathrm{g})$ \\
\hline & 1 & 5.0 & 0.5 & 5000 \\
\hline & 2 & 5.0 & 0.07 & 5000 \\
\hline & 3 & 0.2 & 0.00001 & 100000 \\
\hline \multirow{5}{*}{$\begin{array}{l}\text { Multi-site Transport Model } \\
\text { Parameters-profile fit*** }\end{array}$} & \multicolumn{4}{|c|}{ Column \#2 (7 ml/hr) } \\
\hline & Site & $\begin{array}{l}K_{\mathrm{f}}(\mathrm{ml} / \mathrm{g}- \\
\mathrm{hr})\end{array}$ & $K_{r}(1 / h r)$ & $S_{\max }(c p m / g)$ \\
\hline & 1 & 15.0 & 0.05 & 10000 \\
\hline & 2 & 15.0 & .005 & 10000 \\
\hline & 3 & 0.5 & 0.00001 & 1800 \\
\hline Percent Neptunium Recovery & \multicolumn{4}{|r|}{8} \\
\hline $\mathbf{K}_{\mathrm{d}} * *$ & \multicolumn{4}{|r|}{46.6} \\
\hline
\end{tabular}

*Obtained from ReLap fit of tritium data.

**Retardation factor $\left(\mathrm{R}_{\mathrm{d}}\right)$ is calculated as the ratio of the conserved species average velocity to that of the adsorbed species. This measurement is normally made at $\mathrm{C} / \mathrm{C}_{0}=.5$. The Np recovery did not reach $\mathrm{C} / \mathrm{C}_{0}=.5$, therefore this measurement was made at the first significant solute breakthrough at approximately 100 pore volumes.

***The profile fit parameters were estimated by using Equation 4.2.

\subsection{Spectroscopic Methods to Probe Uranium Sorption/Desorption Heterogeneity with Volcanic Tuff}

\subsection{1. $\quad$ Extended X-Ray Absorption Fine Structure Spectroscopy (EXAFS)}

Sample preparation for the EXAFS spectroscopy is described in detail in

Section 2.5. The objective of this work is to probe the average local structure surrounding uranium sorbed to a zeolitic and smectite-rich volcanic tuff, both at the conclusion of a sorption experiment (prior to desorption) and at the conclusion of a 
desorption experiment. Comparisons of the EXAFS spectra of the sorption and desorption samples were expected to reveal differences in the bonding environments of the uranium surface species remaining on the samples, with the desorption sample presumed to have a greater fraction of more strongly bound species because weaklybound species would desorb more readily. These measurements were conducted to provide evidence to support the theory of "strong" and "weak" sites for uranium sorption in heterogeneous tuff materials.

EXAFS Spectroscopy. XAS data were measured at the Stanford Synchrotron Radiation Lightsource (SSRL) on beamline 11-2 under dedicated operating conditions (3.0 GeV, 80-100 mA) using a Si(220) double crystal monochromator. The $\mathrm{U}_{\mathrm{II}}$ absorption edge (20948 eV) was measured at room temperature in fluorescence mode using a 30-element Ge solid state detector with $3 \mathrm{Al}$ and $\mathrm{Zr3}$ filters. Energy calibration was accomplished using an internal monochromator calibration. Eight to twelve scans were collected for each individual sorption sample and sixteen to twenty scans were collected for each individual desorption sample. The data were then averaged and analyzed using standard procedures (Conradson, Manara et al. 2004; Conradson, Begg et al. 2005). The extended x-ray absorption fine structure (EXAFS) was extracted from the spectra by first subtracting the absorption edge using a sum of an arctangent and a Gaussian fit to the absorption edge and peak. Then, a polynomial spline function was fit to the rest of the spectrum. Fourier transforms (FT) were performed over the range $k \sim 3.4-12.0 \AA^{-1}$ for the smectite-rich samples and $k \sim 2.6$ 12.0 $\AA^{-1}$ for the mordenite-rich samples. The resulting Fourier Transformed $k^{3}$ weighted EXAFS $\chi(R)$ spectra are shown in Figures 4.23 through 4.25. 


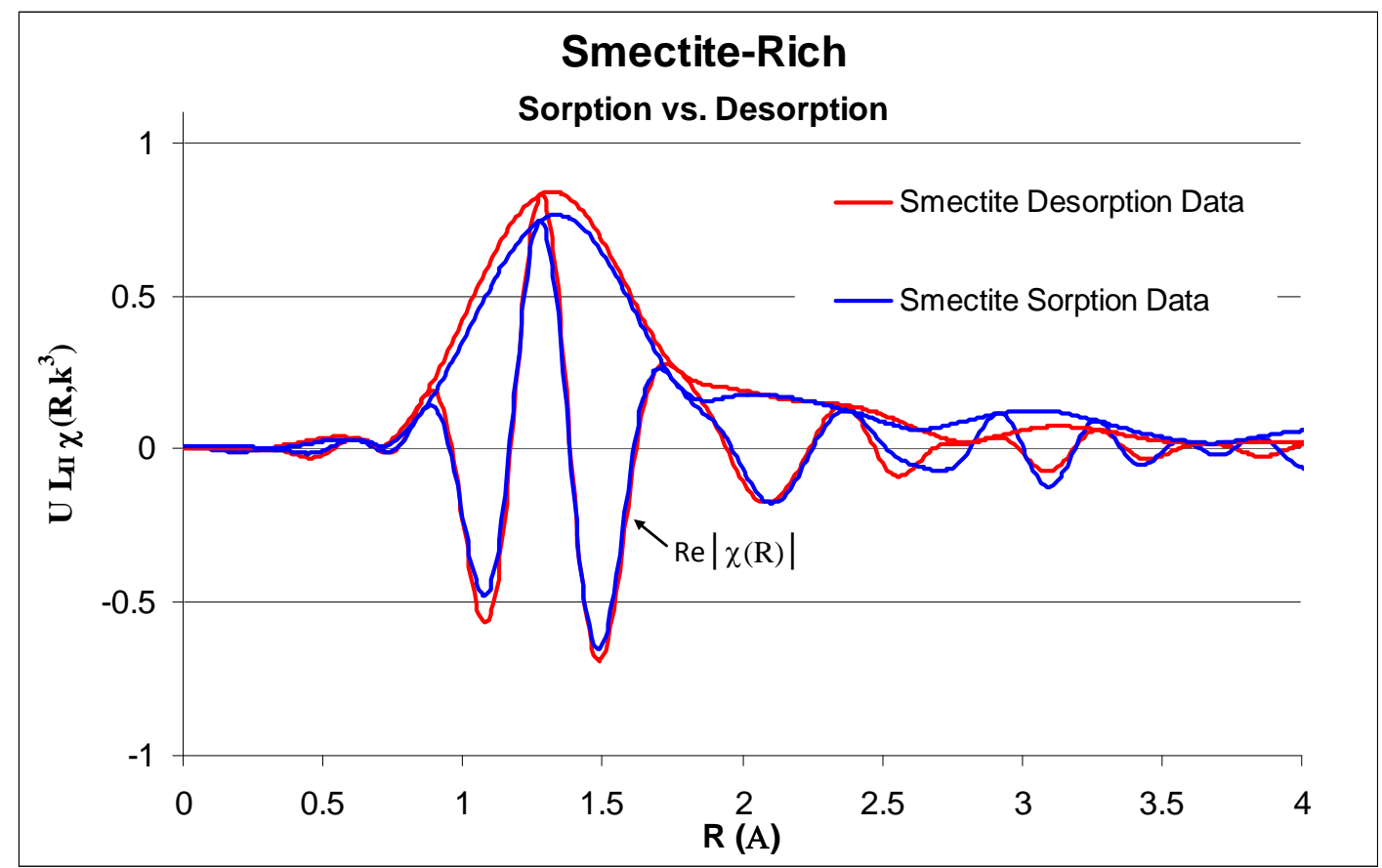

Figure 4.23. Fourier Transform Moduli and Real Components of the smectiterich volcanic tuff EXAFS data comparing the sorption and desorption sample.

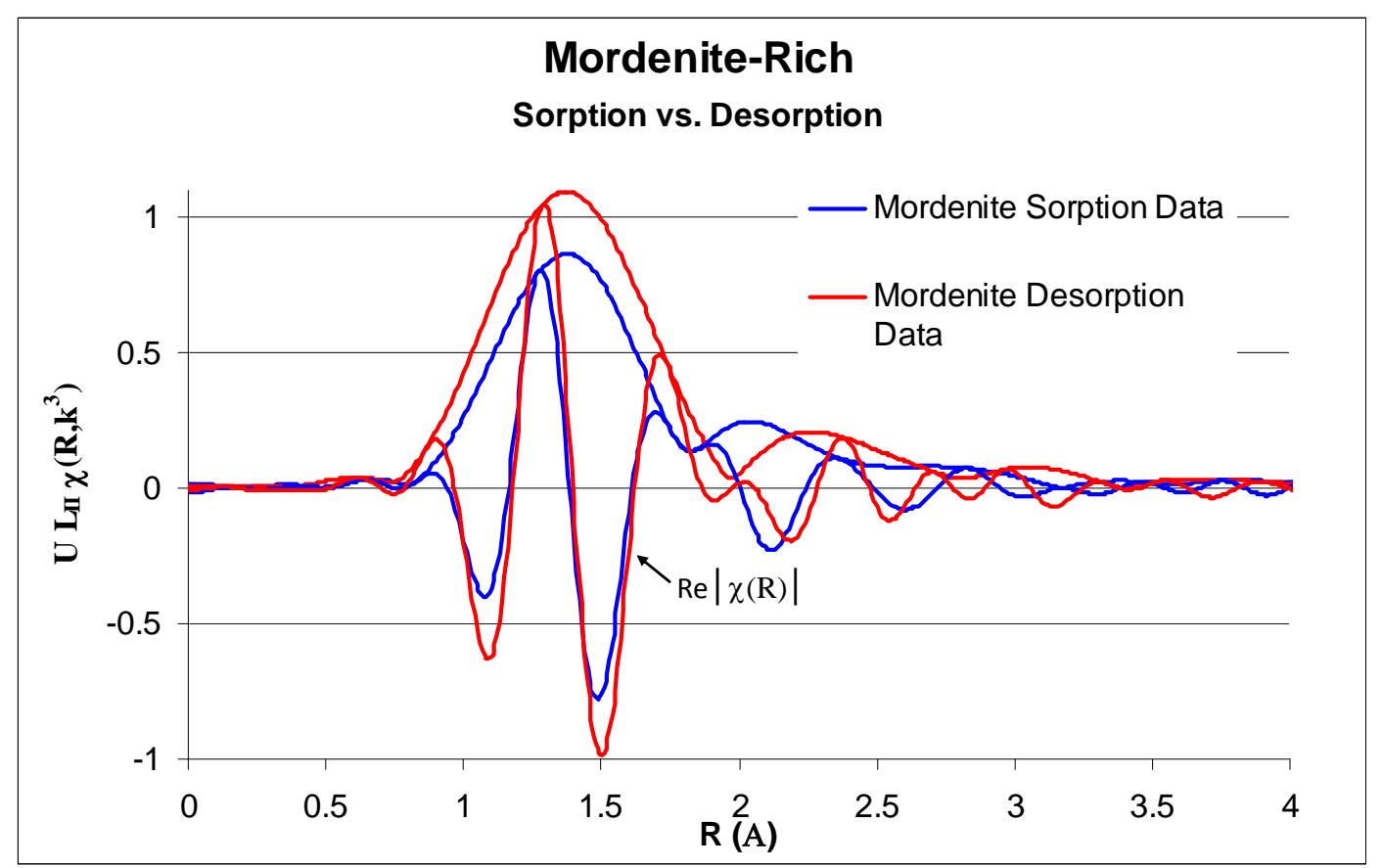

Figure 4.24. Fourier Transform Moduli and Real Components for the mordenite-rich volcanic tuff EXAFS data comparing the sorption and desorption sample. 


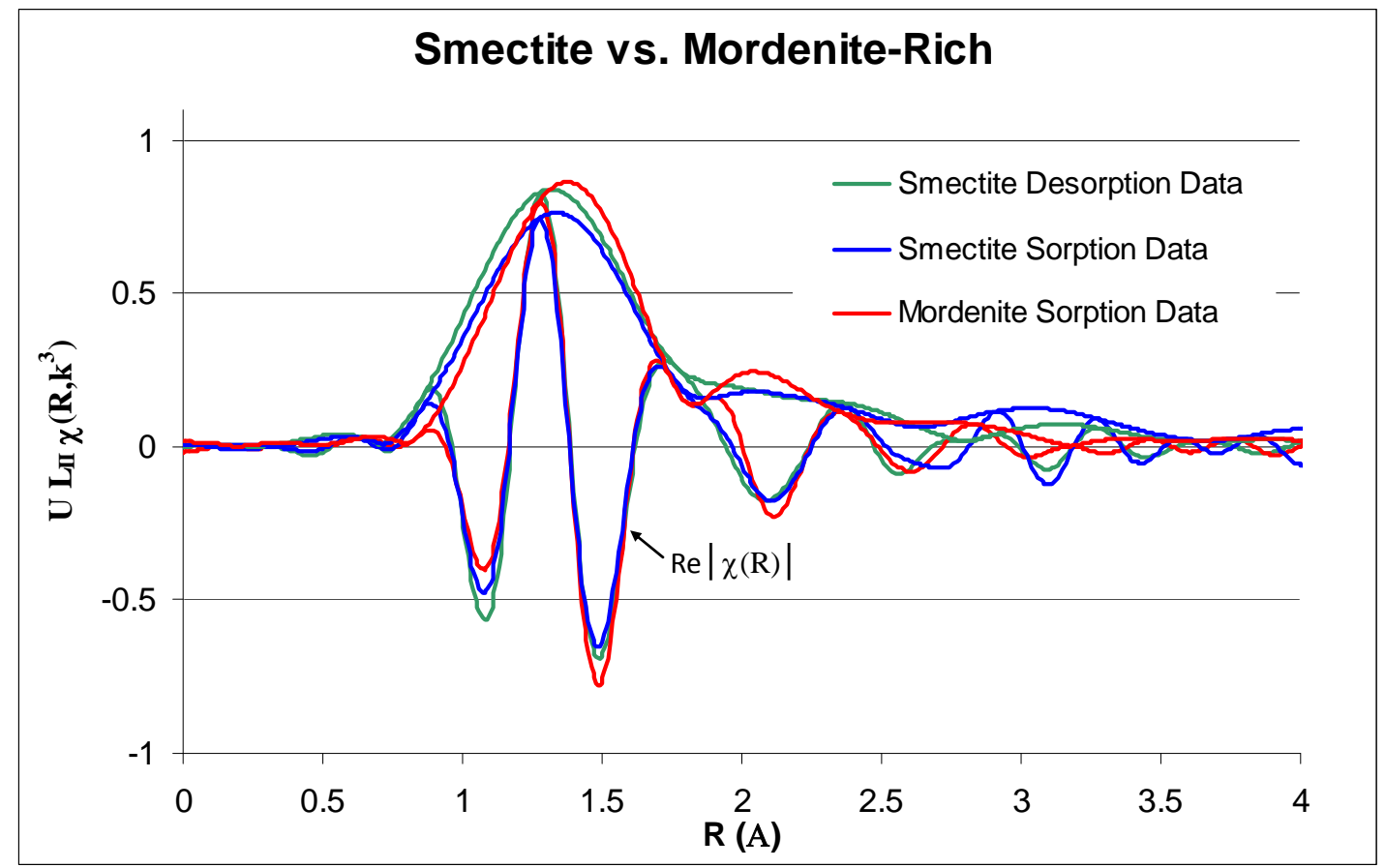

Figure 4.25. Fourier Transform Moduli and Real Components for the smectite-rich sorption and desorption sample and the mordenite-rich sorption sample EXAFS data. The mordenite sorption sample shows more similarities with the smectite samples, than it does with its own mordenite desorption sample.

The peak position in the FT is related to the uranium distance to neighboring atoms (R), and the peak amplitude is related to the number of neighboring atoms $(\mathrm{N})$ and the thermal and static disorder $(\sigma)$ for that shell, where a reduction in $\mathrm{N}$ and/or an increase in $\sigma$ results in a decrease in amplitude. Because the measurements were taken isothermally in this study, an increase in $\sigma$ is most likely due to an increase in the mean-square disorder $\left(\sigma^{2}\right)$ of nearest neighbor distance within a single shell. The larger peak in the FT magnitude near $\mathrm{R} \approx 1.3 \AA$ in all the $\chi(\mathrm{R})$ spectra is the contribution of the axial oxygen atoms in the basic uranyl $\left(\mathrm{UO}_{2}{ }^{2+}\right)$ building block. The next peak around $\mathrm{R} \approx 1.9 \AA$ is the contribution from equatorial oxygen atoms, which comprise the next nearest neighbor shell. Inspection of the $\chi(\mathrm{R})$ spectra for the smectite-rich tuff sample (Figure 4.23) reveals no distinguishable changes to the 
average local structure of uranium between the sorption and desorption sample out to the equatorial oxygen shell distance. Because EXAFS provides only average structural parameters for sorbed uranium, it is difficult to separate out structural features of individual sorption complexes (Chisholm-Brause, Conradson et al. 1994). Approximately $50 \%$ of the uranium from the sorption phase of the experiment remained sorbed at the conclusion of the desorption phase. The structural features for sorbed uranium contributing to the average EXAFS in the sorption sample may also be present in the desorption sample, although the number of complexes of the weaker bound species may be somewhat reduced at $50 \%$ of the coverage. Further analysis of the EXAFS spectra, however, may be conducted in the future to distinguish any small changes present in the equatorial and axial oxygen shells of the sorption and desorption samples that the qualitative evaluation presented here did not (ChisholmBrause, Conradson et al. 1994).

Chisholm-Brause, Conradson et al. concluded through spectroscopic studies that there are at least three distinct sites for uranium sorption on montmorillonites. Although it is not apparent from the qualitative analysis of the EXAFS in this study, the uranium is most likely sorbed to smectite, more specifically sodium and calcium montmorillonite in the smectite-rich sample (see X-ray diffraction patterns in Appendix 3B). QXRD analyses of samples prepared in the same manner as those used in the EXAFS measurements are presented in Table 2.5. The bulk matrix of the smectite-rich sample contains $12.6 \%$ smectite, with $37.6 \%$ K-feldspar, 37.4\% plagioclase, 9.5\% quartz and 4.7\% illite/mica. The samples also contain a nonsettling black residue which was floating on top of the water during the settling phase 
of the sample preparation and deposited on the top of the bulk matrix when centrifuged (See Section 2.5.3 for the sample preparation method). The black residue makes up less than $1 \%$ of the bulk sample and contains smectite (45.4\%), plagioclase (29.3\%), K-feldspar (23.8\%) and quartz (2.2\%). The sorption phase of the long-term desorption experiments in Section 4.1.1 suggests that the smectite clay played the most significant role in uranium sorption in the smectite-rich volcanic tuff sample. This is evidenced by a comparison of the QXRD results in Table 2.4 from both the illite and smectite-rich samples. The illite rich volcanic tuff contains the same mineral phases in similar proportions as the smectite-rich sample, with the exception that it contains no detectible smectite. The illite sample sorbed $42 \%$ less uranium (Table 4.1) than the smectite-rich sample suggesting that smectite is responsible for a large percentage of the uranium removal from the tracer solution in the sorption phase of the experiments. The EXAFS samples contain an even higher percent of smectite and it is reasonable to assume that smectite is responsible for a large majority of the uranium uptake in the EXAFS experiments as well. This is further evidenced by the X-ray mapping of sorbed uranium on a thin section of the smectite-rich sample postdesorption presented in Section 4.2.2.

Inspection of the $\chi(\mathrm{R})$ spectra for the mordenite-rich tuff sample (Figure 4.24) reveals distinguishable changes to the average local structure of uranium between the sorption and desorption sample out to $\mathrm{R} \approx 2.3 \AA$. The amplitudes of the moduli and real parts of the FT in Figure 4.24 within the region from 0.19 to $1.9 \AA$ show an increase in the axial oxygen amplitude and slight decrease in equatorial oxygen amplitude from the sorption to the desorption sample. Further inspection of the real 
part of the FT shows that the nodes (at $\chi(\mathrm{R})=0$ ) do not match between the sorption and desorption sample at the equatorial oxygen shell at $\mathrm{R} \approx 1.9 \AA$. These observations indicate that although the local structure around uranium is similar in both the sorption and desorption sample (presence of axial and equatorial oxygen shells) the average complexes between these samples are not identical. In fact, the $\chi(\mathrm{R})$ spectra of the mordenite-rich sorption sample are more similar to those of the smectite-rich samples (Figure 4.25) than to the mordenite-rich desorption sample. This is interesting because the smectite-rich sample contains a high percentage of smectite clay and no detectable zeolite. The QXRD analysis presented in Table 2.5 indicates that the fine particle size fraction (and black residue) separated out of the mordenite-rich sample concentrated a high percentage of smectite from the bulk matrix (although not detected in the larger particle size faction QXRD in Table 2.4). The fine fraction matrix of the mordenite-rich sample used for EXAFS contains 59\% mordenite and $34.4 \%$ smectite (as sodium montmorillonite) and the black residue (which, like the residue in the smectite rich sample, contributes less than $1 \%$ to the bulk sample) contains $19.5 \%$ mordenite and $49.4 \%$ smectite. Due to the similarity between the mordenite-rich sorption sample and the smectite-rich samples it appears that a greater fraction of the uranium in the mordenite-rich sorption sample is sorbed to smectite clay. The differences in the $\chi(\mathrm{R})$ spectra of the mordenite-rich desorption sample suggest that the average local structure of the uranium remaining sorbed after 1 week of desorption is different than that of the freshly sorbed uranium. Further data reduction and analysis of these samples and EXAFS measurements of uranium sorbed to mordenite model compounds may reveal that the stronger desorption sites for 
uranium are associated with a mordenite mineral phase. This cannot be determined with any certainty by the qualitative analysis presented here.

\subsubsection{X-Ray Mapping}

Micro x-ray absorption spectroscopy imaging. The uranium sorption and desorption in the smectite-rich tuff were further analyzed by $\mathrm{x}$-ray microprobe at SSRL Beam Line 2-3 to spatially map the presence and distribution of uranium. Spatial maps for uranium were collected and processed at the $\mathrm{U}_{\mathrm{III}}$ absorption edge $(17200 \mathrm{eV})$. The samples were measured at room temperature in fluorescence mode using a Ge 3 detector and the $\mathrm{U}_{\mathrm{III}}$ absorption edge was calibrated to the yttrium edge, with the first inflection point defined as $17038 \mathrm{eV}$. Six maps total were collected, 3 of the smectite-rich sorption thin section and 3 of the smectite-rich desorption thin section. The maps were processed using Microtoolkit Version 0.50, Copyright Samuel Webb, 2006, Stanford Synchrotron Radiation Laboratory. Due to interference of rubidium at the uranium adsorption edge, the rubidium contribution (at $17100 \mathrm{eV}$ ) was subtracted from the uranium maps using the "Map Math” function in Microtoolkit. Thin section features associated with high uranium counts were identified using a transmitted light optical petrographic scope.

Microprobe Spatial Maps. Microprobe data were collected on a thin section of the smectite-rich tuff freshly sorbed with uranium and on another duplicate thin section that was desorbed of uranium for a period of 1 week. These measurements were used to compare the spatial distribution of uranium within the sorption and desorption thin sections, and uranium elemental/mineral phase associations. The spatial maps in Figure 4.26 consistently show the highest uranium "hot spots", or 
densely concentrated areas, in the freshly sorbed uranium associated with epoxy bubbles and zircons. Otherwise, the uranium is ubiquitous throughout the sample in lower concentrations.

The epoxy bubbles were identified optically by a circular white rim with a dark center in transmitted light and zircons by their high refractive indices and high birefringence. The hot spots in the epoxy bubbles are most likely uranyl-carbonate precipitates formed from droplets of uranium tracer solution trapped in bubbles after batch sorption and drying of the thin section. The hot spots associated with zircons are more complicated to explain. Zircons typically have uranium incorporated into their structure (Deer 1966). Sorption of uranium by zircons has also been demonstrated by complexion with the Si-O sites on zircon edges (Lomenech, Simoni et al. 2003). Uranium can exist in the $\mathrm{U}(\mathrm{IV}), \mathrm{U}(\mathrm{V})$ and $\mathrm{U}(\mathrm{VI})$ oxidation state in zircons (Zhang and et al. 2003). The uranium in the tracer solution was in the U(VI) oxidation state and a determination of the oxidation state of uranium associated with the zircons (by X-ray Absorption Near-Edge Spectroscopy) in the thin section may have offered evidence as to whether uranium existed in the zircon structure prior to exposure to the uranium tracer solution or post exposure. In hindsight, an x-ray map of the background uranium in the smectite-rich tuff could have established if uranium was associated with the zircons prior to exposure to the uranium tracer solution. 


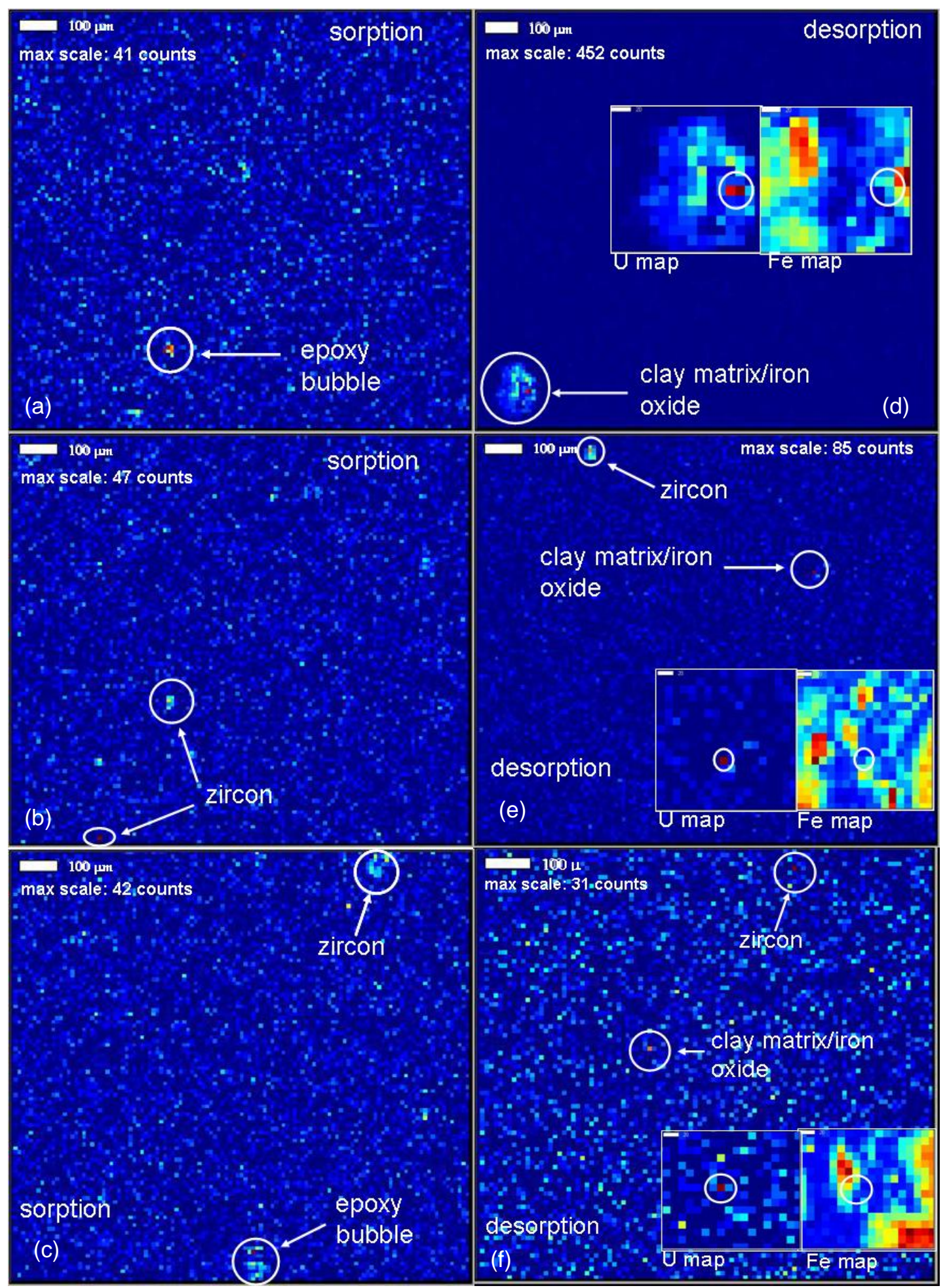

Figure 4.26. $\mu$-XAS images of freshly-sorbed $U$ (a,b,c) and post-desorption $U$ (d,e,f) thin sections of smectite-rich tuff. Colors from blue to red indicate lowest to highest uranium counts and are unique to each map as indicated by the "max scale". The white-bordered insets are magnifications of the clay matrix/iron oxide areas showing the spatial distribution of $U$ and Fe. 
The desorption thin section maps show uranium hot spots associated with the clay matrix, iron oxides and zircons. The clay matrix was identified optically as the fine-grained aggregates. The iron oxides are identified by their inability to transmit light, and are typically present as amorphous coatings on minerals grains. Iron is widely distributed in all of the maps (not shown), although it is not possible to distinguish between crystalline and amorphous phases using only a spatial distribution map. The area of high uranium concentration in the desorption thin section map in Figure 4.26 (d) was examined optically and was found to be an area of clay matrix bordered with amorphous iron oxides. Upon closer inspection of the uranium and iron spatial distribution maps in the insets of Figure 4.26 (d) the uranium is correlated with spots of relatively lower iron counts, suggesting that uranium is associated with the clay minerals, rather than with the iron oxides. Additional maps from the same thin section also showed higher concentrations of uranium correlated with areas of clay matrix and iron oxides (optically identified). Closer inspection of the x-ray maps (Figure 4.26 (e) and (f)) shows that uranium is more highly correlated with areas of lower iron counts in these maps as well.

A comparison of the spatial distribution of uranium in the x-ray maps of the sorption and desorption samples suggest that uranium was more widely distributed in the sorption sample and more concentrated in certain spots in the desorption sample. The maximum uranium counts in the maps from the sorption sample range from 41 to 47 and high counts are only associated with epoxy bubbles and zircons. The maximum uranium counts in the maps from the desorption sample range from 31 to 452 and are associated with zircons and the clay matrix. The highest uranium count 
mapped on the desorption thin section was associated with the clay matrix suggesting that the uranium is more highly correlated with clay minerals in the desorption sample because weakly-bound species would have desorbed from the sample during the desorption phase of the experiment. Spots of higher uranium counts were found in the desorption sample, even though there was more overall uranium sorbed to the sorption sample. This may suggest that the uranium that desorbed from the weaker sites became more associated with the strong sites during the desorption phase of the experiments. Although the EXAFS data presented in Section 4.2.1 did not show any qualitative differences in the average local structure of uranium between a sorption and desorption sample, consideration of the results from the $\mathrm{x}$-ray mapping gives further evidence that the smectite mineral phase is responsible for a greater fraction of the uranium uptake and retention in the smectite-rich volcanic tuff. An increase in the concentration of uranium on the thin section and/or an increase in the number and duration of scans would result in an improvement in the EXAFS data quality. Better data quality would allow for the determination of the average local structure about the uranium atom including the presence, type and number of complexing ligands and whether the uranium complex is bound via outer or inner-sphere sorption at the basal plane or silanol/aluminol edge sites, respectively.

\subsubsection{Electron Probe Microanalysis}

Electron Probe Microanalysis (EPMA) data were collected on thin sections of the smectite and mordenite-rich tuff freshly sorbed with uranium and on duplicate thin sections that were desorbed of uranium for a period of 1 week. These measurements were used to complement the x-ray mapping and to compare the 
spatial distribution of uranium within the sorption and desorption thin sections, and uranium elemental/mineral phase associations. Uranium spatial distribution maps are shown in Figures 4.27 and 4.28 for the smectite and mordenite-rich samples, respectively.

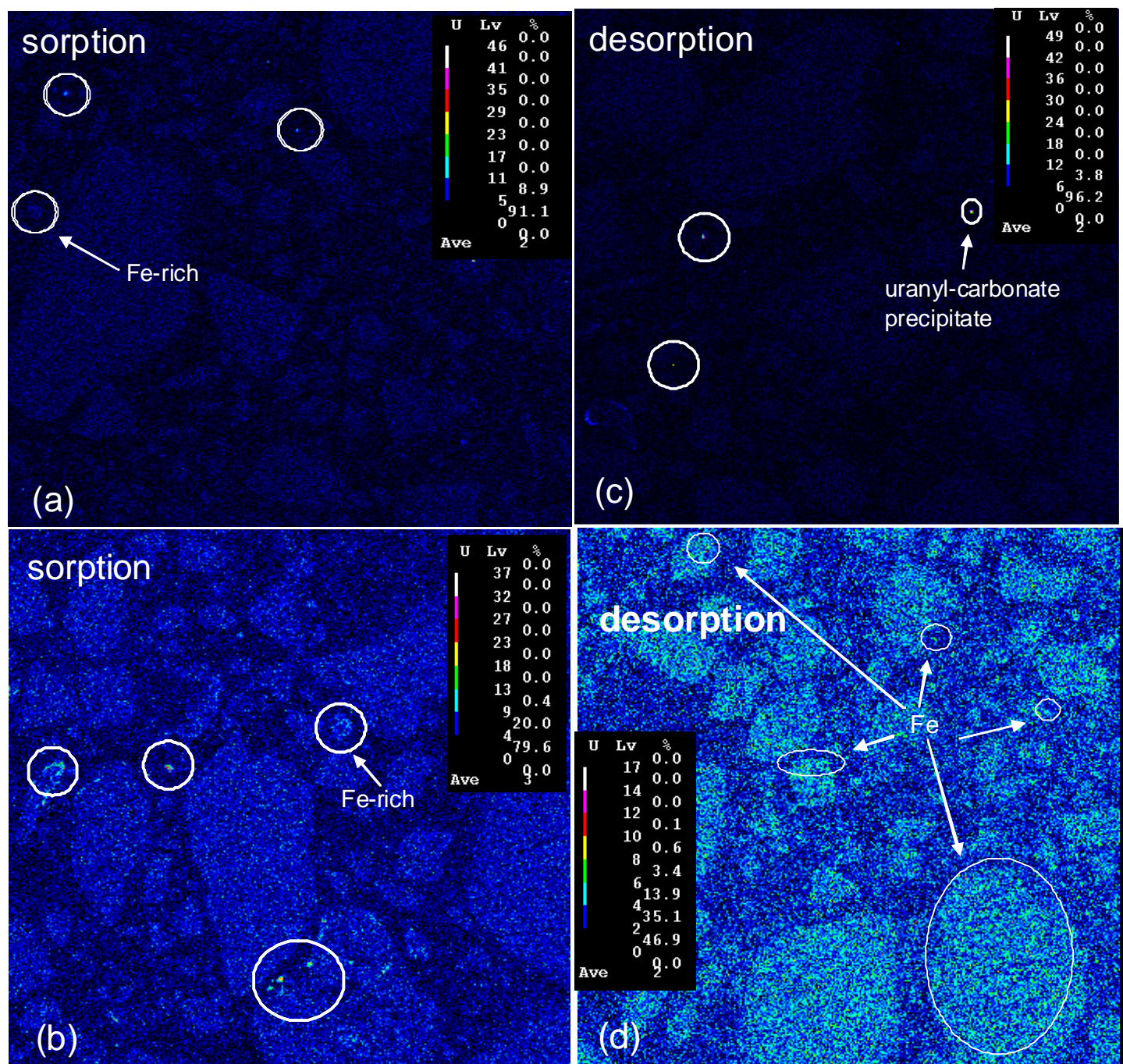

Figure 4.27. Electron Probe Microanalysis images of freshly-sorbed U (left) and post-desorption $U$ (right) thin sections of smectite-rich tuff. Concentrated spots are indicated by a white circle and unless otherwise indicated are associated with mostly sodium, aluminum and silicate, most likely smectite. Each pixel represents a 4 x $4 \mu \mathrm{m}$ spot. 


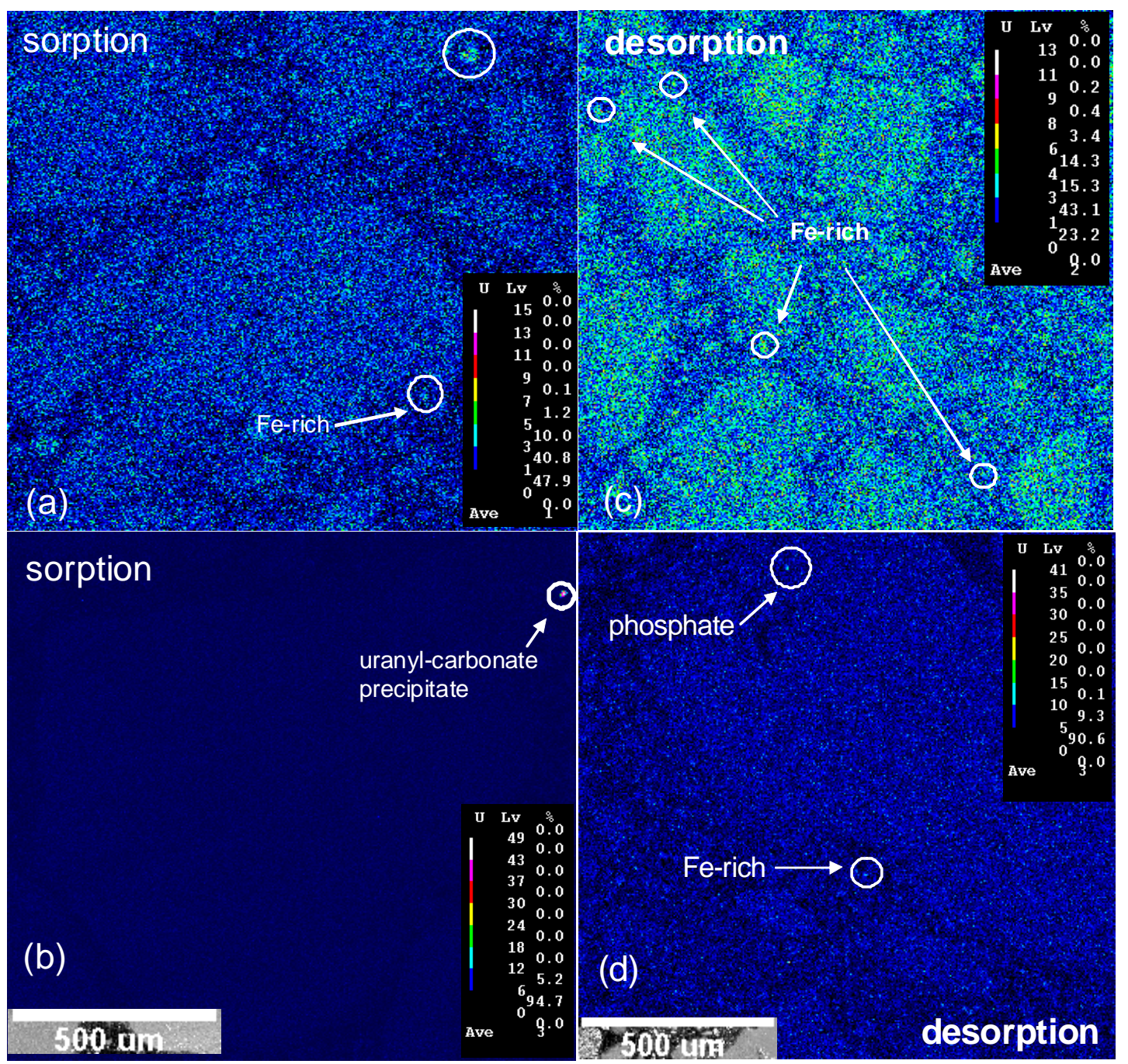

Figure 4.28. Electron Probe Microanalysis images of freshly-sorbed U (left) and post-desorption $\mathbf{U}$ (right) thin sections of mordenite-rich tuff. Concentrated spots are indicated by a white circle. Each pixel represents a $4 \times 4 \mu \mathrm{m}$ spot unless indicated otherwise. (b) is a K-feldspar grain with no visible $U$ associated with it most likely due to the anomalously high uranium counts from a uranyl-carbonate precipitate.

Elemental associations at concentrated uranium spots were analyzed by wavelength dispersive x-ray spectrometers (WDS) and an ultrathin-window energy dispersive spectrometer (EDS). These data were not sufficient to confirm that the hot spots were either associated with smectite in the smectite-rich sample or zeolite in the mordenite-rich sample. The material used for EPMA consists of the fine particle fraction of less than $75 \mu \mathrm{m}$ from the smectite and mordenite-rich volcanic tuff. The 
QXRD analysis for these samples indicates that the materials are different from those used in the EXAFS and x-ray mapping, most notably the lack of smectite in the mordenite-rich sample. The Smectite-rich sample contains $24.6 \%$ quartz, $29.9 \% \mathrm{~K}$ feldspar, 32.7\% plagioclase, 7.6\% illite/mica and 5.2\% smectite. The mordenite-rich sample contains 29.4\% quartz, 22.1\% K-feldspar, 8.2\% plagioclase, 9.7\% illite/mica, 23.3\% mordenite and 7.5\% analcime. The iron-rich spots in the maps were determined by comparing the uranium spatial maps with those of iron (not shown). The uranyl-carbonate precipitates were identified by comparison with the carbon spatial maps and backscatter images (not shown). The remaining spots were associated with sodium, alumina, and silicate, which made up the bulk of all the samples. The samples used in the x-ray mapping presented in Section 4.2.2 indicate that uranium is associated with zircons. Zircons were not spatially mapped in the EPMA and are not identified as being associated with the concentrated uranium spots, although further investigation would be needed to confirm that zircons were not present in the thin sections.

Comparing the smectite-rich samples in Figure 4.27 maps (a) and (b) show uranium is ubiquitous throughout the sorption samples, where map (c) shows the uranium is concentrated in hot spots in the desorption sample. Map (d) has very low uranium counts, and no hot spots were detected. The uranium hot spots were found to be associated with iron, sodium, alumina and silicate. The maps for the mordeniterich sample in Figure 4.28 show that uranium is also associated with iron, sodium, alumina and silicate, as well as phosphate in map (d). The uranium counts for the mordenite-rich sample maps in Figure 4.28 was either very low (maps (a) and (c), or 
very high (maps (b) and (d)), making it difficult to draw conclusions as to whether the uranium was ubiquitous throughout the sorption samples and concentrated in spots in the desorption samples. The map in figure 4.28 (c) is a K-feldspar grain on which uranium was not found, although the scale is thrown off by the anomalously high uranium counts due to the uranyl-carbonate precipitate found in the upper right corner of the map. The EPMA results for smectite-rich samples corroborate the x-ray mapping data in Section 4.2.4 in that the uranium is ubiquitous in low concentrations throughout the sorption sample, and concentrated in hot spots in the desorption sample.

\subsubsection{Proposed Uranium Surface Complexes}

Based on the spectroscopic evidence and known number and type of uranyl carbonate surface complexes on clay minerals (Chisholm-Brause, Conradson et al. 1994; Sylwester, Hudson et al. 2000; Bostick, Fendorf et al. 2002; Catalano and Brown 2005; Arai, McBeath et al. 2006; Schlegel and Descostes 2009), there are four possible surface complexes proposed for uranium sorption in the smectite-rich sample. The first is an electrostatic interaction via an outer-sphere surface complex in which the $\mathrm{CaUO}_{2}\left(\mathrm{CO}_{3}\right)_{3}^{2-}$ species remains intact, and is planar to the protonated edge site surface (Figure 4.29 (a). The remaining proposed surface complexes are $\mathrm{U}(\mathrm{VI})$-biscarbonato ternary complexes via innersphere bonding to silanol and aluminol groups. These include a monouclear $\mathrm{U}(\mathrm{VI})-\mathrm{O}-\mathrm{Si}$ bidentate complex, and a monouclear $\mathrm{U}(\mathrm{VI})-\mathrm{O}-\mathrm{Al}$ monodentate complex which are shown in Figure 4.29 (b) and (c) and a bidentate mononuclear U(VI)-O-Al complex shown in Figure 4.29 (d). In figure 4.29 (d) the aluminum 


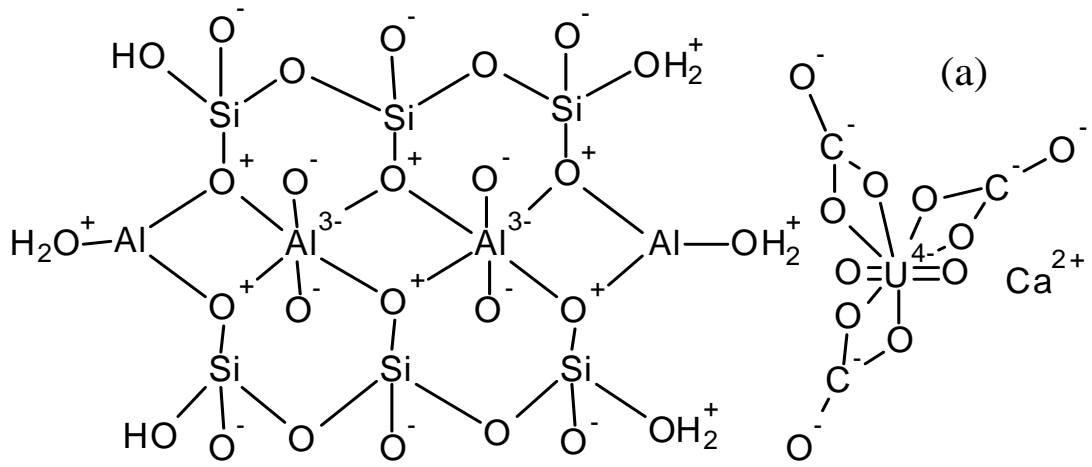

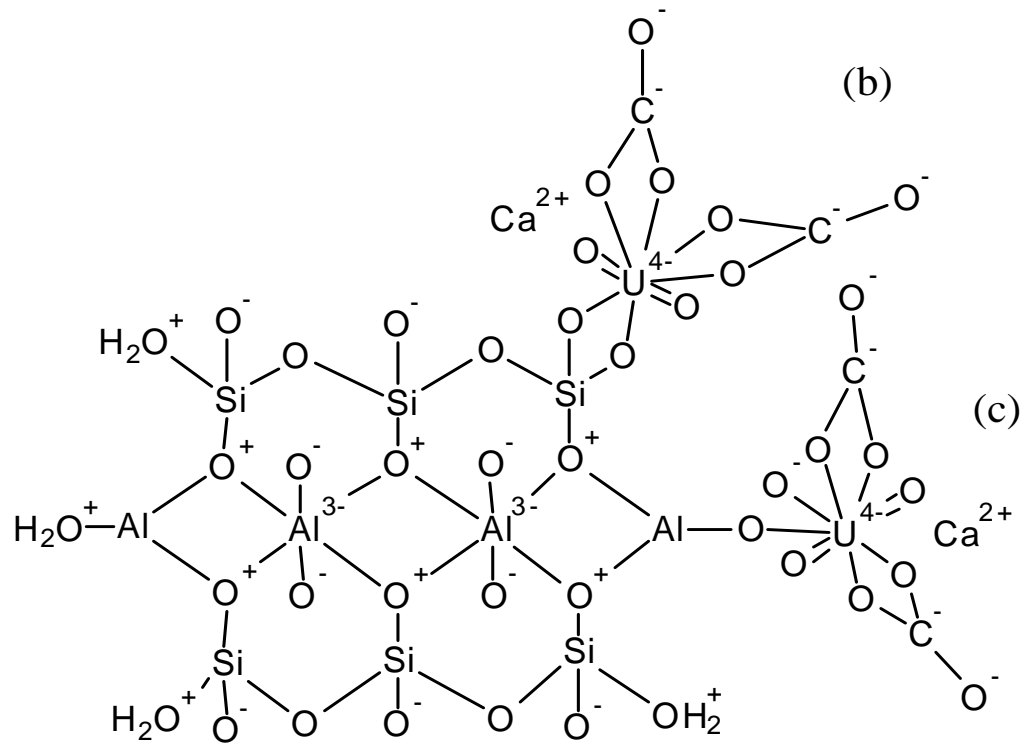

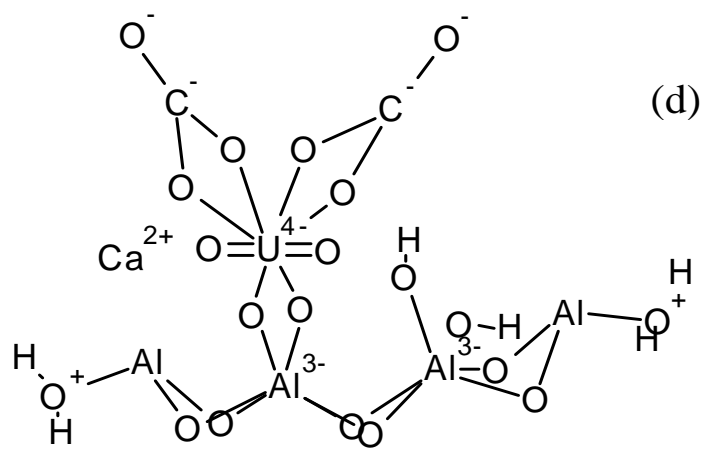

Figure 4.29. Structural Representation of Proposed Uranium Surface Complexes on smectite clay. (a) Planar U(VI) tris-carbonato outer-sphere surface complex. (b) U(VI) bis-carbonato inner-sphere complex via U(VI)-O-Si bidentate linkage. (c) U(VI) bis-carbonato inner-sphere complex via monodentate U(VI)-O-Al linkage. (d) U(VI) bis-carbonato inner-sphere complex via U(VI)-O-Al bidentate linkage. 
octahedral sheet has been isolated and the structure has been rotated $90^{\circ}$ clockwise to obtain a better view of the bidentate U(VI)-O-Al linkage. The weaker bonding sites are most likely associated with the outer-sphere bonding of uranium to the protonated edge sites. The stronger sites are most likely associated with the inner-sphere surface complexes, with some complexes being stronger than others. Zeolites also contain aluminol and silanol groups having amphoteric edge sites (Kuzniatsova, Kim et al. 2007) and uranium sorption is most likely similar to what is proposed in the smectite clay. 


\section{Conclusions}

The extent to which uranium and neptunium will migrate from a high level nuclear waste repository depends on the ability of engineered barriers and natural systems to retard their migration. Migration of uranium and neptunium in the saturated zone depends ultimately on two major factors: (1) The rate and direction of groundwater flow and (2) the ability of the host rock materials to adsorb uranium and neptunium. This study focuses on the second factor, the ability of the saturated volcanic tuff to retard the migration of these radionuclides. The kinetics of $\mathrm{U}(\mathrm{VI})$ and $\mathrm{Np}(\mathrm{V})$ sorption/desorption is an important factor controlling uranium and neptunium fate and transport. The results of this study imply that the use of a single $K_{d}$ value for the partitioning of uranium between the solution and solid phases over-predicts transport rates for uranium in the saturated volcanic tuff. In addition, although the first arrival time of neptunium is predicted well by the batch sorption $K_{d}$ value, the recovery of neptunium is over-predicted by use of this parameter.

Uranium. An average of 2 to $19 \%$ of the uranium initially brought into contact with the various tuffs in the batch sorption and long-term desorption experiments remained sorbed to the solid phase at the conclusion of the experiments. A multi-rate model was effective in describing the kinetics in long-term desorption experiments, where desorption rate constants spanning several orders of magnitude provided the best fit to the data. Mineralogical variability in the tuff will have significant effects on $\mathrm{U}(\mathrm{VI})$ adsorption/desorption kinetics and consequently, $\mathrm{U}(\mathrm{VI})$ concentration within the contaminant plume. Greater sorption and slower desorption 
rate constants will be experienced by uranium in aquifer regions containing devitrified tuffs with high smectite content and zeolitic tuff. When the experiments were scaled up to columns packed with the smectite-rich tuff, the sorption and desorption rate constants used in the multi-rate model for the long-term desorption experiments over-predicted the transport of uranium in the columns. In the up-scaled columns, the amount of sorption increased resulting in a majority of the activity being sorbed in the first few centimeters from the inlet of the column, and when the flow rate was increased (in a separate experiment) the uranium migrated further down the column, suggesting a residence time dependence for uranium sorption/desorption. A small percentage of the uranium broke through starting at approximately 100 pore volumes at both flow rates. The apparent retardation of uranium deduced from the different methods results in the least retardation predicted by batch sorption, followed by the long-term desorption and up-scaled columns, with the greatest apparent retardation predicted from the column profiles.

EXAFS spectra of uranium freshly sorbed to smectite-rich tuff and of uranium after one week of desorption, resulting in $50 \%$ of the initial surface coverage, are similar. These results indicate that the average local bonding structure of uranium in the sorption and desorption samples are the same. Spatial mapping of uranium in smectite-rich tuff indicated that the freshly sorbed uranium was distributed throughout the thin section. Localized areas of higher uranium counts were found in the desorption thin section that appear to be highly correlated with smectite minerals. Comparison of the EXAFS spectra of uranium freshly sorbed to the mordenite-rich tuff and uranium after one week of desorption, resulting in approximately 50\% of the 
initial surface coverage, showed obvious differences. These results indicate that uranium freshly sorbed to mordenite-rich tuff has an average local bonding structure different from that of uranium remaining sorbed after 1 week of desorption. The EXAFS spectra of uranium freshly sorbed to the mordenite-rich tuff showed more similarities to the EXAFS spectra of uranium sorbed to the smectite-rich tuff, suggesting that the smectite fraction that was concentrated in the mordenite-rich tuff during sample preparation may be responsible for the uranium sorption observed in the mordenite-rich tuff, as smectite was the only common mineral present in large quantities in both of the smectite and mordenite-rich samples. Uranyl carbonate surface complexes are most likely similar in both the zeolite and smectite clay, with an outer-sphere mechanism on protonated edge sites being the weaker of the complexes and inner-sphere complexes with silanol and aluminol edge sites being the stronger sites with slower desorption kinetics.

Neptunium. An average of 75 to $91 \%$ of the neptunium initially brought into contact with the tuff in the batch sorption and long-term desorption experiments remained sorbed to the solid phase at the conclusion of the experiments. A multi-rate model was effective in describing the kinetics in long-term desorption experiments, where desorption rate constants spanning several orders of magnitude provided the best fit to the data. Mineralogy appears to be less important for neptunium sorption than for uranium as the amount of neptunium sorbed and retained was within $7 \%$ and $16 \%$, respectively, between the different tuff samples. Although the smectite-rich tuff sorbed and retained the greatest fraction of neptunium in the batch sorption and longterm desorption experiments, normalization of the data to the surface area of the tuff 
sample brings out the strong-sorbing character of the illite-rich tuff. When the experiments were scaled up to columns packed with the smectite-rich tuff, the sorption and desorption rate constants used in the multi-rate model for the long-term desorption experiments under-predicted the transport of neptunium in the columns. The model did not predict any breakthrough within 420 pore volumes, thus not describing the small percentage of the neptunium that broke through starting at approximately 100 pore volumes. These parameters also did not capture the large fraction of neptunium sorbed 2 to 4 centimeters from the inlet of the column at the conclusion of the experiment. The parameters providing the best fit to the neptunium breakthrough data provided a good fit to the long-term desorption data, but was unable to fit the large fraction of neptunium 2 to $4 \mathrm{~cm}$ from the inlet of the column in the post-mortem concentration profile. The post-mortem concentration profile parameters under-predicted the breakthrough data and required a lower $\mathrm{S}_{\max }$ value to fit the long-term desorption data. Even with the $S_{\max }$ value allowed to vary, these parameters over-predicted the amount of neptunium sorbed at the initiation of the long-term desorption experiment and the final rate of desorption was greater than actually observed (so the predicted fraction remaining sorbed would have been much less than the observed remaining fraction at longer times). The main difference between the methods not accounted for in the models was the end-over-end mixing in the long-term desorption experiment, where there were no solids in motion in the upscaled columns. The apparent retardation of neptunium deduced from the different methods results in the least retardation predicted by batch sorption, followed by the 
up-scaled columns and long-term desorption, with the greatest apparent retardation predicted from the column profiles.

Field Scale Implications of this Study. The expected transport scenario in the volcanic tuff is fracture flow. Attenuation of species in a fraction flow system would result from diffusion into and sorption onto matrix materials. It is overly simplistic to explain the sorption of uranium and neptunium in a heterogeneous media, such as the volcanic tuff in this study, by a single partition coefficient. Variability in desorption rates are not always considered, but it may ultimately control uranium and neptunium transport behavior. The $\mathrm{K}_{\mathrm{d}}$ approach implies a continuous displacement of the center of mass of the contaminant plume along the direction of groundwater flow, with both sorbed and aqueous components advancing at the same rate governed by reversible local equilibrium conditions (Lichtner 2010). At least for the smectite-rich volcanic tuff, the results of this study suggest that the uranium and neptunium would persist at high surface concentrations very close to its original source location until U(VI) and $\mathrm{Np}(\mathrm{V})$ is removed by dissolution, desorption, and diffusion, only to re-sorb a short distance down-gradient of the source location. This is consistent with the conceptual model presented in Section 1.1.2.

The multi-rate advection-dispersion-reaction transport model used in this study could not simultaneously provide a good description of both the column profiles and the breakthrough (using the same rate constants) for either the uranium or neptunium columns, indicating that the model was not fully able to describe the rate and extent of $\mathrm{U}(\mathrm{VI})$ and $\mathrm{Np}(\mathrm{V})$ adsorption/desorption reactions taking place in the upscaled columns. In general, the combined breakthrough and profile data suggest that 
while the majority of the radionuclide mass is strongly retarded (profile data), there is a minor fraction that is less strongly retarded (breakthrough data). Multiple firstorder reactions are unable to explain this combined behavior. The inability to simultaneously model the breakthrough and profile data might be explained by (1) disequilibria of uranium and neptunium solution species and/or (2) a dual porosity flow regime within the up-scaled columns. The multiple methods employed in this study provide many more insights and more realistic parameterization of sorption and desorption than simple batch experiments. When coupled with knowledge of mineralogical and geochemical heterogeneities along groundwater flow paths, this multi-method approach should result in significant improvements to predictions of subsurface contaminant transport.

\section{RECOMMENDATIONS FOR FUTURE WORK}

Further analysis and modeling is required to fully understand the behavior of uranium and neptunium in the saturated volcanic tuff. Future work to gain this understanding would include:

- Investigation of uranium and neptunium complexes in solution at different contact times with volcanic tuff using time resolved fluorescence spectrometry to investigate the kinetic limitations of solution equilibrium reestablishment.

- Improvement of EXAFS sample preparation and data collection techniques to isolate strong sorption sites for uranium (and neptunium) and to determine the local bonding environment on volcanic tuff. 
- Improvement of $\mu$-XAS sample preparation and data collection techniques to determine the oxidation state of uranium (and neptunium) through XANES and collect high quality EXAFS at grain size resolution.

- Investigation of the background contribution of zircons with structurally bound uranium in the smectite-rich volcanic tuff using $\mu$-XAS spatial distribution maps.

- Investigation of uranium and neptunium sorption and desorption in iron and manganese oxides to evaluate their effect on transport when present as amorphous grain or fracture coatings.

- Utilization of Transmission Electron Microscopy (TEM) analysis to complement other spectroscopic studies to determine atomic level associations of uranium and neptunium-sorbed volcanic tuff samples.

- Improvement of the multi-rate model to describe the uranium and neptunium sorbed concentration profiles and breakthrough simultaneously in dynamic transport columns fully packed with crushed volcanic tuff, possibly by coupling with a dual porosity and/or solution equilibrium or cation exchange model.

The results of the current study and the proposed future work can be used to improve models for transport and fate of uranium and neptunium in a heterogeneous material such as the saturated tuff found at Yucca Mountain. The understanding of the desorption behavior of uranium and neptunium in heterogeneous systems would result in less conservative performance assessment models than those based solely on $\mathrm{K}_{\mathrm{d}}$ values. Other benefits include the ability to predict uranium and neptunium 
transport behavior in other heterogeneous systems based on bulk mineralogy and water chemistry information with a decreased need for extensive sorption and desorption experiments. In addition, the increased understanding of the governing mechanisms of uranium and neptunium transport would increase confidence in laboratory studies to accurately describe field transport behavior. This field of research can potentially have application in homeland defense, groundwater quality issues and environmental remediation. 


\section{REFERENCES}

Anghel, I., H. J. Turin, et al. (2002). "Lithium sorption to Yucca Mountain tuffs." Applied Geochemistry 17(6): 819-824.

Arai, Y., M. McBeath, et al. (2006). "Uranyl adsorption and surface speciation at the imogolite-water interface: Self-consistent spectroscopic and surface complexation models." Geochimica et Cosmochimica Acta 70(10): 24922509.

Arnold, B. W., S. P. Kuzio, et al. (2003). "Radionuclide transport simulation and uncertainty analyses with the saturated-zone site-scale model at Yucca Mountain, Nevada." Journal of Contaminant Hydrology 62-63(0): 401-419.

Bargar, J. R., R. Reitmeyer, et al. (2000). "Characterization of U(VI)-carbonato ternary complexes on hematite: EXAFS and electrophoretic mobility measurements." Geochimica et Cosmochimica Acta 64(16): 2737-2749.

Bostick, B. C., S. Fendorf, et al. (2002). "Uranyl Surface Complexes Formed on Subsurface Media from DOE Facilities." Soil Sci Soc Am J 66(1): 99-108.

Brunauer, S. E., P. H.; Teller, E. (1938). "Adsorption of gases in multimolecular layers." J. Am. Chem. Soc., vol. 60, p. 309-319 (1938). 60: 309-319.

Catalano, J. G. and G. E. Brown (2005). "Uranyl adsorption onto montmorillonite: Evaluation of binding sites and carbonate complexation." Geochimica et Cosmochimica Acta 69(12): 2995-3005.

Catalano, J. G., T. P. Trainor, et al. (2005). "CTR diffraction and grazing-incidence EXAFS study of U(VI) adsorption onto \&\#x03B1;$\mathrm{Al}<$ sub $>2</$ sub $>0<$ sub $>3</$ sub $>$ and \&\#x03B 1 ;$\mathrm{Fe}<$ sub $>2</$ sub $>\mathrm{O}<$ sub $>3</$ sub $>(11 \& \# \mathrm{x} 0304 ; 02)$ surfaces." Geochimica et Cosmochimica Acta 69(14): 3555-3572.

Çelik, M. S., W. Fernando, et al. (2004). Electrokinetic behavior of clay surfaces. Interface Science and Technology, Elsevier. Volume 1: 57-89.

Chardon, E. S., D. Bosbach, et al. (2008). "Reactions of the feldspar surface with metal ions: Sorption of $\mathrm{Pb}(\mathrm{II}), \mathrm{U}(\mathrm{VI})$ and $\mathrm{Np}(\mathrm{V})$, and surface analytical studies of reaction with $\mathrm{Pb}(\mathrm{II})$ and $\mathrm{U}(\mathrm{VI})$." Geochimica et Cosmochimica Acta 72(2): 288-297. 
Chipera, S. J. and D. L. Bish (2002). "FULLPAT: a full-pattern quantitative analysis program for X-ray powder diffraction using measured and calculated patterns." Journal of Applied Crystallography 35: 744.

Chisholm-Brause, C., S. D. Conradson, et al. (1994). "Speciation of uranyl sorbed at multiple binding sites on montmorillonite." Geochimica et Cosmochimica Acta 58(17): 3625-3631.

Combes, J. M., C. J. Chisholm-Brause, et al. (1992). "EXAFS Spectroscopic Study of Neptunium-V Sorption at the Goethite-Water Interface." Environmental Science and Technology 26(2): 376-382.

Conradson, S. D., B. D. Begg, et al. (2005). "Charge Distribution and Local Structure and Speciation in the $\mathrm{UO}_{2+x}$ and $\mathrm{PuO}_{2+x}$ Binary Oxides for $\mathrm{x} \leq 0.25$." Journal of Solid State Chemistry 178(2): 521-535.

Conradson, S. D., D. Manara, et al. (2004). "Local Structure and Charge Distribution in the $\mathrm{UO}_{2}-\mathrm{U}_{4} \mathrm{O}_{9}$ System." Inorganic Chemistry 43(22): 6922-6935.

Culver, T. B., R. A. Brown, et al. (2000). "Rate-Limited Sorption and Desorption of 1,2-Dichlorobenzene to a Natural Sand Soil Column." Environmental Science \&amp; Technology 34(12): 2446-2452.

Culver, T. B., S. P. Hallisey, et al. (1997). "Modeling the desorption of organic contaminants from long-term contaminated soil using distributed mass transfer rates." Environmental Science and Technology 31(6): 1581-1588.

Cunningham, J. A., J. J. Deitsch, et al. (2005). "Quantification of contaminant sorption-desorption time scales from batch experiments." Environmental Toxicology and Chemistry 24(9): 2160-2166.

Davis, J. A., J. A. Coston, et al. (1998). "Application of the Surface Complexation Concept to Complex Mineral Assemblages." Environmental Science \& Technology 32(19): 2820-2828.

Davis, J. A. and D. B. Kent (1990). "Surface Complexation Modeling in Aqueous Geochemistry." Reviews in Mineralogy 23: 177.

Dean, J. A. (1999). Lange's Handbook of Chemistry, McGraw-Hill.

Deer, H. a. Z. (1966). An Introduction to the Rock Forming Minerals. London, Longman Group Limited. 
Deitsch, J. J., J. A. Smith, et al. (2000). "Distributed-rate model analysis of 1,2dichlorobenzene batch sorption and desorption rates for five natural sorbents." Environmental Science and Technology 34(8): 1469-1476.

Ding, M. (2003). Uranium Sorption in Alluvium from NC-EWDP Wells 19IM1A, 10SA, and 22SA Under Ambient Conditions.

Dong, W. and S. C. Brooks (2006). "Determination of the Formation Constants of Ternary Complexes of Uranyl and Carbonate with Alkaline Earth Metals $\left(\mathrm{Mg}^{2+}, \mathrm{Ca}^{2+}, \mathrm{Sr}^{2+}\right.$, and $\left.\mathrm{Ba}^{2+}\right)$ Using Anion Exchange Method." Environmental Science \& Technology 40(15): 4689-4695.

Drever, J. I. (1997). The Geochemistry of Natural Waters. Upper Saddle River, Prentice Hall.

Duff, M. C. (1996). "Uranium (VI) adsorption on goethite and soil in carbonate solutions." Soil Science Society of America Journal 60(5): 1393-1400.

Eddebbarh, A. A., G. A. Zyvoloski, et al. (2003). "The saturated zone at Yucca Mountain: an overview of the characterization and assessment of the saturated zone as a barrier to potential radionuclide migration." Journal of Contaminant Hydrology 62-63(0): 477-493.

Efurd, D. W., W. Runde, et al. (1998). "Neptunium and plutonium solubilities in a Yucca Mountain groundwater." Environmental Science and Technology 32(24): 3893-3900.

Francis, A. J. (1998). "Biotransformation of uranium and other actinides in radioactive wastes." Journal of Alloys and Compounds 271-273(0): 78-84.

Froideval, A., M. Del Nero, et al. (2003). "pH dependence of uranyl retention in a quartz/solution system: An XPS study." Journal of Colloid and Interface Science 266(2): 221-235.

Guillaumont, R., Fanghanel, T, Neck, V, Fuger, J, Palmer, D.A., Grenthe, I, Rand, M.H. (2003). Chemical Thermodynamics 5, Update on the Chemical Thermodynamics of Uranium, Neptunium, Plutonium, Americium and Technetium. Amsterdam, Elsevier.

Helios Rybicka, E., W. Calmano, et al. (1995). "Heavy metals sorption/desorption on competing clay minerals; an experimental study." Applied Clay Science 9(5): $369-381$. 
Hincapie, B. O., L. J. Garces, et al. (2004). "Synthesis of mordenite nanocrystals." Microporous and Mesoporous Materials 67(1): 19-26.

Ho, C. H. and N. H. Miller (1986). "Adsorption of Uranyl Species from Bicarbonate Solution onto Hematite Particles." J Colloid Interface Sci 110(1): 165.

Hsi, C. K. D. and D. Langmuir (1985). "Adsorption Of Uranyl Onto Ferric Oxyhydroxides - Application Of The Surface Complexation Site-Binding Model." Geochimica et Cosmochimica Acta 49(9): 1931.

Hull, L. C., C. Grossman, et al. (2004). "Hybrid empirical - Theoretical approach to modeling uranium adsorption." Applied Geochemistry 19(5): 721.

Humphrey, A. R. (2001). Sorftware Management Report for ReLap Version 2.0, Los Alamos National Laboratory: 650.

Jerden, J. L. and A. J. Kropf (2007). Surface complexation of neptunium(V) with goethite. MATERIALS RESEARCH SOCIETY SYMPOSIUM PROCEEDINGS, 506 KEYSTONE DRIVE, WARRENDALE, PA 150887563 USA, MATERIALS RESEARCH SOCIETY.

Kaszuba, J. P. and W. H. Runde (1999). "The Aqueous Geochemistry of Neptunium: Dynamic Control of Soluble Concentrations with Applications to Nuclear Waste Disposal." Environmental science \& technology 33(24): 4427-4433.

Keller, S. (2004). Site-Scale Saturated Zone Transport, MDL-NBS-HS-000010. Y. M. Project. Las Vegas, NV, Department of Energy: G-20; Figure G-12.

Kim, Y. and R. J. Kirkpatrick (1998). "High-temperature multi-nuclear NMR investigation of analcime." American Mineralogist 83(3-4): 339-347.

Krestou, A., A. Xenidis, et al. (2003). "Mechanism of aqueous uranium (VI) uptake by natural zeolitic tuff." Minerals Engineering 16(12): 1363-1370.

Kuzniatsova, T., Y. Kim, et al. (2007). "Zeta potential measurements of zeolite Y: Application in homogeneous deposition of particle coatings." Microporous and Mesoporous Materials 103(1-3): 102-107.

Langmuir, D. (1997). Aqueous Environmental Geochemistry. Upper Saddle River, N.J., Prentice Hall, c1997.

Langmuir, D. (1997). Aqueous environmental geochemistry. Upper Saddle River, N.J., Prentice Hall, c1997. 
Lenhart, J. J. and B. D. Honeyman (1999). "Uranium(VI) sorption to hematite in the presence of humic acid." Geochimica et Cosmochimica Acta 63(19-20): 2891.

Lichtner, G. E. H. a. P. C. (2010). "Field-Scale Model for the Natural Attenuation of Uranium at the Handord 300 Area using High Performance Computing." Water Resoruces Research Submitted for Publication.

Liu, C., Z. Shi, et al. (2009). "Kinetics of Uranium(VI) Desorption from Contaminated Sediments: Effect of Geochemical Conditions and Model Evaluation." Environmental Science \& Technology 43(17): 6560-6566.

Liu, C., J. M. Zachara, et al. (2008). "Scale-dependent desorption of uranium from contaminated subsurface sediments." Water Resour. Res. 44.

Lomenech, C., E. Simoni, et al. (2003). "Sorption of uranium (VI) species on zircon: Structural investigation of the solid/solution interface." Journal of Colloid and Interface Science 261(2): 221-232.

Malvern Instruments, L. (2008). Zetasizer Nano User's Manual. England, Malvern Instruments, Ltd.

Meleshyn, A., M. Azeroual, et al. (2009). "Influence of (Calciumâ^')Uranylâ^’'Carbonate Complexation on U(VI) Sorption on Ca- and Na-Bentonites." Environmental science \& technology 43(13): 4896-4901.

Miller, C. T. and J. A. Pedit (1992). "Use of a Reactive Surface-Diffusion Model to Describe Apparent Sorption-Desorption Hysteresis and Abiotic Degradation of Lindane in a Subsurface Material." Environmental Science and Technology 26(7): 1417-1427.

Nitsche, H. (1993). "Radionuclide solubility and speciation studies for the Yucca Mountain site characterization project." LBL: 20-23.

Ogard, A. E. and J. F. Kerrisk (1984). Groundwater chemistry along flow paths between a proposed repository site and the accessible environment. L. A. N. Laboratory. Los Alamos, Los Alamos National Laboratory: 48.

Orgard, A. E. and J. F. Kerrisk (1984). Groundwater chemistry along flow paths between a proposed repository site and the accessible environment. L. A. N. Laboratory. Los Alamos, Los Alamos National Laboratory: 48. 
Qafoku, N. P., J. M. Zachara, et al. (2005). "Kinetic Desorption and Sorption of U(VI) during Reactive Transport in a Contaminated Hanford Sediment." Environmental Science \&amp; Technology 39(9): 3157-3165.

Reich, T., T. Y. Reich, et al. (2007). "Application of XAFS spectroscopy to actinide environmental science." Aip Conference Proceedings 882: 179-183.

Reimus, P. W., M. Ding, et al. (2005). OSTI 3rd Quarter Progress Report for FY 2005: Improved Characterization of Radionuclide Retardation in Volcanics and Alluvium. Los Alamos, New Mexico, Los Alamos National Lab: 5.

Relyea, J. F. (1982). "Theoretical and Experimental Considerations for the use of the Column Method for Determining Retardation Factors." Radioactive Waste Management 3(2): 151-166.

Rogers, P. S. Z. and A. Meijer (1993). Dependence of radionuclide sorption on sample grinding, surface area, and water composition.

Schlegel, M. L. and M. Descostes (2009). "Uranium Uptake by Hectorite and Montmorillonite: A Solution Chemistry and Polarized EXAFS Study." Environmental science \& technology 43(22): 8593-8598.

Schweich, D. and M. Sardin (1981). "Adsorption, Partition, Ion Exchange and Chemical Reaction in Batch Reactors or in Column--A Review." J Hydrol 50(1-3): 1.

Scism (Dean), C. D. (2005). The Sorption/desorption behavior of uranium in transport studies using Yucca Mountain alluvium Department of Chemical Engineering. Albuquerque, New Mexico, University of New Mexico. Master of Science: 96.

Scism (Dean), C. D., P. W. Reimus, et al. (2006). "Uranium and neptunium desorption from yucca mountain alluvium." Proceedings of the 11th International High Level Radioactive Waste Management Conference, IHLRWM: 89-96.

Stammose, D., J. Ly, et al. (1992). "Sorption mechanisms of three actinides on a clayey mineral." Applied Clay Science 7(1-3): 225-238.

Stewart, C. L., L. J. Reimann, et al. (2000). Mineralogic considerations for uranium in-situ leach mining: A Preliminary study of uranium and associated mineralogy of roll-front uranium deposits in Wyoming and Nebraska. 30th 
Annual Hydrometallurgical Conference; September 9-15, 2000; Saskatoon, Canada, Saskatoon, Canada

Canadian Institute of Mining, Metallurgy and Petroleum.

Sylwester, E. R., E. A. Hudson, et al. (2000). "The structure of uranium (VI) sorption complexes on silica, alumina, and montmorillonite." Geochimica et Cosmochimica Acta 64(14): 2431-2438.

Thompson, H. A., G. A. Parks, et al. (1994). Spectroscopic studies of U(VI) sorption at the kaolinite-water interface. Final report. Other Information: PBD: 1 Jun 1994: Medium: P; Size: 125 p.

Toride, F. J. L., ad M. Th. van Genuchten (1999). The CXTFIT Code for Estimating Transport Parameters from Laboratory or Field Tracer Experiements. Research Report. U. S. S. Laboratory. Riverside, CA, Agricultural Research Service: 138.

Triay, I. R., Meijer, Arend, Conca, James L., Kung, K.S., Rundberg, R.S., Strietelmeier, E.A., Tait, C.D., Clark, D.L., Neu, M.P., Hobart, D.E. (1997). Summary and synthesis report on radionuclide retardation for the Yucca Mountain Site Characterization Project : Yucca Mountain Site Characterization Program R. C. Eckhardt. Los Alamos, Los Alamos National Laboratory.

Triay, I. R., B. A. Robinson, et al. (1993). Neptunium retardation with tuffs and groundwaters from Yucca Mountain. Proceedings of the 4th Annual International Conference on High Level Radioactive Waste Management; Apr 26-30 1993; Las Vegas, NV, USA, New York, NY, USA : Publ by ASCE, 1993.

Triay, I. R. F., A C; Weaver, S C; Chipera, S J; Bish, D L (1996). Comparison of neptunium sorption results using batch and column techniques. LA - Los Alamos Scientific Laboratory, Report. L.-L. A. S. Laboratory. Los Alamos, Los Alamos National Lab: pp., 23.

Viswanathan, H. S., B. A. Robinson, et al. (1998). "Reactive transport model of neptunium migration from the potential repository at Yucca Mountain." Journal of Hydrology 209(1-4): 251-280.

Waite, T. D., J. A. Davis, et al. (1994). "Uranium(VI) Adsorption to Ferrihydrite Application of a Surface Complexation Model." Geochimica et Cosmochimica Acta 58(24): 5465. 
Walter, M., T. Arnold, et al. (2005). "An EXAFS and TRLFS investigation on uranium(VI) sorption to pristine and leached albite surfaces." Journal of Colloid and Interface Science 282(2): 293-305.

Wu, Y.-S., M. Ye, et al. (2009). "Fracture-Flow-Enhanced Matrix Diffusion in Solute Transport Through Fractured Porous Media." Transport in Porous Media 81(1): 21-34.

Yabusaki, S., Y. Fang, et al. (2007). "Uranium removal from groundwater via $<$ i $>$ in situ</i> biostimulation: Field-scale modeling of transport and biological processes." Journal of Contaminant Hydrology 93(1-4): 216-235.

Yabusaki, S. B., Y. Fang, and S. R. Waichler (2008). "Building conceptual models of field-scale uranium reactive transport in a dynamic vadose zone-aquifer-river system." Water Resour. Res. 44: W12403.

Yakowitz, H., R. L. Myklebust, et al. (1973). FRAME: An on-line correction procedure for quantitative electron probe microanalysis. USA: 46.

Zhang, M. and et al. (2003). "Oxidation state of uranium in metamict and annealedÂ zircon: near-infrared spectroscopic quantitativeÂ analysis." Journal of Physics: Condensed Matter 15(20): 3445.

Zyvoloski, G. A. (1997). "Summary of the models and methods for the FEHM application; a finite-element heat- and mass-transfer code." $\underline{\mathrm{L} \text { A. }}$ 


\section{APPENDIX 1-PHREEQC Output-uranium speciation in J-13 groundwater}

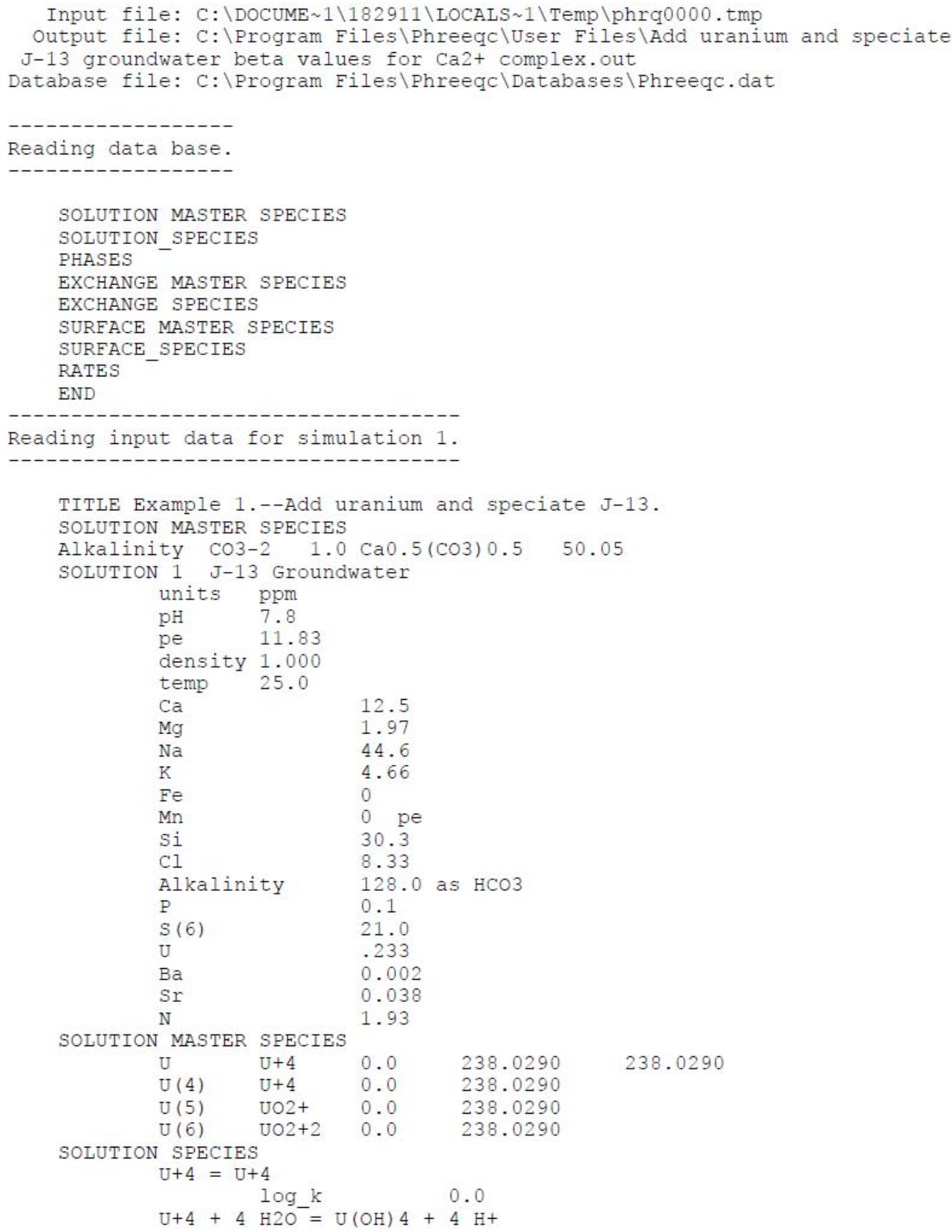




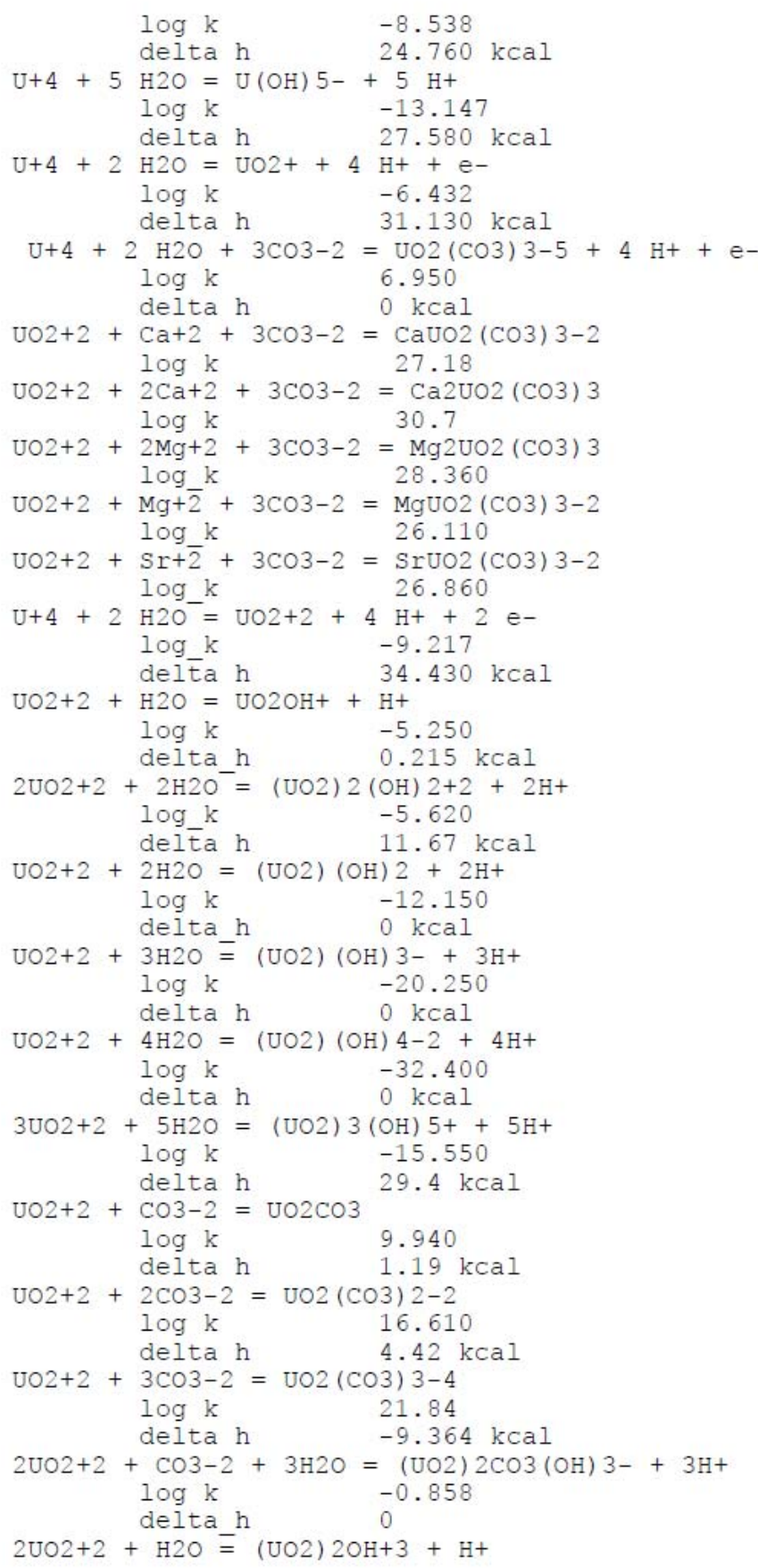




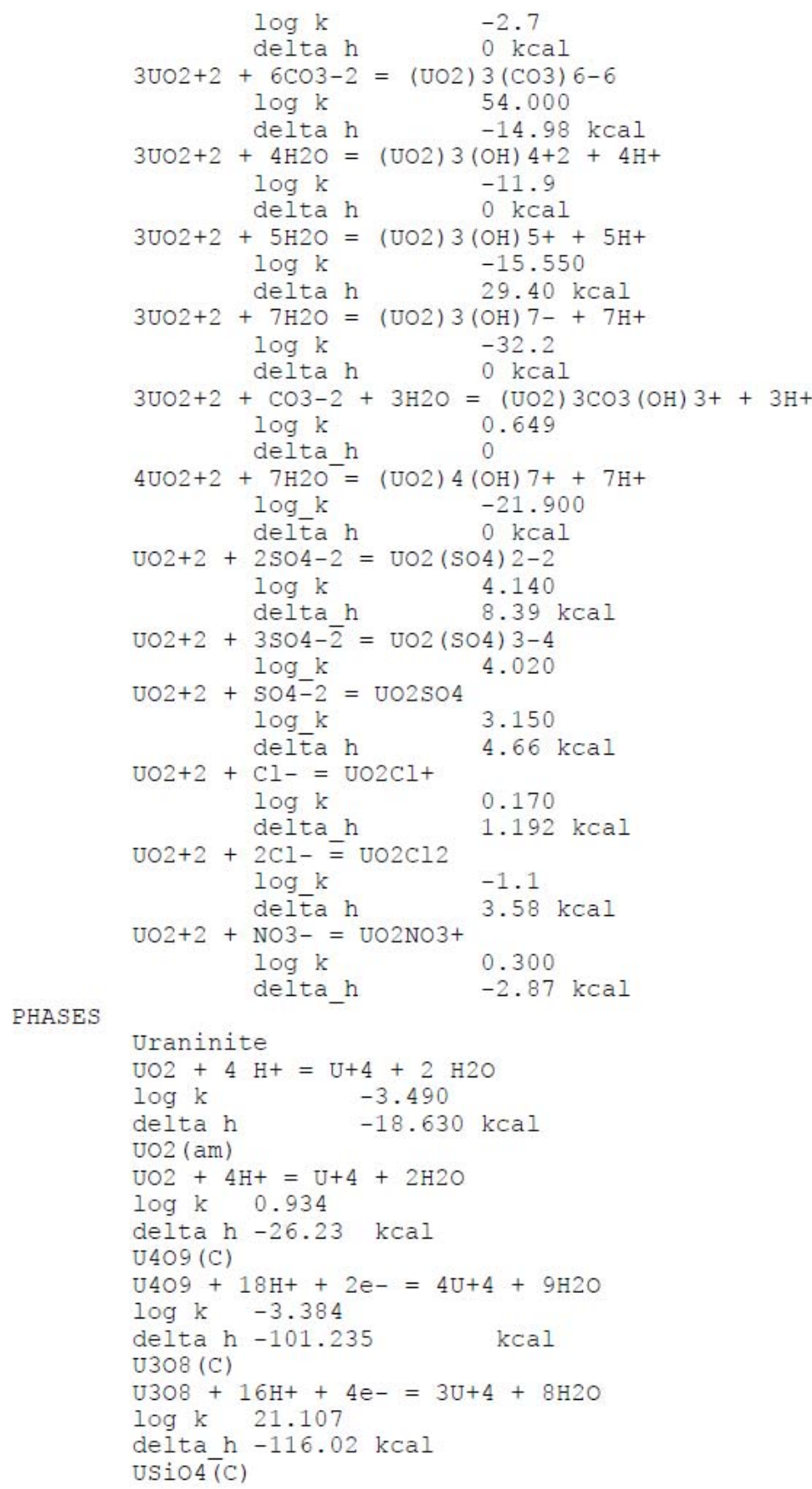




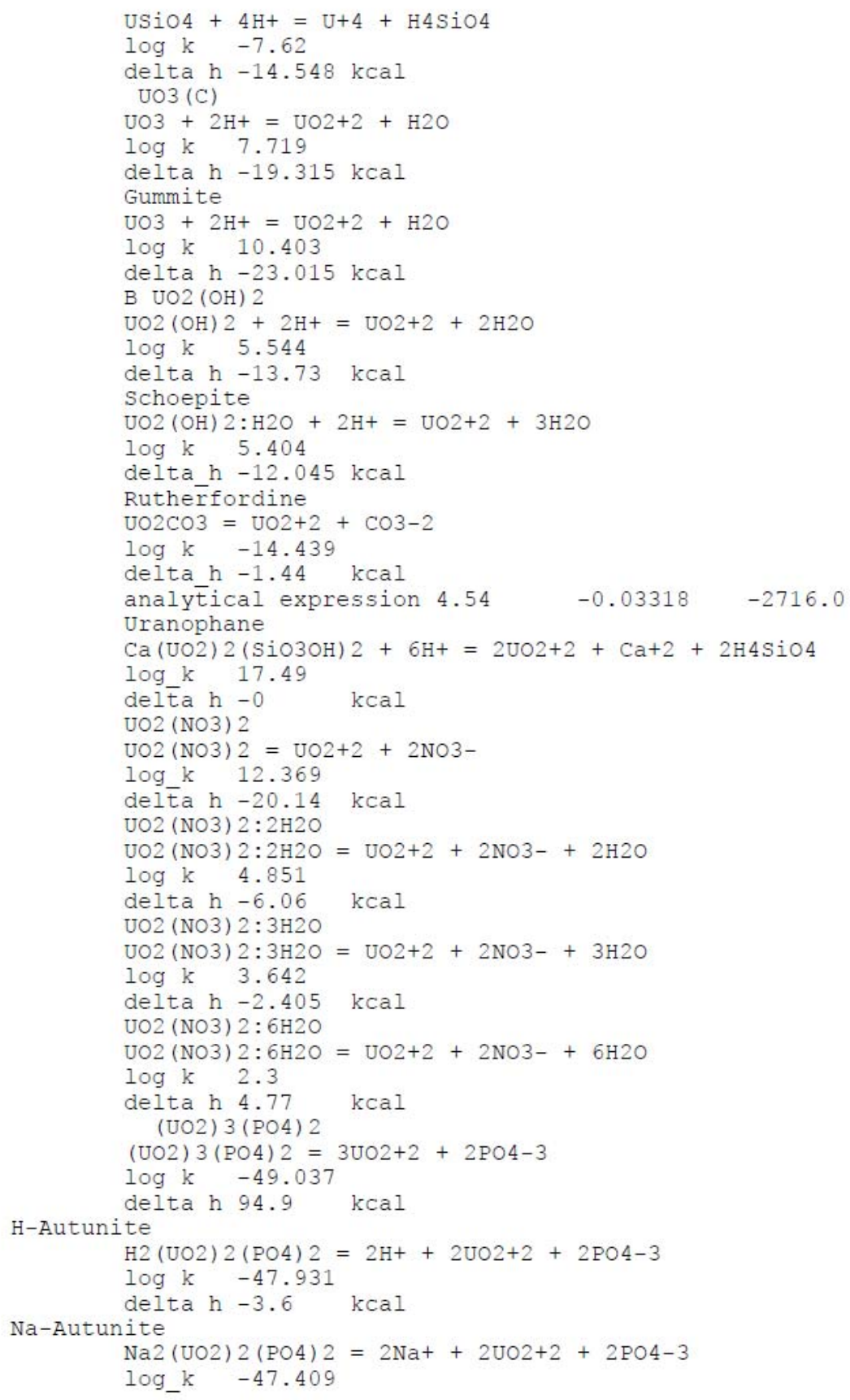




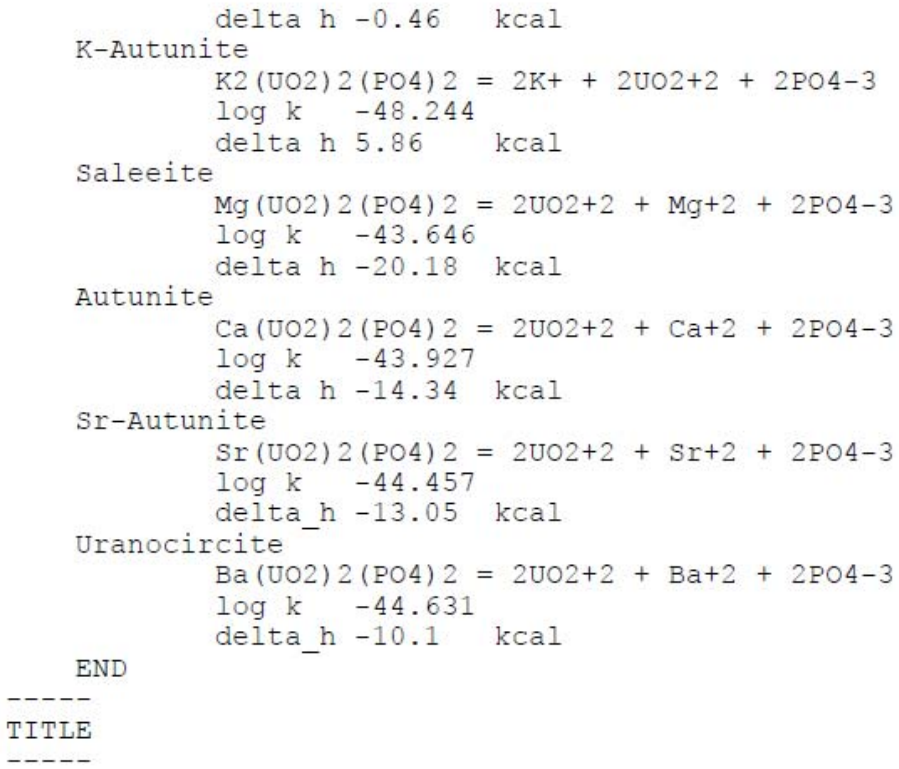




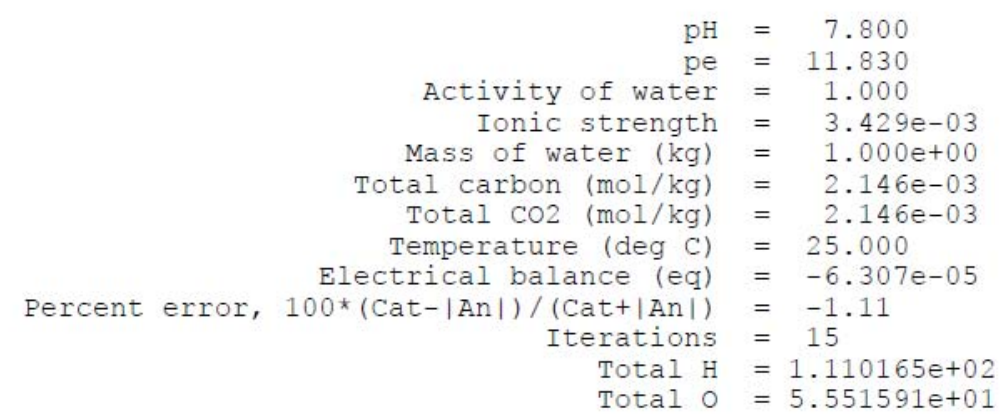

\begin{tabular}{|c|c|c|c|c|c|c|}
\hline & & & & $\log$ & $\log$ & Lo \\
\hline & Species & Molality & Activity & Molality & Activity & Gam \\
\hline $\mathrm{ma}$ & & & & & & \\
\hline 28 & $\mathrm{OH}-$ & $6.736 e-07$ & $6.316 e-07$ & -6.172 & -6.200 & -0.0 \\
\hline 25 & $\mathrm{H}+$ & $1.680 \mathrm{e}-08$ & $1.585 e-08$ & -7.775 & -7.800 & -0.0 \\
\hline 00 & $\mathrm{H} 2 \mathrm{O}$ & $5.551 e+01$ & $9.999 e-01$ & 1.744 & -0.000 & 0.0 \\
\hline $\mathrm{Ba}$ & & $1.457 e-08$ & & & & \\
\hline 09 & $\mathrm{Ba}+2$ & $1.348 e-08$ & $1.049 e-08$ & -7.870 & -7.979 & -0.1 \\
\hline 00 & BaSO4 & $8.475 e-10$ & $8.482 e-10$ & -9.072 & -9.072 & 0.0 \\
\hline 28 & $\mathrm{BaHCO} 3+$ & $2.069 e-10$ & $1.942 e-10$ & -9.684 & -9.712 & -0.0 \\
\hline 00 & $\mathrm{BaCO} 3$ & $3.094 e-11$ & $3.096 e-11$ & -10.509 & -10.509 & 0.0 \\
\hline 28 & $\mathrm{BaOH}+$ & $2.390 e-14$ & $2.243 e-14$ & -13.622 & -13.649 & -0.0 \\
\hline C $(4$ & & $2.146 e-03$ & & & & \\
\hline 27 & $\mathrm{HCO} 3-$ & $2.054 e-03$ & $1.930 e-03$ & -2.687 & -2.714 & -0.0 \\
\hline 00 & $\mathrm{CO} 2$ & $6.874 e-05$ & $6.880 e-05$ & -4.163 & -4.162 & 0.0 \\
\hline 08 & $\mathrm{CO} 3-2$ & $7.326 e-06$ & $5.712 e-06$ & -5.135 & -5.243 & -0.1 \\
\hline 27 & $\mathrm{CaHCO} 3+$ & $6.022 e-06$ & $5.659 e-06$ & -5.220 & -5.247 & -0.0 \\
\hline 00 & $\mathrm{CaCO} 3$ & $2.203 e-06$ & $2.205 e-06$ & -5.657 & -5.657 & 0.0 \\
\hline 00 & $\mathrm{NaHCO} 3$ & $1.972 e-06$ & $1.974 e-06$ & -5.705 & -5.705 & 0.0 \\
\hline 28 & $\mathrm{MgHCO} 3+$ & $1.446 e-06$ & $1.357 e-06$ & -5.840 & -5.867 & -0.0 \\
\hline
\end{tabular}




\begin{tabular}{|c|c|c|c|c|c|c|}
\hline & CaUO2 $(\mathrm{CO} 3) 3-2$ & $5.841 e-07$ & $4.528 e-07$ & -6.234 & -6.344 & -0.1 \\
\hline & $\mathrm{Ca} 2 \mathrm{UO} 2(\mathrm{CO} 3)_{3}$ & $3.442 e-07$ & $3.445 e-07$ & -6.463 & -6.463 & 0.0 \\
\hline & $\mathrm{MgCO} 3$ & $3.272 e-07$ & $3.274 e-07$ & -6.485 & -6.485 & 0.0 \\
\hline & $\mathrm{NaCO} 3-$ & $2.061 e-07$ & $1.934 \mathrm{e}-07$ & -6.686 & -6.714 & -0.0 \\
\hline & UO2 $(\mathrm{CO} 3) 3-4$ & $2.495 e-08$ & $9.008 e-09$ & -7.603 & -8.045 & -0.4 \\
\hline & MgUO2 $(\mathrm{CO} 3) 3-2$ & $1.300 \mathrm{e}-08$ & $1.008 e-08$ & -7.886 & -7.997 & -0.1 \\
\hline & UO2 $(\mathrm{CO} 3)_{2} 2-2$ & $1.198 \mathrm{e}-08$ & $9.286 e-09$ & -7.922 & -8.032 & -0.1 \\
\hline & $\mathrm{SrHCO} 3+$ & $1.010 e-08$ & $9.490 e-09$ & -7.996 & -8.023 & -0.0 \\
\hline & $\operatorname{SrCO} 3$ & $1.171 \mathrm{e}-09$ & $1.172 e-09$ & -8.931 & -8.931 & 0.0 \\
\hline & SrUO2 $(\mathrm{CO} 3)$ 3-2 & $3.911 e-10$ & $3.031 e-10$ & -9.408 & -9.518 & -0.1 \\
\hline & $\mathrm{UO} 2 \mathrm{CO} 3$ & $3.473 e-10$ & $3.475 e-10$ & -9.459 & -9.459 & 0.0 \\
\hline & $\mathrm{BaHCO} 3+$ & $2.069 e-10$ & $1.942 e-10$ & -9.684 & -9.712 & -0.0 \\
\hline & $\mathrm{Mg} 2 \mathrm{UO} 2(\mathrm{CO} 3) 3$ & $1.075 e-10$ & $1.076 e-10$ & -9.968 & -9.968 & 0.0 \\
\hline & $\mathrm{BaCO} 3$ & $3.094 e-11$ & $3.096 e-11$ & -10.509 & -10.509 & 0.0 \\
\hline & $(\mathrm{UO} 2) 2 \mathrm{CO} 3(\mathrm{OH}) 3-$ & $1.034 \mathrm{e}-11$ & $9.707 e-12$ & -10.985 & -11.013 & -0.0 \\
\hline & $(\mathrm{UO} 2)^{\prime} 3(\mathrm{CO} 3) 6-6$ & $1.172 \mathrm{e}-19$ & $1.184 \mathrm{e}-20$ & -18.931 & -19.927 & -0.9 \\
\hline & $(\mathrm{UO} 2) 3 \mathrm{CO} 3(\mathrm{OH}) 3+$ & $2.322 e-24$ & $2.179 e-24$ & -23.634 & -23.662 & -0.0 \\
\hline & UO2 $\left(\mathrm{CO}_{3}\right) 3-5$ & $1.390 \mathrm{e}-25$ & $2.829 e-26$ & -24.857 & -25.548 & -0.6 \\
\hline & $\mathrm{Ca}+2$ & $2.948 e-04$ & $2.298 e-04$ & -3.530 & -3.639 & -0.1 \\
\hline & $\mathrm{CaSO} 4$ & $7.388 e-06$ & $7.394 e-06$ & -5.131 & -5.131 & 0.0 \\
\hline & $\mathrm{CaHCO}_{3}+$ & $6.022 e-06$ & $5.659 e-06$ & -5.220 & -5.247 & -0.0 \\
\hline & $\mathrm{CaCO} 3$ & $2.203 e-06$ & $2.205 e-06$ & -5.657 & -5.657 & 0.0 \\
\hline & CaUO2 $(\mathrm{CO} 3)^{3-2}$ & $5.841 e-07$ & $4.528 e-07$ & -6.234 & -6.344 & -0.1 \\
\hline & $\mathrm{Ca} 2 \mathrm{UO} 2(\mathrm{CO} 3) 3$ & $3.442 e-07$ & $3.445 e-07$ & -6.463 & -6.463 & 0.0 \\
\hline & $\mathrm{CaHPO} 4$ & $2.301 e-07$ & $2.303 e-07$ & -6.638 & -6.638 & 0.0 \\
\hline & $\mathrm{CaPO} 4-$ & $3.664 e-08$ & $3.438 e-08$ & -7.436 & -7.464 & -0.0 \\
\hline & $\mathrm{CaH} 2 \mathrm{PO} 4+$ & $2.924 e-09$ & $2.744 \mathrm{e}-09$ & -8.534 & -8.562 & -0.0 \\
\hline
\end{tabular}




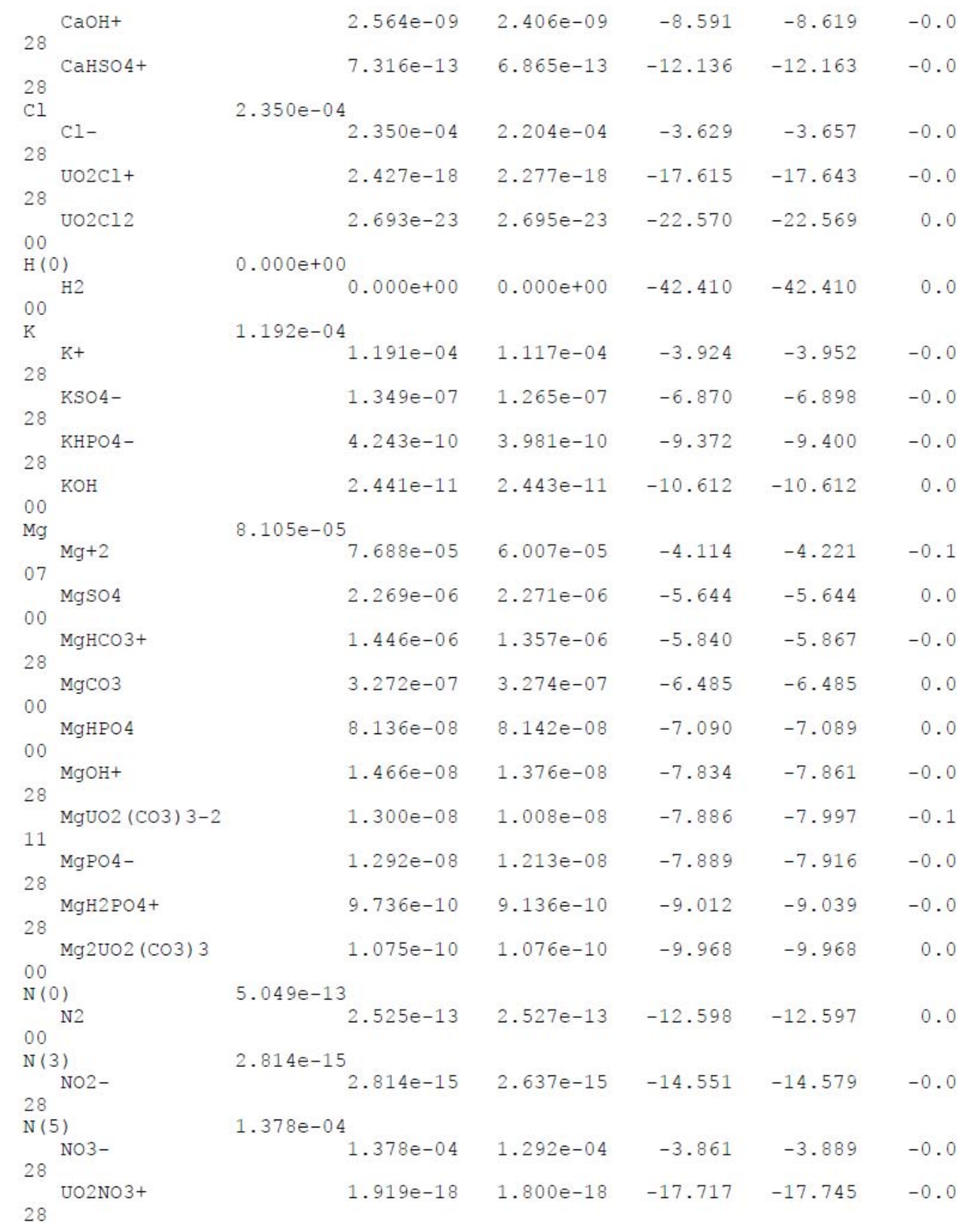




\begin{tabular}{|c|c|c|c|c|c|c|}
\hline $\mathrm{Na}$ & & $1.940 e-03$ & & & & \\
\hline 27 & $\mathrm{Na}+$ & $1.937 e-03$ & $1.818 e-03$ & -2.713 & -2.740 & -0.0 \\
\hline 0 & $\mathrm{NaHCO} 3$ & $1.972 \mathrm{e}-06$ & $1.974 \mathrm{e}-06$ & -5.705 & -5.705 & 0.0 \\
\hline 8 & $\mathrm{NaSO} 4-$ & $1.566 \mathrm{e}-06$ & $1.470 \mathrm{e}-06$ & -5.805 & -5.833 & -0.0 \\
\hline 8 & $\mathrm{NaCO} 3-$ & $2.061 e-07$ & $1.934 e-07$ & -6.686 & -6.714 & -0.0 \\
\hline 8 & $\mathrm{NaHPO} 4-$ & $6.908 e-09$ & $6.482 e-09$ & -8.161 & -8.188 & -0.0 \\
\hline & $\mathrm{NaOH}$ & $7.573 e-10$ & $7.579 e-10$ & -9.121 & -9.120 & 0.0 \\
\hline 010 & & $5.503 e-08$ & & & & \\
\hline & $\mathrm{O} 2$ & $2.752 e-08$ & $2.754 e-08$ & -7.560 & -7.560 & 0.0 \\
\hline . & & $3.229 e-06$ & & & & \\
\hline 1 & $\mathrm{HPO} 4-2$ & $2.360 e-06$ & $1.828 e-06$ & -5.627 & -5.738 & -0.1 \\
\hline 7 & $\mathrm{H} 2 \mathrm{PO} 4-$ & $4.972 e-07$ & $4.668 e-07$ & -6.303 & -6.331 & -0.0 \\
\hline 0 & CaHPO4 & $2.301 e-07$ & $2.303 e-07$ & -6.638 & -6.638 & 0.0 \\
\hline 0 & $\mathrm{MgHPO} 4$ & $8.136 e-08$ & $8.142 e-08$ & -7.090 & -7.089 & 0.0 \\
\hline 28 & $\mathrm{CaPO} 4-$ & $3.664 e-08$ & $3.438 e-08$ & -7.436 & -7.464 & -0.0 \\
\hline 28 & $\mathrm{MgPO} 4-$ & $1.292 \mathrm{e}-08$ & $1.213 e-08$ & -7.889 & -7.916 & -0.0 \\
\hline 28 & NaHPO4- & $6.908 e-09$ & $6.482 e-09$ & -8.161 & -8.188 & -0.0 \\
\hline 28 & $\mathrm{CaH} 2 \mathrm{PO} 4+$ & $2.924 e-09$ & $2.744 e-09$ & -8.534 & -8.562 & -0.0 \\
\hline 28 & $\mathrm{MgH} 2 \mathrm{PO} 4+$ & $9.736 \mathrm{e}-10$ & $9.136 e-10$ & -9.012 & -9.039 & -0.0 \\
\hline 28 & KHPO4- & $4.243 e-10$ & $3.981 e-10$ & -9.372 & -9.400 & -0.0 \\
\hline 49 & $\mathrm{PO} 4-3$ & $9.233 e-11$ & $5.201 e-11$ & -10.035 & -10.284 & -0.2 \\
\hline $\begin{array}{l}S(6 \\
09\end{array}$ & 5) $\mathrm{SO}-2$ & $\begin{array}{r}2.187 e-04 \\
2.073 e-04\end{array}$ & $1.613 e-04$ & -3.683 & -3.792 & -0.1 \\
\hline 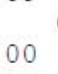 & CaSO4 & $7.388 e-06$ & $7.394 e-06$ & -5.131 & -5.131 & 0.0 \\
\hline 0 & $\mathrm{MgSO} 4$ & $2.269 e-06$ & $2.271 e-06$ & -5.644 & -5.644 & 0.0 \\
\hline 28 & $\mathrm{NaSO} 4-$ & $1.566 \mathrm{e}-06$ & $1.470 \mathrm{e}-06$ & -5.805 & -5.833 & -0.0 \\
\hline 28 & $\mathrm{KSO} 4-$ & $1.349 e-07$ & $1.265 e-07$ & -6.870 & -6.898 & -0.0 \\
\hline 00 & $\mathrm{SrSO} 4$ & $1.010 e-08$ & $1.011 e-08$ & -7.996 & -7.995 & 0.0 \\
\hline & BaSO4 & $8.475 e-10$ & $8.482 e-10$ & -9.072 & -9.072 & 0.0 \\
\hline & HSO 4- & $2.649 e-10$ & $2.485 e-10$ & -9.577 & -9.605 & -0.0 \\
\hline
\end{tabular}




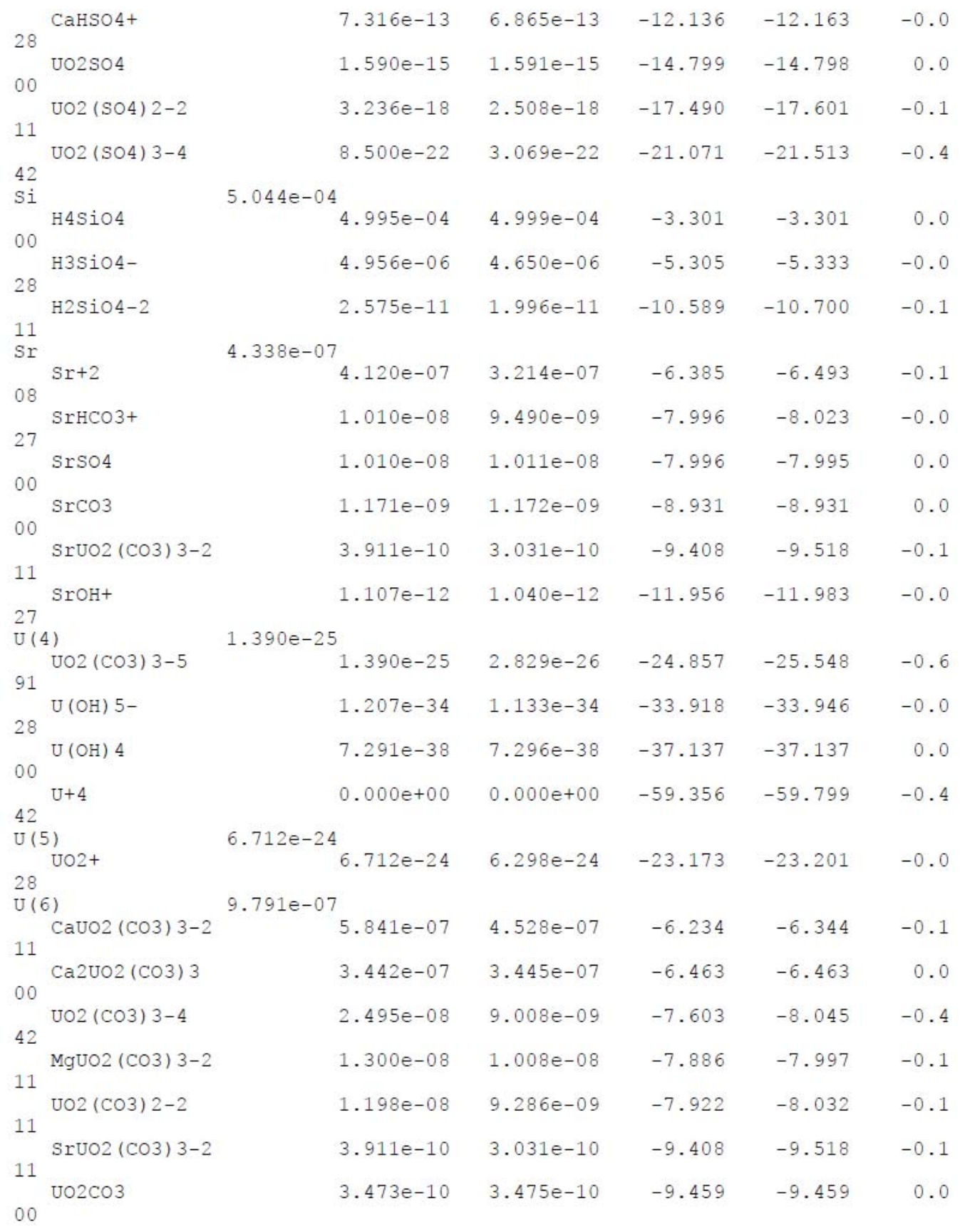




\begin{tabular}{|c|c|c|c|c|c|}
\hline $\mathrm{Mg} 2 \mathrm{UO} 2(\mathrm{CO} 3) 3$ & $1.075 \mathrm{e}-10$ & $1.076 \mathrm{e}-10$ & -9.968 & -9.968 & 0.0 \\
\hline$(\mathrm{UO} 2)(\mathrm{OH}) 2$ & $1.967 e-11$ & $1.968 e-11$ & -10.706 & -10.706 & 0.0 \\
\hline$(\mathrm{UO} 2)(\mathrm{OH}) 3-$ & $1.051 \mathrm{e}-11$ & $9.864 e-12$ & -10.978 & -11.006 & -0.0 \\
\hline$(\mathrm{UO} 2) 2 \mathrm{CO} 3(\mathrm{OH}) 3-$ & $1.034 \mathrm{e}-11$ & $9.707 e-12$ & -10.985 & -11.013 & -0.0 \\
\hline $\mathrm{UO} 2 \mathrm{OH}+$ & $2.641 e-12$ & $2.478 e-12$ & -11.578 & -11.606 & -0.0 \\
\hline $\mathrm{UO} 2+2$ & $9.011 e-15$ & $6.985 e-15$ & -14.045 & -14.156 & -0.1 \\
\hline $\mathrm{UO} 2 \mathrm{SO} 4$ & $1.590 \mathrm{e}-15$ & $1.591 e-15$ & -14.799 & -14.798 & 0.0 \\
\hline$(\mathrm{UO} 2)(\mathrm{OH}) 4-2$ & $5.684 e-16$ & $4.406 e-16$ & -15.245 & -15.356 & -0.1 \\
\hline UO2 ( $\mathrm{SO} 4$ ) 2-2 & $3.236 e-18$ & $2.508 e-18$ & -17.490 & -17.601 & -0.1 \\
\hline $\mathrm{UO} 2 \mathrm{Cl}+$ & $2.427 e-18$ & $2.277 e-18$ & -17.615 & $-17 \cdot 643$ & -0.0 \\
\hline UO2NO3+ & $1.919 e-18$ & $1.800 e-18$ & -17.717 & -17.745 & -0.0 \\
\hline$(\mathrm{UO} 2) 2(\mathrm{OH}) 2+2$ & $6.010 e-19$ & $4.659 e-19$ & -18.221 & $-18 \cdot 332$ & -0.1 \\
\hline$(\mathrm{UO} 2) 3(\mathrm{CO} 3) 6-6$ & $1.172 \mathrm{e}-19$ & $1.184 \mathrm{e}-20$ & -18.931 & -19.927 & -0.9 \\
\hline$(\mathrm{UO} 2) 3(\mathrm{OH}) 5+$ & $1.023 e-19$ & $9.602 e-20$ & -18.990 & -19.018 & -0.0 \\
\hline$(\mathrm{UO} 2) 3(\mathrm{OH}) 7-$ & $9.119 e-21$ & $8.556 e-21$ & -20.040 & -20.068 & -0.0 \\
\hline UO2 ( $\mathrm{SO} 4)$ 3-4 & $8.500 e-22$ & $3.069 e-22$ & -21.071 & -21.513 & -0.4 \\
\hline $\mathrm{UO} 2 \mathrm{Cl} 2$ & $2.693 e-23$ & $2.695 e-23$ & -22.570 & -22.569 & 0.0 \\
\hline (UO2) $20 \mathrm{H}+3$ & $1.089 e-23$ & $6.143 e-24$ & -22.963 & -23.212 & -0.2 \\
\hline$(\mathrm{UO} 2) 3(\mathrm{OH}) 4+2$ & $8.770 e-24$ & $6.799 e-24$ & -23.057 & -23.168 & -0.1 \\
\hline$(\mathrm{UO} 2) 3 \mathrm{CO} 3(\mathrm{OH}) 3+$ & $2.322 e-24$ & $2.179 e-24$ & -23.634 & -23.662 & -0.0 \\
\hline$(\mathrm{UO} 2) 4(\mathrm{OH}) 7+$ & $1.271 e-24$ & $1.193 e-24$ & -23.896 & -23.924 & -0.0 \\
\hline
\end{tabular}

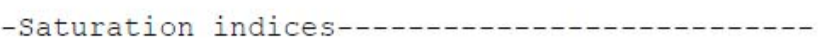

$\begin{array}{lrrrl}\text { Phase } & \text { SI log IAP } & \log \mathrm{KT} & \\ & & & & \\ \text { (UO2) 3(PO4)2 } & -14.00 & -63.04 & -49.04 & \text { (UO2) 3(PO4) 2 } \\ \text { Anhydrite } & -3.07 & -7.43 & -4.36 & \text { CaSO4 } \\ \text { Aragonite } & -0.55 & -8.88 & -8.34 & \mathrm{CaCO} 3 \\ \text { Autunite } & -8.59 & -52.52 & -43.93 & \mathrm{Ca}(\mathrm{UO} 2) 2(\mathrm{PO} 4) 2 \\ \text { B UO2(OH) } 2 & -4.10 & 1.44 & 5.54 & \mathrm{UO2}(\mathrm{OH}) 2 \\ \text { Barite } & -1.80 & -11.77 & -9.97 & \mathrm{BaSO4} \\ \text { Calcite } & -0.40 & -8.88 & -8.48 & \mathrm{CaCO3}\end{array}$




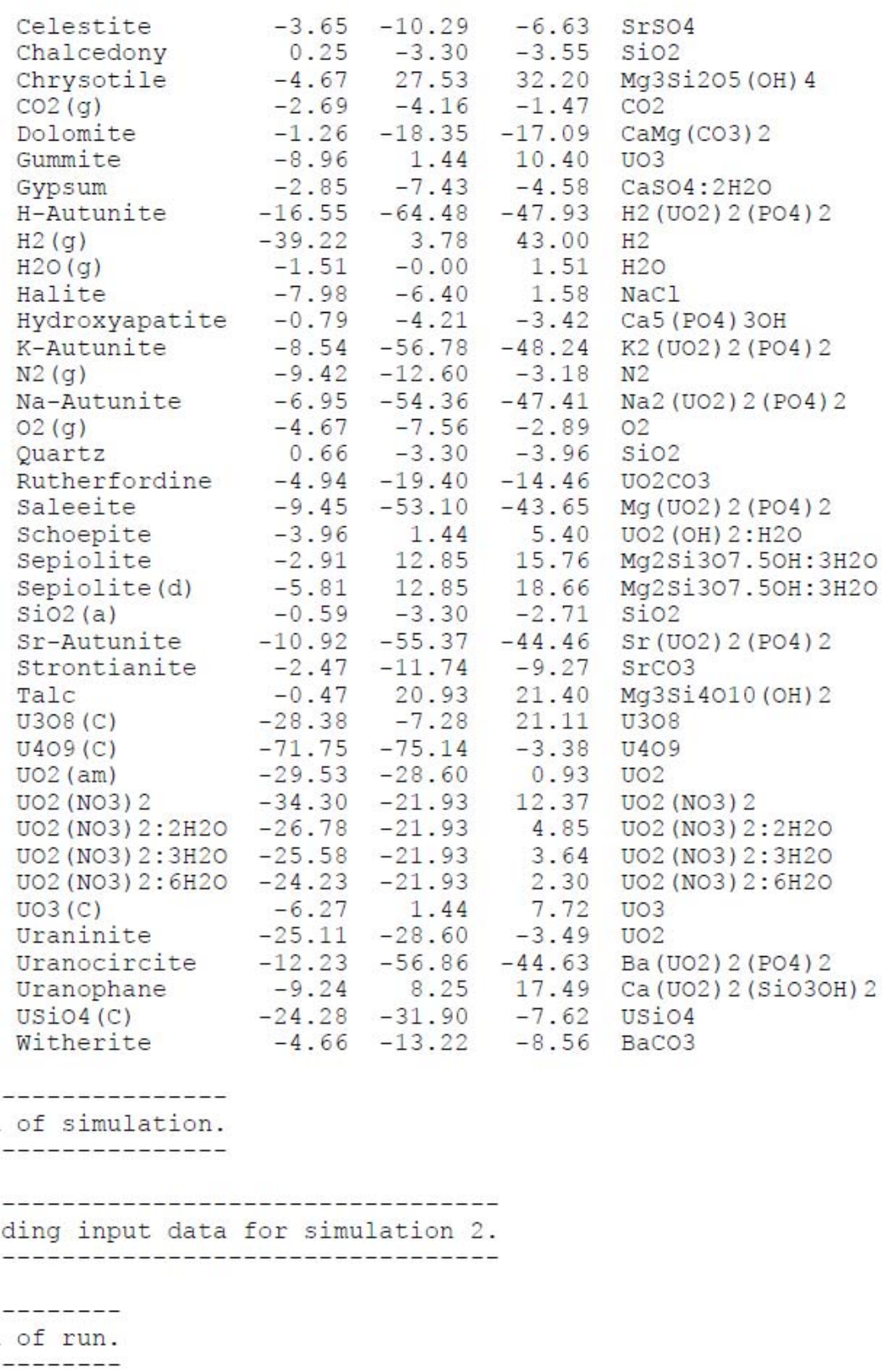




\title{
APPENDIX 2A-BET Surface Area Measurements-Bedded Prow Pass (SMF \#01006006)
}

\author{
Quantachrome Corporation \\ Page 1 \\ NOVA 1200 , Version 7.01 \\ High Speed Gas Sorption Analyzer \\ Summary Analysis Report \\ Data File $\quad=$ N9b0401.dat \\ User ID \\ $=\mathrm{CAD}$ \\ Sample ID \\ Sample Cell Number $=2$ \\ $=00106006$ \\ Analysis Setup = Setup_02.dat \\ Comments : \\ Degas at $200 \mathrm{c}$ for $3 \mathrm{c} 3 \mathrm{hr}$ no heat overn \\ Sample weight $=1.2006 \mathrm{~g}$ \\ Sample Density $=\mathrm{N} / \mathrm{A}$ \\ Sample Volume \\ Sample Volume \\ $=0.4709 \mathrm{~mL}$ \\ Po Type \\ = CALCULATED \\ PO \\ $=$ MEASURED \\ Adsorbate Name $=$ Nitrogen \\ Bath Temperature \\ $=600.47 \mathrm{~mm} \mathrm{Hg}$ \\ ADSORPTION SETUP \\ Tolerance $=0.10 \mathrm{~mm} \mathrm{Hg}$ \\ Equil Time $=60 \mathrm{sec}$ \\ Dwell Time $=180 \mathrm{sec}$ \\ DESORPTION SETUP \\ Tolerance $=0.10 \mathrm{~mm} \mathrm{Hg}$ \\ Equil Time $=60 \mathrm{sec}$ \\ Analysis Started : Wed Nov 04 08:23:17 2009 \\ Analysis Finished : Wed Nov 04 09:03:16 2009 \\ Elapsed Time \\ : 39.98 Minutes

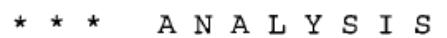 \\ R E S U L T S * * * \\ 6 POINT BET \\ * Specific Surface Area $=2.7201$ sq. $\mathrm{m} / \mathrm{g}$ \\ Slope $\quad=1275.8221$ \\ Intercept $\quad=4.4550$ \\ Correlation Coefficient $=1.0000$ \\ BET C \\ $=287.3780$ \\ SINGLE POINT BET (Point @ 0.1532 P/PO)
}

* Specific Surface Area $=2.6637 \mathrm{sq} \cdot \mathrm{m} / \mathrm{g}$ 

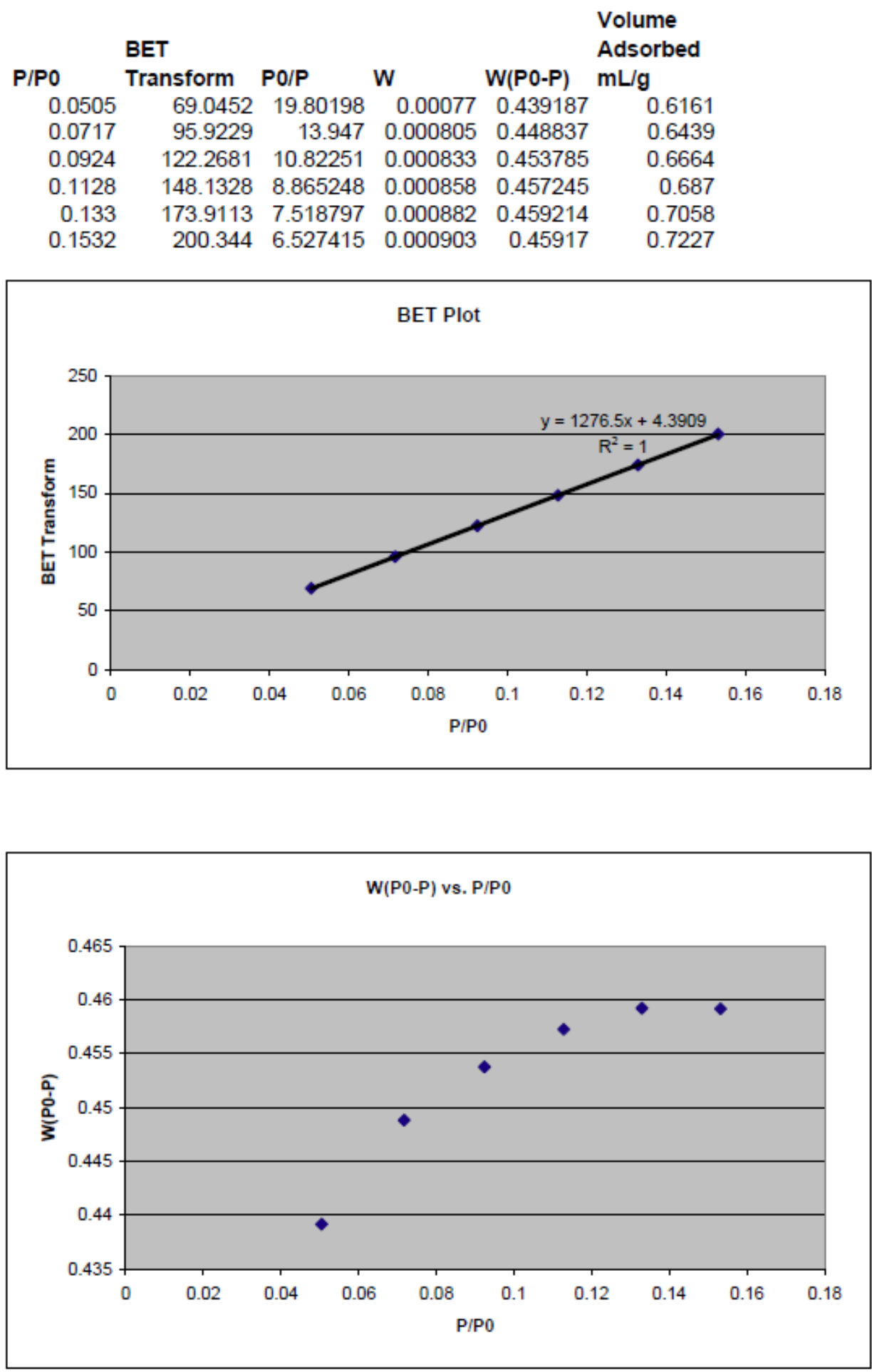


\section{APPENDIX 2B-BET Surface Area Measurements-Lower Bullfrog (SMF \#01006012)}

Quantachrome Corporation
NOVA 1200, Version 7.01
High Speed Gas Sorption Analyzer
Summary Analysis Report

6 POINT BET

* Specific Surface Area = $7.5729 \mathrm{sq} . \mathrm{m} / \mathrm{g}$

Slope $\quad=459.1741$

Intercept $\quad=0.6891$

Correlation Coefficient $=0.9997$

BET C $\quad=667.3644$

SINGLE POINT BET (Point @ 0.0516 P/PO)

* Specific Surface Area $=7.4351 \mathrm{sq} . \mathrm{m} / \mathrm{g}$ 


\begin{tabular}{|c|c|c|c|c|c|}
\hline PO & $\begin{array}{l}\text { BET } \\
\text { Transform }\end{array}$ & P0/P & W & $W(P 0-P)$ & $\begin{array}{l}\text { Volume } \\
\text { Adsorbed } \\
\mathrm{mL} / \mathrm{g}\end{array}$ \\
\hline 0.0001 & 0.4546 & 10000 & 0.00022 & 0.131936 & 0.1102 \\
\hline 0.0198 & 9.9875 & 50.50505 & 0.002023 & 1.189051 & 1.6169 \\
\hline 0.0251 & 12.4296 & 39.84064 & 0.002071 & 1.21118 & 1.6601 \\
\hline & & & & & \\
\hline 0.04 & 4 & 23. & 0.0 & 13 & 1.759 \\
\hline 0.0516 & 24.1676 & 19.37984 & 0.002251 & 1.280584 & 1.8012 \\
\hline
\end{tabular}
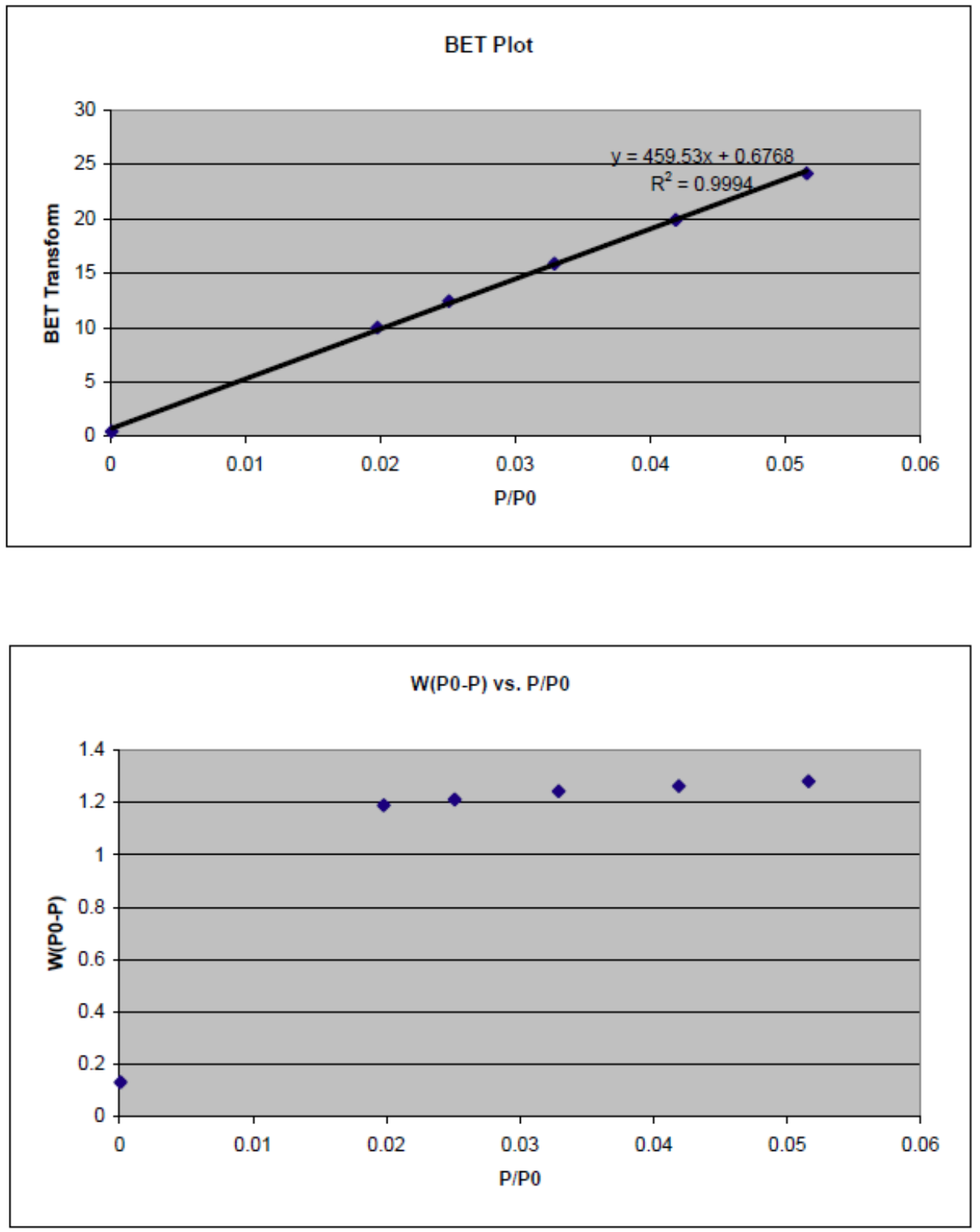


\section{APPENDIX 2C-BET Surface Area Measurements-Central Bullfrog (SMF \#0016536)}

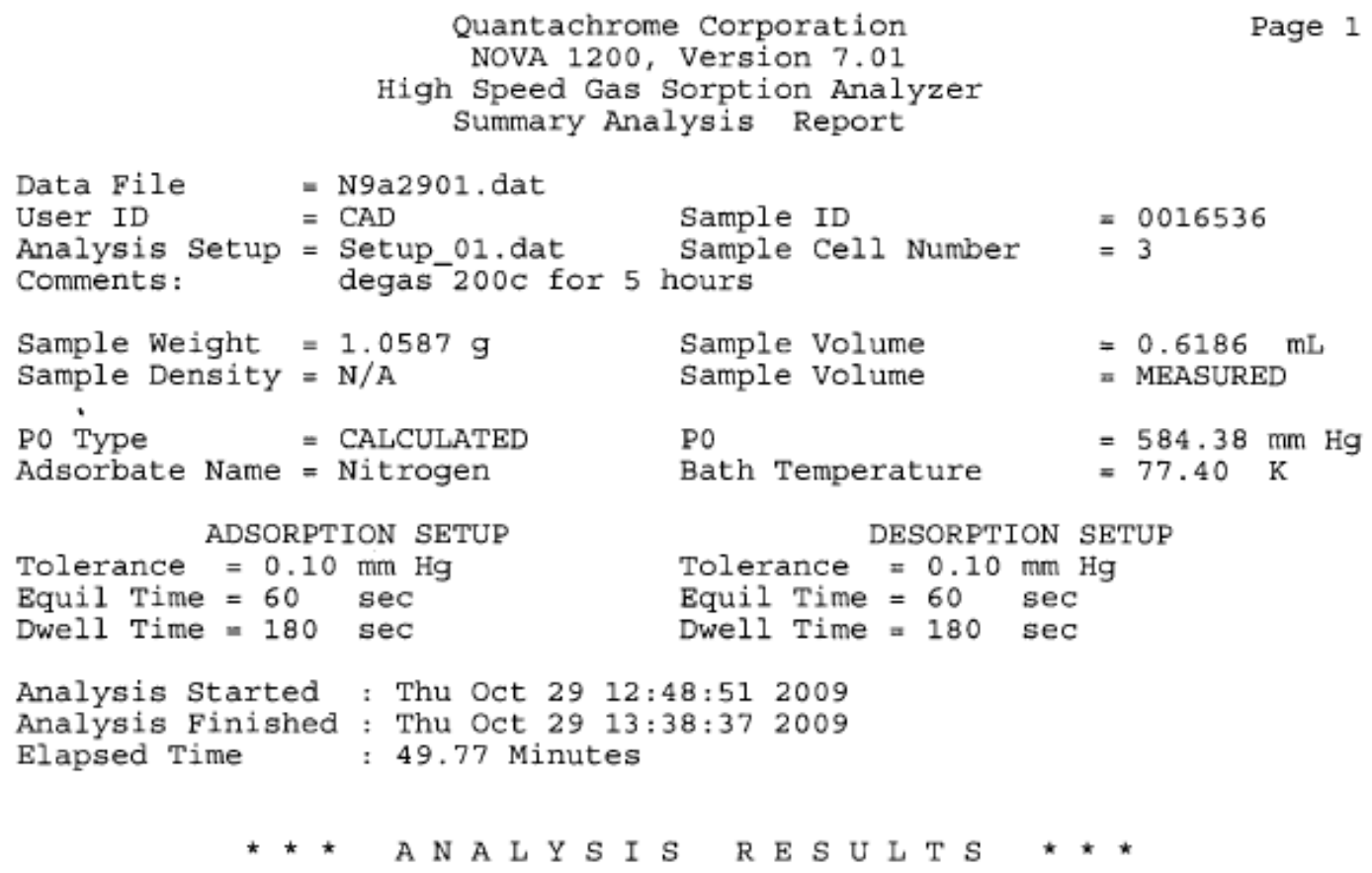

6 POINT BET

* Specific Surface Area $=4.2017$ sq. $\mathrm{m} / \mathrm{g}$

Slope $\quad=825.9802$

Intercept $\quad=2.8567$

Correlation Coefficient $=0.9999$

BET C $\quad=290.1372$

SINGLE POINT BET (Point (\$) 0.2991 P/PO)

* Specific Surface Area $=4.1536 \mathrm{sq} \cdot \mathrm{m} / \mathrm{g}$ 


\begin{tabular}{|c|c|c|c|c|c|c|c|c|}
\hline P/P0 & $\begin{array}{l}\text { BET } \\
\text { Transform }\end{array}$ & $\mathrm{P} 0 / \mathrm{P}$ & W & $W(P 0-P)$ & $\begin{array}{l}\text { Volume } \\
\text { Adsorbed } \\
\mathrm{mL} / \mathrm{g}\end{array}$ & L & $\begin{array}{l}\text { multiplication } \\
\text { factor }\end{array}$ & $N$ \\
\hline 0.108329 & 92.9391791 & 9.231179 & 0.00131 & 0.68114 & 1.04527 & 0.001168 & 1.12 & 0.00131 \\
\hline 0.143101 & 121.076683 & 6.988078 & 0.00138 & 0.69068 & 1.10351 & 0.001233 & 1.12 & 0.00138 \\
\hline 0.180967 & 151.757717 & 5.525877 & 0.00146 & 0.69686 & 1.16454 & 0.001302 & 1.12 & 0.00146 \\
\hline 0.220008 & 183.821689 & 4.545297 & 0.00153 & 0.69942 & 1.22743 & 0.001372 & 1.12 & 0.00153 \\
\hline 0.259663 & 216.988738 & 3.851138 & 0.00162 & 0.69931 & 1.29317 & 0.001445 & 1.12 & 0.00162 \\
\hline 0.299136 & 250.783712 & 3.342964 & 0.00170 & 0.69705 & 1.36161 & 0.001522 & 1.12 & 0.00170 \\
\hline
\end{tabular}
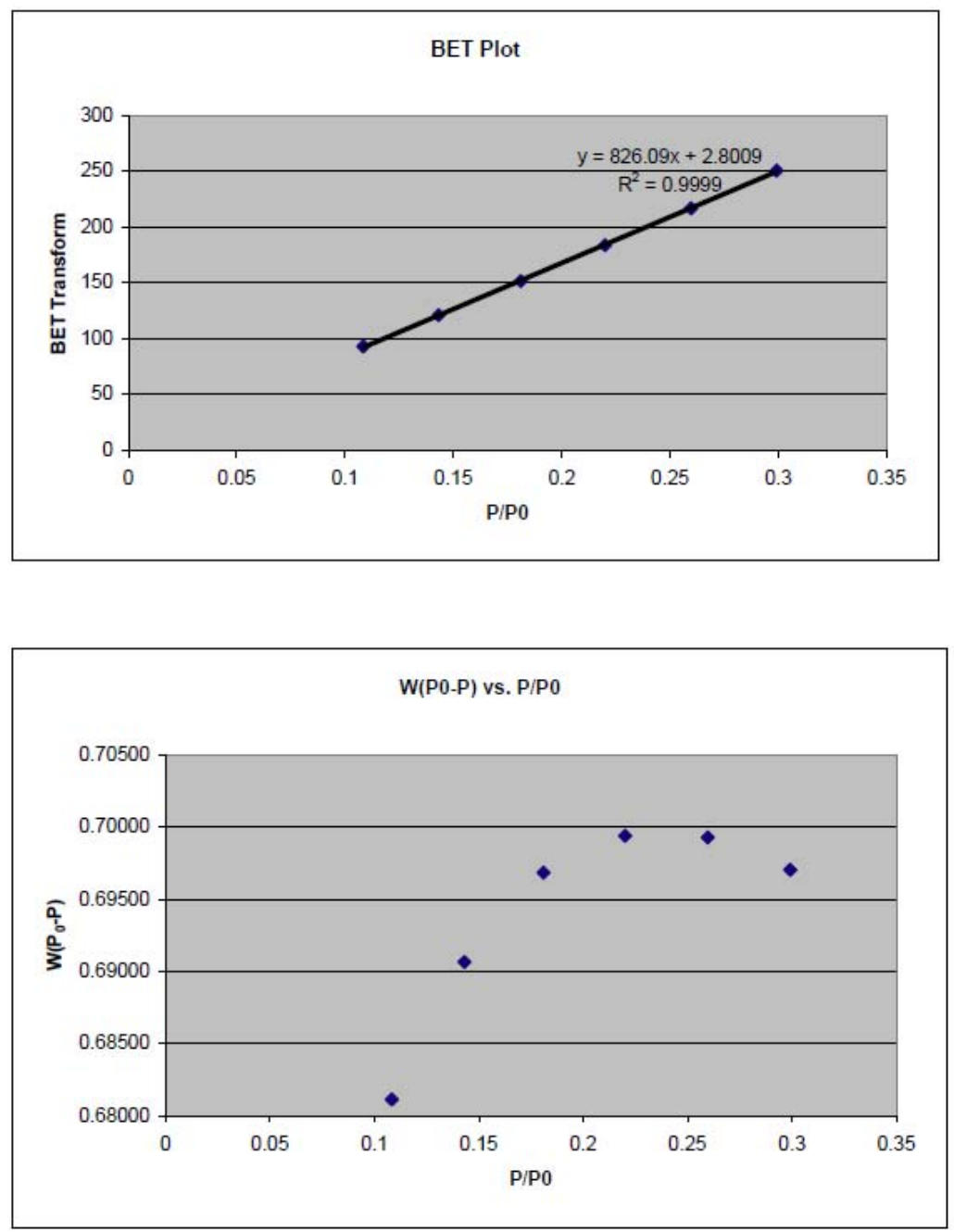


\section{APPENDIX 2D-BET Surface Area Measurements-Upper Prow Pass (SMF \#0047478)}

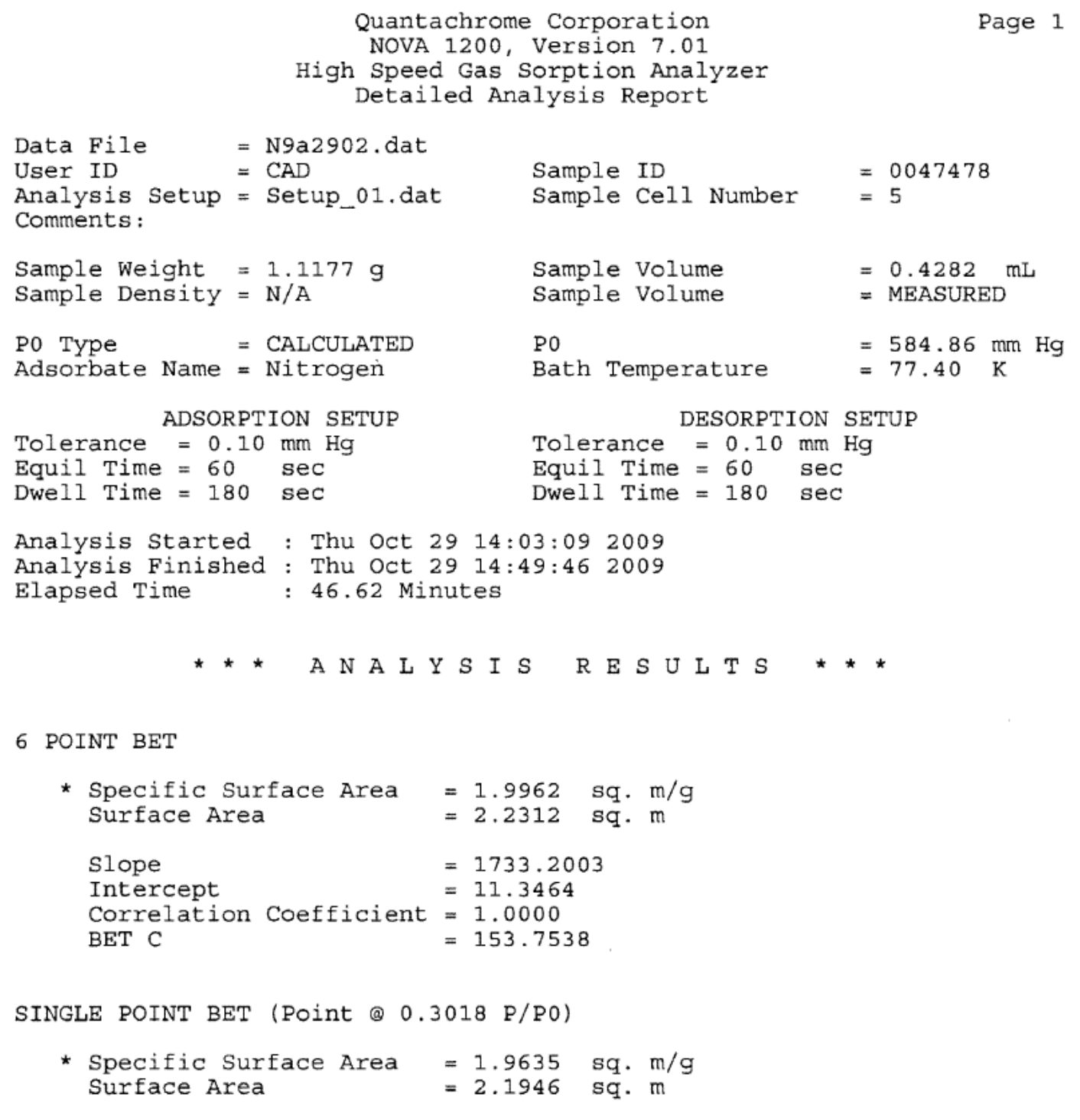



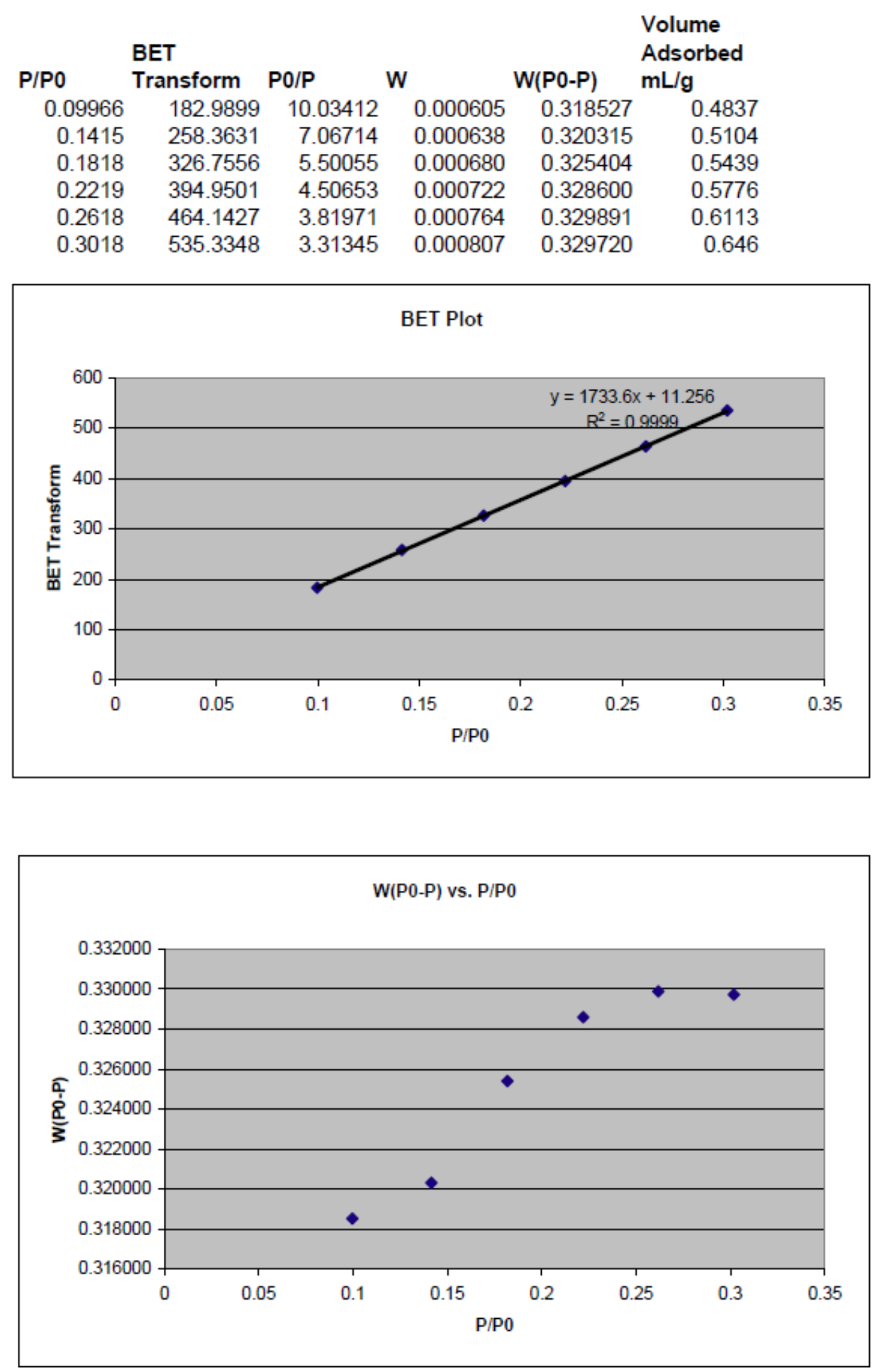


\title{
APPENDIX 3A-QXRD Analysis and XRD Patterns-75-500 $\mu \mathrm{m}$ grain size fraction used in column experiments
}

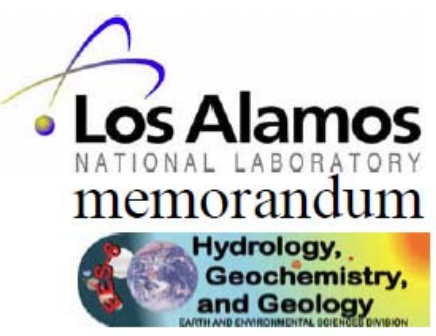

\author{
To/MS: Cynthia Dean, EES-6/J514 \\ From/MS: Hongwu Xu, EES-6/H805 \\ Phone/Fax: 5-9266/5-2676 \\ Date: $6 / 3 / 2008$ \\ Subject: QXRD of Yucca Mountain samples
}

Quantitative XRD Analysis of Yucca Mountain Tuff Samples

1) Experimental methods

Each sample was ground and mixed with corundum powders in a weight ratio sample : $\mathrm{Al}_{2} \mathrm{O}_{3}=$ $80: 20$. XRD measurements were conducted with a Simens D500 theta-theta or theta-two theta diffractometer using $\mathrm{CuK} \alpha$ radiation. Data were collected from 2 to $70^{\circ} 2 \theta$ in step scan mode with steps of $0.02^{\circ}$ and count times of 8 or $12 \mathrm{~s}$ per step. Quantitative phase analyses were performed with the FullPat program.

2) Analysis Results (wt\%)

\begin{tabular}{|c|c|c|c|c|c|}
\hline Sample & $0100-6006$ & $0100-6012$ & $\begin{array}{l}0016-536 \\
-75-500\end{array}$ & $\begin{array}{l}0016-536 \\
\text { Fines }\end{array}$ & $0047-478$ \\
\hline Quartz & 29.5 & 24.1 & 26.2 & 12.4 & 36.0 \\
\hline K-Feldspar & 28.3 & 22.4 & 29.1 & 33.1 & 27.0 \\
\hline Plagioclase & 17.6 & 11.2 & 31.1 & 29.8 & 26.6 \\
\hline Analcime & 19.9 & 12.2 & - & - & - \\
\hline Illite/Mica & 7.2 & 13.0 & 11.2 & 7.1 & 4.6 \\
\hline Mordenite & - & 18.3 & - & - & - \\
\hline Smectite & - & - & 2.2 & 17.8 & - \\
\hline Kaolinite & - & - & - & - & 5.9 \\
\hline Total & 102.5 & 101.2 & 99.8 & 100.2 & 100.1 \\
\hline
\end{tabular}

3) XRD patterns 

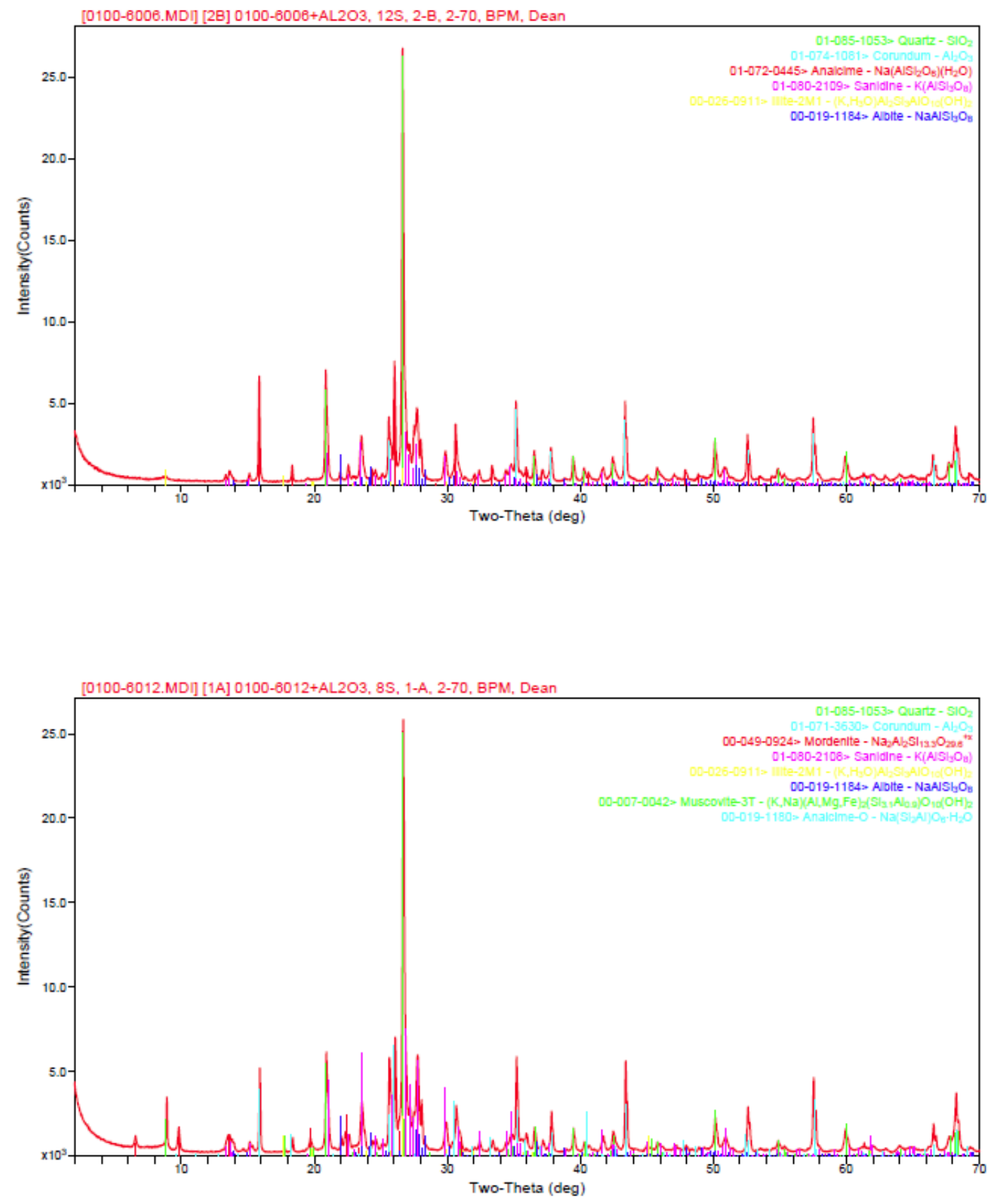

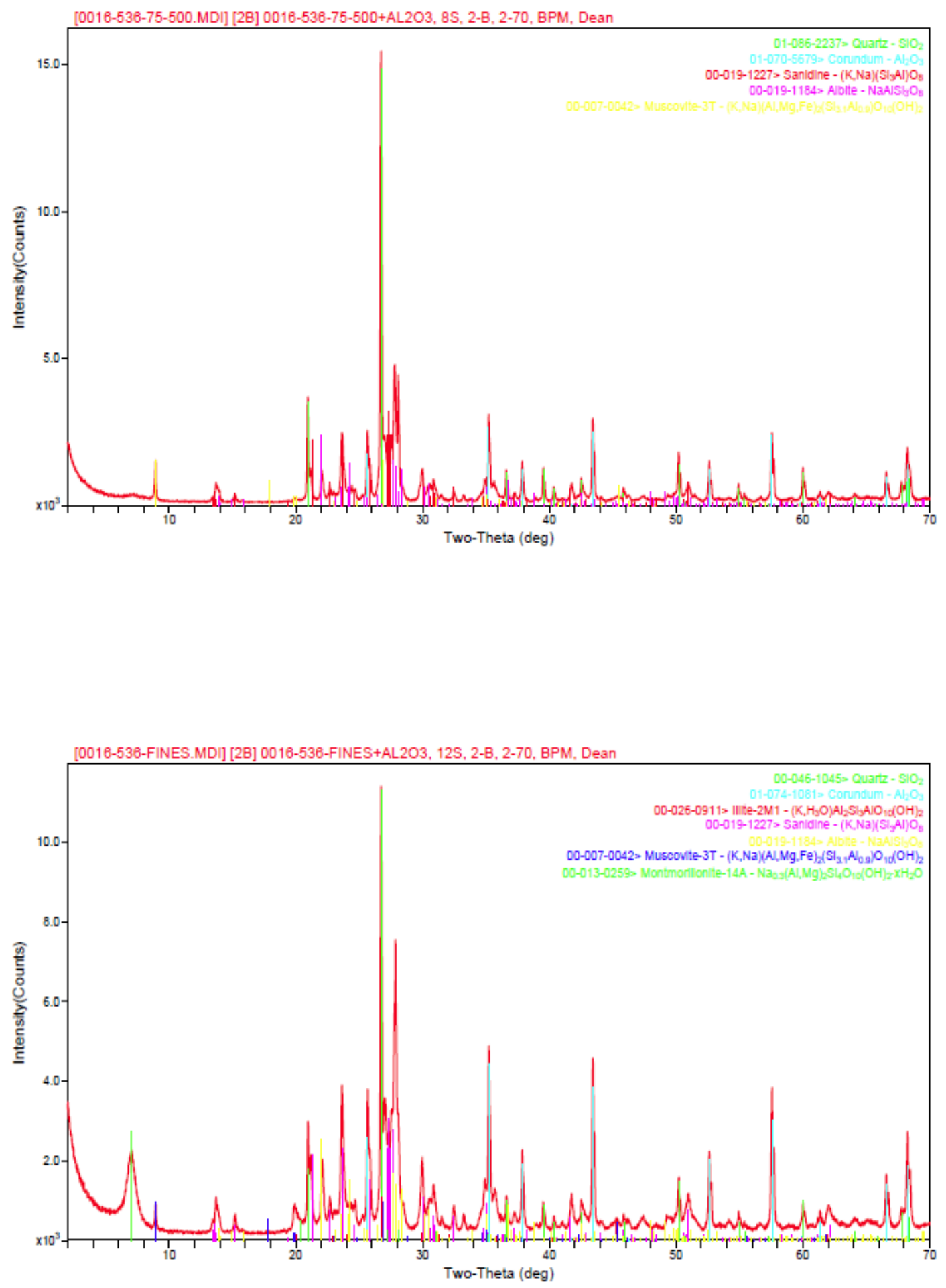


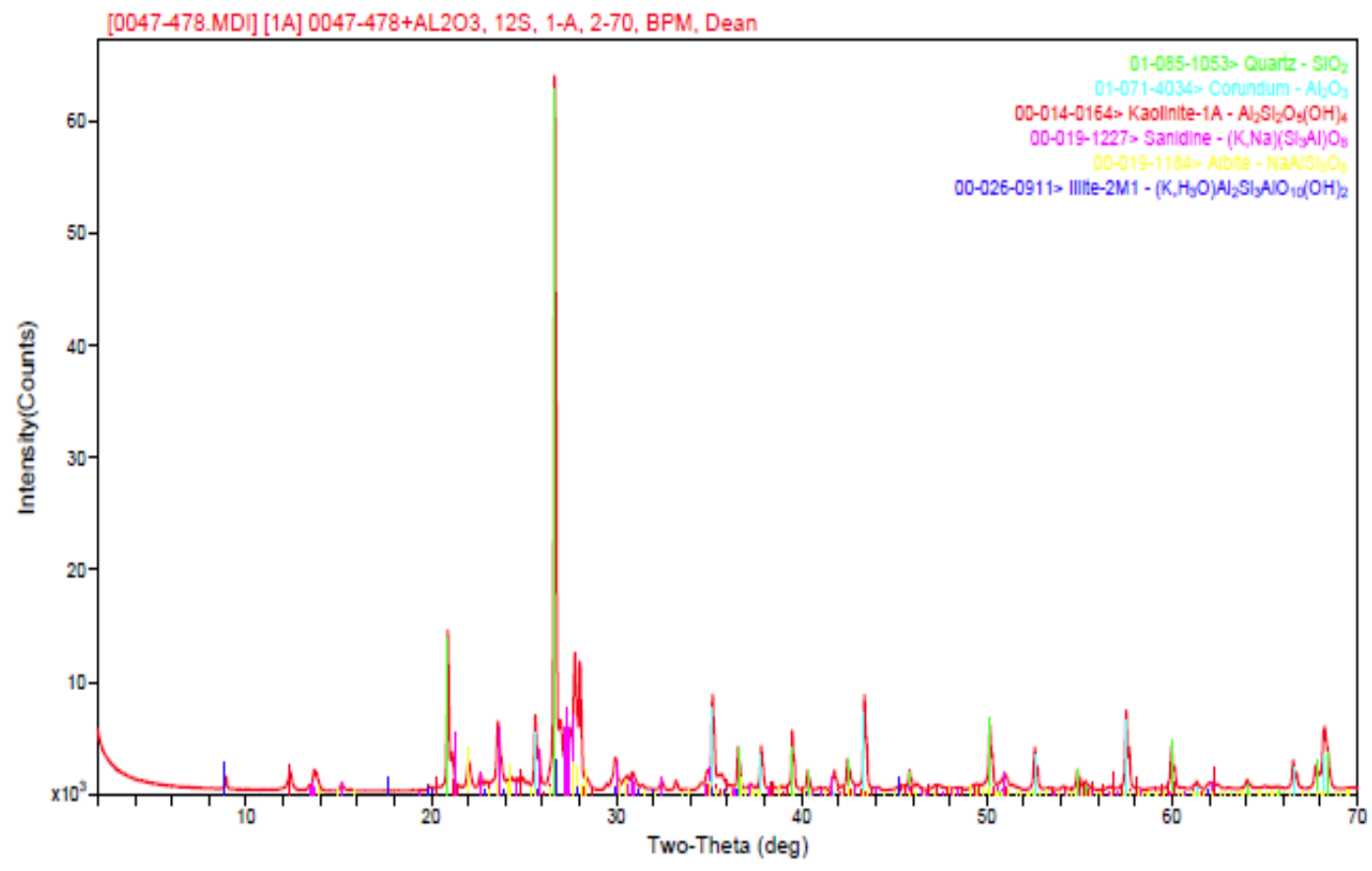




\title{
APPENDIX 3B-QXRD Analysis and XRD Patterns-fine fraction from settling procedure for EXAFS samples
}

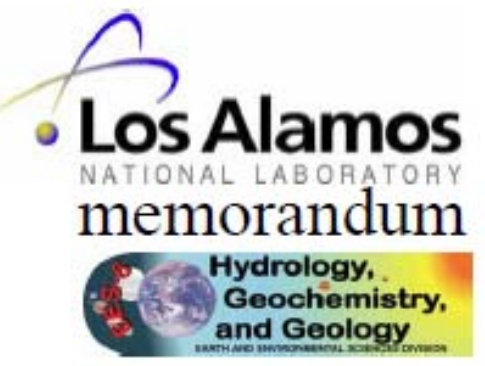

\author{
To/MS: Cynthia Dean, EES-6/J514 \\ From/MS: Hongwu Xu, EES-6/H805 \\ Phone/Fax: $5-9266 / 5-2676$ \\ Date: $7 / 20 / 2008$ \\ Subject: QXRD of Yucca Mountain samples
}

\section{Quantitative XRD Analysis of Yucca Mountain Tuff Samples}

1) Experimental methods

Each sample was ground and mixed with conundum powders in a weight ratio sample : $\mathrm{Al}_{2} \mathrm{O}_{3}=$ $80: 20$. XRD measurements were conducted with a Simens D500 theta-theta or theta-two theta diffractometer using $\mathrm{CuK} \alpha$ radiation. Data were collected from 2 to $70^{\circ} 2 \theta$ in step scan mode with steps of $0.02^{\circ}$ and count times of 8 or $12 \mathrm{~s}$ per step. Quantitative phase analyses were performed with the FullPat program.

2) Analysis Results (wt\%)

\begin{tabular}{lcccc}
\hline Sample & 1006012_matrix & 1006012_black & 16536_matrix & 16536_black \\
\hline & & & & \\
Quartz & 3.3 & 0.8 & 9.5 & 2.2 \\
K-Feldspar & 9.5 & 6.8 & 37.6 & 23.8 \\
Plagioclase & 2.4 & 6.9 & 37.4 & 29.3 \\
Analcime & 1.6 & 1.4 & - & - \\
Illite/Mica & 4.0 & - & 4.7 & - \\
Mordenite & 59.0 & 34.4 & - & - \\
Smectite & 19.5 & 49.4 & 12.6 & 45.4 \\
& & & & \\
\hline
\end{tabular}

3) XRD patterns 
1006012_matrix

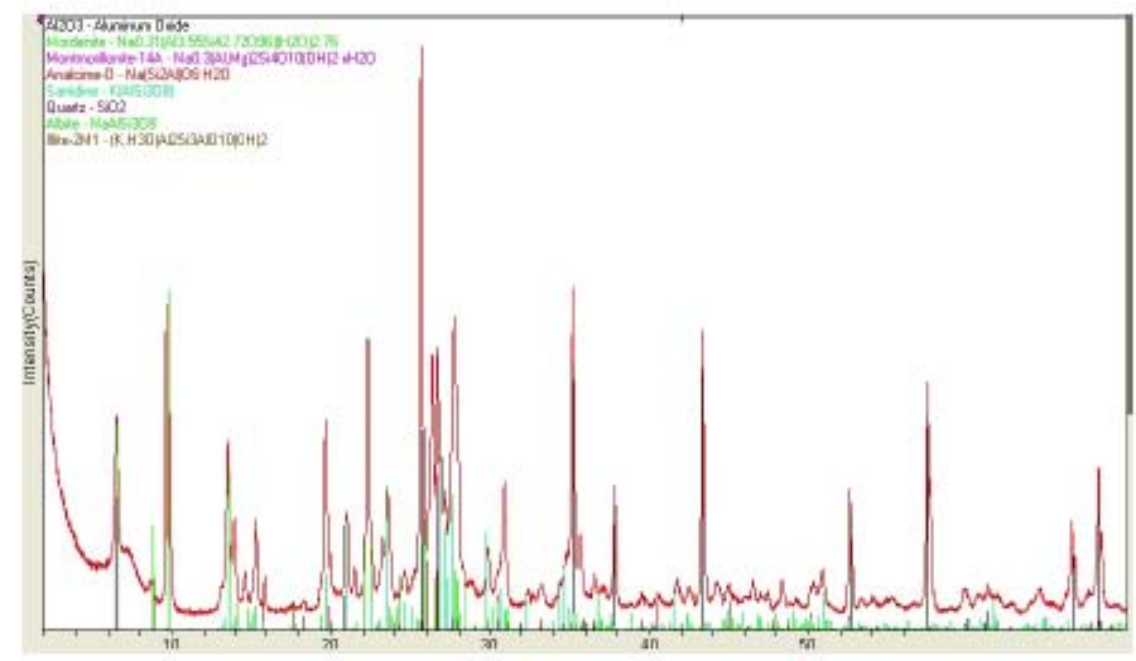

1006012_black

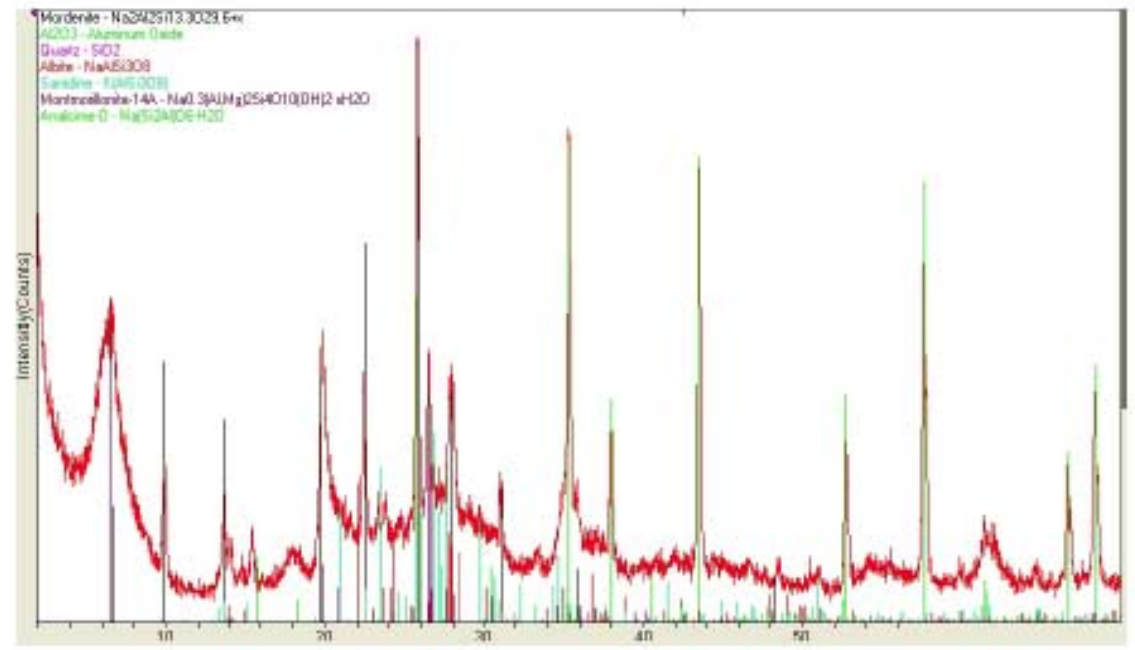


16536_matrix

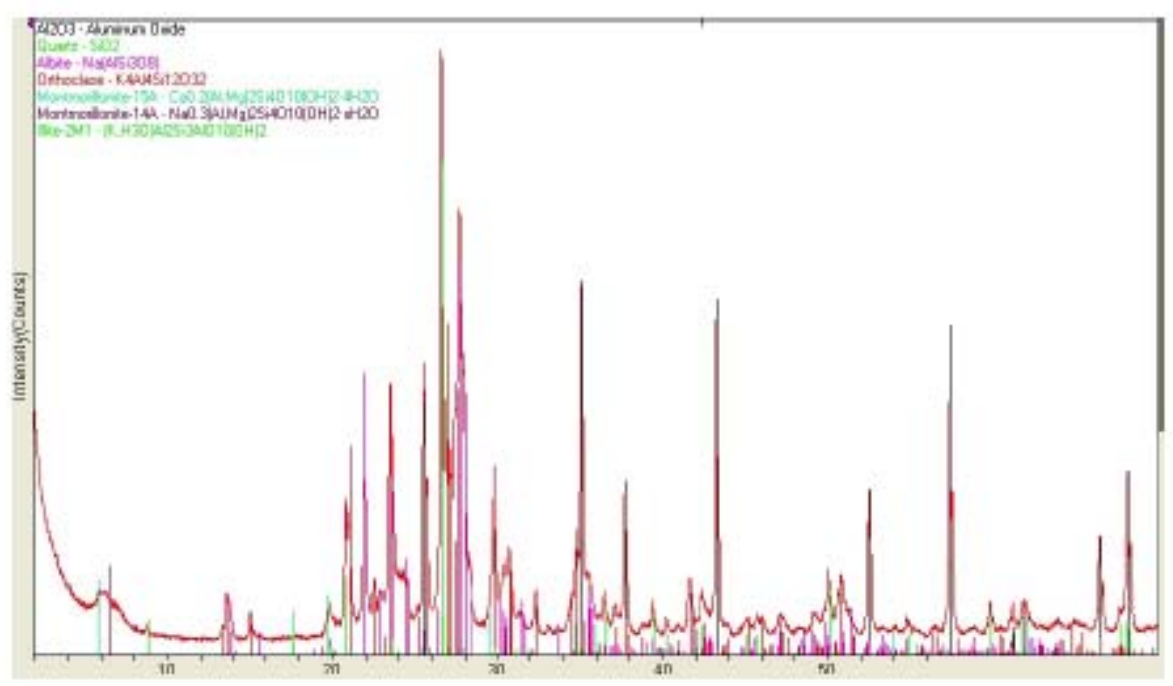

16536_black

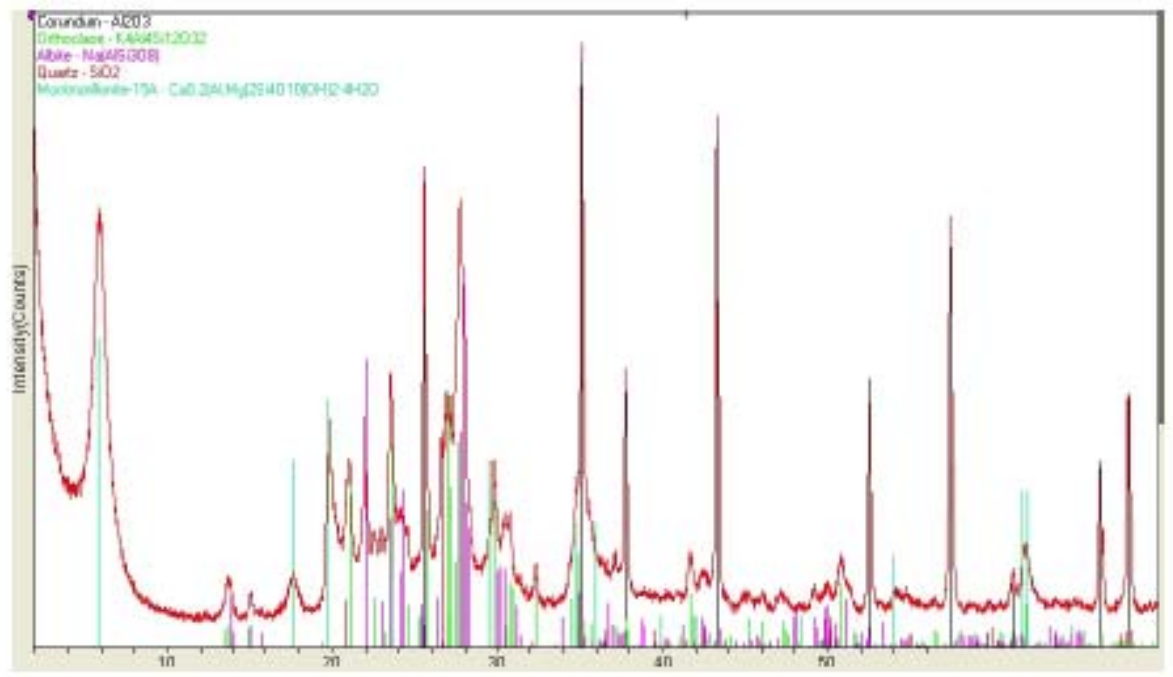




\section{APPENDIX 4-Zeta Potential Analysis}
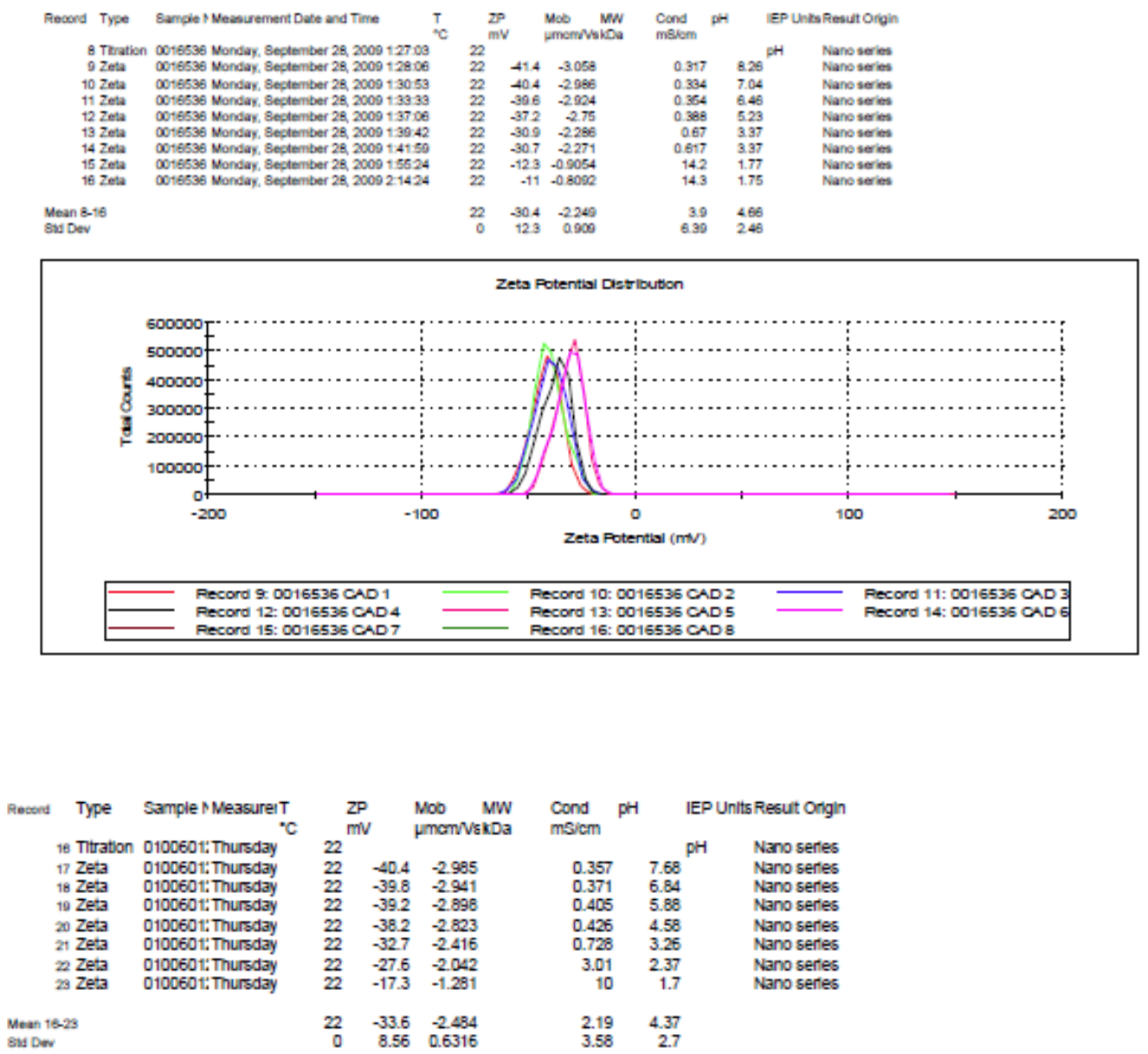

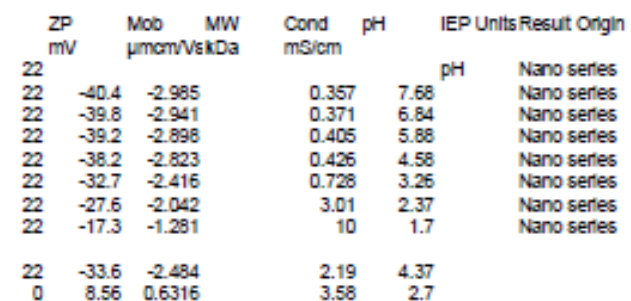

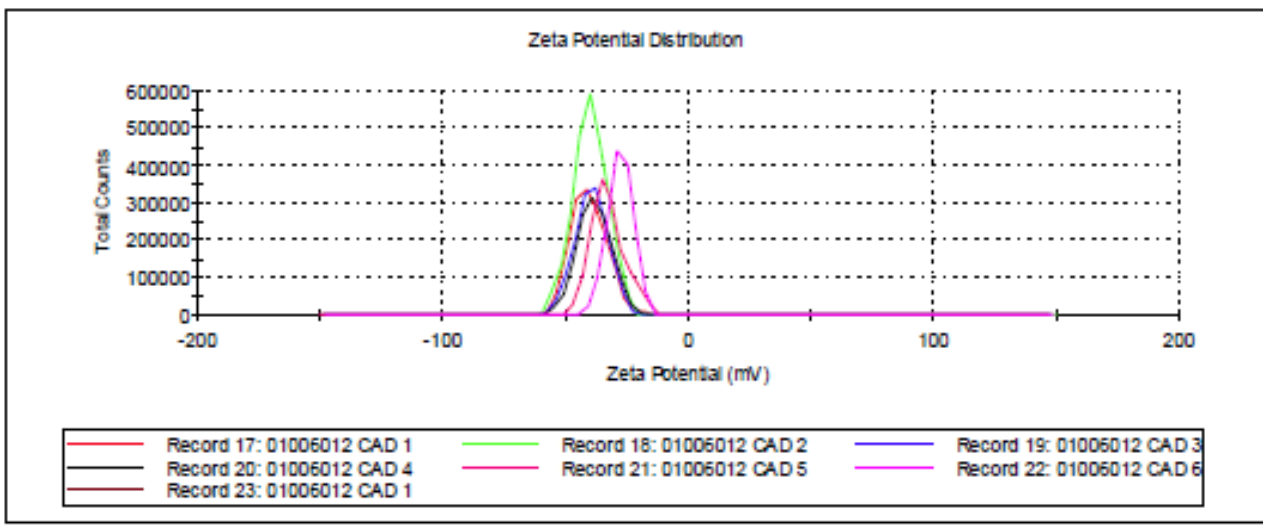


This report has been reproduced directly from the best available copy. It is available electronically on the Web (http://www.doe.gov/bridge).

Copies are available for sale to U.S. Department of Energy employees and contractors from:

Office of Scientific and Technical Information

P.O. Box 62

Oak Ridge, TN 37831

(865) 576-8401

Copies are available for sale to the public from: National Technical Information Service

U.S. Department of Commerce

5285 Port Royal Road

Springfield, VA 22161

(800) 553-6847 
- Los Alamos NATIONAL LABORATORY 